\title{
Perioperative care of hip fracture patients
}

Citation for published version (APA):

Smeets, S. (2019). Perioperative care of hip fracture patients. [Doctoral Thesis, Maastricht University]. Ipskamp Printing BV. https://doi.org/10.26481/dis.20191011ss

Document status and date:

Published: 01/01/2019

DOI:

10.26481/dis.20191011ss

Document Version:

Publisher's PDF, also known as Version of record

\section{Please check the document version of this publication:}

- A submitted manuscript is the version of the article upon submission and before peer-review. There can be important differences between the submitted version and the official published version of record.

People interested in the research are advised to contact the author for the final version of the publication, or visit the DOI to the publisher's website.

- The final author version and the galley proof are versions of the publication after peer review.

- The final published version features the final layout of the paper including the volume, issue and page numbers.

Link to publication

\footnotetext{
General rights rights.

- You may freely distribute the URL identifying the publication in the public portal. please follow below link for the End User Agreement:

www.umlib.nl/taverne-license

Take down policy

If you believe that this document breaches copyright please contact us at:

repository@maastrichtuniversity.nl

providing details and we will investigate your claim.
}

Copyright and moral rights for the publications made accessible in the public portal are retained by the authors and/or other copyright owners and it is a condition of accessing publications that users recognise and abide by the legal requirements associated with these

- Users may download and print one copy of any publication from the public portal for the purpose of private study or research.

- You may not further distribute the material or use it for any profit-making activity or commercial gain

If the publication is distributed under the terms of Article $25 \mathrm{fa}$ of the Dutch Copyright Act, indicated by the "Taverne" license above, 


\title{
PERIOPERATIVE CARE OF HIP FRACTURE PATIENTS
}

\author{
STEF J.M. SMEETS
}

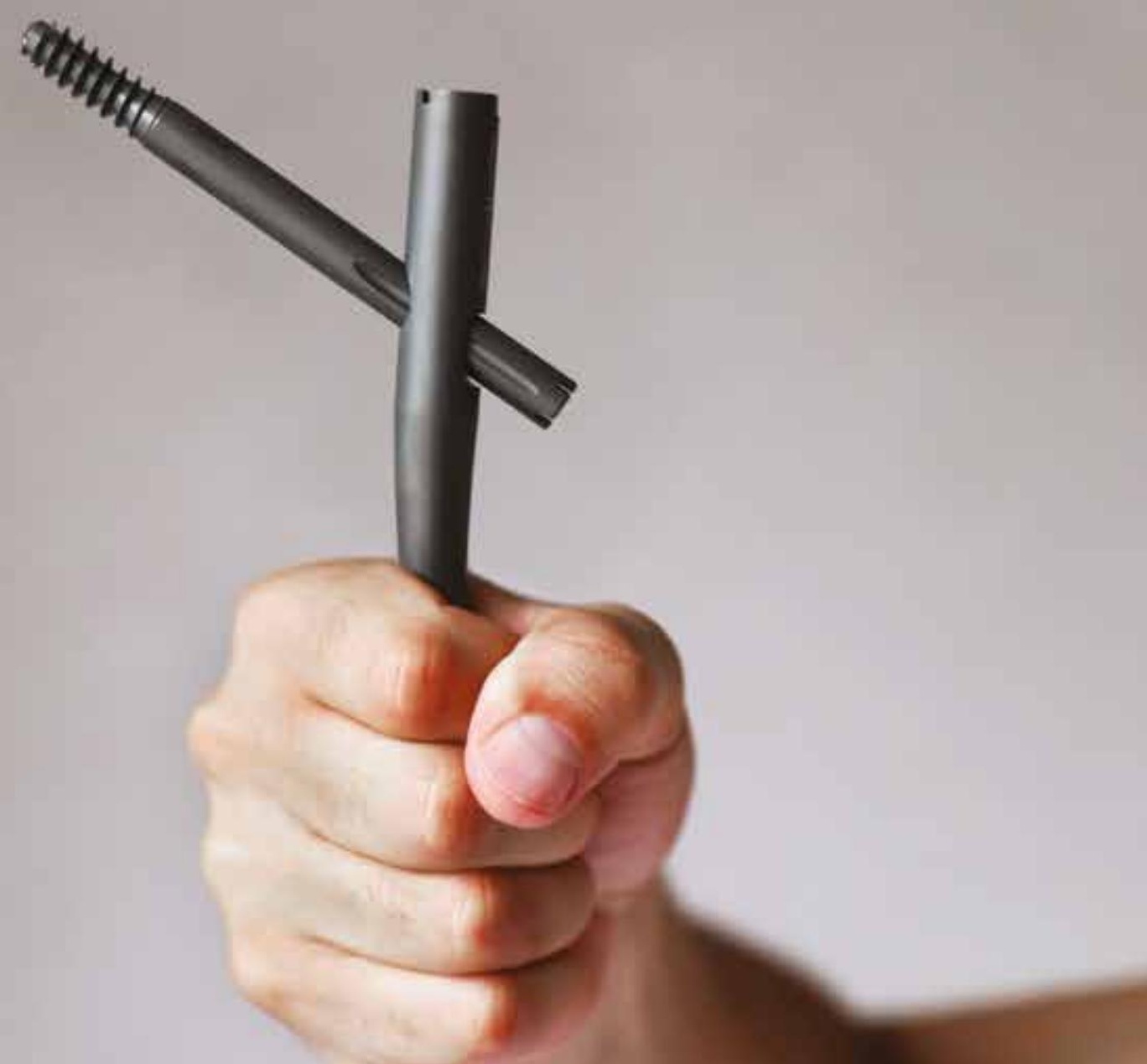



Perioperative care of hip fracture patients 


\section{$3^{\circ}$ MIX FSC responsible sources \begin{tabular}{ll} 
Fww.fsc.org & FSC \\
\hline
\end{tabular}}

Financial support by Maastricht University and Chipsoft for the publication of this thesis is gratefully acknowledged.

(C) Copyright Stef J.M. Smeets, Maastricht 2019

ISBN: 978-94-028-1675-4

Photos and cover design: Ayfa van Oeteren \& Stef J.M. Smeets

Layout: Lena Bilet

Printed by: Ipskamp Printing 


\section{Perioperative care of hip fracture patients}

\section{Proefschrift}

ter verkrijging van de graad van doctor aan de Universiteit Maastricht, op gezag van de Rector Magnificus, Prof.dr. Rianne M. Letschert volgens het besluit van het College van Decanen, in het openbaar te verdedigen op vrijdag 11 oktober 2019 om 14.00 uur

door

Stef Jozef Marie Smeets 
Promotores

Prof. dr. M. Poeze

\author{
Co-promotor \\ Dr. J.P.A.M. Verbruggen \\ Dr. G.D. Slooter
}

\title{
Beoordelingscommissie
}

Prof. dr. L.W. van Rhijn, Orthopedisch chirurg (voorzitter, MUMC, Maastricht)

Prof. dr. W.F.F.A. Buhre, Anestesioloog (MUMC, Maastricht)

Dr. R.K.J. Simmermacher, chirurg (UMC, Utrecht)

Dr. M.J. Heetveld, chirurg (Spaarne Gasthuis, Haarlem) 



\section{TABLE OF \\ CONTENTS}

Chapter 1

Chapter 2

Chapter 3

Chapter 4

Chapter 5

Chapter 6

Chapter 7

Chapter 8 
The patellar pubic percussion test (PPPT): A simple 44 bedside tool for suspected occult hip fractures

Preoperative cardiac evaluation of geriatric patients 56 with hip fracture

Cardiac overscreening hip fracture patients 76

Effect of blood transfusion on survival after hip 96 fracture surgery

Z-effect after intramedullary nailing systems for trochanteric femur fractures

Summarizing discussion, future perspectives and 134 conclusions

Appendices:

ACC/AHA appendices

Nederlandse samenvatting

162

Valorization addendum

166

About the author

169

List of publications

Dankwoord 

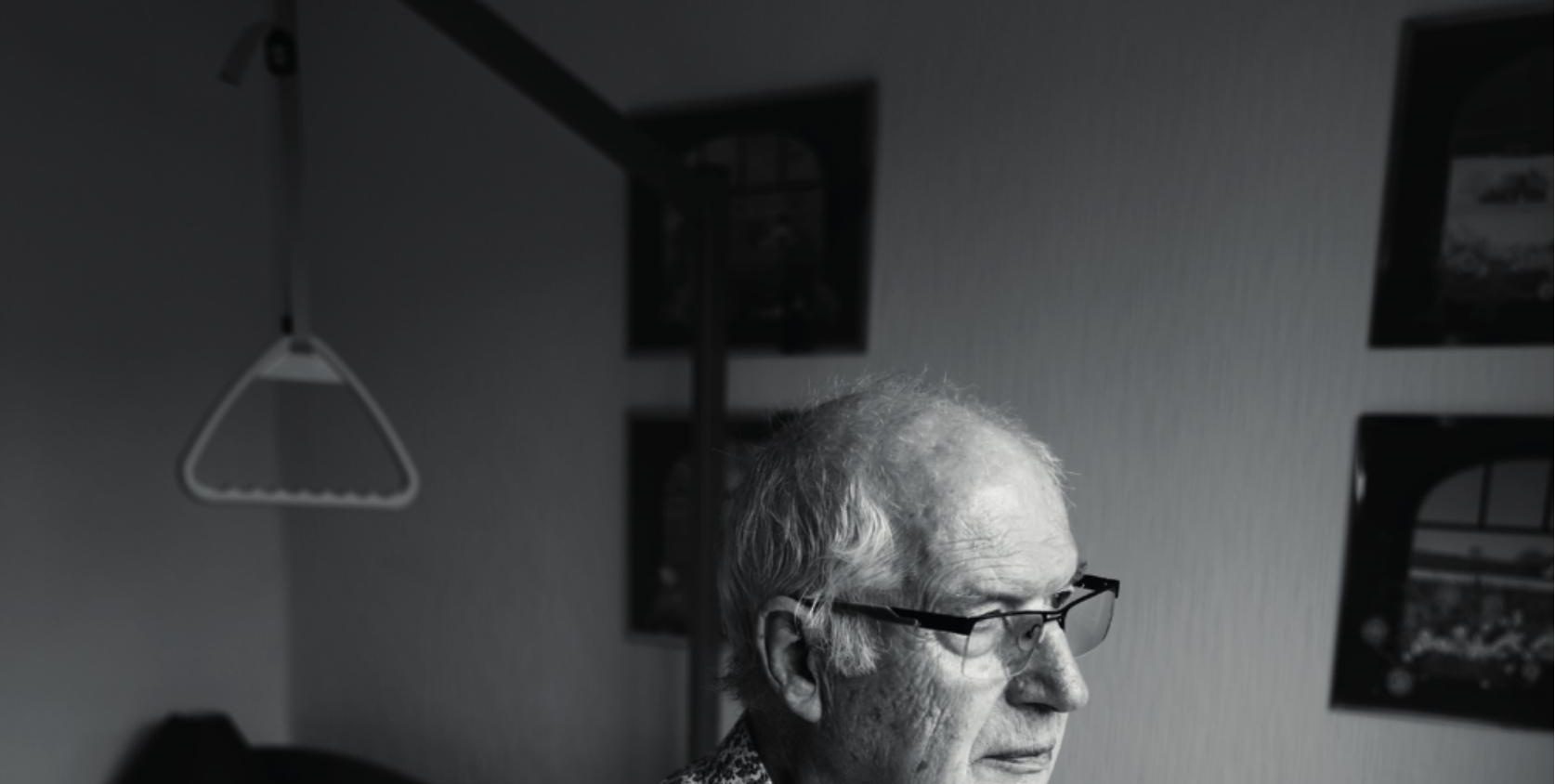


\section{CHAPTER

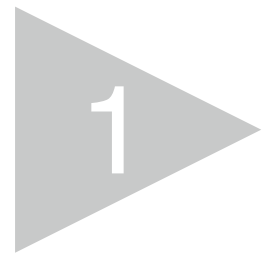

General introduction into hip fractures

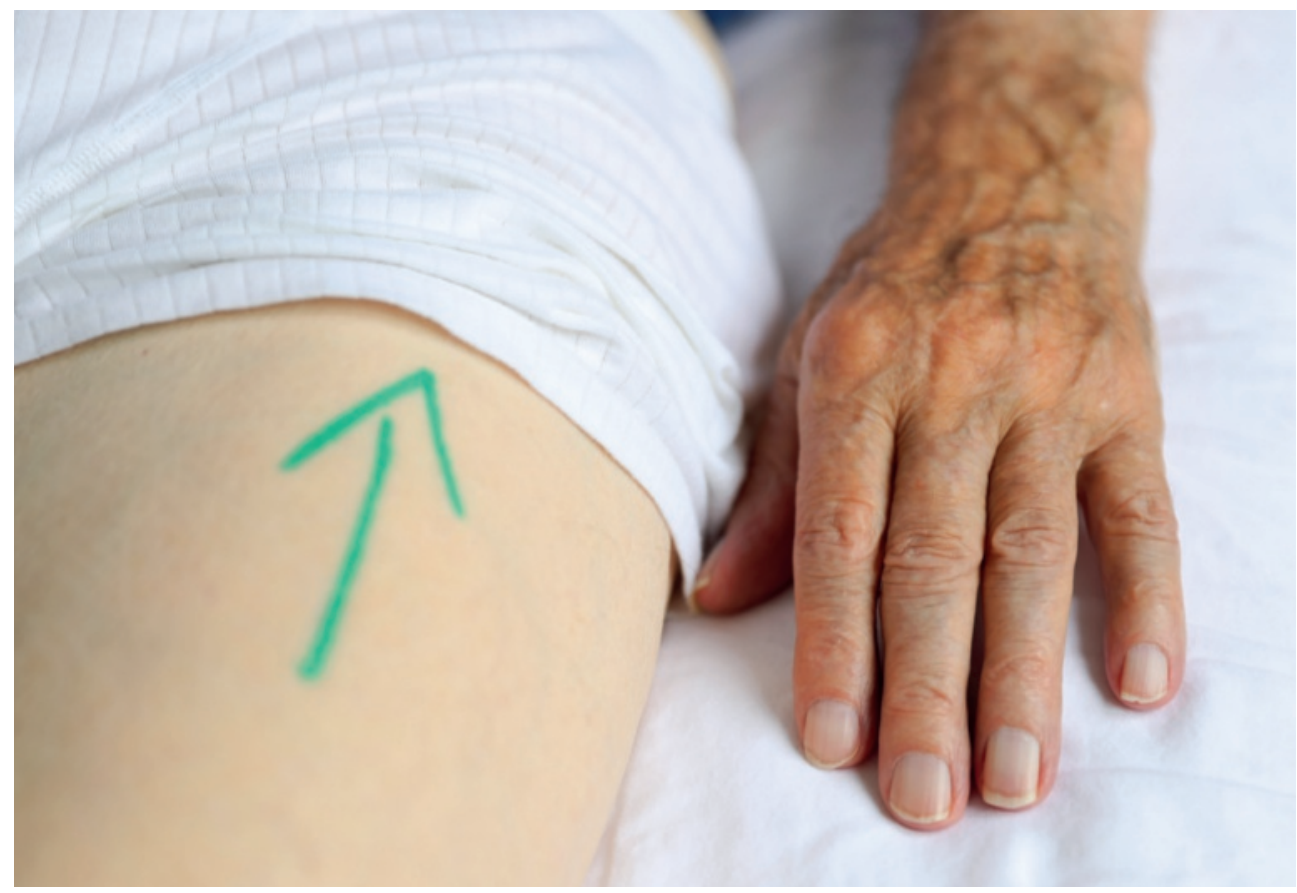




\section{EPIDEMIOLOGY OF HIP FRACTURES}

Hip fractures are one of the most common injuries after falls in the elderly population. Over $97 \%$ is due to a simple fall in or around the house [1]. The incidence of hip fractures increases with age [2]. In 2010 over 20.000 patients sustained a hip fracture in the Netherlands [3]. A further increase is expected as a result of a growing population in general, the effects of aging and increased prevalence of risk factors for fall-related hip fractures, such as osteoporosis [4]. In the Netherlands a male to female ratio of 1:3 existed in 1996 and decreased to approximately $1: 1.7$ nowadays $[5,6]$, due to better screening, prevention and treatment of osteoporosis. Furthermore $56 \%$ of hip fractures in women and $37 \%$ in men results from osteoporosis [5].

\section{PERIOPERATIVE CARE OF HIP FRACTURE PATIENTS}

\section{DIAGNOSTIC WORKUP}

Usually, a patient with a hip fracture has a characteristic history of a low-energy trauma, upper leg pain and inability to walk. On examination the affected leg might be shortened and externally rotated, most likely in the case of displaced neck of femur fractures [7]. However, clinical presentation can be more subtle.

Although, radiographs have a 90-98\% sensitivity to detect a hip fracture $[8,9]$, on occasion a hip fracture may not be apparent on radiographic examination. The term occult fracture describes clinical signs of a fracture without clear radiographic abnormalities. In the case of expected occult hip fracture further diagnostic imaging with $\mathrm{CT}$ or $\mathrm{MRI}$ is indicated, although clinical decision rules for additional imaging do not exist. Previous studies show that in $2-10 \%$ patients the hip fractures cannot be diagnosed by plain radiographs alone [8, 10-12]. A missed fracture is more likely to happen in patients with poor mobility and cognitive impairment [13]. Both CT and MRI show high sensitivity and specificity [14], to detect occult hip fractures with high interobserver agreement [15]. MRI has a sensitivity of $100 \%$ and up to $100 \%$ specificity depending on the experience of the radiologist [16]. CT has a sensitivity of approximately $87 \%$ up to $100 \%$ in the case of multidetector CT (MDCT)/multislice technique and a specificity of $98-100 \%$ [17-19]. Due to immediate availability of CT in most hospitals and patient comfort, CT may be preferred according to the 
Dutch 2016 guidelines for proximal femur fractures [20]. Clinical predictors fail to be diagnostic for occult hip fractures. Pain on axial loading of the limb and prefracture restricted patient mobility were both associated with the presence of a fracture $(p<0.005)$. Both factors had an identical positive predictive value of 0.76 and negative predictive value of 0.69 . Both predictors combined did not improve the probability for occult fracture [21]. Physical examination with the patellar pubic percussion test (PPPT) shows an interestingly high sensitivity of $97 \%$ and $85 \%$ specificity in diagnosing hip fracture. The PPPT is performed by finger tapping on the patella and by interpretation of the produced sound over the pubic bone using a stethoscope. In case of a fracture, a more dull sound is heard. In this thesis we investigated the strength and reproducibility of the PPPT and if the PPPT was able to detect overt hip fractures and occult hip fractures that may not be determined by a standard radiological examination. The trend in modern practice shows an increased use of MRI or CT for suspected occult hip fracture [22].

\section{PREOPERATIVE SCREENING}

Standard workup at the emergency room consists of a detailed history, a complete physical examination, an electrocardiography and standard biochemical and hematologic tests. The anesthesiologist performs the preoperative screening and decides whether adjacent consultations, like a cardiac consultation, are necessary.

Early operative treatment within $24-48$ hours is advocated to minimize the potential morbidity/mortality associated with delay to surgery [23-27]. Preoperative assessment has the potential of being time consuming and may lead to unnecessary delay to surgery. Although some patients might benefit from delaying surgery to stabilize acute medical issues, that must be addressed prior to surgery, to minimize perioperative risk. Bottle et al. found that patients with a delayed procedure were much more likely to have one or more comorbidities. These findings suggest that comorbidities do affect timing of surgery [28]. A delay to surgery of $>48$ hours was in $35 \%$ the result of stabilization of medical conditions, while for a delay of $25-48$ hours this was only $8 \%$ [29]. Delay to surgery is multifactorial and is frequently system related delay such as unavailability of an operating room or team and trauma lists $[29,30]$.

\section{HIP FRACTURE SURGERY, RISKY SURGERY?}

To reduce the cardiac risk the American College of Cardiology and the American 
Heart Association (ACC/AHA) have developed guidelines for preoperative assessment for non-cardiac surgery with frequent updates. The keypoint of these guidelines are summarized in an algorithm indicating the stepwise approach of patients using clinical predictors to identify their risk category. See the appendices (chapter 8) for a summary of the most relevant findings from the 2007 and updated 2014 ACC/AHA guidelines regarding preoperative cardiac screening for hip fracture surgery.

Patients can be subdivided in a low, intermediate or high risk group. The purpose of preoperative evaluation by this approach is not to give medical clearance but rather to perform an evaluation of the patients current medical status, make recommendations concerning patient management and risk of cardiac complications over the entire perioperative period [31, 32].

Hip surgery is considered as intermediate risk surgery, due to the quantity of hemodynamic stress it induces [31]. This means that major ischemic cardiac complications occur in less than $5 \%$ of the time. However, the overall incidence of perioperative myocardial ischemia in elderly patients undergoing hip fracture surgery has been reported to be 22-53\% [33, 34]. Another study showed that an isolated increased troponin, without symptoms matching an acute coronary syndrome (ACS), was not associated with a significant increase in death and/or rehospitalization within 6 months [35]. Identification of cardiac ischemia is difficult, and myocardial infarction is probably under diagnosed since classic symptoms may be atypical or absent [36]. Previous studies indicated that the principal causes of in-hospital death after hip fracture were cardiac failure and myocardial infarction, occurring early after the fracture $[37,38]$.

The ACC/AHA guidelines recommend non-invasive cardiac testing in high risk patients with active/acute cardiac comorbidity and to consider non-invasive cardiac testing for intermediate risk patients with low functional capacity determined by metabolic equivalent of task score (MET, see appendices Table 1). Non-invasive testing includes stress testing such as dipyridamole-thallium cardiac scintigraphy and the more frequently used transthoracic echocardiography (TTE). TTE provides information about cardiac risk and function, which can directly affect the need for preoperative cardiac interventions or have implications for intraoperative anesthesia care and perioperative fluid management [39]. Some conditions with significant contribution to perioperative mortality, like aortic stenosis [40] and pulmonary 
hypertension [41] are difficult to diagnose without TTE [42]. The incidence of previously undiagnosed aortic stenosis in a hip fracture population, detected by echocardiography is 6.9\% (patients with known aortic stenosis not included) [43]. Furthermore TTE can provide information about haemodynamic states such as hypovolaemia, left ventricular systolic and/or diastolic failure and right heart failure [44]. The most common indication for TTE in hip fracture patients are heart murmurs heard by auscultation, to determine any significant valvular abnormalities [43, 45].

Preoperative cardiac assessment in the hip fracture population is often time consuming and may lead to unnecessary delay to surgery [46, 47] and should therefore be restricted to those patients at risk who's patient management is likely to be changed by this cardiac consultation [26, 48-50]. Nevertheless, preoperative TTE for patients with a hip fracture is frequently performed outside the recommendations of established guidelines [51]. In this thesis we extensively studied preoperative cardiac screening and outcome after hip fracture surgery in relation with cardiac risk.

\section{ANESTHESIA}

General and neuroaxial anesthesia are most used in hip fracture surgery. What anesthesia technique results in a better outcome remains controversial in literature. Potential complications of general anaesthesia include adverse reactions to drugs, difficulty in maintaining or establishing an airway, damage to the teeth or upper airways, severe hypotension and its potential cerebro- and cardiovascular ischemia, aspiration of gastric contents, and postoperative nausea and vomiting [52]. The use of general anesthesia in patients with chronic obstructive pulmonary disease (COPD) is associated with a higher incidence of composite morbidity, pneumonia, prolonged ventilator dependence and unplanned postoperative intubation [53]. The need for postoperative analgesia remains after general anesthesia. Postoperative intravenous patient-controlled analgesia (PCA) with morphine, continuous femoral nerve block (FNB) and continuous epidural analgesia provide similar pain relief and allow comparable hip rehabilitation and duration of hospital stay after total-hip arthroplasty (THA) [54].

Central neuroaxial blockade provides excellent intraoperative anesthesia, prolonged postoperative analgesia and avoids most side effects such as intraoperative hypothermia, nausea, vomiting and reduced morphine consumption [55-57]. Also in neuroaxial anesthesia there are disadvantages such as intraoperative hypotension, 
which may lead to cerebrovascular or myocardial ischaemia, inadequate regional block, urinary retention and headache [58]. Neuronal damage such as epidural haematoma or infection are very rare complications [58]. Therapeutic anticoagulation use $[59,60]$ and severe aortic stenosis [61] are contraindications to neuroaxial anesthesia, although there is evidence that with continuous spinal anesthesia patients with severe aortic stenosis can be safely managed with a lower risk of hemodynamic effects due to vasodilatation in the lower body half [62].

Hypotension is common in both general and spinal anesthesia, especially after induction. Although there is evidence showing that spinal anesthesia provides a more stable hemodynamic profile requiring less intervention to keep mean arterial pressure (MAP) close to baseline value in the elderly hip fracture population with American Society of Anesthesiologists (ASA) classification 3-4, in comparison with general anesthesia $[63,64]$. Spinal anesthesia using titrated doses of bupivacaine provided better blood pressure stability than propofol or sevoflurane anesthesia, with significantly less use of inotropic agents [64]. Furthermore, the maximal decrease in mean arterial pressure was lower for spinal anesthesia [64].

Despite these findings, a number of different reviews failed to show a clear clinical difference in mortality or postoperative complications associated with type of anesthesia [56, 65-68].

\section{PERIOPERATIVE TRANSFUSION REGIMEN}

Anemia in hip fracture patients is very common 39-69\%. Patients with hip fracture may have anemia for a variety of reasons, for example due to the trauma, intraoperative blood loss, pre-existing medical conditions, the use of anticoagulants or perioperative haemodilution. The total blood loss after hip surgery is underestimated and much greater than what has been determined intraoperatively, commonly exceeding $1000 \mathrm{ml}[69]$.

Anemia has been demonstrated to have a significant effect on mortality after hip fracture surgery. In a large study with 7319 hip fracture patients a hazard ratio $(\mathrm{HR})$ for 30-day mortality for patients with anemia was calculated at 1.66 (Cl: 1.431.91, $\mathrm{P}<0.0001$ ) and adjusted for comorbidities [70]. Furthermore, Foss et al. found a linear relationship between the degree of anemia and ability to mobilize independently. A multivariate analysis showed that anemia was an independent risk factor for not being able to walk on the third postoperative day [71]. 
The timing of erythrocyte blood transfusion (pre-, intra-, or postoperatively) and appropriate threshold for transfusion is a controversial topic of debate. A 2015 Cochrane review concluded there was only limited evidence available to support a liberal $(\mathrm{Hb}<10 \mathrm{~g} / \mathrm{dl})$ instead of a restrictive $(\mathrm{Hb}<8 \mathrm{~g} / \mathrm{dl})$ transfusion trigger after hip fracture surgery [72]. The FOCUS study, a large international randomized multicenter study has reported long term survival results demonstrating no difference in mortality between high-risk elderly patients treated with a liberal $(\mathrm{Hb}<10 \mathrm{~g} / \mathrm{dl})$ and those with a restrictive transfusion threshold $(\mathrm{Hb}<8 \mathrm{~g} / \mathrm{dl})$ [73]. At the time the studies in this thesis were performed the general applicable transfusion protocol for patients with a cardiac history was to transfuse for hemoglobin levels $<10 \mathrm{~g} / \mathrm{dl}$, for elderly without a cardiac history at $<8 \mathrm{~g} / \mathrm{dl}$.

One other topic which may be beneficial in reducing blood loss is the use of tranexamic acid (TXA). This fibrin clot stabilizer demonstrated to deliver a reduction in blood loss in major trauma by preventing haemorrhage and reduced the 28day all-cause mortality by $1.5 \%$ [74-76]. In a hip fracture population, tranexamic acid has demonstrated to be safe, cost-effective and reduces the need for blood transfusion [77, 78]. One transfusion was prevented with every 8 patients given prophylactic TXA [77]. There were no significant differences in mortality rates with TXA use $[77,79]$ or increased risk of venous thromboembolic (VTE) events [80, 81].

In this thesis we investigated the incidence of erythrocyte blood transfusion (EBT) after hip fracture surgery and reported on the effects of EBT on outcome.

\section{CLASSIFICATION AND TREATMENT OPTIONS}

Treatment options for hip fracture depend on fracture type and patient characteristics. Hip fractures can be subdivided into intracapsular or femoral neck fractures and extracapsular or trochanteric fractures (see figure 1).

\section{INTRACAPSULAR FRACTURES}

For intracapsular fractures the classification by Garden is most frequently used (see figure 2), followed by the Pauwels classification (see figure 3). 


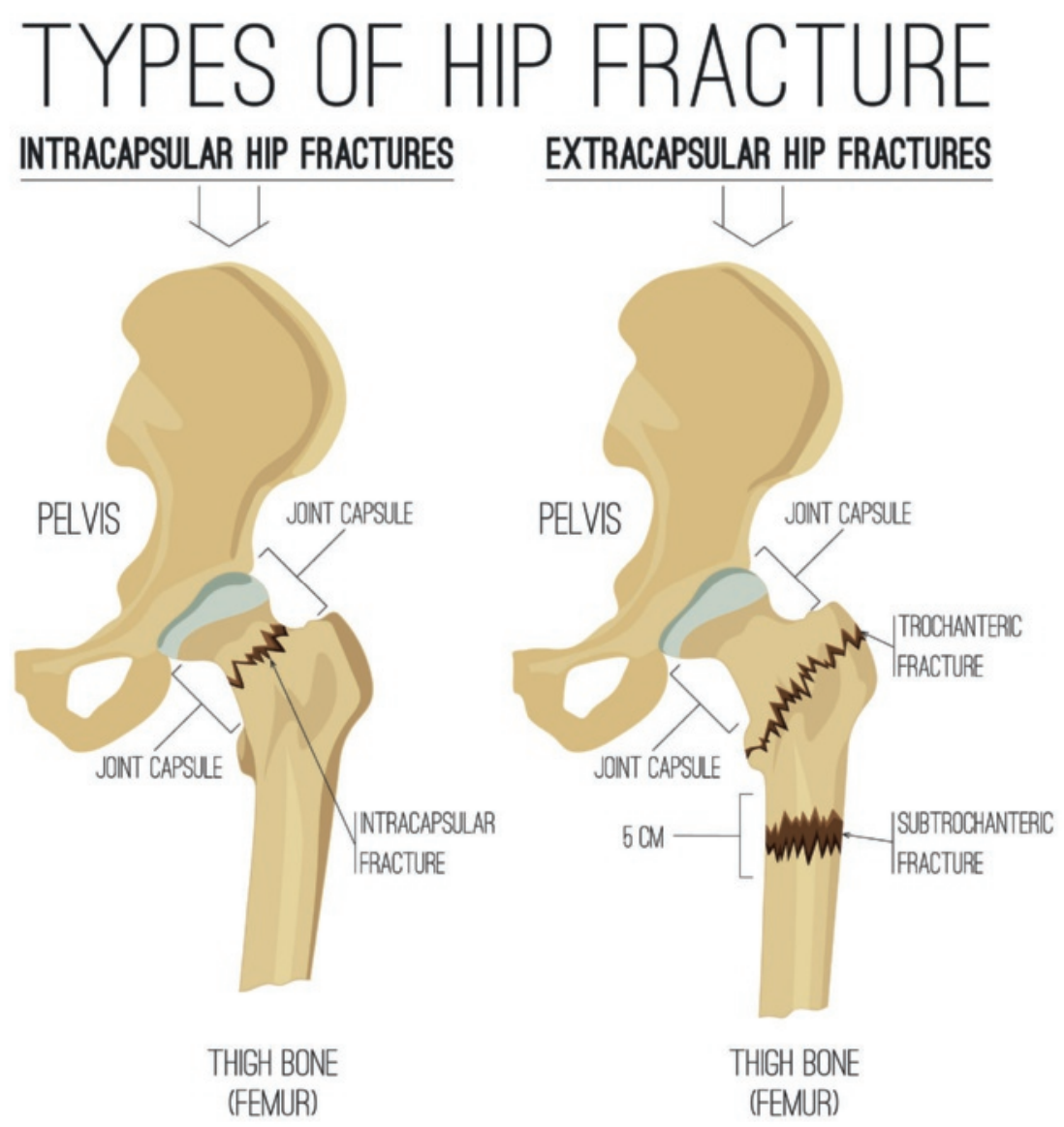

Figure 1. Types of hip fractures.

The Pauwels classification can only be used after reposition and is based on the vertical orientation of the fracture line [83]. The angle formed by extending the fracture line upwards to meet an imaginary horizontal line drawn through the transtubercular (iliac crest) plane on AP radiograph is described as 'Pauwels angle'. The steeper this angle, the greater the instability of the fracture. It is recommended by the Dutch guidelines for proximal femur fractures [20] to use the Garden classification for intracapsular fractures (see figure 3). The Garden classification is easier in use and only uses the anteroposterior radiograph. 

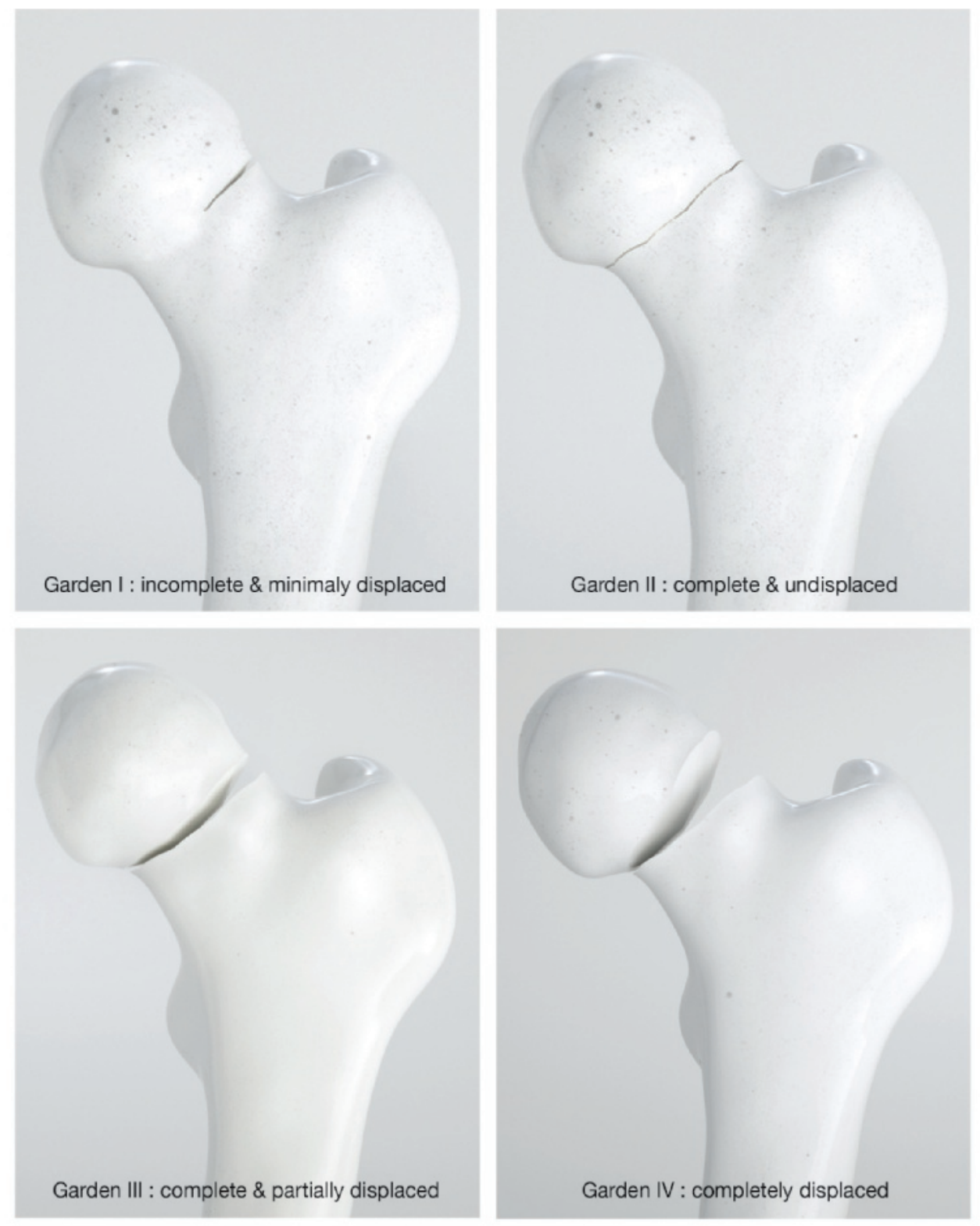

Figure 2. Garden classification for intracapsular hipfractures [84]. Illustration by S.J.M. Smeets. 


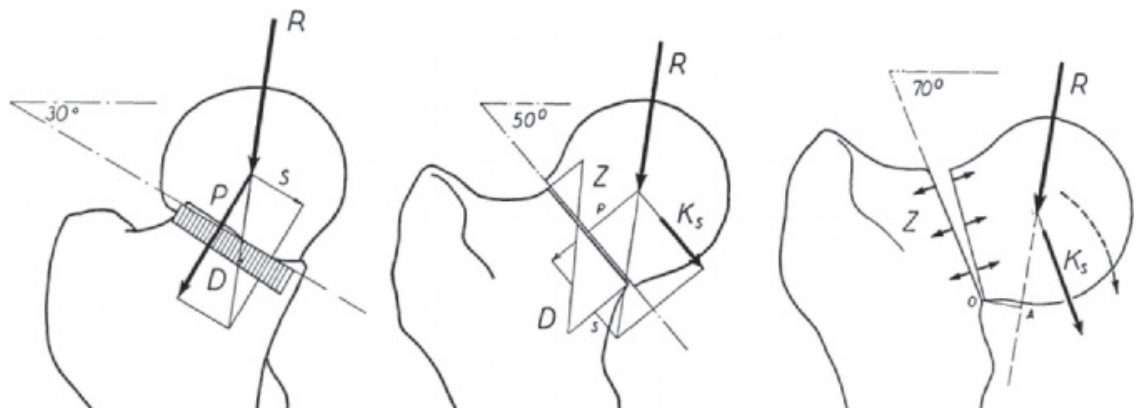

Figure 3. Pauwels classification for intracapsular hipfractures [82]. Adapted from original by Pauwels.

Garden I and II are considered stable fractures and are non-displaced. These fractures are preferably treated with internal fixation (IF) to save the femoral head. For example, cannulated screws or the dynamic hip screw (DHS), with or without anti-rotation screw can be used $[85,86]$. There is a place for conservative treatment for Garden I patients, but due to the risk of avascular head necrosis (AVN) and the necessity for more profound surgery afterwards, the Dutch guidelines state that internal fixation is preferred [20]. Furthermore, internal fixation is associated with reduced length of hospital stay, improved rehabilitation and higher union rates compared to conservative treated patients [87]. In a large systematic review involving twenty-nine studies with 5071 patients (1120 patients treated conservatively and 3951 surgically) union rates were 68.8\% (642/933) and 92.6\% $(635 / 686)$ respectively, $(p<0.001)$. The avascular necrosis rate in the conservatively treated group was $10.3 \%$ (39/380), while it was $7.7 \%(159 / 2074)$ in the surgically treated group $(p=0.09)$ [88].

Garden III and IV are unstable fractures and displaced. These fractures are treated with internal fixation, hemi-arthroplasty or total hip arthroplasty (THP) depending on age, activity level of the patient and comorbidity. Internal fixation is preferred in most patients up to 60 years. Pre-existent significant osteoarthritis and pathological fractures are exception criteria [89-93]. Failure rates of IF progressively increase with age from $5.9 \%$ in patients $<40$ years, $24.9 \%-38 \%$ in patients over 65 years and up to $42-55 \%$ in patients over 70 years of age [94-99]. Risk factors for failure after IF are a history of alcohol abuse, renal or respiratory disease, therefore arthroplasty should be considered in those patients [100]. The strongest association was found for renal failure. For patients aged 65-79 year with a high vitality-score based on preoperative mobility, living situation, ASA score, mental status and bone density and an optimal reposition and fixation show a $25 \%$ conversion rate to arthroplasty 
[101]. In patients $>80$ years revision surgery after IF is needed in almost $50 \%$ of patients regardless vitality. Nevertheless, functional outcome (Harris Hip Score) is similar after primary THP compared to secondary THP after osteonecrosis of the femoral head (ONFH) after failed primary IF [102]. IF should be considered as a minimally invasive procedure in the case of immobile or palliative patients irrespective of age [20].

The role of cognitive disorders in the choice of treatment of femoral neck fractures is under discussion. Demented patients had a significantly higher mortality rate and functional outcome after hemi-arthroplasty for displaced intracapsular femoral neck fractures compared to patients without mental impairment [103]. However, hemi-arthroplasty compared to IF showed no excess morbidity or mortality up to 1 -year postoperative, better functional outcome, and significant less re-operations in patients with severe cognitive dysfunction [104, 105]. Dementia should therefore not be a reason for disqualifying those patients from the most appropriate surgical method.

In general IF can be used up to 80 years of age for ASA 1-2 patients, after shared decision making with the patient, in consideration of the chance of revision surgery and the patients activity level and comorbidity. Primary arthroplasty should be considered in most patients $>60$ years of age with displaced femoral neck fracture, with a comparable low re-operation risk of approximately $2-8 \%$ for hemi-arthroplasty and THP [106-110]. The healthy, lucid, $>60-80$ year old patients are preferably treated with total hip arthroplasty. The older, impaired or institutionalized patient with high comorbidity, would benefit from a hemiarthroplasty [20, 111, 112]. Cemented hemi-arthroplasty and THP are preferred above uncemented implants due to fewer implant-related complications and similar mortality and functional outcome [113, 114].

\section{EXTRACAPSULAR FRACTURES}

Trochantericfracturescan beclassified by the AO-classification(Arbeitsgemeinschaft für Osteosynthesefragen, see figure 4) [115]. The complete classification has low inter- and intraobserver agreement and has limited predictive use for the outcome of treatment. Therefore, classification by the main sub-groups (A1, A2, A3) is recommended $[20,116,117]$. All trochanteric fractures are extracapsular, so there is minimal risk of osteonecrosis of the femoral head. 
31-A1 are simple, two-part pertrochanteric fractures $(A O)$ : The fracture line can begin anywhere on the greater trochanter and end either above or below the lesser trochanter. The medial cortex is interrupted in only one place. These fractures cause significant shortening, but they are stable after reduction and fixation, largely because of the excellent contact of the fracture surfaces and no comminution. The lesser trochanter, the so-called medial buttress, is intact. These fractures may be treated with a sliding hip screw and plate (SHS), or a cephalomedullary nail. In a randomized controlled trial 600 trochanteric fractures were treated with Dynamic
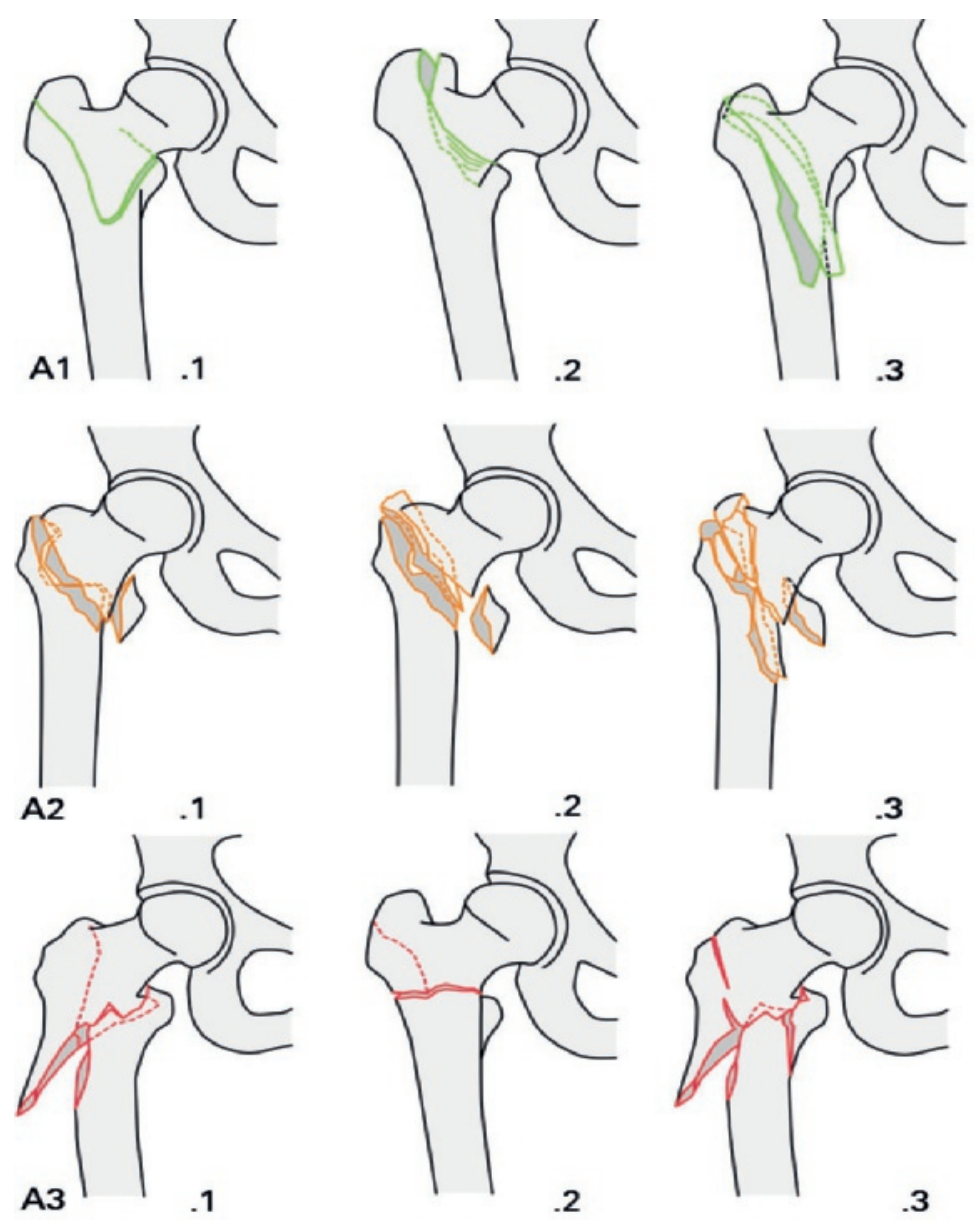

Figure 4. Arbeitsgemeinschaft für Osteosynthesefragen/Orthopaedic Trauma Association classification of pertrochanteric fractures. Copyright the AO Foundation, Switzerland. (Source: AO Surgery Reference). 
Hip Screw (DHS) or Proximal Femur Nail (PFN) and had comparable outcome [118]. Since there is no evidence for a superior technique, SHS is a considerably cheaper implant and therefor recommended by the Dutch guidelines [20].

31-A2 are multifragmentary pertrochanteric fractures $(A O)$ : The fracture line can start laterally anywhere on the greater trochanter and runs towards the medial cortex which is broken in two places. This results in the detachment of a third fragment, which includes the lesser trochanter. These fractures cause significant shortening and tend to be unstable after reduction and fixation, because the medial buttress is compromised. These fractures may be treated with a sliding hip screw, or a cephalomedullary nail. From a review including 909 patients, intramedullary nail (IMN) fixation was found to be the superior treatment of choice for 31-A2 trochanteric fractures as compared with SHS fixation. The results showed that the IMN group was associated with less operative blood loss, leg shortening, wound infections, length of hospital stay, and achieved a higher Parker score as compared to the SHS group. No significant difference was found for fracture fixation complications, postoperative complications, and 1 year mortality [119]. Currently there exists no consensus about the best fixation method for these unstable trochanteric fractures.

31-A3 are true intertrochanteric fractures $(A O)$ : They are subdivided according to the fracture pattern. The fracture line passes between the two trochanters, above the lesser trochanter medially and below the crest of the $\mathrm{m}$. vastus lateralis, laterally. Both femoral cortices are involved. These fractures cause significant shortening and tend to be unstable after reduction and fixation, because both cortices are involved. Furthermore, a subtrochanteric fracture is defined as any fracture occurring at the lesser trochanter or at a distance of approximately $5 \mathrm{~cm}$ below the lesser trochanter [120]. These fractures may be treated with a sliding hip screw, $95^{\circ}$ blade-plate or a cephalomedullary nail [121]. With the use of intramedullary implants operative time and fixation failure rates are reduced [122].

In unstable fracture patterns, intramedullary devices appear to have a biomechanical advantage over extramedullary devices, lowering the forces imposed on the implant due to the shorter lever arm of the fixation [123, 124]. A long nail has a longer working length and can protect the remnants of the femur shaft below the fracture site for periprosthetic fractures $[125,126]$. 


\section{OUTCOME AFTER HIP FRACTURE SURGERY}

\section{MORBIDITY}

Over $90 \%$ of hip fracture patients are older than 65-year-old and have pre-existing medical comorbidities [127]. Age and comorbidities contribute in a great extend to prognosis and treatment. Common comorbidities are cardiovascular (24\%), dementia (24\%), stroke (13\%) and respiratory disease (14\%) [128]. Even with optimal care, elderly hip fracture patients suffer high morbidity and mortality rates, and often demand for expensive hospital aftercare [129]. Postoperative complications can arise from surgery itself, comorbidity or implant related complications. Complications can be subdivided into medical and surgical complications.

The American Society of Anesthesiologists (ASA) classification is associated with the risk of postoperative medical complications. Hip fracture patients with ASA 3 had a 3.8 times greater chance and ASA 4 patients a 7.4 times greater chance of having a medical complication in comparison with ASA 2 patients [130]. The incidence of major postoperative complications after hip fracture surgery is $20 \%$ $63.9 \%$ [123, 131-134]. Common complications are anemia requiring erythrocyte blood transfusion (22-56\%), delirium (30-50\%), pneumonia (4-10\%), pulmonary embolus (1-2\%), deep infection (1\%), urinary tract infection (4-18\%), gastrointestinal haemorrhage (1-3\%), myocardial infarction (1-2\%), stroke (1-2\%) and pressure sores (10-40\%) [26, 71, 128, 131, 135-142].

\section{MORTALITY}

Postoperative complications increase short and long-term mortality [127]. Patients with acute heart failure or a postoperative pneumonia had a 30-day mortality of $65 \%$ and $43 \%$, respectively [131]. Mortality rates after hip fracture surgery are high: in-hospital: 5\%-11\%, 1-month: 3\%-13\%, 3-month: 10\%-28\% and 1 -year: 17\%-43\% [26, 137, 143]. Independent predictors for 1-month mortality in patients with hip fracture included male sex, age >86 year, two or more comorbidities, anemia, and a mini mental test score $\leq 6$ of 10 [144]. Furthermore, survivors of hip fractures have a significant lower life expectancy in comparison with the general population (age and sex matched) [145]. Hip fracture reduced life expectancy by 1.8 years or $25 \%$ compared with an age- and sex-matched general population [145]. 
Various surgical complications might occur after hip fracture surgery, and are correlated with patient characteristics like high ASA score [146], osteoporosis [147], malnutrition [148, 149], diabetes [150, 151], unstable fracture type, poor fracture reduction, poor quality of the osteosynthesis and choice of implant type [152]. Surgical complications are frequently fracture specific, for example the main problems in intracapsular fractures are biological due to vascularization of the femoral head and disruption of the periosteum of the neck of femur, both major contributors to fracture healing in this type of fractures. In extracapsular fractures surgical complications occur frequently due to mechanical issues in relation with load-bearing [129].

\section{INTRACAPSULAR FRACTURES}

Two major complications may arise following treatment of an intracapsular fracture by internal fixation: non-union and avascular necrosis (AVN) or osteonecrosis of the femoral head (ONFH). Non-union rates vary greatly from 10-45\% [106, 153]. Factors associated with re-operation include high age, displaced femoral neck fractures, degree of comminution, quality of reduction and non-union [154, 155]. Avascular necrosis of the femoral head occurs in $9 \%-18 \%$ of patients. Risk factors include high age, the degree of initial fracture displacement and delay to surgery [156-158]. Failed internal fixation has a significant impact on the patient with a twofold increase of length of hospital stay and patients are more likely to suffer a downgrade in their residential status upon discharge and disability may become permanent [159].

Total hip arthroplasty is an effective salvage procedure after failed osteosynthesis of hip fractures. Most patients have good pain relief and functional improvements, in spite of technical difficulties and higher complication rates compared to primary arthroplasty [160, 161]. With arthroplasty different surgical complications are encountered. Dislocation after arthroplasty was historically a common complication, reported in approximately $4-14 \%$ of patients and more frequently in THP compared to hemi-arthroplasty and after revision or salvage arthroplasty compared to primary arthroplasty. The majority of dislocations occur posteriorly, typically after flexion, adduction and internal rotation of the leg. Enhanced soft tissue repair after a posterior approach or a modified lateral approach and implant developments such as dual mobility cups effectively reduced the incidence of dislocation to around $1 \%$ [162-164]. Although clear evidence, these implants are not standardly used due 
to lack of evidence regarding wear and component longevity [165]. Osteolysis is a process in which bone is resorbed due to a macrophage-induced inflammatory response to particulate debris. The major problem over time associated with THP today is loss of fixation due to osteolysis or aseptic loosening. The risk of aseptic loosening leading to revision surgery is about 1 percent per year [166]. The incidence of infection after primary THP is low and varies between 0-1.7\% [167]. Prosthetic joint infection is a devastating complication for the patient and comes with severe costs and need for several reoperations.

\section{EXTRACAPSULAR FRACTURES}

Nonunion is less common in extracapsular fractures and occurs mainly in severely comminuted unstable fractures with bone loss in approximately $1 \%-2 \%$ [168]. The explanation for this low non-union incidence can be found in the fact that the fracture occurs primarily in cancellous bone with good vascularity, thus minimizing the risk of avascular necrosis and non-union. The typical appearance of AVN is varus collapse of the proximal fragment and cut-out of the compression screw. Screw cut-out occurs in between $1.1 \%$ and $6.8 \%$ of patients treated for an extracapsular fracture, and accounts for $85 \%$ of fixation failures [169-171]. The main causes of cut-out are fracture instability [172] and the incorrect placement of the lag screw. A position of the lag screw center-center or inferior-center (over the calcar) is preferred above other positions $[171,173]$. The most important predictor for cut-out is the tip apex distance (TAD), from the screw tip to the margin of the subchondral bone [174]. When the TAD was greater than $35 \mathrm{~mm}$, the cut-out rate was $30 \%$, while when TAD exceeded $45 \mathrm{~mm}$, the cut-out rate increased to $60 \%$. The best results have been reported with a TAD of less than $5 \mathrm{~mm}$ [173]. Other lag screw related problems are breakage and screw cut-through, sometimes with perforation of the acetabulum or other vital structures in the pelvis. To avoid implant failure in unstable trochanteric fractures different implant types with different screw designs have been developed. With the introduction of dual lag screw implants, a new complication occurred, known as the Z-effect. The Z-effect describes the appearance of lateral migration of the inferior lag screw and medial migration of the superior lag screw during the weight bearing rehabilitation period $[175,176]$. In this thesis we studied implant failure, in particular the Z-effect, after the use of dual lag screw implants for the treatment of trochanteric fractures. 


\section{ORTHOGERIATRICS}

Orthogeriatrics describes the multi-disciplinary approach to the management of frail and often complex patients presenting with fragility fracture to ensure that they receive appropriate and timely intervention to allow the best possible outcome [177]. An understanding of how the impact of trauma, anesthesia and surgery will affect patients with physical and cognitive frailty is essential. Three models of Orthogeriatric interventions were identified in literature [178]:

Model 1: Routine Geriatric Consultation - Care that takes place within an orthopaedic ward with consistent geriatrician consultation on older patients. In this model, the geriatrician is a consultant.

Model 2: Geriatric Ward - Care within a geriatric ward with the orthopaedic surgeon acting as a consultant and responsibility for the care is with the geriatrician.

Model 3: Shared Care - An integrated care model where the patient is within an orthopaedic ward, but both the orthopaedic surgeon and geriatrician share responsibility for the care of the patient. This model describes the geriatrician as an integral part of the orthopaedic team with team involvement.

Orthogeriatric care has resulted in demonstrable improvements in care for patients with hip fracture. An integrated orthogeriatric treatment in a Centre for Geriatric Traumatology in the Netherlands, showed a significant decrease in the 1-year mortality rate in the frail elderly patients with a hip fracture compared to the historical control patients who were treated with standard care $(23.2 \%$ vs $35.1 \%)$. A metaanalysis of orthogeriatric collaboration was associated with a significant reduction of in-hospital mortality (RR $0.60,95 \% \mathrm{Cl} 0.43-0.84$ ) and long-term mortality (RR $0.83,95 \% \mathrm{Cl} 0.74-0.94$ ). Length of stay (standardized mean difference, SMD -0.25 , $95 \% \mathrm{Cl}-0.44-0.05)$ was significantly reduced, particularly in the shared care model in comparison with other models (SMD $-0.61,95 \% \mathrm{Cl}-0.95--0.28)$, but heterogeneity limited this interpretation [178]. 


\section{AIM AND OUTLINE OF THIS THESIS}

The general aim of this thesis was to study several aspects of the diagnostic and therapeutic workup of the elderly patient with a fractured hip.

In chapter 2 we investigated the strength and reproducibility of the patella pubic percussion test (PPPT) to diagnose occult hip fractures. In chapter $\mathbf{3}$ and 4 we used the American College of Cardiology and American Heart Association guidelines for non-cardiac surgery to study preoperative cardiac screening in the elderly population with hip fracture. Furthermore, we reported on effects of delay to surgery and outcome after surgery in relation with cardiac risk. We investigated predictors for early and late mortality after hip fracture surgery. Chapter 5 reports on the incidence of erythrocyte blood transfusion (EBT) after hip fracture surgery and elaborates on the association between EBT and outcome. In chapter 6 we studied implant failure, in particular the Z-effect, after the use of dual lag screw implants for the treatment of trochanteric fractures. Finally, in chapter $\mathbf{7}$ the results of this thesis are discussed in a broader perspective. A summarizing discussion is provided which answers the following clinically relevant questions regarding this thesis and future perspectives:

1. Does the Patella Pubic Percussion Test (PPPT) have a place in modern practice?

2. Preoperative cardiac screening, how important is it?

3. Blood transfusions, do or don't?

4. What is the best implant choice for unstable trochanteric fractures?

In the appendices (Chapter 8) the most relevant findings from the 2007 and updated 2014 ACC/AHA guidelines regarding preoperative cardiac screening for hip fracture surgery are listed. 


\section{REFERENCES}

1. Lanting L.C. SC, Hertog PC den, Burgmans MJP: Heupfractuur, omvang van het probleem, hoe vaak komen heupfracturen voor en hoeveel mensen sterven eraan? Nationaal Kompas Volksgezondheid, Rijksinstituut voor Volksgezondheid en Milieu 2010.

2. Lanting LC SC, Hertog PC den, Brugmans MJP: Neemt het aantal mensen met heupfracturen toe of af? Nationaal Kompas Volksgezondheid 2006.

3. Ziekenhuisopnamen heupfracturen; geslacht, leeftijd en diagnose-indeling. National database, Centraal Bureau voor de Statistiek 2010.

4. Van der Klift M. BH, de Laet C.E.D.H., Pols H.A.P., Poos M.J.J.C., Gijsen R. : Neemt het aantal mensen met osteoporose toe of af? Nationaal Kompas Volksgezondheid, RIVM; 20032003.

5. Lotters FJ, van den Bergh JP, de Vries F, Rutten-van Molken MP: Current and Future Incidence and Costs of Osteoporosis-Related Fractures in The Netherlands: Combining Claims Data with BMD Measurements. Calcif Tissue Int 2016, 98(3):235-243.

6. Report on osteoporosis in the European Community: action for prevention. European Commission, Employment, Industrial Relations and Social Affairs DG 1998.

7. Browner B. D. LAM, Jupiter J.B., Trafton P.G., Krettek C.: Skeletal Trauma. 2008, 2:1914-1917.

8. Parker MJ: Missed hip fractures. Arch Emerg Med 1992, 9(1):23-27.

9. Stevens K, Tao C, Lee SU, Salem N, Vandevenne J, Cheng C, Neumann G, Valentin-Opran A, Lang P: Subchondral fractures in osteonecrosis of the femoral head: comparison of radiography, CT, and MR imaging. AJR Am J Roentgenol 2003, 180(2):363-368.

10. Perron AD, Miller MD, Brady WJ: Orthopedic pitfalls in the ED: radiographically occult hip fracture. Am J Emerg Med 2002, 20(3):234-237.

11. Dominguez S, Liu P, Roberts C, Mandell M, Richman PB: Prevalence of traumatic hip and pelvic fractures in patients with suspected hip fracture and negative initial standard radiographs--a study of emergency department patients. Academic emergency medicine : official journal of the Society for Academic Emergency Medicine 2005, 12(4):366-369.

12. Gill SK, Smith J, Fox R, Chesser TJ: Investigation of occult hip fractures: the use of CT and MRI. TheScientificWorldJournal 2013, 2013:830319.

13. Hossain M, Akbar SA, Andrew G: Misdiagnosis of occult hip fracture is more likely in patients with poor mobility and cognitive impairment. Acta orthopaedica Belgica 2010, 76(3):341-346.

14. Haubro M, Stougaard C, Torfing T, Overgaard S: Sensitivity and specificity of CT- and MRI-scanning in evaluation of occult fracture of the proximal 
femur. Injury 2015, 46(8):1557-1561.

15. Collin D, Dunker D, Gothlin JH, Geijer M: Observer variation for radiography, computed tomography, and magnetic resonance imaging of occult hip fractures. Acta radiologica (Stockholm, Sweden : 1987) 2011, 52(8):871874.

16. Verbeeten KM, Hermann KL, Hasselqvist M, Lausten GS, Joergensen P, Jensen CM, Thomsen HS: The advantages of MRI in the detection of occult hip fractures. Eur Radiol 2005, 15(1):165-169.

17. Thomas RW, Williams HL, Carpenter EC, Lyons K: The validity of investigating occult hip fractures using multidetector CT. Br J Radiol 2016, 89(1060):20150250.

18. Sadozai Z, Davies R, Warner J: The sensitivity of ct scans in diagnosing occult femoral neck fractures. Injury 2016, 47(12):2769-2771.

19. Mandell JC, Weaver MJ, Khurana B: Computed tomography for occult fractures of the proximal femur, pelvis, and sacrum in clinical practice: single institution, dual-site experience. Emerg Radiol 2018.

20. Werkgroep Nederlandse Vereniging van Heelkunde \& Nederlandse Orthopaedische Vereniging: Conceptrichtlijn Proximale femurfracturen. 2016.

21. Hossain M, Barwick C, Sinha AK, Andrew JG: Is magnetic resonance imaging (MRI) necessary to exclude occult hip fracture? Injury 2007, 38(10):1204-1208.

22. Jordan R, Dickenson E, Westacott D, Baraza N, Srinivasan K: A vast increase in the use of CT scans for investigating occult hip fractures. Eur $\mathrm{J}$ Radiol 2013, 82(8):e356-359.

23. Shiga $T$, Wajima $Z$, Ohe $Y$ : Is operative delay associated with increased mortality of hip fracture patients? Systematic review, meta-analysis, and meta-regression. Canadian journal of anaesthesia $=$ Journal canadien d'anesthesie 2008, 55(3):146-154.

24. Khan SK, Kalra S, Khanna A, Thiruvengada MM, Parker MJ: Timing of surgery for hip fractures: a systematic review of 52 published studies involving 291,413 patients. Injury 2009, 40(7):692-697.

25. Simunovic N, Devereaux PJ, Sprague S, Guyatt GH, Schemitsch E, Debeer $J$, Bhandari M: Effect of early surgery after hip fracture on mortality and complications: systematic review and meta-analysis. CMAJ : Canadian Medical Association journal $=$ journal de l'Association medicale canadienne 2010, 182(15):1609-1616. 
26. Smeets SJ, Poeze M, Verbruggen JP: Preoperative cardiac evaluation of geriatric patients with hip fracture. Injury 2012, 43(12):2146-2151.

27. Moja L, Piatti A, Pecoraro V, Ricci C, Virgili G, Salanti G, Germagnoli L, Liberati A, Banfi G: Timing matters in hip fracture surgery: patients operated within 48 hours have better outcomes. A meta-analysis and meta-regression of over 190,000 patients. PloS one 2012, 7(10):e46175.

28. Bottle A, Aylin P: Mortality associated with delay in operation after hip fracture: observational study. BMJ (Clinical research ed) 2006, 332(7547):947-951.

29. Orosz GM, Hannan EL, Magaziner J, Koval K, Gilbert M, Aufses A, Straus E, Vespe E, Siu AL: Hip fracture in the older patient: reasons for delay in hospitalization and timing of surgical repair. Journal of the American Geriatrics Society 2002, 50(8):1336-1340.

30. Charalambous CP, Yarwood S, Paschalides C, Siddique I, Hirst P, Paul A: Factors delaying surgical treatment of hip fractures in elderly patients. Ann R Coll Surg Engl 2003, 85(2):117-119.

31. Fleisher LA, Beckman JA, Brown KA, Calkins H, Chaikof E, Fleischmann KE, Freeman WK, Froehlich JB, Kasper EK, Kersten JR et al.: ACC/AHA 2007 guidelines on perioperative cardiovascular evaluation and care for noncardiac surgery: a report of the American College of Cardiology/American Heart Association Task Force on Practice Guidelines (Writing Committee to Revise the 2002 Guidelines on Perioperative Cardiovascular Evaluation for Noncardiac Surgery): developed in collaboration with the American Society of Echocardiography, American Society of Nuclear Cardiology, Heart Rhythm Society, Society of Cardiovascular Anesthesiologists, Society for Cardiovascular Angiography and Interventions, Society for Vascular Medicine and Biology, and Society for Vascular Surgery. Circulation 2007, 116(17):e418-499.

32. Fleisher LA, Fleischmann KE, Auerbach AD, Barnason SA, Beckman JA, Bozkurt B, Davila-Roman VG, Gerhard-Herman MD, Holly TA, Kane GC et al.: 2014 ACC/AHA guideline on perioperative cardiovascular evaluation and management of patients undergoing noncardiac surgery: executive summary: a report of the American College of Cardiology/American Heart Association Task Force on practice guidelines. Developed in collaboration with the American College of Surgeons, American Society of Anesthesiologists, American Society of Echocardiography, American Society of Nuclear Cardiology, Heart Rhythm Society, Society for Cardiovascular Angiography and Interventions, Society of Cardiovascular 
Anesthesiologists, and Society of Vascular Medicine Endorsed by the Society of Hospital Medicine. Journal of nuclear cardiology : official publication of the American Society of Nuclear Cardiology 2015, 22(1):162215.

33. Chong CP, van Gaal WJ, Savige J, Lim WK: Cardiac injury and troponin testing after orthopaedic surgery. Injury 2011, 42(9):855-863.

34. Spurrier E, Wordsworth D, Martin S, Norris R, Parker MJ: Troponin T in hip fracture patients: prognostic significance for mortality at one year. Hip Int 2011, 21(6):757-761.

35. Vallet H, Breining A, Le Manach Y, Cohen-Bittan J, Meziere A, Raux M, Verny M, Riou B, Khiami F, Boddaert J: Isolated cardiac troponin rise does not modify the prognosis in elderly patients with hip fracture. Medicine 2017, 96(7):e6169.

36. Hietala P, Strandberg M, Strandberg N, Gullichsen E, Airaksinen KE: Perioperative myocardial infarctions are common and often unrecognized in patients undergoing hip fracture surgery. J Trauma Acute Care Surg 2013, 74(4):1087-1091.

37. Nettleman MD, Alsip J, Schrader M, Schulte M: Predictors of mortality after acute hip fracture. J Gen Intern Med 1996, 11(12):765-767.

38. Perez JV, Warwick DJ, Case CP, Bannister GC: Death after proximal femoral fracture--an autopsy study. Injury 1995, 26(4):237-240.

39. Canty DJ, Royse CF, Kilpatrick D, Bowyer A, Royse AG: The impact on cardiac diagnosis and mortality of focused transthoracic echocardiography in hip fracture surgery patients with increased risk of cardiac disease: a retrospective cohort study. Anaesthesia 2012, 67(11):1202-1209.

40. Kertai MD, Bountioukos M, Boersma E, Bax JJ, Thomson IR, Sozzi F, Klein $\mathrm{J}$, Roelandt JR, Poldermans D: Aortic stenosis: an underestimated risk factor for perioperative complications in patients undergoing noncardiac surgery. The American journal of medicine 2004, 116(1):8-13.

41. Ramakrishna G, Sprung J, Ravi BS, Chandrasekaran K, McGoon MD: Impact of pulmonary hypertension on the outcomes of noncardiac surgery: predictors of perioperative morbidity and mortality. Journal of the American College of Cardiology 2005, 45(10):1691-1699.

42. Das P, Pocock C, Chambers J: The patient with a systolic murmur: severe aortic stenosis may be missed during cardiovascular examination. QJM : monthly journal of the Association of Physicians 2000, 93(10):685-688.

43. McBrien ME, Heyburn G, Stevenson M, McDonald S, Johnston NJ, Elliott 
JR, Beringer TR: Previously undiagnosed aortic stenosis revealed by auscultation in the hip fracture population--echocardiographic findings, management and outcome. Anaesthesia 2009, 64(8):863-870.

44. Royse CF: Ultrasound-guided haemodynamic state assessment. Best practice \& research Clinical anaesthesiology 2009, 23(3):273-283.

45. Christ M, Sharkova Y, Geldner G, Maisch B: Preoperative and perioperative care for patients with suspected or established aortic stenosis facing noncardiac surgery. Chest 2005, 128(4):2944-2953.

46. Alibhai M, Sharma A, Alibhai MK, Fawdington RA, Moreau AP: Does preoperative echocardiography delay hip fracture surgery? Indian journal of anaesthesia 2013, 57(4):408-410.

47. Mutlu H, Bilgili F, Mutlu S, Karaman O, Cakal B, Ozkaya U: The effects of preoperative non-invasive cardiac tests on delay to surgery and subsequent mortality in elderly patients with hip fracture. Journal of back and musculoskeletal rehabilitation 2016, 29(1):49-54.

48. Stitgen A, Poludnianyk K, Dulaney-Cripe E, Markert R, Prayson M: Adherence to Preoperative Cardiac Clearance Guidelines in Hip Fracture Patients. J Orthop Trauma 2015, 29(11):500-503.

49. Jettoo P, Kakwani R, Junejo S, Talkhani I, Dixon P: Pre-operative echocardiogram in hip fracture patients with cardiac murmur--an audit. J Orthop Surg Res 2011, 6:49.

50. O'HEireamhoin S, Beyer T, Ahmed M, Mulhall KJ: The role of preoperative cardiac investigation in emergency hip surgery. J Trauma 2011, 71(5):13451347.

51. Adair C, Swart E, Seymour R, Patt J, Karunakar MA: Clinical Practice Guidelines Decrease Unnecessary Echocardiograms Before Hip Fracture Surgery. The Journal of bone and joint surgery American volume 2017, 99(8):676-680.

52. Luger TJ, Kammerlander C, Gosch M, Luger MF, Kammerlander-Knauer $\mathrm{U}$, Roth $\mathrm{T}$, Kreutziger $\mathrm{J}$ : Neuroaxial versus general anaesthesia in geriatric patients for hip fracture surgery: does it matter? Osteoporos Int 2010, 21(Suppl 4):S555-572.

53. Hausman MS, Jr., Jewell ES, Engoren M: Regional versus general anesthesia in surgical patients with chronic obstructive pulmonary disease: does avoiding general anesthesia reduce the risk of postoperative complications? Anesth Analg 2015, 120(6):1405-1412.

54. Singelyn FJ, Ferrant T, Malisse MF, Joris D: Effects of intravenous patient- 
controlled analgesia with morphine, continuous epidural analgesia, and continuous femoral nerve sheath block on rehabilitation after unilateral totalhip arthroplasty. Regional anesthesia and pain medicine 2005, 30(5):452457.

55. Macario A, Dexter F: What are the most important risk factors for a patient's developing intraoperative hypothermia? Anesthesia and analgesia 2002, 94(1):215-220, table of contents.

56. Macfarlane AJ, Prasad GA, Chan VW, Brull R: Does regional anaesthesia improve outcome after total hip arthroplasty? A systematic review. British journal of anaesthesia 2009, 103(3):335-345.

57. Pavlin JD, Kent CD: Recovery after ambulatory anesthesia. Current opinion in anaesthesiology 2008, 21(6):729-735.

58. Longo S: Regional versus general anesthesia. Current opinion in anaesthesiology 2000, 13(5):539-543.

59. Scibelli G, Maio L, Savoia G: Regional anaesthesia and antithrombotic agents: instructions for use. Minerva anestesiologica 2017, 83(3):321 - 335.

60. Standl T: [New oral anticoagulants. Regional anaesthesia and new oral anticoagulants]. Anasthesiologie, Intensivmedizin, Notfallmedizin, Schmerztherapie : AINS 2014, 49(3):192-195.

61. R.L. Hines KEM, Stoelting's anesthesia and co-existing disease (6th ed.), Elsevier Saunders, Philadelphia (2012), pp. 40-42: Stoelting's anesthesia and co-existing disease. 2012, 6th edition:pp. 40-42.

62. Moore JM: Continuous spinal anesthesia. American journal of therapeutics 2009, 16(4):289-294.

63. Messina A, Frassanito L, Colombo D, Vergari A, Draisci G, Della Corte F, Antonelli M: Hemodynamic changes associated with spinal and general anesthesia for hip fracture surgery in severe ASA III elderly population: a pilot trial. Minerva anestesiologica 2013, 79(9):1021-1029.

64. Biboulet P, Jourdan A, Van Haevre V, Morau D, Bernard N, Bringuier S, Capdevila $X$ : Hemodynamic profile of target-controlled spinal anesthesia compared with 2 target-controlled general anesthesia techniques in elderly patients with cardiac comorbidities. Regional anesthesia and pain medicine 2012, 37(4):433-440.

65. Parker MJ, Urwin SC, Handoll HH, Griffiths R: General versus spinal/epidural anaesthesia for surgery for hip fractures in adults. The Cochrane database of systematic reviews 2000(2):Cd000521.

66. Parker MJ, Handoll HH, Griffiths R: Anaesthesia for hip fracture surgery in 
adults. The Cochrane database of systematic reviews 2001(4):Cd000521.

67. Parker MJ, Handoll HH, Griffiths R: Anaesthesia for hip fracture surgery in adults. The Cochrane database of systematic reviews 2004(4):Cd000521.

68. Roberts KC, BroxWT, Jevsevar DS, Sevarino K: Management of hip fractures in the elderly. The Journal of the American Academy of Orthopaedic Surgeons 2015, 23(2):131-137.

69. Foss NB, Kehlet H: Hidden blood loss after surgery for hip fracture. J Bone Joint Surg Br 2006, 88(8):1053-1059.

70. Praetorius K, Madsen CM, Abrahamsen B, Jorgensen HL, Lauritzen JB, Laulund AS: Low Levels of Hemoglobin at Admission Are Associated With Increased 30-Day Mortality in Patients With Hip Fracture. Geriatr Orthop Surg Rehabil 2016, 7(3):115-120.

71. Foss NB, Kristensen MT, Kehlet $\mathrm{H}$ : Anaemia impedes functional mobility after hip fracture surgery. Age Ageing 2008, 37(2):173-178.

72. Brunskill SJ, Millette SL, Shokoohi A, Pulford EC, Doree C, Murphy MF, Stanworth S: Red blood cell transfusion for people undergoing hip fracture surgery. Cochrane Database Syst Rev 2015(4):CD009699.

73. Carson JL, Sieber F, Cook DR, Hoover DR, Noveck H, Chaitman BR, Fleisher L, Beaupre L, Macaulay W, Rhoads GG et al.: Liberal versus restrictive blood transfusion strategy: 3-year survival and cause of death results from the FOCUS randomised controlled trial. Lancet 2015, 385(9974):11831189 .

74. Hodgetts TJ, Mahoney PF, Kirkman E: Damage control resuscitation. J R Army Med Corps 2007, 153(4):299-300.

75. Kirkman E, Watts S, Hodgetts T, Mahoney P, Rawlinson S, Midwinter M: A proactive approach to the coagulopathy of trauma: the rationale and guidelines for treatment. J R Army Med Corps 2007, 153(4):302-306.

76. Cap AP, Baer DG, Orman JA, Aden J, Ryan K, Blackbourne LH: Tranexamic acid for trauma patients: a critical review of the literature. J Trauma 2011, 71(1 Suppl):S9-14.

77. Lee C, Freeman R, Edmondson M, Rogers BA: The efficacy of tranexamic acid in hip hemiarthroplasty surgery: an observational cohort study. Injury 2015, 46(10):1978-1982.

78. Wang W, Yu J: Tranexamic acid reduces blood loss in intertrochanteric fractures: A meta-analysis from randomized controlled trials. Medicine (Baltimore) 2017, 96(52):e9396.

79. Watts CD, Houdek MT, Sems SA, Cross WW, Pagnano MW: Tranexamic 
Acid Safely Reduced Blood Loss in Hemi- and Total Hip Arthroplasty for Acute Femoral Neck Fracture: A Randomized Clinical Trial. J Orthop Trauma 2017, 31(7):345-351.

80. Baskaran D, Rahman S, Salmasi Y, Froghi S, Berber O, George M: Effect of tranexamic acid use on blood loss and thromboembolic risk in hip fracture surgery: systematic review and meta-analysis. Hip Int 2017:0.

81. Zhang $P, \mathrm{He} J$, Fang $\mathrm{Y}$, Chen P, Liang $\mathrm{Y}$, Wang J: Efficacy and safety of intravenous tranexamic acid administration in patients undergoing hip fracture surgery for hemostasis: A meta-analysis. Medicine (Baltimore) 2017, 96(21):e6940.

82. Pauwels F: Der schenkelhalsbruch ein mechanisches problem Zeitschrift für orthopädische chirurgie 1935.

83. Pauwels F: Gesammete Abhandungen zur funktionellen Anatomie des Bewegungs apparates 1965.

84. Garden RS: Low-angle fixation in fractures of the femoral neck. The Bone \& Joint Journal 1961.

85. Mears SC: Classification and surgical approaches to hip fractures for nonsurgeons. Clinics in geriatric medicine 2014, 30(2):229-241.

86. Mittal R, Banerjee S: Proximal femoral fractures: Principles of management and review of literature. J Clin Orthop Trauma 2012, 3(1):15-23.

87. Handoll HH, Parker MJ: Conservative versus operative treatment for hip fractures in adults. The Cochrane database of systematic reviews 2008(3):Cd000337.

88. Xu DF, Bi FG, Ma CY, Wen ZF, Cai XZ: A systematic review of undisplaced femoral neck fracture treatments for patients over 65 years of age, with a focus on union rates and avascular necrosis. J Orthop Surg Res 2017, 12(1):28.

89. Habermann ET, Sachs R, Stern RE, Hirsh DM, Anderson WJ, Jr.: The pathology and treatment of metastatic disease of the femur. Clinical orthopaedics and related research 1982(169):70-82.

90. Lane JM, Sculco TP, Zolan S: Treatment of pathological fractures of the hip by endoprosthetic replacement. The Journal of bone and joint surgery American volume 1980, 62(6):954-959.

91. Marco RA, Sheth DS, Boland PJ, Wunder JS, Siegel JA, Healey JH: Functional and oncological outcome of acetabular reconstruction for the treatment of metastatic disease. The Journal of bone and joint surgery American volume 2000, 82(5):642-651. 
92. Clarke HD, Damron TA, Sim FH: Head and neck replacement endoprosthesis for pathologic proximal femoral lesions. Clinical orthopaedics and related research 1998(353):210-217.

93. Algan SM, Horowitz SM: Surgical treatment of pathologic hip lesions in patients with metastatic disease. Clinical orthopaedics and related research 1996(332):223-231.

94. Parker MJ, Raghavan R, Gurusamy K: Incidence of fracture-healing complications after femoral neck fractures. Clinical orthopaedics and related research 2007, 458:175-179.

95. Chua D, Jaglal SB, Schatzker J: Predictors of early failure of fixation in the treatment of displaced subcapital hip fractures. Journal of orthopaedic trauma 1998, 12(4):230-234.

96. Tidermark J, Ponzer S, Svensson O, Soderqvist A, Tornkvist H: Internal fixation compared with total hip replacement for displaced femoral neck fractures in the elderly. A randomised, controlled trial. The Journal of bone and joint surgery British volume 2003, 85(3):380-388.

97. Rogmark C, Carlsson A, Johnell O, Sernbo I: A prospective randomised trial of internal fixation versus arthroplasty for displaced fractures of the neck of the femur. Functional outcome for 450 patients at two years. The Journal of bone and joint surgery British volume 2002, 84(2):183-188.

98. Leonardsson O, Sernbo I, Carlsson A, Akesson K, Rogmark C: Long-term follow-up of replacement compared with internal fixation for displaced femoral neck fractures: results at ten years in a randomised study of 450 patients. The Journal of bone and joint surgery British volume 2010, 92(3):406-412.

99. Murphy DK, Randell T, Brennan KL, Probe RA, Brennan ML: Treatment and displacement affect the reoperation rate for femoral neck fracture. Clinical orthopaedics and related research 2013, 471(8):2691-2702.

100. Duckworth AD, Bennet SJ, Aderinto J, Keating JF: Fixation of intracapsular fractures of the femoral neck in young patients: risk factors for failure. The Journal of bone and joint surgery British volume 2011, 93(6):811-816.

101. Heetveld MJ, Raaymakers EL, Luitse JS, Nijhof M, Gouma DJ: Femoral neck fractures: can physiologic status determine treatment choice? Clinical orthopaedics and related research 2007, 461:203-212.

102. Zhang X, Liu Y, Ren K, Liu J, Zhu B, Sun Z: [Secondary total hip arthroplasty for osteonecrosis of femoral head after failed internal fixation of femoral neck fracture]. Zhongguo xiu fu chong jian wai ke za zhi = Zhongguo xiufu 
chongjian waike zazhi $=$ Chinese journal of reparative and reconstructive surgery 2010, 24(3):257-261.

103. van Dortmont LM, Douw CM, van Breukelen AM, Laurens DR, Mulder PG, Wereldsma JC, van Vugt AB: Outcome after hemi-arthroplasty for displaced intracapsular femoral neck fracture related to mental state. Injury 2000, 31(5):327-331.

104. Hedbeck CJ, Inngul C, Blomfeldt R, Ponzer S, Tornkvist H, Enocson A: Internal fixation versus cemented hemiarthroplasty for displaced femoral neck fractures in patients with severe cognitive dysfunction: a randomized controlled trial. Journal of orthopaedic trauma 2013, 27(12):690-695.

105. Olofsson B, Stenvall M, Lundstrom M, Gustafson Y, Svensson O: Mental status and surgical methods in patients with femoral neck fracture. Orthopedic nursing 2009, 28(6):305-313.

106. Blomfeldt R, Tornkvist H, Ponzer S, Soderqvist A, Tidermark J: Comparison of internal fixation with total hip replacement for displaced femoral neck fractures. Randomized, controlled trial performed at four years. The Journal of bone and joint surgery American volume 2005, 87(8):1680-1688.

107. Langslet E, Frihagen F, Opland V, Madsen JE, Nordsletten L, Figved W: Cemented versus uncemented hemiarthroplasty for displaced femoral neck fractures: 5-year followup of a randomized trial. Clinical orthopaedics and related research 2014, 472(4):1291-1299.

108. Tol MC, van den Bekerom MP, Sierevelt IN, Hilverdink EF, Raaymakers EL, Goslings JC: Hemiarthroplasty or total hip arthroplasty for the treatment of a displaced intracapsular fracture in active elderly patients: 12-year follow-up of randomised trial. The bone \& joint journal 2017, 99-b(2):250-254.

109. van den Bekerom MP, Hilverdink EF, Sierevelt IN, Reuling EM, Schnater JM, Bonke H, Goslings JC, van Dijk CN, Raaymakers EL: A comparison of hemiarthroplasty with total hip replacement for displaced intracapsular fracture of the femoral neck: a randomised controlled multicentre trial in patients aged 70 years and over. The Journal of bone and joint surgery British volume 2010, 92(10):1422-1428.

110. Taylor F, Wright M, Zhu M: Hemiarthroplasty of the hip with and without cement: a randomized clinical trial. The Journal of bone and joint surgery American volume 2012, 94(7):577-583.

111. Rogmark $\mathrm{C}$, Johnell $\mathrm{O}$ : Primary arthroplasty is better than internal fixation of displaced femoral neck fractures: a meta-analysis of 14 randomized studies with 2,289 patients. Acta orthopaedica 2006, 77(3):359-367. 
112. National Clinical Guideline C: National Institute for Health and Clinical Excellence: Guidance. In: The Management of Hip Fracture in Adults. edn. London: Royal College of Physicians (UK)

National Clinical Guideline Centre.; 2011.

113. Veldman HD, Heyligers IC, Grimm B, Boymans TA: Cemented versus cementless hemiarthroplasty for a displaced fracture of the femoral neck: a systematic review and meta-analysis of current generation hip stems. The bone \& joint journal 2017, 99-b(4):421-431.

114. Chammout G, Muren O, Laurencikas E, Boden H, Kelly-Pettersson P, Sjoo $H$, Stark A, Skoldenberg O: More complications with uncemented than cemented femoral stems in total hip replacement for displaced femoral neck fractures in the elderly. Acta orthopaedica 2017, 88(2):145-151.

115. M M: AO Classification of Fractures - Long Bones. Springer-Verlag, Berlin Heidelberg 1987.

116. Blundell CM, Parker MJ, Pryor GA, Hopkinson-Woolley J, Bhonsle SS: Assessment of the $\mathrm{AO}$ classification of intracapsular fractures of the proximal femur. The Journal of bone and joint surgery British volume 1998, 80(4):679-683.

117. Pervez H, Parker MJ, Pryor GA, Lutchman L, Chirodian N: Classification of trochanteric fracture of the proximal femur: a study of the reliability of current systems. Injury 2002, 33(8):713-715.

118. Parker MJ, Bowers TR, Pryor GA: Sliding hip screw versus the Targon PF nail in the treatment of trochanteric fractures of the hip: a randomised trial of 600 fractures. The Journal of bone and joint surgery British volume 2012, 94(3):391-397.

119. Zhu Q, Xu X, Yang X, Chen X, Wang L, Liu C, Lin P: Intramedullary nails versus sliding hip screws for AO/OTA 31-A2 trochanteric fractures in adults: A meta-analysis. International journal of surgery (London, England) 2017, 43:67-74.

120. Fielding JW, Cochran GV, Zickel RE: Biomechanical characteristics and surgical management of subtrochanteric fractures. The Orthopedic clinics of North America 1974, 5(3):629-650.

121. Lundy DW: Subtrochanteric femoral fractures. J Am Acad Orthop Surg 2007, 15(11):663-671.

122. Kuzyk PR, Bhandari M, McKee MD, Russell TA, Schemitsch EH: Intramedullary versus extramedullary fixation for subtrochanteric femur fractures. Journal of orthopaedic trauma 2009, 23(6):465-470. 
123. Papasimos S, Koutsojannis CM, Panagopoulos A, Megas P, Lambiris E: A randomised comparison of $\mathrm{AMBI}$, TGN and PFN for treatment of unstable trochanteric fractures. Archives of orthopaedic and trauma surgery 2005, 125(7):462-468.

124. Haynes RC, Poll RG, Miles AW, Weston RB: Failure of femoral head fixation: a cadaveric analysis of lag screw cut-out with the gamma locking nail and AO dynamic hip screw. Injury 1997, 28(5-6):337-341.

125. Kim KK, Won Y, Smith DH, Lee GS, Lee HY: Clinical Results of Complex Subtrochanteric Femoral Fractures with Long Cephalomedullary Hip Nail. Hip \& pelvis 2017, 29(2):113-119.

126. Chung P.H. KS, Kim J.P., Kim Y.S., Lee H.M., Huh D.J.: Treatment of unstable pertrochanteric fractures with a long intramedullary nail. Hip Pelvis. 2013(25):25:51-56.

127. Menzies IB, Mendelson DA, Kates SL, Friedman SM: The impact of comorbidity on perioperative outcomes of hip fractures in a geriatric fracture model. Geriatric orthopaedic surgery \& rehabilitation 2012, 3(3):129-134.

128. Chong CP, Savige JA, Lim WK: Medical problems in hip fracture patients. Archives of orthopaedic and trauma surgery 2010, 130(11):1355-1361.

129. Carpintero P, Caeiro JR, Carpintero R, Morales A, Silva S, Mesa M: Complications of hip fractures: A review. World journal of orthopedics 2014, 5(4):402-411.

130. Donegan DJ, Gay AN, Baldwin K, Morales EE, Esterhai JL, Jr., Mehta S: Use of medical comorbidities to predict complications after hip fracture surgery in the elderly. The Journal of bone and joint surgery American volume 2010, 92(4):807-813.

131. Roche JJ, Wenn RT, Sahota O, Moran CG: Effect of comorbidities and postoperative complications on mortality after hip fracture in elderly people: prospective observational cohort study. BMJ (Clinical research ed) 2005, 331(7529): 1374.

132. Monte-Secades R, Pena-Zemsch M, Rabunal-Rey R, Bal-Alvaredo M, Pazos-Ferro A, Mateos-Colino A: [Risk factors for the development of medical complications in patients with hip fracture]. Revista de calidad asistencial : organo de la Sociedad Espanola de Calidad Asistencial 2011, 26(2):76-82.

133. Moerman S, Mathijssen NMC, Niesten DD, Riedijk R, Rijnberg WJ, Koeter S, Kremers van de Hei K, Tuinebreier WE, Molenaar TL, Nelissen R et al.: More complications in uncemented compared to cemented hemiarthroplasty 
for displaced femoral neck fractures: a randomized controlled trial of 201 patients, with one year follow-up. BMC musculoskeletal disorders 2017, 18(1):169.

134. Ovesen O, Andersen M, Poulsen T, Nymark T, Overgaard S, Rock ND: The trochanteric gamma nail versus the dynamic hip screw: a prospective randomised study. One-year follow-up of 146 intertrochanteric fractures. Hip international : the journal of clinical and experimental research on hip pathology and therapy 2006, 16(4):293-298.

135. Gustafson Y, Berggren D, Brannstrom B, Bucht G, Norberg A, Hansson LI, Winblad B: Acute confusional states in elderly patients treated for femoral neck fracture. Journal of the American Geriatrics Society 1988, 36(6):525530.

136. Beaupre LA, Jones CA, Saunders LD, Johnston DW, Buckingham J, Majumdar SR: Best practices for elderly hip fracture patients. A systematic overview of the evidence. Journal of general internal medicine 2005, 20(11):1019-1025.

137. Lawrence VA, Hilsenbeck SG, Noveck H, Poses RM, Carson JL: Medical complications and outcomes after hip fracture repair. Archives of internal medicine 2002, 162(18):2053-2057.

138. Martinsen MI, Valland H, Solheim LF, Holvik K, Ranhoff A: A restrictive policy for red blood cell transfusion in older hip fracture patients: experiences from a patient register. BMC research notes 2016, 9:75.

139. Desai SJ, Wood KS, Marsh J, Bryant D, Abdo H, Lawendy AR, Sanders DW: Factors affecting transfusion requirement after hip fracture: can we reduce the need for blood? Canadian journal of surgery Journal canadien de chirurgie 2014, 57(5):342-348.

140. Engoren M, Mitchell E, Perring P, Sferra J: The effect of erythrocyte blood transfusions on survival after surgery for hip fracture. The Journal of trauma 2008, 65(6):1411-1415.

141. Verlicchi F, Desalvo F, Zanotti G, Morotti L, Tomasini I: Red cell transfusion in orthopaedic surgery: a benchmark study performed combining data from different data sources. Blood transfusion = Trasfusione del sangue 2011, 9(4):383-387.

142. Sathiyakumar V, Greenberg SE, Jahangir AA, Mir HH, Obremskey WT, Sethi MK: Impact of type of surgery on deep venous thrombi and pulmonary emboli: a look at twenty seven thousand hip fracture patients. Int Orthop 2015, 39(10):2017-2022. 
143. Giannoulis D, Calori GM, Giannoudis PV: Thirty-day mortality after hip fractures: has anything changed? European journal of orthopaedic surgery \& traumatology : orthopedie traumatologie 2016, 26(4):365-370.

144. Maxwell MJ, Moran CG, Moppett IK: Development and validation of a preoperative scoring system to predict 30 day mortality in patients undergoing hip fracture surgery. British journal of anaesthesia 2008, 101(4):511-517.

145. Braithwaite RS, Col NF, Wong JB: Estimating hip fracture morbidity, mortality and costs. Journal of the American Geriatrics Society 2003, 51(3):364-370.

146. Clement ND, Green K, Murray N, Duckworth AD, McQueen MM, CourtBrown CM: Undisplaced intracapsular hip fractures in the elderly: predicting fixation failure and mortality. A prospective study of 162 patients. Journal of orthopaedic science : official journal of the Japanese Orthopaedic Association 2013, 18(4):578-585.

147. Windolf M, Braunstein V, Dutoit C, Schwieger K: Is a helical shaped implant a superior alternative to the Dynamic Hip Screw for unstable femoral neck fractures? A biomechanical investigation. Clinical biomechanics (Bristol, Avon) 2009, 24(1):59-64.

148. Aldebeyan S, Nooh A, Aoude A, Weber MH, Harvey EJ: Hypoalbuminaemia-a marker of malnutrition and predictor of postoperative complications and mortality after hip fractures. Injury 2017, 48(2):436-440.

149. Bell JJ, Pulle RC, Crouch AM, Kuys SS, Ferrier RL, Whitehouse SL: Impact of malnutrition on 12-month mortality following acute hip fracture. ANZ journal of surgery 2016, 86(3):157-161.

150. Ekstrom W, Al-Ani AN, Saaf M, Cederholm T, Ponzer S, Hedstrom M: Health related quality of life, reoperation rate and function in patients with diabetes mellitus and hip fracture--a 2 year follow-up study. Injury 2013, 44(6):769775.

151. Norris R, Parker M: Diabetes mellitus and hip fracture: a study of 5966 cases. Injury 2011, 42(11):1313-1316.

152. Sambandam SN, Chandrasekharan J, Mounasamy V, Mauffrey C: Intertrochanteric fractures: a review of fixation methods. European journal of orthopaedic surgery \& traumatology : orthopedie traumatologie 2016, 26(4):339-353.

153. Mathews V, Cabanela ME: Femoral neck nonunion treatment. Clinical orthopaedics and related research 2004(419):57-64.

154. Gregersen M, Krogshede A, Brink O, Damsgaard EM: Prediction of 
Reoperation of Femoral Neck Fractures Treated With Cannulated Screws in Elderly Patients. Geriatric orthopaedic surgery \& rehabilitation 2015, 6(4):322-327.

155. Weil NL, van Embden D, Hoogendoorn JM: Radiographic fracture features predicting failure of internal fixation of displaced femoral neck fractures. European journal of trauma and emergency surgery : official publication of the European Trauma Society 2015, 41(5):501-507.

156. Song HK, Choi HJ, Yang KH: Risk factors of avascular necrosis of the femoral head and fixation failure in patients with valgus angulated femoral neck fractures over the age of 50 years. Injury 2016, 47(12):2743-2748.

157. Lu-Yao GL, Keller RB, Littenberg B, Wennberg JE: Outcomes after displaced fractures of the femoral neck. A meta-analysis of one hundred and six published reports. The Journal of bone and joint surgery American volume 1994, 76(1): 15-25.

158. Jain R, Koo M, Kreder HJ, Schemitsch EH, Davey JR, Mahomed NN: Comparison of early and delayed fixation of subcapital hip fractures in patients sixty years of age or less. The Journal of bone and joint surgery American volume 2002, 84-a(9):1605-1612.

159. Broderick JM, Bruce-Brand R, Stanley E, Mulhall KJ: Osteoporotic hip fractures: the burden of fixation failure. TheScientificWorldJournal 2013, 2013:515197.

160. Yang Z, Liu H, Xie X, Tan Z, Qin T, Kang P: Total Hip Arthroplasty for Failed Internal Fixation After Femoral Neck Fracture Versus That for Acute Displaced Femoral Neck Fracture: A Comparative Study. The Journal of arthroplasty 2015, 30(8):1378-1383.

161. Srivastav S, Mittal V, Agarwal S: Total hip arthroplasty following failed fixation of proximal hip fractures. Indian journal of orthopaedics 2008, 42(3):279286.

162. Ko CK, Law SW, Chiu KH: Enhanced soft tissue repair using locking loop stitch after posterior approach for hip hemiarthroplasty. The Journal of arthroplasty 2001, 16(2):207-211.

163. Pellicci PM, Bostrom M, Poss R: Posterior approach to total hip replacement using enhanced posterior soft tissue repair. Clinical orthopaedics and related research 1998(355):224-228.

164. Demos HA, Rorabeck CH, Bourne RB, MacDonald SJ, McCalden RW: Instability in primary total hip arthroplasty with the direct lateral approach. Clinical orthopaedics and related research 2001(393):168-180. 
165. Kaiser D, Kamath AF, Zingg P, Dora C: Double mobility cup total hip arthroplasty in patients at high risk for dislocation: a single-center analysis. Archives of orthopaedic and trauma surgery 2015, 135(12):1755-1762.

166. Katz JN, Wright EA, Wright J, Malchau H, Mahomed NN, Stedman M, Baron JA, Losina E: Twelve-year risk of revision after primary total hip replacement in the U.S. Medicare population. The Journal of bone and joint surgery American volume 2012, 94(20):1825-1832.

167. Marang-van de Mheen PJ, Bragan Turner E, Liew S, Mutalima N, Tran T, Rasmussen S, Nelissen R, Gordon A: Variation in Prosthetic Joint Infection and treatment strategies during 4.5 years of follow-up after primary joint arthroplasty using administrative data of 41397 patients across Australian, European and United States hospitals. BMC musculoskeletal disorders 2017, 18(1):207.

168. Koval KJ, Zuckerman JD: Hip Fractures: II. Evaluation and Treatment of Intertrochanteric Fractures. The Journal of the American Academy of Orthopaedic Surgeons 1994, 2(3):150-156.

169. Lorich DG, Geller DS, Nielson JH: Osteoporotic pertrochanteric hip fractures: management and current controversies. Instructional course lectures 2004, 53:441-454.

170. Lobo-Escolar A, Joven E, Iglesias D, Herrera A: Predictive factors for cutting-out in femoral intramedullary nailing. Injury 2010, 41(12):1312-1316.

171. Hsueh KK, Fang CK, Chen CM, Su YP, Wu HF, Chiu FY: Risk factors in cutout of sliding hip screw in intertrochanteric fractures: an evaluation of 937 patients. International orthopaedics 2010, 34(8):1273-1276.

172. Kim WY, Han CH, Park JI, Kim JY: Failure of intertrochanteric fracture fixation with a dynamic hip screw in relation to pre-operative fracture stability and osteoporosis. International orthopaedics 2001, 25(6):360-362.

173. Kyle RF, Cabanela ME, Russell TA, Swiontkowski MF, Winquist RA, Zuckerman JD, Schmidt AH, Koval KJ: Fractures of the proximal part of the femur. Instructional course lectures 1995, 44:227-253.

174. Baumgaertner MR, Curtin SL, Lindskog DM, Keggi JM: The value of the tipapex distance in predicting failure of fixation of peritrochanteric fractures of the hip. The Journal of bone and joint surgery American volume 1995, 77(7):1058-1064.

175. Pires RE, Santana EO, Jr., Santos LE, Giordano V, Balbachevsky D, Dos Reis FB: Failure of fixation of trochanteric femur fractures: Clinical recommendations for avoiding Z-effect and reverse Z-effect type 
complications. Patient safety in surgery 2011, 5:17.

176. Werner-Tutschku W, Lajtai G, Schmiedhuber G, Lang T, Pirkl C, Orthner $E$ : [Intra- and perioperative complications in the stabilization of per- and subtrochanteric femoral fractures by means of PFN]. Der Unfallchirurg 2002, 105(10):881-885.

177. Wilson $\mathrm{H}$ : Orthogeriatrics in Hip Fracture. Open Orthop J 2017, 11:11811189.

178. Grigoryan KV, Javedan H, Rudolph JL: Orthogeriatric care models and outcomes in hip fracture patients: a systematic review and meta-analysis. J Orthop Trauma 2014, 28(3):e49-55.

179. Folbert EC, Hegeman JH, Vermeer M, Regtuijt EM, van der Velde D, Ten Duis HJ, Slaets JP: Improved 1-year mortality in elderly patients with a hip fracture following integrated orthogeriatric treatment. Osteoporos Int 2017, 28(1):269-277. 



\section{CHAPTER}

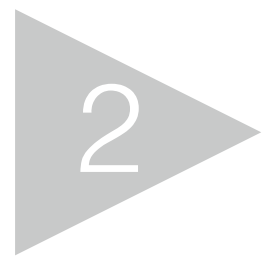

The patellar pubic percussion test (PPPT): A simple bedside tool for suspected occult hip fractures

S.J.M. Smeets, W. Vening, M.B. Winkes, G.P. Kuijt, G.D. Slooter, P.V. van Eerten

International Orthopaedics Nov 2018

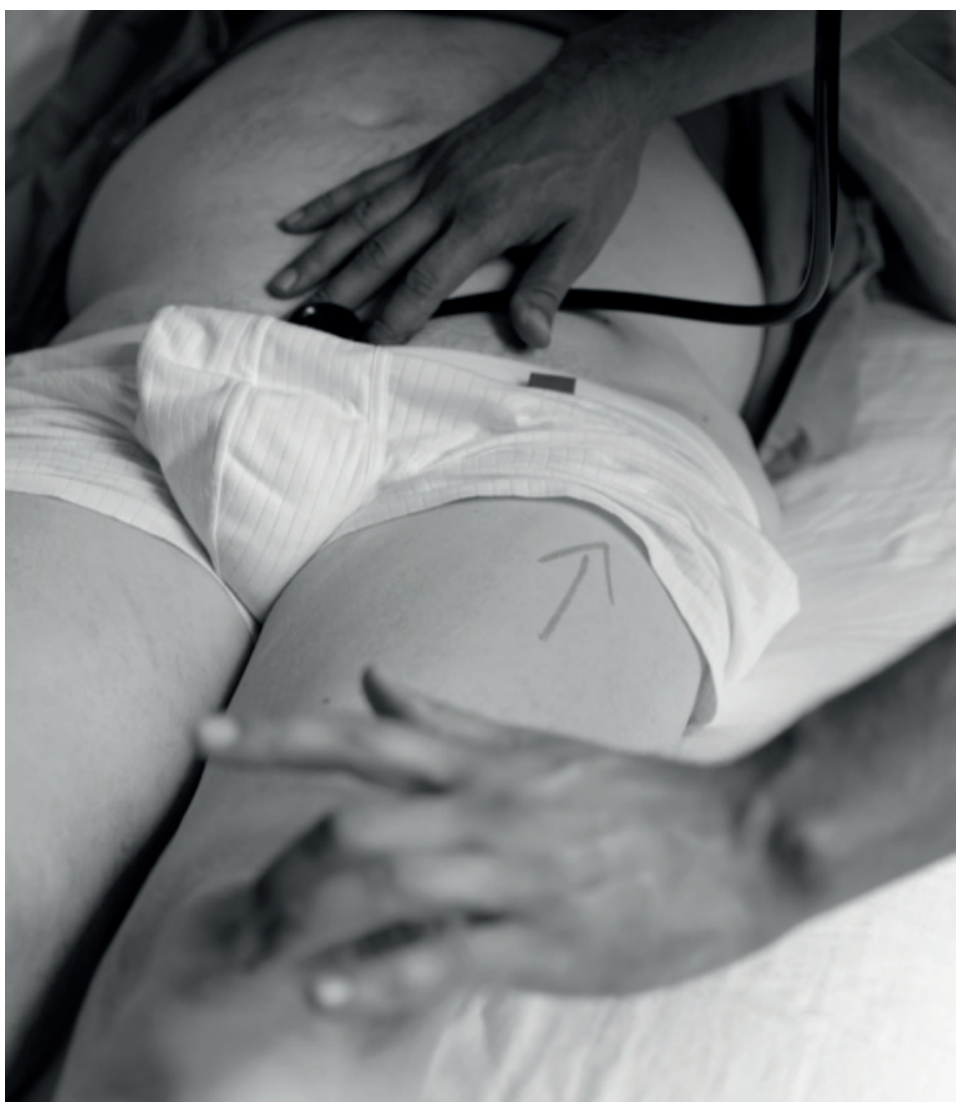




\section{ABSTRACT}

Background: Patellar finger tapping produces a typical sound that can be detected by a stethoscope positioned on the pubic bone (PPPT, patellar pubic percussion test). Characteristics of this sound are determined by continuity of bone between patella and pelvis. We hypothesized that a PPPT was able to detect overt hip fractures and occult hip fractures that may not be determined by a standard radiological examination.

Methods: Two independent observers performed a PPPT in patients with a suspected hip or pelvic fracture, just before a conventional radiograph (X-ray) was performed. The PPPT test was scored as negative (similar to contralateral side) or positive (different). Patients with a positive PPPT but with a negative $\mathrm{X}$-ray underwent an additional CT scan.

Results:191 patients with suspected hip or pelvic fracture were included. A total of 161 patients (84\%) were diagnosed with a fracture (hip, $n=142$; pelvic, $n=19$ ). A 85\% sensitivity, a $70 \%$ specificity, a 0.94 positive predictive value and a 0.47 negative predictive value of the PTTT were calculated. The interobserver reliability (kappa) was 0.7. Eleven CT-scans as indicated by a mismatch between PPPT (positive) and $X$-ray (no fracture) identified 8 fractures (73\%). A multivariate analysis demonstrated that a painful passive movement and the PPPT predicted a hip fracture.

Conclusion: The PPPT is a simple bedside diagnostic tool that is sensitive in detecting clinically straight forward hip fractures as well as occult hip fractures. The PPPT can support decision making for additional radiological examinations in case of potential occult pelvis or hip fractures. 


\section{INTRODUCTION}

Annually, over 20.000 patients sustain a hip fracture in the Netherlands [1]. A typical patient with a hip fracture has a characteristic history of an adequate trauma and upper leg pain in the presence of a limited range of motion. However, occasionally a patient presents with an occult hip fracture. The term occult describes a clinical fracture without clear radiographic evidence. The gut feeling of the attending clinician will determine whether an additional CT or MRI-scan is justified. In contrast, undiagnosed hip fractures may lead to fracture displacement and avascular necrosis due to treatment delay [2]. The use of a stethoscope in diagnosing fractures was first described by Henry Bowditch in his 1846 book termed 'the young stethoscopist' [3]. Alternatively, Bache used a tuning fork test in diagnosing femoral neck fractures [4]. In this procedure, a vibrating $128 \mathrm{~Hz}$ tuning fork is positioned over the medial femoral condyle or patella. By placing a stethoscope over the pubic symphysis, a characteristic sound may be heard. The patellar pubic percussion test (PPPT) is based on this phenomenon [5-7]. A PPPT is performed by finger tapping on the patella and by interpretation of the produced sound over the pubic bone using a stethoscope. In case of a fracture, a more dull sound may be heard. We hypothesized that a PPPT was a reliable test and able to detect occult hip fractures that were not identified by standard radiological examination.

\section{METHODS}

This blinded prospective study was performed in Máxima Medical Center (MMC), Veldhoven, the Netherlands, a large teaching hospital in a rural environment in the south-eastern part of the Netherlands. Patients presenting to the emergency ward who were referred with hip or pelvic trauma were enrolled between March 2014 and June 2015. Patients were excluded if they had previously undergone hip or knee surgery. After informed consent, an emergency physician completed a standardized form with the following items: sex, age, ASA classification, side of injured hip, type of injury, leg position on inspection, ability to weight-bear, assessment of active and passive hip flexion and the occurrence of pain during axial loading of the hip. Subsequently, two physicians independently performed a PPPT just before standard X-rays were performed. A PPPT was termed positive when a difference in tapping sound between the right and the left patella was heard, or negative when 
both sounds were identical. A blinded radiologist performed the evaluation of the $X$-rays. An additional CT was performed if the PPPT was positive whereas the $\mathrm{X}$-ray was judged as no fracture. The medical ethical committee of MMC approved the study.

\section{STATISTICAL ANALYSIS}

Statistical analysis was performed using SPSS Windows version 23 (Chicago, Illinois). Data were expressed as mean \pm standard deviation if normally distributed, or as median and range if not. Sensitivity, specificity and the positive predictive and negative predictive value were calculated. The interobserver reliability was calculated using a Cohen's kappa coefficient (interpretation of Kappa values $\leq 0$ as indicating no agreement; $0.01-0.20$ as none to slight; $0.21-0.40$ as fair; $0.41-0.60$ as moderate; $0.61-0.80$ as substantial; and $0.81-1.00$ as almost perfect agreement) $[8,9]$. Multivariate logistic regression analysis was used to analyse predicting properties of standard physical examination as well as the PPPT for a hip or pelvic fracture. All significant univariate variables were entered in the multivariate logistic regression analyses. For all tests, $\mathrm{P} \leq .05$ was considered significant.

\section{RESULTS}

191 patients (male/female 61/130, median age 84 year, range 26-101) with suspected traumatic hip injuries were included during the 16-month study period. A total of 161 patients were diagnosed with a fracture (hip, $n=142$; pelvic, $n=19$ ). Patient characteristics are presented in Table 1. The PPPT demonstrated an 87\% sensitivity and $55 \%$ specificity for hip fractures only (intra- and extracapsular, Table 2). Regarding a hip or a pelvic fracture, sensitivity and specificity were $85 \%$ and $70 \%$, respectively with a 0.94 positive predictive value of and a 0.47 negative predictive value. The likelihood ratio for a positive test was 2.9 and for a negative test 0.2. The interobserver reliability was good (kappa 0.7). The PPPT did not distinguish displaced from occult fractures.

Eleven CT-scans were required as dictated by a positive PPPT (suspicion on a fracture) and a negative X-ray (no suspicion of a fracture). A total of 8 additional fractures were identified by these 11 scans $(4 \%, 8 / 191)$. One intracapsular hip fracture was operated whereas the remaining 7 ( 6 pelvic fractures and 1 trochanteric 
Table 1. Characteristics of patients undergoing a PPPT for suspected hip/pelvic fracture $(n=191)$

\begin{tabular}{|c|c|}
\hline General & \\
\hline Gender, male/fermale, $\mathrm{n}$ & $61 / 130$ \\
\hline Age, median (range), y & $84(26-101)$ \\
\hline Injured side, left/right, n & $97 / 94$ \\
\hline Injury type, n (\%) & \\
\hline Fall & $166(87)$ \\
\hline Bike & $21(11)$ \\
\hline High energy & $4(2)$ \\
\hline Physical examination & \\
\hline Leg position during admission & \\
\hline Normal position & $71(37)$ \\
\hline Endo-rotation & $8(4)$ \\
\hline Exo-rotation & $112(59)$ \\
\hline Pain during axial loading of hip & \\
\hline Yes & $147(77)$ \\
\hline No & $44(23)$ \\
\hline Active hip flexion, n (\%) & \\
\hline Possible & $15(8)$ \\
\hline Too painful & $173(92)$ \\
\hline Passive hip flexion, n (\%) & \\
\hline Possible & $35(19)$ \\
\hline Too painful & $154(81)$ \\
\hline Patellar Pubic Percussion Test, & \\
\hline Observer 1 & $149 / 191(78)$ \\
\hline Observer 2 & $137 / 185(74)$ \\
\hline Diagnosis & \\
\hline Diagnosis after $\mathrm{X}$-ray and/or ac & \\
\hline No fracture & $30(16)$ \\
\hline Intracapsular hip fracture & $91(48)$ \\
\hline Extracapsular hip fracture & $51(27)$ \\
\hline Pelvic fracture & $19(10)$ \\
\hline
\end{tabular}


Table 2. PPPT characteristics in the diagnosis of hip fracture or hip/pelvic fracture

\begin{tabular}{|c|c|c|c|c|}
\hline & Sensitivity, \% & Specificity, \% & PPV, \% & NPV, \% \\
\hline Observer 1 & $89(126 / 142)$ & $53(26 / 49)$ & $85(126 / 149)$ & $62(26 / 42)$ \\
\hline Observer 2 & $85(115 / 136)$ & $57(28 / 49)$ & $85(115 / 136)$ & $57(28 / 49)$ \\
\hline Mean & 87 & 55 & 85 & 59 \\
\hline \multicolumn{5}{|c|}{ Test characteristics for diagnosing a hip or pelvic fracture } \\
\hline & Sensitivity, \% & Specificity, \% & PPV, \% & NPV, \% \\
\hline Observer 1 & $87(140 / 161)$ & $70(21 / 30)$ & $94(140 / 149)$ & $50(21 / 42)$ \\
\hline Observer 2 & $83(128 / 155)$ & $70(21 / 30)$ & $93(128 / 137)$ & $44(21 / 48)$ \\
\hline Mean & 85 & 70 & 94 & 47 \\
\hline
\end{tabular}

avulsion fracture) were treated conservatively. Three additional CT scans were made although the PPPT was negative. Two were performed as the $\mathrm{X}$-rays interpretations were doubted. The first CT diagnosed a pelvic fracture whereas the second identified an intracapsular hip fracture necessitating operation. A third CT scan was executed for extensive pain and inability to ambulate after hospital admittance and revealed a pubic fracture that was treated conservatively.

In 17/191 (9\%) of the cases, there was disagreement in PPPT findings between both observers. Interestingly, a hip or pelvic fracture was diagnosed in all these 17 patients. In all false positive cases $(n=9)$ there was agreement between both observers. In two of these 9 patients severe unilateral arthrosis was present.

Univariate analyses of standard physical examination tests showed that pain during axial loading, painful passive testing, an abnormal position of the leg and a positive PPPT test were significant predictors for hip fracture. All significant univariate variables including the PPPT and X-rays were entered in a multivariate logistic regression analyses and are presented in table 3. Passive painful testing and the PPPT results were significant predictors for pelvic or hip fractures. 
Table 3. Predictors for hip/pelvic fracture (multivariate regression analysis)

\begin{tabular}{l|ccc}
\hline \multicolumn{1}{c|}{ Variable } & $\begin{array}{c}\text { Significance } \\
\text { (p-value) }\end{array}$ & t-value & $\begin{array}{c}95 \% \text { confidence } \\
\text { Interval }\end{array}$ \\
Abnormal position of the leg & 0.4 & -0.9 & -0.08 to 0.03 \\
Axial pain & 0.9 & 0.1 & -0.06 to 0.07 \\
Painful passive physical examination & 0.002 & -3.2 & -0.2 to -0.05 \\
Patellar Pubic Percussion Test (PPPT) & 0.03 & -2.2 & -0.12 to -0.007 \\
X-ray & $<0.001$ & -19.2 & -0.9 to -0.7
\end{tabular}

\section{DISCUSSION}

Aim of the present study was to investigate the role and strength of the PPPT to detect (occult) hip and pelvic fractures. For hip and pelvic fractures, the Patellar Pubic Percussion Test (PPPT) was found to have a $85 \%$ sensitivity of and a $70 \%$ specificity. The positive predictive value was 0.94 . The PPPT performs optimal as a tool to diagnose a fracture. On the other hand, a negative PPPT does not necessarily exclude a fracture. The specificity was lower for hip fractures only, possibly because of an influence of a pelvic fracture on PPPT results.

It may be questioned whether a PPPT has a role in modern day practice. There are no strong parameters physicians can rely on whether to decide an additional $\mathrm{MRI}$ or CT is necessary if a diagnosis is doubted following plain X-rays. Most likely this will be decided by physical examination, the patients ability to mobilize and pain presentation. The diagnostic algorithm presented in this study might help in the decision-making for additional radiologic examination. The PPPT is a validated, simple, cheap and bedside available test with satisfactory sensitivity, positive predictive value and interobserver variability. The PPPT may have a place in risk stratification for occult hip fractures and contributes to minimize the risk of missing diagnosis. An untreated hip fracture can lead to a considerable delay to surgery and suboptimal outcome, apart from medicolegal consequences [10-13]. We do acknowledge that in the case of a negative PPPT this does not exclude a fracture and a patient might still need further radiological examination. It depends on local protocol or resources whether an additional CT- or MRI scan is preferred. Although $\mathrm{MRI}$ is considered the gold standard for detecting occult hip fractures [14-16], CT has comparable reliability, is cheaper and more available in the acute setting [1719]. 
One limitation of the PPPT is that the affected leg has to be compared to the unaffected leg. As a consequence, no reliable comparison can be made with contralateral prior knee or hip prosthesis / osteosynthesis, or if unilateral severe arthrosis is present. It is not unlikely that patients had a previous hip fracture since the incidence of recurrent hip fracture is $5-10 \%[20,21]$

Arthrosis affects bone conduction but is expected to occur bilaterally. In this study we found 2 cases of false positive PPPT due to severe unilateral arthrosis. However, the PPPT can be useful in most other patients. Other factors that could diminish sound conduction are obesity, local hematoma or oedema and could result in only subtle differences between both legs, suggesting that some training with the PPPT is preferable.

A previous study on the PPPT showed a sensitivity of $96 \%$ and specificity of $85 \%$, although these findings were based on 1 observer only. Blinding in our study was used at two different time point in the study. The PPPT was performed before X-rays were taken whereas the 2 observers performed the PPPT independently from each other. Moreover, the radiologist was blinded for the results of the PPPT as well. Nevertheless, total blinding was limited by the patient's presentation whereas observer bias or estimator's bias cannot be excluded. In 17/191 (9\%) of cases, observers disagreed. A possible explanation for this relative high percentage is possibly related to the sometimes subtle differences in sound.

Can a PTTT be useful in other clinical situations? In the pre-hospital setting, health care workers such as general practitioners or ambulance personnel may use the test to determine a possible pelvic or hip fracture. This has in turn implications for how to immobilize a patient or prepare the patient for transportation to the emergency ward. Furthermore, the PPPT could be useful in areas or in health care settings with scarce resources.

In conclusion, the PPPT is a sensitive bedside tool that clinicians should include in their physical examination toolbox. The PPPT can guide in decision making for additional radiological examinations in the case of expected occult fracture of the pelvis or hip. 


\section{REFERENCES}

1. Lanting LC SC, Hertog PC den, Brugmans MJP: Neemt het aantal mensen met heupfracturen toe of af? Nationaal Kompas Volksgezondheid 2006.

2. Clough TM: Femoral neck stress fracture: the importance of clinical suspicion and early review. Br J Sports Med 2002, 36(4):308-309.

3. Bowditch $\mathrm{H}$ : The young stethoscopist, or the student's aid to auscultation. 1846.

4. Bache JB, Cross AB: The Barford test. A useful diagnostic sign in fractures of the femoral neck. The Practitioner 1984, 228(1389):305-308.

5. Carter MC: A reliable sign for the diagnosis of fractures of the hip and pelvis. Orthopedics 1983, 6(3):307-308.

6. Peltier LF: The diagnosis of fractures of the hip and femur by auscultatory percussion. Clinical orthopaedics and related research 1977(123):9-11.

7. Adams SL, Yarnold PR: Clinical use of the patellar-pubic percussion sign in hip trauma. The American journal of emergency medicine 1997, 15(2):173175.

8. Cohen J: A coefficient of agreement for nominal scales. . Educ Psychol Meas 1960.

9. Landis JR, Koch GG: The measurement of observer agreement for categorical data. Biometrics 1977, 33(1):159-174.

10. Bottle A, Aylin P: Mortality associated with delay in operation after hip fracture: observational study. BMJ 2006, 332(7547):947-951.

11. Novack V, Jotkowitz A, Etzion O, Porath A: Does delay in surgery after hip fracture lead to worse outcomes? A multicenter survey. International journal for quality in health care : journal of the International Society for Quality in Health Care / ISQua 2007, 19(3):170-176.

12. Pioli G, Lauretani F, Davoli ML, Martini E, Frondini C, Pellicciotti F, Zagatti A, Giordano A, Pedriali I, Nardelli A et al.: Older people with hip fracture and IADL disability require earlier surgery. The journals of gerontology Series A, Biological sciences and medical sciences 2012, 67(11):1272-1277.

13. Nyholm AM, Gromov K, Palm H, Brix M, Kallemose T, Troelsen A: Time to Surgery Is Associated with Thirty-Day and Ninety-Day Mortality After Proximal Femoral Fracture: A Retrospective Observational Study on Prospectively Collected Data from the Danish Fracture Database Collaborators. The Journal of bone and joint surgery American volume 2015, 97(16):13331339.

14. Haubro M, Stougaard C, Torfing T, Overgaard S: Sensitivity and specificity of CT- and MRI-scanning in evaluation of occult fracture of the proximal femur. Injury 2015, 46(8):1557-1561.

15. Collin D, Geijer M, Gothlin JH: Computed tomography compared to magnetic resonance imaging in occult or suspect hip fractures. A retrospective study 
in 44 patients. European radiology 2016.

16. Deleanu B, Prejbeanu R, Tsiridis E, Vermesan D, Crisan D, Haragus H, Predescu V, Birsasteanu F: Occult fractures of the proximal femur: imaging diagnosis and management of 82 cases in a regional trauma center. World journal of emergency surgery : WJES 2015, 10:55.

17. Hakkarinen DK, Banh KV, Hendey GW: Magnetic resonance imaging identifies occult hip fractures missed by 64-slice computed tomography. The Journal of emergency medicine 2012, 43(2):303-307.

18. Gill SK, Smith J, Fox R, Chesser TJ: Investigation of occult hip fractures: the use of CT and MRI. TheScientificWorldJournal 2013, 2013:830319.

19. Heikal S, Riou P, Jones L: The use of computed tomography in identifying radiologically occult hip fractures in the elderly. Annals of the Royal College of Surgeons of England 2014, 96(3):234-237.

20. Lyles KW, Colon-Emeric CS, Magaziner JS, Adachi JD, Pieper CF, Mautalen C, Hyldstrup L, Recknor C, Nordsletten L, Moore KA et al.: Zoledronic Acid in Reducing Clinical Fracture and Mortality after Hip Fracture. The New England journal of medicine 2007, 357:nihpa40967.

21. Lloyd BD, Williamson DA, Singh NA, Hansen RD, Diamond TH, Finnegan TP, Allen BJ, Grady JN, Stavrinos TM, Smith EU et al.: Recurrent and injurious falls in the year following hip fracture: a prospective study of incidence and risk factors from the Sarcopenia and Hip Fracture study. The journals of gerontology Series A, Biological sciences and medical sciences 2009, 64(5):599-609.

22. Tiru M, Goh SH, Low BY: Use of percussion as a screening tool in the diagnosis of occult hip fractures. Singapore medical journal 2002, 43(9):467-469. 


\section{CHAPTER}

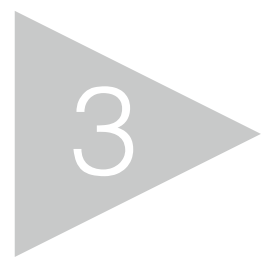

Preoperative cardiac evaluation of geriatric patients with hip fracture
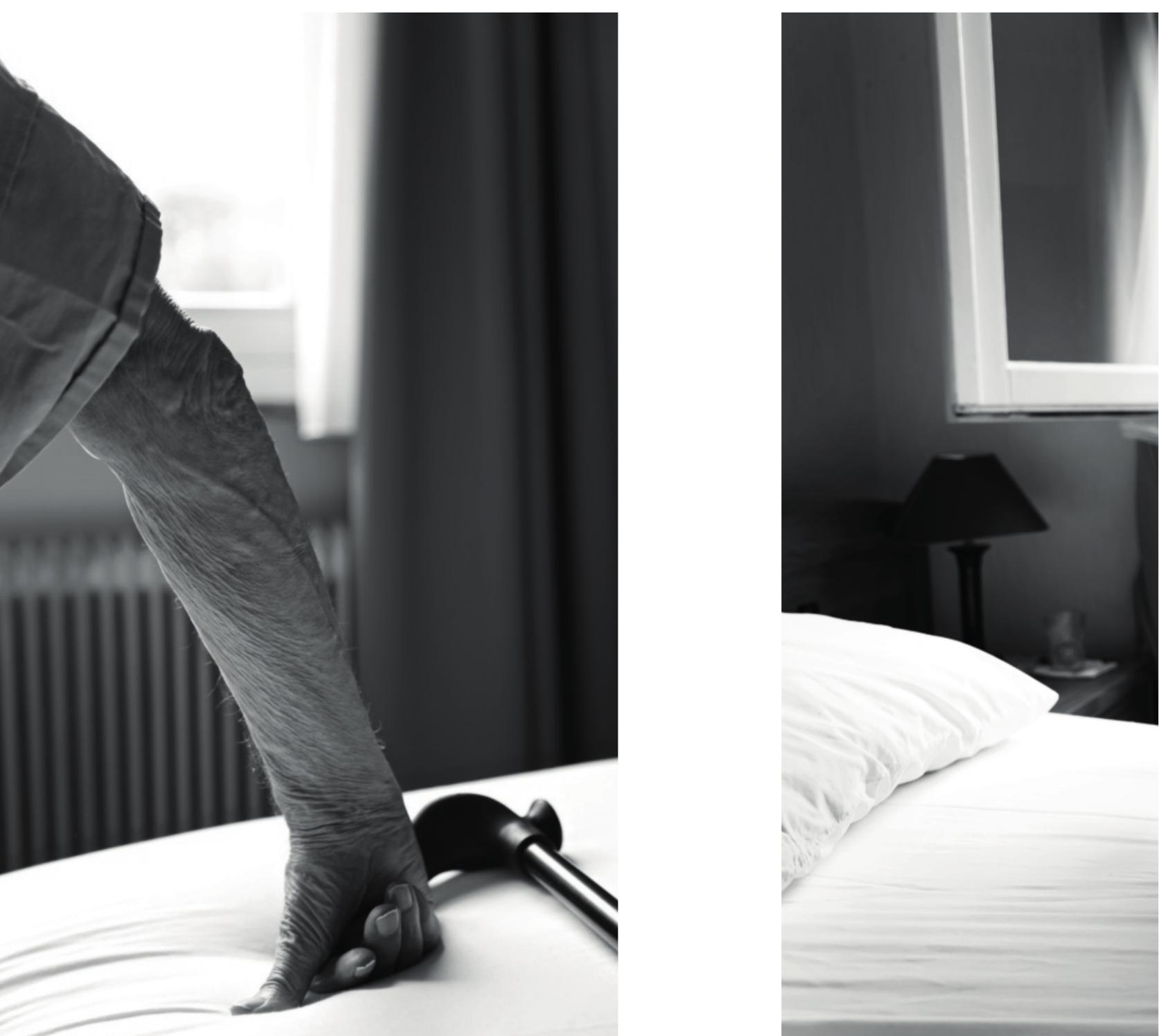
S.J.M.Smeets, M. Poeze, J.P.A.M. Verbruggen

Injury Dec 2012

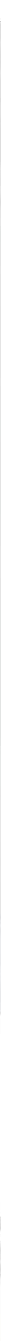




\section{ABSTRACT}

Background: The American College of Cardiology (ACC) and the American Heart Association (AHA) have developed guidelines for perioperative assessment of patients in case of non-cardiac surgery. The aim of this study was to investigate if the preoperative cardiac evaluation of geriatric patients with hip fracture was in accordance with these guidelines and what the effects were on outcome.

Methods: In a retrospective study 388 patients with hip fracture treated in the department of Trauma surgery of the Maastricht University Medical Center in the Netherlands. All patients were treated between 2003 and 2006 with two year followup. The preoperative cardiac screening was analysed with respect to content and to which level this followed the ACC/AHA guidelines. These guidelines were used to classify cardiac risk into low, intermediate and high risk and related to the outcome measurements delay to surgery, perioperative complications and mortality.

Results: According to the ACC/AHA guidelines $82 \%$ of patients received correct preoperative cardiac screening in the low vs. $46 \%$ in the intermediate and $86 \%$ in the high risk group. The most frequent reason for incorrect preoperative cardiac screening was overscreening (>95\%). The delay to surgery increased by 9.9 hours in the case of overscreening $(p=0.03)$. A previous cardiac history was a significant risk factor for early mortality. Delay of $>48$ hours was associated with more cardiovascular complications and mortality both on univariate and multivariate analysis.

Conclusion: Preoperative cardiac screening is frequently unnecessary after hip fracture, especially in patients with intermediate risk predictors and increases the delay to surgery. Delay of $>48$ hours was associated with more cardiovascular complications and mortality postoperatively. The implementation of the ACC/ AHA guidelines may prevent unnecessary cardiac consultations which reduces preoperative resources, delay to surgery and possibly decreases postoperative complications. 


\section{INTRODUCTION}

Hip fractures are one of the most common orthopedic trauma causes leading to hospital admission in the elderly population and are associated with high morbidity and mortality rates. Treatment can sometimes be chosen conservatively but the majority of patients with hip fracture will undergo surgery. Because of advanced age and comorbidities, the surgical risk is increased.

Cardiac events are responsible for 30-60\% perioperative complications in noncardiac surgery and are the cause of postoperative mortality following non-cardiac surgery in more than $50 \%$ of patients [1, 2]. The overall incidence of perioperative myocardial ischemia in elderly patients undergoing hip fracture surgery has been reported to be 35-42\% [3-6]. Previous studies indicated that the principal causes of in-hospital mortality after hip fracture were cardiac failure and myocardial infarction, which occurred early after the fracture [7-13].

To evaluate preoperatively the risk of cardiac disease in non-cardiac surgery the American College of Cardiology (ACC) and the American Heart Association (AHA) have developed guidelines. According to the ACC/AHA guidelines hip surgery is considered as intermediate risk surgery [14]. The keypoint of these guidelines are summarized in an algorithm indicating the stepwise approach of patients using clinical predictors to identify their risk category. The purpose of preoperative evaluation (including both screening and cardiac consultation) by this approach is not to give medical clearance but rather to perform an evaluation of the patients current medical status and make recommendations concerning the risk assessment and management of cardiac problems over the entire perioperative period [14]. However, preoperative assessment may be time consuming and lead to unnecessary delay and should therefore be restricted to those with the potential to change patient management.

In order to investigate the application of these guidelines and its impact on the current daily practice of the management of patients with hip fractures this study was undertaken. Our hypothesis was that preoperative cardiac evaluation, when not recommended by the ACC/AHA guidelines (overscreening), lead to increased delay to surgery with an increased rate of complicated outcome. 


\section{MATERIALS AND METHODS}

\section{STUDY POPULATION}

This retrospective study was conducted in the department of Trauma surgery in the Maastricht University Medical Center in the Netherlands, a level 1 trauma center. From 1st of January 2003 till 31st of December 2006 all patients treated for hip fracture were included with a two-year follow-up. We selected all patients aged 65 and above. Polytrauma patients, patients with pathological hip fractures and patients treated with a total hip arthroplasty were excluded. Patients with a malignancy in their history were not excluded. All patients were operated by the department of trauma surgery using a protocolised treatment algorithm regarding hip replacement or internal fixation. All medical records were evaluated for the following content: patient characteristics, fracture type, type of arthroplasty or fracture fixation, delay to surgery, cardiac risk factors, preoperative assessment, cardiac consultations and their content, postoperative complications, mortality and the use of blood transfusions. Death certificates were obtained from the National population register.

\section{PREOPERATIVE CARDIAC EVALUATION}

Standard workup after admission to the emergency department consisted of a detailed history, a complete physical examination, an electrocardiography and standard biochemical and hematologic tests. The anesthesiologist conducted a preoperative consultation and decided whether a cardiac consultation was necessary. This decision was not protocolized or following ACC/AHA guidelines and depended on the attending physician. Our main goal was to evaluate the preoperative cardiac evaluation, using the algorithm proposed in the ACC/AHA guidelines. All patients were retrospectively screened according to these guidelines. The preoperative assessment was compared with the advised preoperative treatment according to the guidelines. In this study there is a difference between the terms 'cardiac screening' and 'cardiac consultation'. Screening accounts for the risk assessment of all patients divided into three different risk categories (Table 1). 'Correctly screened' accounts for those patients who were operated without cardiac consultation with a stable cardiac situation or in the absence of a cardiac history, or patients who received a cardiac consultation when necessary according to the guidelines. We distinguished two possibilities for preoperative cardiac screening that was not in line with the guidelines: under- and overscreening. Cardiac consultation 
accounts only for the patients who were evaluated by a cardiologist after screening. We analysed the preoperative cardiac consultations and their content. Correct cardiac consultations were executed in accordance with the guidelines and the content was sufficient in relation with the patient's medical condition. For example when non-invasive testing was advised but not performed this was scored as 'not correct'.

Secondary outcome measurements were delay to surgery and overscreening as a risk factor for delay to surgery. Furthermore, we scored perioperative complications and death. We analyzed the complication rates in relation with delay to surgery. The mortality rates were determined as in-hospital and after 30-day, 1-year and 2-years.

\section{Table 1. The American College of Cardiology/American Heart Association clinical predictors}

\begin{tabular}{|c|c|c|}
\hline Low Risk & Intermediate Risk & High Risk \\
\hline Advanced age & Mild angina pectoris & $\begin{array}{l}\text { Unstable coronary } \\
\text { syndromes }\end{array}$ \\
\hline Abnormal ECG & Prior myocardial infarction & $\begin{array}{l}\text { Decompensated cardiac } \\
\text { heart failure }\end{array}$ \\
\hline Rhythm other than sinus & $\begin{array}{l}\text { Compensated or prior } \\
\text { cardiac heart failure }\end{array}$ & Significant arrhythmias \\
\hline Low functional capacity & Diabetes Mellitus & Severe valvular disease \\
\hline \multicolumn{3}{|l|}{ History of stroke } \\
\hline $\begin{array}{l}\text { Uncontrolled } \\
\text { hypertension }\end{array}$ & & \\
\hline
\end{tabular}

\section{STATISTICAL ANALYSIS}

All analyses were performed with SPSS 16.0 statistical software for windows (SPSS Inc., Chicago, Illinois, USA). $\mathrm{P}<0.05$ was considered to be statistically significant. Data were presented as mean for normally distributed or median when nonnormally distributed variables. Percentages were used when appropriate. One-way ANOVA was used to compare normally distributed and the Mann Whitney U-test for non-normally distributed continuous variables with Bonferroni correction for multiple testing. A Pearsons chi-square test $\left(X^{2}\right)$ was used to investigate whether distributions of categorical variables differed from one another. We used a KaplanMeier survival curve to investigate the mortality rates for each of the cardiac risk groups, comparing outcome using log rank analysis. Univariate analysis of the postoperative complications was performed to identify predictors for mortality. All 
important variables for mortality were entered in a multivariate logistic regression analysis.

\section{RESULTS}

388 patients were eligible for inclusion and analyzed. Of 9 patients time to surgery could not be calculated accurately. In 1\% (4/388) of patients follow-up after discharge could not be obtained because they lived abroad. These data were regarded as missing data, were other available data of these patients were still used in other analysis. Table 2 shows the patient and operation characteristics. $46 \%(178 / 388)$ of the patients had a cardiac history, which did not necessarily mean active cardiac conditions. In total 10\% (37/388) of patients were predicted to have a high perioperative complication risk (high risk group), 29\% (113/388) an intermediate risk and $61 \%(238 / 388)$ a low risk using the ACC/AHA clinical predictors (Table 1).

\section{PREOPERATIVE CARDIAC EVALUATION}

According to the guidelines $82 \%$ (195/238) in the low risk group and 86\% (32/37) in the high risk group received correct preoperative cardiac screening in comparison with $46 \%(52 / 113)$ in the intermediate risk group ( $p<0.001$, low and high risk in comparison with intermediate risk). Of all patients $28 \%$ (109/388) did not receive the correct preoperative screening. The main reason was overscreening in $95 \%$ of the cases (104/109) and underscreening in $5 \%$ of the cases (5/109).

In total 38\% (147/388) of patients received a cardiac consultation after screening of which $2 \%(1 / 44)$ in the low risk group, $12 \%(8 / 66)$ in the intermediate and $86 \%$ $(32 / 37)$ in the high risk group were in accordance with the guidelines $(p<0.001$, for low and intermediate risk in comparison with high risk). One of the reasons for a cardiac consultation in the low risk group was a heart murmur without clinical symptoms that was further investigated by a cardiologist.

\section{DELAY}

The median delay to surgery was respectively 20, 24 and 32 hours for the low, intermediate and high risk group. ( $p=0.01$, low risk in comparison with high risk). 
ACC/AHA cardiac risk group

\begin{tabular}{l|ccc}
\hline Patient and operation characteristics & $\begin{array}{c}\text { Low } \\
(n=238)\end{array}$ & $\begin{array}{c}\text { Intermediate } \\
(n=113)\end{array}$ & $\begin{array}{c}\text { High } \\
(n=37)\end{array}$ \\
Mean age (years) & 81 & 83 & 84 \\
Male sex & $23 \%(55)$ & $32 \%(37)$ & $27 \%(10)$ \\
Mobility: Independent & $46 \%(110)$ & $45 \%(51)$ & $41 \%(15)$ \\
$\quad$ With walking aid & $32 \%(75)$ & $23 \%(26)$ & $32 \%(12)$ \\
$\quad$ Strongly impaired & $19 \%(45)$ & $26 \%(29)$ & $24 \%(9)$ \\
$\quad$ Immobile & $3 \%(8)$ & $6 \%(7)$ & $4 \%(1)$ \\
Housing: Independent & $47 \%(111)$ & $48 \%(54)$ & $54 \%(20)$ \\
$\quad$ Home care & $27 \%(64)$ & $32 \%(36)$ & $24 \%(9)$ \\
$\quad$ Care home & $17 \%(41)$ & $10 \%(11)$ & $14 \%(5)$ \\
$\quad$ Nursing Home & $9 \%(22)$ & $11 \%(12)$ & $8 \%(3)$ \\
Intracapsular fractures & $58 \%(138)$ & $62 \%(70)$ & $62 \%(23)$ \\
Extracapsular fractures & $42 \%(100)$ & $38 \%(43)$ & $38 \%(14)$ \\
General anesthesia & $31 \%(74)$ & $44 \%(50)^{\star}$ & $59 \%(22)^{\star} /{ }^{\star \star}$ \\
Spinal anesthesia & $69 \%(164)$ & $56 \%(63)^{\star}$ & $41 \%(15)^{\star} / /^{\star \star}$ \\
Mediana operation time min. (range) & $64(23-252)$ & $66(20-210)$ & $69(20-116)$ \\
Mediana delay to surgery hrs. (range) & $20(0.8-258)$ & $24(2-95)$ & $32 *(10-90)$ \\
$>24$ hrs. & $32 \%(76)$ & $47 \%(53)^{\star}$ & $70 \%(26)^{\star} /{ }^{\star \star}$ \\
$\quad>48$ hrs. & $6 \%(15)$ & $6 \%(7)$ & $22 \%(8)^{\star} / /^{\star \star}$ \\
Cardiac history & $18 \%(44)$ & $86 \%(97)^{\star}$ & $100 \%(37)^{\star}$ \\
\hline
\end{tabular}

${ }^{a}$ Median: for non-normally distributed variable. ${ }^{*}$ Significant difference in compare with low risk group, $p<0.05 .{ }^{* \star}$ Significant difference in compare with intermediate risk group, $p<0.05$.

The total mean increase of delay between non-overscreening vs. overscreening was $9.9 \mathrm{hrs}(p=0.03)$. The mean delay to surgery increased by 8.0 hours when patients had a cardiac consultation $(p=0.001)$. Multivariate analysis showed a cardiac consultation as a significant factor for increased delay to surgery, while age, sex, a cardiac history and preoperative mobility were not influencing delay to surgery.

\section{COMPLICATIONS}

The postoperative complications are shown in table 3. A delay of more than 48 
hours resulted in significantly more cardiovascular complications $(p<0.001$, table 4 ) and increased risk of in-hospital mortality (RR 3.4, 95\% Cl 1.2-9.7; $p=0.02)$ and 30-day mortality (RR 2.7, 95\% Cl 1.2-6.1; $\mathrm{p}=0.02$ ). A delay of more than 24 hours was not associated with a significantly increased mortality rate.

In addition, there were significantly more respiratory and cardiovascular complications in the high and intermediate risk group in comparison with the low risk group. This was related with a significantly higher risk for in-hospital mortality. Pulmonary complications (RR 10.9, 95\% Cl 4.6-26; $p=0.001$ ), and cardiovascular complications (RR 13.4, 95\% Cl 5.7-31.7; $p<0.001$ ) were significant risk factors for inhospital mortality. Furthermore, a multivariate regression analysis for cardiovascular complications showed high age, cardiac history and delay $>48$ hours as significant risk factors.

\section{MORTALITY}

The mortality rates are summarized in table 5. A Kaplan-Meier curve for survival was made with a follow up of 24 months in figure 1 (lost to follow-up after discharge $1 \%(4 / 388)$ ). The mortality rates increased with the cardiac risk category. This led to significantly higher mortality in high risk patients for the in-hospital, 30-day mortality and 2-year mortality in comparison with low risk patients. In-hospital mortality was due to cardiovascular complications in $61 \%$ of cases, followed by respiratory failure in $28 \%$ of cases and in $11 \%$ because of other reasons.

A Cox multiple regression analysis for mortality for the complete follow-up period of 24 months showed a cardiac history, high age and male sex as significant risk factors. With linear regression analysis were risk factors for early and late mortality individually investigated (see table 6). A cardiac history and delay to surgery of $>48$ hours were predictors for in-hospital mortality. A delay of $>48$ hours and high age were risk factors for 30-day mortality. Male sex and high age were risk factors for late mortality (1-year and 2-year mortality). 
Table 3. Complications

ACC/AHA cardiac risk group

\begin{tabular}{|c|c|c|c|c|}
\hline Complications & $\begin{array}{l}\text { Low } \\
\%(n)\end{array}$ & $\begin{array}{c}\text { Intermediate } \\
\%(n)\end{array}$ & $\begin{array}{l}\text { High } \\
\%(n)\end{array}$ & $\begin{array}{l}\text { Total } \\
\%(n)\end{array}$ \\
\hline Delirium & $40 \%(96)$ & $35 \%(40)$ & $35 \%(13)$ & $38 \%(149)$ \\
\hline Wound infection & $7 \%(17)$ & $4 \%(5)$ & $8 \%(3)$ & $6 \%(25)$ \\
\hline Blood transfusion & $40 \%(96)$ & $42 \%(47)$ & $43 \%(16)$ & $41 \%$ (159) \\
\hline Urinary tract Infection & $16 \%(39)$ & $17 \%(19)$ & $30 \%(11)^{\star}$ & $18 \%(69)$ \\
\hline Pressure sores & $12 \%(28)$ & $15 \%(17)$ & $16 \%(6)$ & $13 \%(51)$ \\
\hline Respiratory & $11 \%(25)$ & $12 \%(13)$ & $24 \%(9)^{\star} / \star \star$ & $12 \%(47)$ \\
\hline Pneumonia & $7 \%(17)$ & $9 \%(10)$ & $14 \%(5)$ & $8 \%(32)$ \\
\hline Pulmonary embolism & $1 \%(2)$ & $1 \%(1)$ & $3 \%(1)$ & $1 \%(4)$ \\
\hline Respiratory failure & $3 \%(6)$ & $2 \%(2)$ & $8 \%(3)^{\star}$ & $3 \%(11)$ \\
\hline Gastrointestinal tract bleeding & $2 \%(5)$ & $4 \%(4)$ & $5 \%(2)$ & $3 \%(11)$ \\
\hline Gastrointestina|a & $3 \%(6)$ & $1 \%(1)$ & $8 \%(3)$ & $3 \%(10)$ \\
\hline Cardiovascular & $6 \%(14)$ & $8 \%(9)$ & $35 \%(13)^{\star / * *}$ & $9 \%(36)$ \\
\hline Stroke & $2 \%(4)$ & $0 \%(0)$ & $5 \%(2)^{\star \star}$ & $25 \%(6)$ \\
\hline Rhythm disorders & $2 \%(5)$ & $2 \%(2)$ & $8 \%(3)^{\star} /{ }^{\star \star}$ & $3 \%(10)$ \\
\hline AMI & $1 \%(2)$ & $5 \%(6)^{*}$ & $11 \%(4)^{*}$ & $3 \%(12)$ \\
\hline Cardiac failure & $1 \%(3)$ & $2 \%(2)$ & $14 \%(5)^{\star} /{ }^{\star \star}$ & $3 \%(10)$ \\
\hline DVT & $2 \%(4)$ & $3 \%(3)$ & $3 \%(1)$ & $2 \%(8)$ \\
\hline Implant failure ${ }^{b}$ & $11 \%(26)$ & $15 \%(17)$ & $5 \%(2)$ & $12 \%(45)$ \\
\hline In-hospital mortality & $3 \%(7)$ & $4 \%(5)$ & $16 \%(6)^{\star} /{ }^{\star \star}$ & $5 \%(18)$ \\
\hline
\end{tabular}

aPostoperative ileus, obstipation or extensive diarrhea. ${ }^{\text {b }}$ Re-operation, luxation or deep infection of the arthroplasty or fracture fixation. Respiratory complications consist of pneumonia, pulmonary embolism and respiratory failure together. Cardiovascular complications consist of stroke, rhythm disorders, acute myocardial infarction (AMI) and cardiac failure. DVT = deep venous thrombosis. ${ }^{*}$ Significant difference in compare with low risk group, $p<0.05$. ** Significant difference in compare with intermediate risk group, $p<0.05$. The $p$-levels of the different cardiovascular complications in the high risk group in comparison with the low risk group are $<0.001$. 
Table 4. Cardiovascular complications in relation with delay to surgery

\begin{tabular}{l|ccc}
\hline & Delay $<48 \mathrm{hrs}$ & Delay $>48 \mathrm{hrs}$ & P-value \\
Cardiovascular & $6.7 \%(24 / 358)$ & $30 \%(9 / 30)$ & $<0.001$ \\
Stroke & $1.1 \%(4 / 358)$ & $6.7 \%(2 / 30)$ & 0.02 \\
Rhythm disorders & $1.7 \%(6 / 358)$ & $13.3 \%(4 / 30)$ & $<0.001$ \\
AMl & $2.8 \%(10 / 358)$ & $6.7 \%(2 / 30)$ & 0.2 \\
Cardiac failure & $1.7 \%(6 / 358)$ & $13.3 \%(4 / 30)$ & $<0.001$ \\
In-hospital mortality & $3.9 \%(14 / 358)$ & $13.3 \%(4 / 30)$ & 0.02 \\
30-day mortality & $7.6 \%(27 / 355)$ & $20.7 \%(6 / 29)$ & 0.02
\end{tabular}

AMI, Acute Myocardial Infarction

\section{Table 5. Mortality rates}

\begin{tabular}{l|cccc}
\hline \multicolumn{1}{c|}{ Mortality } & Low risk (n) & Intermediate risk (n) & High risk (n) & Total (n) \\
In-hospital & $3 \%(7 / 238)$ & $4 \%(5 / 113)$ & $16 \%(6 / 37)^{\star} /{ }^{\star \star}$ & $5 \%(18 / 388)$ \\
30-day & $6 \%(14 / 236)$ & $10 \%(11 / 111)$ & $22 \%(8 / 37)^{\star}$ & $9 \%(33 / 384)$ \\
1-year & $27 \%(63 / 236)$ & $29 \%(32 / 111)$ & $38 \%(14 / 37)^{\star}$ & $29 \%(109 / 384)$ \\
2-year & $36 \%(85 / 236)$ & $40 \%(44 / 111)$ & $54 \%(20 / 37)^{\star}$ & $39 \%(149 / 384)$
\end{tabular}

* Significant difference between the high risk group and the low risk group, $\mathrm{p}<0.05$; ${ }^{* *}$ Significant difference between the high risk group and the intermediate risk group, $p<0.05$.

Table 6. Regression analysis for mortality

\begin{tabular}{l|cccc}
\hline \multicolumn{1}{c|}{ Mortality } & $\begin{array}{c}\text { In-hospital } \\
(\mathrm{p} \text {-value })\end{array}$ & $\begin{array}{c}30 \text {-day } \\
(\mathrm{p} \text {-value })\end{array}$ & $\begin{array}{c}\text { 1-year } \\
(\mathrm{p} \text {-value })\end{array}$ & $\begin{array}{c}2 \text {-year } \\
(\mathrm{p} \text {-value })\end{array}$ \\
Sex & 0.7 & 0.7 & 0.004 & $<0.001$ \\
Age & 0.1 & 0.02 & 0.01 & 0.003 \\
Delay $>48 \mathrm{hrs}^{*}$ & 0.03 & 0.02 & 0.1 & 0.9 \\
Cardiac history* & 0.01 & 0.09 & 0.2 & 0.08
\end{tabular}

*Variables entered in the logistic regression analysis 


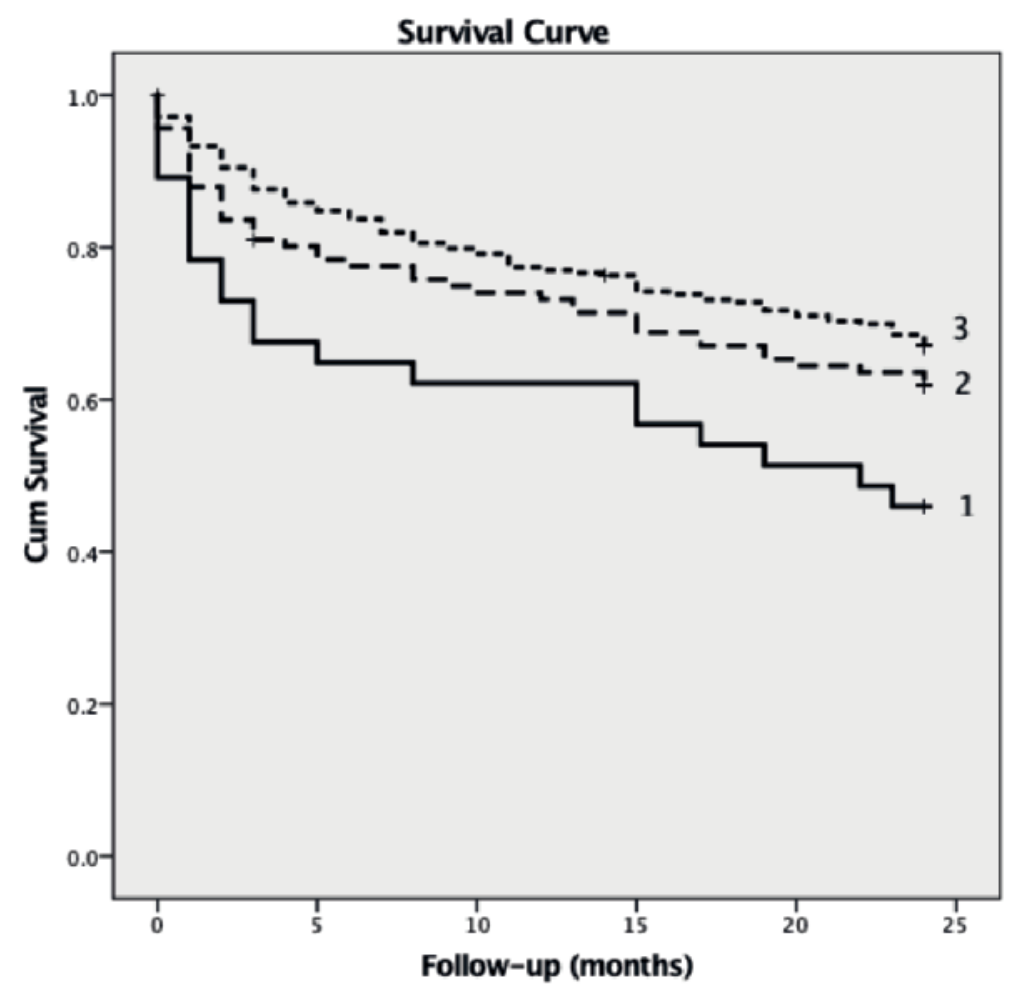

Figure 1. Kaplan Meier Survival curve. ACC/AHH risk categories; $1=$ High risk, 2=Intermediate risk, 3=Low risk

\section{DISCUSSION}

The ACC/AHA guidelines are considered to be the standard of care for preoperative cardiac evaluation. The major conclusion of this study is that in daily practice preoperative cardiac evaluation in patients with a hip fracture is frequently not according to these guidelines, especially in patients with intermediate level of perioperative risk. This non-compliance increases the delay to surgery. Importantly, a delay of $>48$ hours was associated with more cardiovascular complications and mortality.

A considerable percentage of patients in the low risk group and the high risk group were correctly screened preoperatively according to the guidelines compared to only $46 \%$ in the intermediate risk group. Apparently, the high and low risk patients are relatively easy to identify, of which the high risk patients usually receive an 
adequate preoperative workup subsequently. However, the majority of patients belonged to the low and intermediate risk group. Especially, the intermediate group seems to represent the most problematic group with respect to the preoperative screening. A high number of patients in the intermediate risk group underwent time consuming cardiac consultations without the right indication. According to the ACC/AHA guidelines the patients who require noninvasive cardiac testing are those with active high risk cardiac conditions and those with intermediate risk clinical predictors combined with poor functional capacity. Whether a consultation is justified for patients in the intermediate risk is decided by their functional capacity, measured by metabolic equivalent of task (MET's). The minimum is set at 4 MET's indicating that a person is able to walk a few hundred meters on level ground at 2-3 mph or do light work at the house. This is rather arbitrary and could be one of the reasons why cardiac evaluations are sometimes performed with the wrong indication. Siu et al. reported about the clinical dilemma for orthopedic surgeons to carefully assess hip fracture patients and identify those patients that require further cardiac evaluation. The result was an adapted 3-step clinical protocol based on the ACC/AHA recommendations, tailored for the geriatric patient with hip fracture [15]. An implemented protocol like this could more efficiently filter the patients at risk and prepare the remainder patients for surgery. The flow chart is visualized in figure 2 . Preoperative work up is not the only factor causing delay. Delay is multifactorial and system related factors such as unavailability of an operating room or team and trauma lists are contributory. A policy of prioritizing hip fracture patients for surgery should be pursued by concerning physicians.

The main reason for incorrect preoperative cardiac screening was overscreening in $95 \%$ of the cases. In the low and intermediate risk category in total $92 \%$ (101/110) cardiac consultations were redundant according to the guidelines. In our department a cardiac history as such appeared to be a reason for requesting cardiac consultation, in contrast to the indications for a consultation in the guidelines. As a result, the recommendations by the cardiologists did not always lead to changes in patient management. Frequent conclusions or recommendations were formulated as 'increased risk' and 'continue $\beta$-blockade treatment'. More importantly, not only can incorrect preoperative cardiac evaluation lead to non-contributing measures, there have been indications that delay to surgery secondary to cardiac clearance is a risk factor for increased postoperative complications that is independent of a patients general medical condition[16]. The mean delay to surgery in this study increased by 8.0 hours when a cardiac consultation was performed. Although this 
delay is partly explained by patients who needed further preoperative testing and stabilization, still more than two-third of these consultations were not indicated and therefore caused unnecessary delay. Bottle et al. found that delay to surgery is associated with an increased risk of death and that patients with a delayed procedure were much more likely to have one or more comorbidities. These findings suggest that comorbidities indeed affect management, including timing of surgery [17]. Charalambous et al. showed that obtaining echocardiograms can take considerable time in the absence of an agreed protocol with the cardiology department prioritizing patients with hip fractures [18]. A delay to surgery of more than 48 hours was related with an increased risk of cardiovascular complications in this study.

A recent study from Vigoda et al. investigated a large group anesthesiologist residents and their decisions on preoperative cardiac evaluation in specific scenarios. Only half of the correct preoperative cardiac evaluations were in accordance with the ACC/AHA guidelines [19]. Together with the findings of this study this suggests that the guidelines should be more under attention to reach more awareness.

The mortality rates increased with the cardiac risk category. Patients with poor general health and multiple comorbidities are more likely to have worst outcome. A multivariate regression analysis for mortality showed a cardiac history and delay of more than 48 hours as risk factors for in-hospital mortality. This is in line with some large systematic reviews who report a beneficial effect of early surgery with a lower risk of death and lower rates of postoperative complications [20-23]. Whereas others concluded no association between mortality and timing of surgical repair $[24,25]$.

Previous identified risk factors for early mortality were high ASA score, high age, male sex, more than 3 comorbidities and a low mental status [26, 27]. In this study was a cardiac history a risk factor for in-hospital mortality. This association does not mean that a prior cardiac history as a single issue is a reason for preoperative cardiac consultation (which is in agreement with the ACC/AHA guidelines). The question to be answered in these cases is if the cardiac risk categorization is influenced by further preoperative testing. Furthermore, perioperative myocardial injury is common in elderly patients with hip fracture and frequently unrecognized clinically. Previous studies showed that postoperative myocardial damage, measured by elevated troponin I levels, is related to an increased number of post operative 


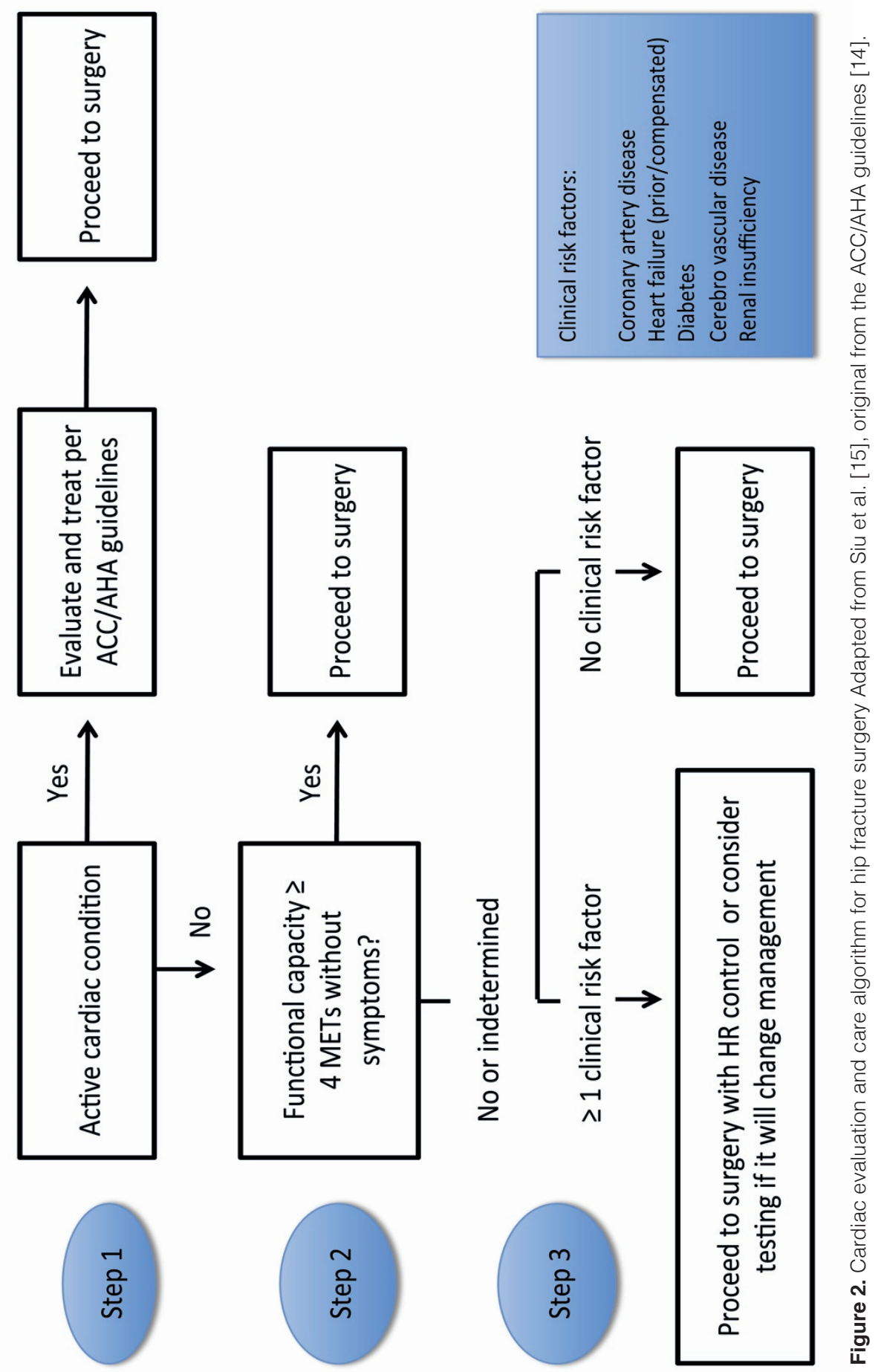


cardiac events, frequently in the absence of previous history of coronary artery disease $[3,28,29]$. This makes additional preoperative testing in order to further recategorize patients into different risk groups besides the workup suggested by the ACC/AHA guidelines not effective.

A number of remarks must be made when interpreting these results. Regardless the completeness of the collected data and the high level of completed followup, selection bias cannot be excluded because of the retrospective study design. Furthermore, the number of patients are relatively small for the individual risk groups, making the risk of type II error higher. Although the delay to surgery was clearly increased due to performance, this delay is multifactorial and system related factors were not included in our analysis.

In conclusion: the need for medical evaluation and stabilization before hip fracture surgery is essential and should be for each patient individually titrated according to the perioperative risk and take place in an efficient mode with attention for timing to surgery, in accordance with the ACC/AHA guidelines. The implementation of the ACC/AHA guidelines should be standard practice in every hospital and may have the potential to reduce preoperative resources and possibly decrease delay to surgery and early morbidity and mortality. 


\section{REFERENCES}

1. Mangano DT, Browner WS, Hollenberg M, London MJ, Tubau JF, Tateo IM: Association of perioperative myocardial ischemia with cardiac morbidity and mortality in men undergoing noncardiac surgery. The Study of Perioperative Ischemia Research Group. N Engl J Med 1990, 323(26):1781-1788.

2. Hertzer NR, Beven EG, Young JR, O'Hara PJ, Ruschhaupt WF, 3rd, Graor RA, Dewolfe VG, Maljovec LC: Coronary artery disease in peripheral vascular patients. A classification of 1000 coronary angiograms and results of surgical management. Ann Surg 1984, 199(2):223-233.

3. Dawson-Bowling S, Chettiar K, Cottam H, Worth R, Forder J, FitzgeraldO'Connor I, Walker D, Apthorp H: Troponin T as a predictive marker of morbidity in patients with fractured neck of femur. Injury 2008, 39(7):775780.

4. Marsch SC, Schaefer HG, Skarvan K, Castelli I, Scheidegger D: Perioperative myocardial ischemia in patients undergoing elective hip arthroplasty during lumbar regional anesthesia. Anesthesiology 1992, 76(4):518-527.

5. Scheinin H, Virtanen T, Kentala E, Uotila P, Laitio T, Hartiala J, Heikkila $\mathrm{H}$, Sariola-Heinonen K, Pullisaar O, Yli-Mayry S et al.: Epidural infusion of bupivacaine and fentanyl reduces perioperative myocardial ischaemia in elderly patients with hip fracture--a randomized controlled trial. Acta Anaesthesiol Scand 2000, 44(9):1061-1070.

6. Juelsgaard P, Sand NP, Felsby S, Dalsgaard J, Jakobsen KB, Brink O, Carlsson PS, Thygesen K: Perioperative myocardial ischaemia in patients undergoing surgery for fractured hip randomized to incremental spinal, single-dose spinal or general anaesthesia. Eur J Anaesthesiol 1998, 15(6):656-663.

7. Perez JV, Warwick DJ, Case CP, Bannister GC: Death after proximal femoral fracture--an autopsy study. Injury 1995, 26(4):237-240.

8. Morrison RS, Chassin MR, Siu AL: The medical consultant's role in caring for patients with hip fracture. Ann Intern Med 1998, 128(12 Pt 1):1010-1020.

9. Pioli G, Barone A, Giusti A, Oliveri M, Pizzonia M, Razzano M, Palummeri E: Predictors of mortality after hip fracture: results from 1-year follow-up. Aging Clin Exp Res 2006, 18(5):381-387.

10. Vidal El, Coeli CM, Pinheiro RS, Camargo KR, Jr.: Mortality within 1 year after hip fracture surgical repair in the elderly according to postoperative period: a probabilistic record linkage study in Brazil. Osteoporos Int 2006, 17(10):1569-1576.

11. Kenzora JE, McCarthy RE, Lowell JD, Sledge CB: Hip fracture mortality. Relation to age, treatment, preoperative illness, time of surgery, and complications. Clin Orthop Relat Res 1984(186):45-56.

12. Vestergaard P, Rejnmark L, Mosekilde L: Has mortality after a hip fracture 
increased? J Am Geriatr Soc 2007, 55(11):1720-1726.

13. Tosteson AN, Gottlieb DJ, Radley DC, Fisher ES, Melton LJ, 3rd: Excess mortality following hip fracture: the role of underlying health status. Osteoporos Int 2007, 18(11):1463-1472.

14. Fleisher LA, Beckman JA, Brown KA, Calkins $H$, Chaikof E, Fleischmann KE, Freeman WK, Froehlich JB, Kasper EK, Kersten JR et al.: ACC/AHA 2007 guidelines on perioperative cardiovascular evaluation and care for noncardiac surgery: a report of the American College of Cardiology/American Heart Association Task Force on Practice Guidelines (Writing Committee to Revise the 2002 Guidelines on Perioperative Cardiovascular Evaluation for Noncardiac Surgery): developed in collaboration with the American Society of Echocardiography, American Society of Nuclear Cardiology, Heart Rhythm Society, Society of Cardiovascular Anesthesiologists, Society for Cardiovascular Angiography and Interventions, Society for Vascular Medicine and Biology, and Society for Vascular Surgery. Circulation 2007, 116(17):e418-499.

15. Siu CW, Sun NC, Lau TW, Yiu KH, Leung F, Tse HF: Preoperative cardiac risk assessment in geriatric patients with hip fractures: an orthopedic surgeons' perspective. Osteoporos Int 2010, 21(Suppl 4):S587-591.

16. Cluett J, Caplan J, Yu W: Preoperative cardiac evaluation of patients with acute hip fracture. Am J Orthop 2008, 37(1):32-36.

17. Bottle A, Aylin P: Mortality associated with delay in operation after hip fracture: observational study. BMJ 2006, 332(7547):947-951.

18. Charalambous CP, Yarwood S, Paschalides C, Siddique I, Hirst P, Paul A: Factors delaying surgical treatment of hip fractures in elderly patients. Ann R Coll Surg Engl 2003, 85(2):117-119.

19. Vigoda MM, Sweitzer B, Miljkovic N, Arheart KL, Messinger S, Candiotti K, Lubarsky D: 2007 American College of Cardiology/American Heart Association (ACC/AHA) Guidelines on perioperative cardiac evaluation are usually incorrectly applied by anesthesiology residents evaluating simulated patients. Anesth Analg 2011, 112(4):940-949.

20. Shiga T, Wajima Z, Ohe Y: Is operative delay associated with increased mortality of hip fracture patients? Systematic review, meta-analysis, and meta-regression. Can J Anaesth 2008, 55(3):146-154.

21. Khan SK, Kalra S, Khanna A, Thiruvengada MM, Parker MJ: Timing of surgery for hip fractures: a systematic review of 52 published studies involving 291,413 patients. Injury 2009, 40(7):692-697.

22. Simunovic N, Devereaux PJ, Sprague S, Guyatt GH, Schemitsch E, Debeer J, Bhandari M: Effect of early surgery after hip fracture on mortality and complications: systematic review and meta-analysis. Cmaj, 182(15):16091616.

23. Novack V, Jotkowitz A, Etzion O, Porath A: Does delay in surgery after hip 
fracture lead to worse outcomes? A multicenter survey. Int J Qual Health Care 2007, 19(3):170-176.

24. Holt G, Smith R, Duncan K, Finlayson DF, Gregori A: Early mortality after surgical fixation of hip fractures in the elderly: an analysis of data from the scottish hip fracture audit. J Bone Joint Surg Br 2008, 90(10):1357-1363.

25. Orosz GM, Magaziner J, Hannan EL, Morrison RS, Koval K, Gilbert M, McLaughlin M, Halm EA, Wang JJ, Litke A et al.: Association of timing of surgery for hip fracture and patient outcomes. Jama 2004, 291(14):17381743.

26. Soderqvist A, Ekstrom W, Ponzer S, Pettersson H, Cederholm T, Dalen N, Hedstrom M, Tidermark J: Prediction of mortality in elderly patients with hip fractures: a two-year prospective study of 1,944 patients. Gerontology 2009, 55(5):496-504.

27. Roche JJ, Wenn RT, Sahota O, Moran CG: Effect of comorbidities and postoperative complications on mortality after hip fracture in elderly people: prospective observational cohort study. Bmj 2005, 331(7529):1374.

28. Fisher AA, Southcott EN, Goh SL, Srikusalanukul W, Hickman PE, Davis MW, Potter JM, Budge MM, Smith PN: Elevated serum cardiac troponin I in older patients with hip fracture: incidence and prognostic significance. Arch Orthop Trauma Surg 2008, 128(10):1073-1079.

29. Chong CP, Lam QT, Ryan JE, Sinnappu RN, Lim WK: Incidence of postoperative troponin I rises and 1-year mortality after emergency orthopaedic surgery in older patients. Age Ageing 2009, 38(2):168-174. 


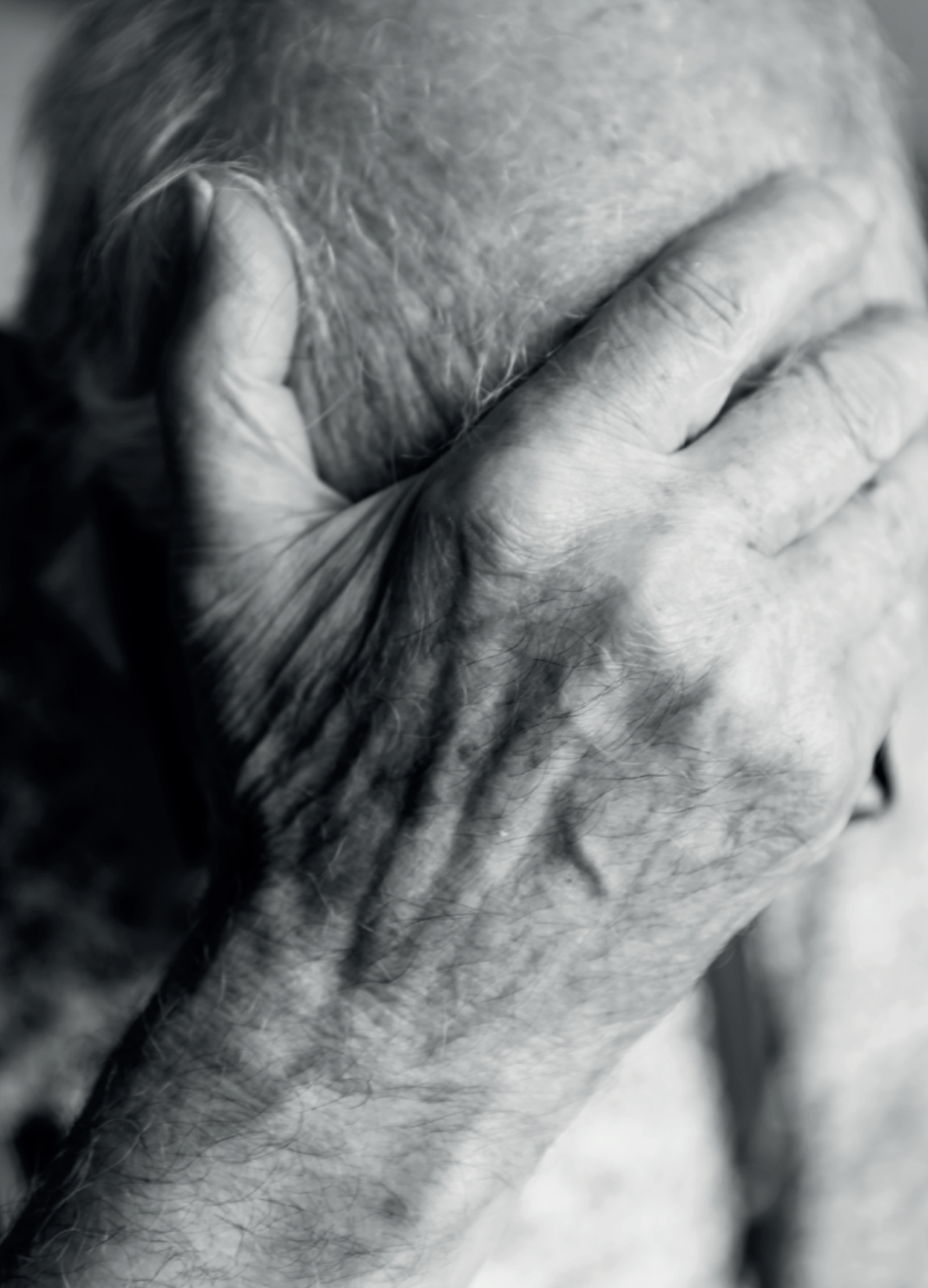




\section{CHAPTER 4}

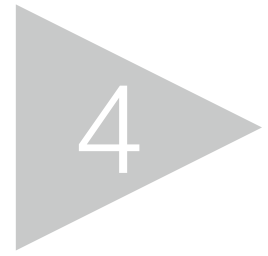

Cardiac overscreening hip fracture patients

S.J.M.Smeets, B.P.W. van Wunnik, M. Poeze, G.D. Slooter, J.P.A.M. Verbruggen

Archives of Orthopaedic and Trauma Surgery Aug 2019

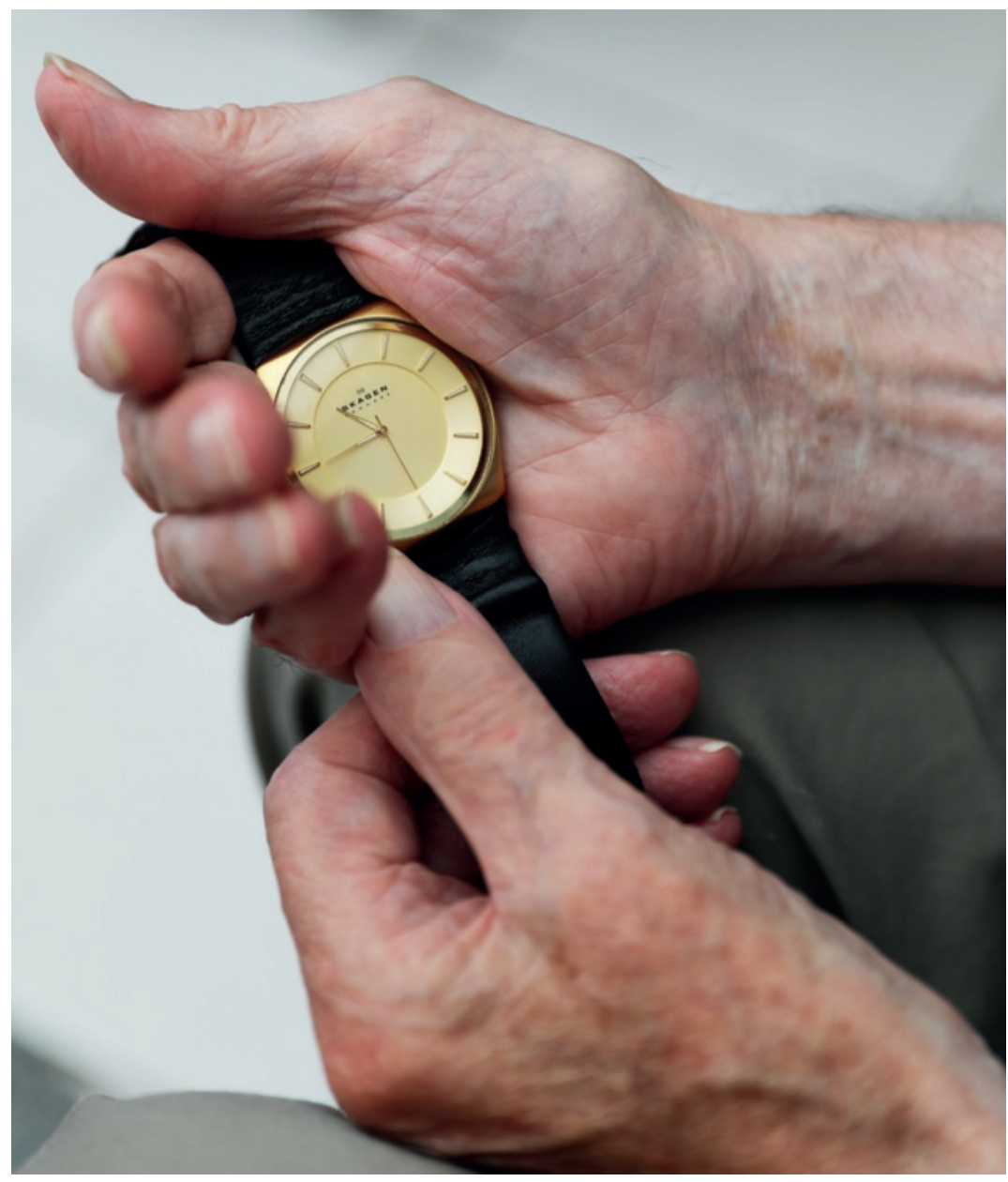




\section{ABSTRACT}

Background: The aim of this study was to prospectively investigate the adherence to the American College of Cardiology (ACC) and the American Heart Association $(\mathrm{AHA})$ guidelines for perioperative assessment of patients with hip fracture in daily clinical practice and how this might affect outcome.

Methods: This prospective cohort study from Maastricht University Medical Centre included 166 hip fracture patients within a 3-year inclusion period. The preoperative cardiac screening and adherence to the ACC/AHA guideline were analysed. Cardiac risk was classified as low, intermediate and high risk. Secondary outcome measurements were delay to surgery, perioperative complications and in-hospital, 30-day, 1-year and 2-year mortality.

Results: According to the ACC/AHA guideline $87 \%$ of patients received correct preoperative cardiac screening. The most important reason for incorrect preoperative cardiac screening was overscreening (>90\%). Multivariate analysis showed that a cardiac consultation $(p=0.003)$ and overscreening $(p=0.02)$ as significant predictors for increased delay to surgery, while age, sex, previous cardiac history and preoperative mobility were not. High risk patients had in comparison with low risk patients a significantly higher relative risk ratio for in-hospital mortality (RR 6, 95\% Cl 2-17). Multivariate analysis showed that previous cardiac history and increased delay to surgery were predictors for early mortality. High age and previous cardiac history were risk factors for late mortality.

Conclusion: Preoperative cardiac screening for hip fracture patients in adherence to the ACC/AHA guideline is associated with a diminished use of preoperative resources. Overscreening leads to greater delay to surgery, which poses a risk for perioperative complications and early mortality. 


\section{INTRODUCTION}

Hip fractures are one of the most common orthopaedic causes leading to hospital admission in the geriatric population and are associated with high morbidity and mortality rates [1]. All hip fracture patients receive preoperative screening for perioperative risk assessment, usually by the anesthesiologist. Preoperative screening includes often a preoperative cardiac consultation. The reason for this is not cardiac clearance, but cardiac risk assessment to determinate changes in perioperative patient management, including anaesthesia, pharmacological and perioperative monitoring [2]. Preoperative cardiac consultation in patients with hip fractures is often time consuming and may lead to delay to surgery. Early operative treatment within 24-48 hours is advocated to minimize the potential morbidity/ mortality associated with delay to surgery [3-5]. Therefore, extended cardiac evaluation should be restricted if it is unlikely to change perioperative patient management [6-9].

According to the American College of Cardiology and the American Heart Association (ACC/AHA) guidelines hip surgery is considered intermediate risk surgery, due to the quantity of hemodynamic stress it induces [2]. This means that major ischemic cardiac complications occur in less than $5 \%$ of the time. However, the overall incidence of perioperative myocardial ischemia in elderly patients undergoing hip fracture surgery has been reported to be $22-53 \%[10,11]$. In addition, previous studies indicated that the principal causes of in-hospital death after hip fracture were cardiac failure and myocardial infarction, occurring early after the fracture $[12,13]$.

To reduce the risk of perioperative cardiac events the ACC/AHA have developed guidelines for preoperative risk stratification and cardiac assessment. The keypoint of these guidelines are summarized in an algorithm indicating the stepwise approach of patients using clinical predictors to identify their cardiac risk category.

In this study we prospectively evaluated whether the routine preoperative screening of hip fracture patients as performed in our department is in accordance with the ACC/AHA guidelines and the consequences for daily practice in preoperative management and postoperative complications in a cohort of hip fracture patients. 


\section{MATERIALS AND METHODS}

\section{STUDY POPULATION}

This prospective study was conducted in the Maastricht University Hospital in the Netherlands, a level 1 trauma centre. All patients with a hip fracture admitted to the emergency department were eligible for inclusion. During a 3-year period, patients of 65 years and above were included. After surgery there was a 2-year follow-up observation period or until death. Polytrauma patients, pathological hip fractures or patients with hip fractures who did not have surgery, were excluded. The department of trauma surgery and orthopaedic surgery used a protocolised treatment algorithm regarding hip replacement or internal fixation based on our National guidelines 'Proximal femur fractures', 2016 [14].

At admission the following score forms were recorded: the ASA (American Society of Anesthesiologists) score for physical status [15], the Barthel index for pre-injury functional evaluation [16], Metabolic Equivalent of Task (MET) score for functional capacity [17], Mini Mental State Examination (MMSE) for cognitive impairment [18] and the Palmer \& Parker score for mobility [19]. Furthermore, the preoperative cardiac workup was described on the evaluation form using the ACC/AHA guideline template. Standard workup after admission to the emergency room consisted of a detailed history, a complete physical examination, an electrocardiography and standard biochemical and hematologic tests. During preoperative screening the anesthesiologist decided whether a cardiac consultation was necessary. Extensive cardiac evaluation consisted of an evaluation of the patients performance state, medication review, assessment of the electrocardiogram, physical examination, an echocardiography on indication and advice was given regarding the cardiac risk in relation with the intended operation and recommendations on patient management in the perioperative period. The Maastricht Ethical committee approved the waiver of the requirement to obtain a signed consent form. All the questions and score forms were taken within the presence of a first-degree family member or sometimes legal representative in the case of dementia.

\section{PRIMARY OUTCOME MEASUREMENTS}

Our main goal was to evaluate the preoperative cardiac evaluation in daily practice, using the algorithm proposed in the ACC/AHA guideline. Clinical predictors for each risk group are shown in Table 1. 'Correctly screened' accounts for those patients 
who had surgery without cardiac consultation with a stable cardiac situation or in the absence of a cardiac history, or patients who received a cardiac consultation when indicated by the guideline. We defined two possibilities for preoperative cardiac screening that was not in line with the guidelines. 'Underscreening' was defined as a cardiac consultation that was indicated by the guidelines, but not executed. In other terms: preoperative cardiac screening that fell short. 'Overscreening' was defined as a cardiac consultation that was not indicated by the guideline, but still performed. In other terms: preoperative cardiac screening that was too extensively. Subsequently, the primary investigator (SM) analysed the content of the preoperative cardiac consultations in relation to the patient's medical condition and discussed this with the research group and principal investigator (VE). These additional quality measures were taken to crosscheck our interpretations of the AC/ AHA guidelines.

Table 1. The American College of Cardiology/American Heart Association clinical predictors

Low Risk

Advanced age
Abnormal ECG
Rhythm other than
Low functional cap
History of stroke
Uncontrolled
hypertension

Intermediate Risk

Mild angina pectoris

Prior myocardial infarction

Compensated or prior cardiac heart failure

Diabetes Mellitus
High Risk Unstable coronary
syndromes

Decompensated cardiac heart failure

Significant arrhythmias

Severe valvular disease

\section{SECONDARY OUTCOME MEASUREMENTS}

Secondary outcome measurements were delay to surgery, perioperative complications and early and late mortality. We analysed the complication rates in relation with delay to surgery. Mortality rates were recorded in-hospital and at 30day, 1-year and 2-year interval. 


\section{STATISTICAL ANALYSIS}

All analyses were performed with SPSS 23 statistical software for windows (SPSS Inc., Chicago, Illinois, USA). P<0.05 was considered to be statistically significant. Data were presented as mean with standard deviation (SD) or as percentages when appropriate. In case of non-normal distributed, data were presented as median with interquartile range (IR). One-way ANOVA were used to compare normally distributed and the Mann Whitney U-test for non-normally distributed continuous variables with Bonferroni correction for multiple testing. A Pearsons chi-square $\left(x^{2}\right)$ test was used to investigate whether distributions of categorical variables differed from one another. We used a Kaplan-Meier survival curve to investigate the mortality rates for each of the cardiac risk groups, comparing outcome using log rank analysis. A univariate logistic analysis of the postoperative complications was performed to identify risk factors early mortality. All important variables from univariate analysis for mortality were entered in a multivariate regression analysis.

\section{RESULTS}

In the study period 166 consecutive patients were eligible for inclusion. Patient and operative characteristics are presented with the representative cardiac risk groups in table 2. There were no significant differences in preoperative status concerning ASA score, the Barthel index for functional evaluation, Metabolic Equivalent of Task (MET) score for functional capacity, Mini Mental State Examination (MMSE) for cognitive impairment and the Palmer \& Parker score for mobility.

In total $8 \%(13 / 166)$ of patients were predicted to have a high perioperative complication risk, $27 \%(45 / 166)$ an intermediate risk and 65\% (108/166) a low risk. In 11 (6.6\%) patient's preoperative mobility scores could not be accurately determined at admittance due to cognitive impairment and unavailability of relatives to give correct information. These data were regarded as missing data, other available data of these patients were still used for analysis. There were no significant differences concerning operative characteristics between the cardiac risk groups (Table 2). 
ACC/AHA cardiac risk group

\begin{tabular}{|c|c|c|c|c|}
\hline Variables & $\begin{array}{c}\text { Low } \\
\%(n) n=108\end{array}$ & $\begin{array}{l}\text { Intermediate } \\
\%(n) n=45\end{array}$ & $\begin{array}{c}\text { High } \\
\%(n) \text { n=13 }\end{array}$ & $\begin{array}{c}\text { Total } \\
\%(n) n=166\end{array}$ \\
\hline \multirow{5}{*}{$\begin{array}{l}\text { Median age (years) } \\
\text { Female Sex } \\
\text { ASA (median) } \\
\text { Barthel Index (median) } \\
\text { Palmer \& Parker score (median) }\end{array}$} & 85 (IR 11) & 83 (IR 11) & 84 (IR 6) & 84 (R 65-99) \\
\hline & $68 \%(73)$ & $67 \%(30)$ & $85 \%(11)$ & $69 \%(114)$ \\
\hline & 3 (IR 1) & $3(\operatorname{IR~} 0)$ & $4(\operatorname{IR~} 0)$ & 3 (R 1-4) \\
\hline & 18 (IR 7) & 17 (IR 7) & 13 (IR 11) & 17 (R 1-20) \\
\hline & $6(\operatorname{IR~5)}$ & $6(\operatorname{IR~5)}$ & 4 (IR 5) & 6 (R 0-9) \\
\hline \multirow{2}{*}{$\begin{array}{l}\text { MET (median) } \\
\text { MMSE (median) }\end{array}$} & $4(\operatorname{IR~} 3)$ & $4(\operatorname{IR~} 3)$ & 2 (IR 3) & $4(\mathrm{R} 0-10)$ \\
\hline & 25 (IR 12) & 25 (IR 12) & 17 (IR 15) & 21 (R 0-30) \\
\hline \multirow[t]{2}{*}{ Mobility not impaired } & $39 \%(40 / 102)$ & $40 \%(17 / 43)$ & $18 \%(2 / 11)$ & $38 \%$ 59/156 \\
\hline & $48 \%(49 / 102)$ & $33 \%(14 / 43)$ & $36 \%(4 / 11)$ & $43 \% 67 / 156$ \\
\hline \multirow{2}{*}{$\begin{array}{l}\text { Strongly impaired / indoors } \\
\text { Immobile - transfers }\end{array}$} & $10 \%(10 / 102)$ & $23 \%(10 / 43)$ & $36 \%(4 / 11)$ & $15 \% 24 / 156$ \\
\hline & $3 \%(3 / 102)$ & $5 \%(2 / 43)$ & $9 \%(1 / 11)$ & $4 \% 6 / 156$ \\
\hline Intracapsular fractures & $47 \%(50 / 107)$ & $51 \%(23 / 45)$ & $62 \%(8 / 13)$ & $48 \%(80)$ \\
\hline Extracapsular fractures & $53 \%(57 / 107)$ & $49 \%(22 / 45)$ & $38 \%(5 / 13)$ & $51 \%(85)$ \\
\hline General anaesthesia & $57 \%(56 / 99)$ & $60 \%(25 / 42)$ & $73 \%(8 / 11)$ & $54 \%(89)$ \\
\hline \multirow{2}{*}{$\begin{array}{l}\text { Spinal anaesthesia } \\
\text { Operation time (min., mean) }\end{array}$} & $43 \%(43 / 99)$ & $40 \%(17 / 42)$ & $27 \%(3 / 11)$ & $38 \%(63)$ \\
\hline & 69 (SD 28) & 70 (SD 27) & 85 (SD 25) & 71 (SD 28) \\
\hline \multirow[t]{2}{*}{ Delay to surgery (hrs., median) } & 23 (IR 20) & 25 (IR 17) & 31 (IR 46) & 27 (R 2-135) \\
\hline & $44 \%(47 / 106)$ & $53 \%(23 / 43)$ & $62 \%(8 / 13)$ & $47 \%(78)$ \\
\hline \multirow{2}{*}{$\begin{array}{l}\quad>48 \text { hrs. } \\
\text { Hospital stay (days, median) }\end{array}$} & $10 \%(10 / 106)$ & $5 \%(2 / 43)$ & $38 \%(5 / 13)^{\star} /{ }^{\star \star}$ & $10 \%(17)$ \\
\hline & $8(\operatorname{IR~} 6)$ & 10 (IR 9) & 16 (IR 9) & 9 (R 2-59) \\
\hline
\end{tabular}

ASA = American Society of Anesthesiologists score, range 1-6; Barthel Index score for functional capacity, range 0-20; Palmer and Parker score for mobility, range 0-9; MET= metabolic equivalent of task score for physical activity, range 0 - >10; MMSE= mini mental state examination score for measure cognitive impairment, range 0-30; $\mathrm{IR}=$ interquartile range in case of non-normal distributed data, $\mathrm{R}=$ range of data, minimum-maximum; $\mathrm{SD}=$ standard deviation, in case of normal distributed data. ${ }^{*}$ Significant difference in compare with low risk group, $\mathrm{p}<0.05 .{ }^{\star *}$ Significant difference in compare with intermediate risk group, $\mathrm{p}<0.05$. 
According to the guideline 93\% (100/108) in the low risk group, 76\% (34/45) in the intermediate risk group and $85 \%(11 / 13)$ in the high risk group received correct preoperative cardiac screening (Table 3). Of all patients $13 \%$ (21/166) did not receive the correct preoperative screening. The main reason for this was due to overscreening in $90 \%$ of the cases (19/21); 59\% (98/166) of the patients had a cardiovascular history, which did not necessarily imply active cardiac conditions. The chance to receive a cardiac consultation increased with the patient's perioperative cardiac risk group assignment, 9\%,33\% and 100\% in the low, intermediate and high risk group respectively. We found no significant differences in outcome in the overscreening group vs correctly screened patients.

\section{Table 3. Preoperative cardiac evaluations}

\begin{tabular}{|c|c|c|c|c|}
\hline & \multicolumn{4}{|c|}{ ACC/AHA cardiac risk group } \\
\hline & $\stackrel{\text { Low }}{\%(n) ~} n=108$ & $\begin{array}{l}\text { Intermediate } \\
\%(n) n=45\end{array}$ & 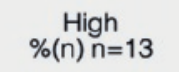 & $\begin{array}{c}\text { Total } \\
\%(n) n=166\end{array}$ \\
\hline Cardiac history & $28 \%(30)$ & $80 \%(36)^{\star}$ & $92 \%(12)^{\star / * \star}$ & $47 \%(78)$ \\
\hline Cardiac consultation & $9 \%(10)$ & $33 \%(15)^{*}$ & $100 \%(13)^{* / * *}$ & $23 \%(38)$ \\
\hline Correct cardiac screening $\$$ & $93 \%(100)$ & $76 \%(34)^{\star}$ & $85 \%(11)^{\star}$ & $87 \%(145)$ \\
\hline Overscreening & $7 \%(8)$ & $20 \%(9)$ & $15 \%(2)$ & $11 \%(19)$ \\
\hline Underscreening & 0 & $4 \%(2)$ & 0 & $12 \%(2)$ \\
\hline
\end{tabular}

\section{DELAY TO SURGERY}

The median delay to surgery was 23 hours (IR 20), 23 hours (IR 17) and 31 hours (IR 46) for the low, intermediate and high risk group respectively. The mean delay to surgery increased by 9.0 hours (SD 25-44) when patients had a cardiac consultation $(p=0.06)$. High risk patients received significantly more preoperative cardiac consultations and had more often a delay to surgery of $>48$ hours $(p<0.005$ in comparison with the low risk an intermediate risk group). Multivariate analysis showed that a cardiac consultation $(p=0.003)$ and overscreening $(p=0.02)$ were significant risk factors for increased delay to surgery, while age, sex, preoperative cardiac history and preoperative mobility were not influencing delay to surgery. In univariate analysis patients with a delay to surgery of $>48 \mathrm{hr}$ had significantly more 
respiratory complications $(p=0.04)$. In multivariate analysis an increased delay to surgery was an independent predictor for in-hospital mortality $(p=0.03)$ and 30-day mortality $(p=0.02)$ independent from cardiac risk category.

\section{POSTOPERATIVE COMPLICATIONS}

Postoperative complications are presented by cardiac risk group in table 4 . Respiratory and cardiovascular complications occurred significantly more often in the high risk group in comparison with the intermediate and low risk group $(p<0.02)$. This was related to a significantly higher risk for in-hospital death. Pulmonary complications (RR 37.95\% Cl 9-156; $\mathrm{p}<0.0001$ ), and cardiovascular complications (RR 9.95\% Cl 3-24; $p<0.0001$ ) were significant risk factors for in-hospital mortality. In a multivariate analysis an increased delay to surgery was an independent risk factor for respiratory complications $(p=0.009)$. Furthermore, a multivariate regression analysis for cardiovascular complications showed that a cardiac history was a significant risk factor, but not age, sex or delay to surgery $(p=0.001)$.

\section{MORTALITY}

The mortality rates by cardiac risk group are summarized in table 5. A Kaplan-Meier curve for survival was made with a follow up of 24 months in figure 1 (lost to follow-up after discharge $n=9$ ). The mortality rates increased with the cardiac risk category. This led to significantly higher mortality in high risk patients for the in-hospital, 30day, 1-year and 2-year mortality in comparison with low risk patients. High risk patients had in comparison with low risk patients a relative risk ratio (RR) of 6 (95\% Cl 2-17) for in-hospital mortality, RR 5 (95\% Cl 2-12) for 30-day mortality, RR 2 (95\% Cl 1.3-4) for 1-year mortality and RR $2(95 \% \mathrm{Cl} 2-4)$ for 2-year mortality. In-hospital mortality was due to cardiovascular complications in $50 \%$ of cases, followed by respiratory failure in $36 \%$ of cases and in $14 \%$ because of other reasons.

Mortality rates in relation with a prior cardiac history are presented in table 6 . These results show that a previous cardiac history is related with $>3.5$ fold higher early mortality, or $>1.7$ fold higher late mortality in comparison with no previous cardiac history.

A Cox multiple regression analysis for mortality for the complete follow-up period of 24 months showed that high age was the only significant risk factor. With linear regression analysis we studied potential risk factors for early and late mortality (see 
table 7). A cardiac history and increased delay to surgery were predictors for early mortality (in-hospital and 30-day). A high age and a cardiac history were found risk factors for late mortality.

Table 4. Complications

ACC/AHA cardiac risk group

\begin{tabular}{|c|c|c|c|c|}
\hline Complications & $\stackrel{\text { Low }}{\text { Lo(n) } n=108}$ & $\begin{array}{l}\text { Intermediate } \\
\%(n) n=45\end{array}$ & 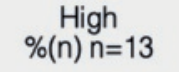 & $\begin{array}{c}\text { Total } \\
\%(n) n=166\end{array}$ \\
\hline Number of complications & $1(\operatorname{IR} 1)$ & $1($ IR 1$)$ & 2 (IR 2) & 1 (R 0-7) \\
\hline Delirium & $25 \%(27)$ & $20 \%(9)$ & $31 \%(4)$ & $24 \%(40)$ \\
\hline Wound infection & $6 \%(6)$ & $13 \%(6)$ & 0 & $7 \%(12)$ \\
\hline Blood transfusion & $43 \%(46)$ & $38 \%(17)$ & $61 \%(8)$ & $43 \%(71)$ \\
\hline Urinary tract Infection & $17 \%(18)$ & $16 \%(7)$ & 0 & $15 \%(25)$ \\
\hline Pressure sores & $4 \%(4)$ & $9 \%(4)$ & 0 & $5 \%(8)$ \\
\hline Respiratory & $11 \%(12)$ & $11 \%(5)$ & $46 \%(6)^{\star} /{ }^{\star \star}$ & $14 \%(23)$ \\
\hline Pneumonia & $8 \%(9)$ & $9 \%(4)$ & $31 \%(4)^{\star}$ & $10 \%(17)$ \\
\hline Pulmonary embolism & 0 & 0 & 0 & 0 \\
\hline Respiratory failure & $5 \%(5)$ & $7 \%(28)$ & $23 \%(28)^{\star}$ & $7 \%(11)$ \\
\hline Gastrointestinal tract bleeding & $4 \%(4)$ & $2 \%(1)$ & 0 & $3 \%(5)$ \\
\hline Gastrointestinala & $2 \%(2)$ & $2 \%(1)$ & 0 & $2 \%(28)$ \\
\hline Cardiovascular & $6 \%(7)$ & $31 \%(14)^{\star}$ & $62 \%(8)^{\star} / \star \star$ & $17 \%(29)$ \\
\hline Stroke & $1 \%(1)$ & $2 \%(1)$ & 0 & $1 \%(2)$ \\
\hline Rhythm disorders & $2 \%(2)$ & $13 \%(6)^{\star}$ & 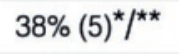 & $8 \%(13)$ \\
\hline $\mathrm{AMI}$ & $2 \%(2)$ & $9 \%(4)$ & $15 \%(2)$ & $5 \%(8)$ \\
\hline Cardiac failure & $5 \%(5)$ & $11 \%(5)$ & $38 \%(5)^{\star} / \star \star$ & $9 \%(15)$ \\
\hline Neurological & $1 \%(1)$ & $2 \%(1)$ & 0 & $1 \%(2)$ \\
\hline Implant failure ${ }^{b}$ & $7 \%(8)$ & $2 \%(1)$ & $8 \%(1)$ & $6 \%(10)$ \\
\hline \multicolumn{5}{|c|}{$\begin{array}{l}\text { Postoperative ileus, extensive diarrhea, ischemia. }{ }^{b} \text { Re-operation, luxation or deep infection of } \\
\text { le arthroplasty or fracture fixation. Respiratory complications consist of pneumonia, pulmonary } \\
\text { mbolism and respiratory failure together. Cardiovascular complications consist of stroke, rhythm } \\
\text { isorders, acute myocardial infarction (AMI) and cardiac failure. IR }=\text { interquartile range in case } \\
\text { f non-normal distributed data, } R=\text { range of data, minimum-maximum. }{ }^{*} \text { Significant difference in } \\
\text { ompare with low risk group, } p<0.05 .{ }^{* *} \text { Significant difference in compare with intermediate risk } \\
\text { roup, } p<0.05 \text {. }\end{array}$} \\
\hline
\end{tabular}




\section{Table 5. Mortality rates}

ACC/AHA cardiac risk group

\begin{tabular}{l|cccc}
\hline \multicolumn{1}{c|}{ Mortality } & $\begin{array}{c}\text { Low } \\
\%(\mathrm{n})\end{array}$ & $\begin{array}{c}\text { Intermediate } \\
\%(\mathrm{n})\end{array}$ & $\begin{array}{c}\text { High } \\
\%(\mathrm{n})\end{array}$ & $\begin{array}{c}\text { Total } \\
\%(\mathrm{n})\end{array}$ \\
\hline In-hospital & $6 \%(6 / 108)$ & $9 \%(4 / 45)$ & $31 \%(4 / 13)^{\star} /{ }^{\star \star}$ & $8 \%(14 / 166)$ \\
30-days & $9 \%(9 / 102)$ & $16 \%(7 / 43)$ & $41 \%(5 / 12)^{\star}$ & $13 \%(21 / 157)$ \\
1-year & $25 \%(25 / 102)$ & $37 \%(16 / 43)$ & $58 \%(7 / 12)^{\star}$ & $31 \%(48 / 157)$ \\
2-year & $30 \%(31 / 102)$ & $44 \%(19 / 43)$ & $75 \%(9 / 12)^{\star}$ & $38 \%(59 / 157)$ \\
\hline
\end{tabular}

* Significant difference in compare with low risk group, $p<0.05 .{ }^{* *}$ Significant difference in compare with intermediate risk group, $p<0.05$.

Figure 1. Survival Curve

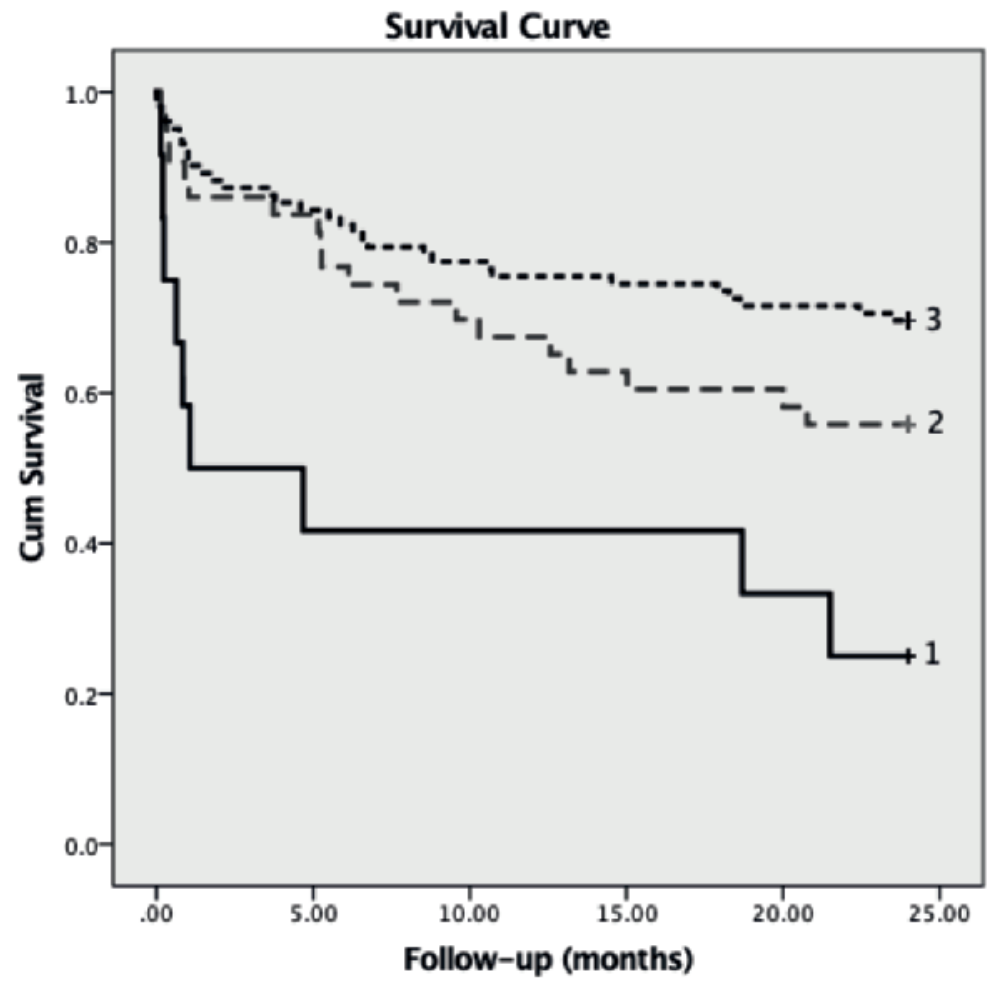

$\mathrm{ACC} / \mathrm{AHH}$ risk categories; $1=$ High risk, 2= ntermediate risk, 3=Low risk 
Table 6. Mortality rates in relation with prior cardiac history

\begin{tabular}{c|ccc}
\hline Mortality & $\begin{array}{c}\text { No cardiac history } \\
\%(n)\end{array}$ & $\begin{array}{c}\text { Cardiac history } \\
\%(n)\end{array}$ & P-value \\
\hline In-hospital & $2 \%(2 / 88)$ & $15 \%(12 / 78)$ & 0.002 \\
30-day & $6 \%(5 / 83)$ & $22 \%(16 / 74)$ & 0.004 \\
1-year & $24 \%(20 / 83)$ & $38 \%(28 / 74)$ & $<0.05$ \\
2-year & $28 \%(23 / 83)$ & $49 \%(36 / 74)$ & 0.005 \\
\hline
\end{tabular}

$\mathrm{p}<0.05$ is considered statistically significant

Table 7. Regression analysis for mortality

\begin{tabular}{|l|cccc}
\hline Variables & $\begin{array}{c}\text { In-hospital } \\
\text { mortality } \\
(\mathrm{p} \text {-value) }\end{array}$ & $\begin{array}{c}30 \text {-day } \\
\text { mortality } \\
(\mathrm{p} \text {-value) }\end{array}$ & $\begin{array}{c}\text { 1-year } \\
\text { mortality } \\
\text { (p-value) }\end{array}$ & $\begin{array}{c}\text { 2-year } \\
\text { mortality } \\
\text { (p-value) }\end{array}$ \\
Sex & 0.2 & 0.1 & 0.2 & 0.6 \\
Age & 0.7 & 0.7 & 0.001 & $<0.0001$ \\
Delay to surgery & 0.03 & 0.02 & 0.1 & 0.2 \\
Cardiac history & 0.005 & 0.008 & 0.2 & 0.04 \\
\hline
\end{tabular}

$\mathrm{p}<0.05$ is considered statistically significant

\section{DISCUSSION}

In this prospective cohort study $87 \%$ of patients received preoperative cardiac screening in adherence to the ACC/AHA guideline. The most frequent reason for incorrect preoperative cardiac screening was overscreening (>90\%). High risk patients received significantly more preoperative cardiac consultations and experienced more often a delay to surgery of $>48$ hours. Multivariate analysis showed that a cardiac consultation and overscreening are significant predictors for increased delay to surgery, while age, sex, a previous cardiac history and preoperative mobility were not. Early mortality (in-hospital and 30-day) was determined by a previous cardiac history and increased delay to surgery. High age and a previous cardiac history were predictors for late mortality.

Preoperative cardiac screening for hip fracture patients has been subject to debate between surgeons and anesthesiologists. Therefore, the ACC/AHA provides guidelines for preoperative cardiac screening to minimize the risk for perioperative cardiac complications and preventing overuse of medical resources. High risk patients might benefit from delaying hip fracture surgery to optimize or stabilizing the 
cardiac comorbidities. Nevertheless, delaying surgery with a cardiac consultation that is not recommended or contributing could lead to worse outcome. Cardiac consultations increase delay to surgery, which is confirmed by several other studies $[20,7]$. However, in this study, no significant differences in postoperative complications in the overscreening group vs correctly screened patients were found, which may be due to a small sample size. Another important issue is the content of cardiac consultations. Consultations are frequently limited to a statement of the increased surgical risk and make general recommendations concerning fluid balance, maintaining hemoglobin levels and continuing beta-blocker medication.

Stitgen et al showed that $85 \%$ of patients were correctly screened according to the ACC/AHA guideline [6]. In our previous retrospective study on this matter $(n=388)$, we demonstrated $72 \%$ correctly screened patients [7] vs $87 \%$ in this study. The number of cardiac consultations has dropped to $23 \%$ in this study vs. $38 \%$ in our previous study. In addition, we found a marked decline in patients who were overscreened: $13 \%$ vs. $27 \%$ in our previous study. The most profound findings were in the intermediate risk group, where $24 \%$ of patients were not screened in accordance to the guidelines vs $54 \%$ in our previous study. The reason for incorrect preoperative cardiac screening in both our studies remained in $>90 \%$ of cases due to overscreening. We consider increased awareness of surgeons as well as anesthesiologists of the ACC/AHA guidelines and a reduced incidence of instant cardiac consultations requested by the physician at the emergency department for cardiac clearance are contributing to these findings. Sometimes the goal of preoperative screening seems to be to strive for 'cardiac clearance', some sort of cardiac approval that must be obtained before operation.

According to ACC/AHA guideline patients who require noninvasive cardiac testing are those with active high risk cardiac conditions and those with intermediate risk clinical predictors combined with poor functional capacity. Whether a consultation is justified for patients in the intermediate risk group is decided by their functional capacity, measured by metabolic equivalent of task (MET's), which is rather arbitrary. Currently, there exist no other clinical screening tools to identify those patients who need a cardiac consultation prior to hip fracture surgery.

It has been suggested to routinely perform an echocardiography in elderly patients with hip fractures [21]. Some authors have reported a benefit of routine echocardiography on mortality after hip fracture surgery [22], where others have 
not $[23,24]$. Screening all hip fracture patients with transthoracic echocardiography (TTE) identified in $8 \%$ of patients significant aortic stenosis. Conversely severe aortic stenosis is no contraindication for surgery and does not influence early mortality $[25,26]$. Another study found that preoperative TTE lead to an increased delay to surgery [9]. Delay to surgery is associated with worse outcome after hip fracture surgery $[27,5,28,29,23,30]$. Furthermore, TTE screening has cost implications, as this needs to be a continuously available service. There are no recommendations available from randomized controlled trials on the use of TTE screening in a hip fracture population. One retrospective matched-control study showed lower postoperative and 1-year mortality rates after focused TTE screening in a hip fracture population [22]. Unclear is whether these patients were only intermediate risk patients or also high risk patients and what their functional capacity was. Screening patients with a high chance of pathology is more logical than screening all hip fracture patients, therefore in the low risk group is TTE screening probably not useful and secondly not indicated by the ACC/AHA guideline.

A preoperative cardiac consultation rarely affects surgical management, but may influence anesthesiologic management, especially cardiovascular and fluid management after non-invasive testing with TTE in high risk or intermediate risk patients with low METs. The ACC/AHA guidelines recommendation is level B evidence and is merely based on dobutamine stress echocardiography which is rarely used in the hip fracture population. Instead, bedside echocardiography without stress testing is performed to report on global cardiac and valvular function and volume status. The guideline states that non-invasive cardiac testing is reasonable for intermediate risk patients with $<4$ METs if it will change patient management. As a result of this, TTE is probably most frequently overused in the intermediate risk group. Other indications for preoperative TTE are new developed dyspnoea without known aetiology or decompensated heart failure [31]. A study showed that TTE in accordance with the ACC/AHA guideline in only $14 \%$ of patients revealed disease with the potential to modify anesthesia or medical management [32]. If non-invasive cardiac testing like TTE prior to surgery is indicated, this should be performed without delay to surgery.

Not every form of anesthesia is equally suitable for every geriatric patient [33]. To improve outcome of high risk patients, some intraoperative strategies were studied in literature. Continuous spinal anesthesia (CSA), with (minimally invasive) hemodynamic monitoring is suggested as alternative anesthesia in the case of 
severe aortic stenosis with minimal hemodynamic changes intraoperatively in hip fracture patients $[34,35]$. CSA compared with combined spinal epidural anesthesia (CSE) showed better sensory blockade level and lower hemodynamic changes in 240 patients following major orthopaedic surgery [36]. According to a Cochrane systematic review, other advanced hemodynamic monitoring strategies, such as esophageal Doppler monitoring, goal-directed hemodynamic treatment (with LiDCO monitor) or Swan Ganz pulmonary-artery catheter in comparison with standard care and conventional fluid management did not show improvement on postoperative outcome after hip fracture surgery [37].

Respiratory and cardiovascular complications occurred significantly more often in the high risk group in comparison with the intermediate and low risk group and increased the risk for in-hospital death 5-fold to a 30-day mortality rate of $31 \%$. Another study found that pneumonia and heart failure after hip fracture surgery lead to a mortality rate of $43 \%$ and $65 \%$ respectively [38]. Three or more comorbidities, respiratory disease and malignancy were preoperative variables that were significantly related to increased 30-day mortality. In a multivariate regression analysis, we showed that a previous cardiac history was a predictor for early and late mortality. The increased early mortality in the cardiac history group, could be explained by postoperative respiratory and cardiovascular complications and the increased late mortality could be explained by the effect of comorbidity on the long-term. We did not examine whether patients with a cardiac history had equal recovery chances compared to patients without a cardiac history. Mortality after hip fracture remains high and extremely high for high risk patients. Hip fractures are associated with an in-hospital mortality rate of $7-14 \%$, reaching up to $36 \%$ within 1 year of surgery [39-41,7,42,43]. Over the past 3 decades, mortality rates after hip fracture surgery hardly changed. 1-year mortality for intertrochanteric fractures remained about $23 \%$ after 1999 [44]. Although a steady decrease was found in the UK were 11\% 30-day mortality in 2003 decreased to 8\% in 2013 [45]. A combined number of improvements of care, including the implementation of fast-track care pathways, input from orthogeriatricians, quick patient medical optimization, early surgery and advanced rehabilitation protocols have contributed to this $[33,45]$.

In conclusion, preoperative cardiac screening in adherence to the ACC/ AHA guideline is associated with a diminished use of preoperative resources. Overscreening leads to greater delay to surgery, which poses a risk for perioperative complications and early mortality. 


\section{REFERENCES}

1. Sathiyakumar V, Avilucea FR, Whiting PS, Jahangir AA, Mir HR, Obremskey WT, et al. Risk factors for adverse cardiac events in hip fracture patients: an analysis of NSQIP data. Int Orthop. 2016;40(3):439-45.

2. Fleisher LA, Beckman JA, Brown KA, Calkins H, Chaikof E, Fleischmann $\mathrm{KE}$, et al. ACC/AHA 2007 guidelines on perioperative cardiovascular evaluation and care for noncardiac surgery: a report of the American College of Cardiology/American Heart Association Task Force on Practice Guidelines (Writing Committee to Revise the 2002 Guidelines on Perioperative Cardiovascular Evaluation for Noncardiac Surgery): developed in collaboration with the American Society of Echocardiography, American Society of Nuclear Cardiology, Heart Rhythm Society, Society of Cardiovascular Anesthesiologists, Society for Cardiovascular Angiography and Interventions, Society for Vascular Medicine and Biology, and Society for Vascular Surgery. Circulation. 2007;116(17):e418-99.

3. Shiga T, Wajima Z, Ohe Y. Is operative delay associated with increased mortality of hip fracture patients? Systematic review, meta-analysis, and meta-regression. Can J Anaesth. 2008;55(3):146-54.

4. Khan SK, Kalra S, Khanna A, Thiruvengada MM, Parker MJ. Timing of surgery for hip fractures: a systematic review of 52 published studies involving 291,413 patients. Injury. 2009;40(7):692-7.

5. Simunovic N, Devereaux PJ, Sprague S, Guyatt GH, Schemitsch E, Debeer J, et al. Effect of early surgery after hip fracture on mortality and complications: systematic review and meta-analysis. CMAJ. 2010;182(15):1609-16.

6. Stitgen A, Poludnianyk K, Dulaney-Cripe E, Markert R, Prayson M. Adherence to Preoperative Cardiac Clearance Guidelines in Hip Fracture Patients. J Orthop Trauma. 2015;29(11):500-3.

7. Smeets SJ, Poeze M, Verbruggen JP. Preoperative cardiac evaluation of geriatric patients with hip fracture. Injury. 2012;43(12):2146-51.

8. Jettoo P, Kakwani R, Junejo S, Talkhani I, Dixon P. Pre-operative echocardiogram in hip fracture patients with cardiac murmur--an audit. J Orthop Surg Res. 2011;6:49.

9. O'HEireamhoin S, Beyer T, Ahmed M, Mulhall KJ. The role of preoperative cardiac investigation in emergency hip surgery. J Trauma. 2011;71(5):13457.

10. Chong CP, van Gaal WJ, Savige J, Lim WK. Cardiac injury and troponin testing after orthopaedic surgery. Injury. 2011;42(9):855-63.

11. Spurrier E, Wordsworth D, Martin S, Norris R, Parker MJ. Troponin T in hip fracture patients: prognostic significance for mortality at one year. Hip Int. 2011;21(6):757-61.

12. Nettleman MD, Alsip J, Schrader M, Schulte M. Predictors of mortality after 
acute hip fracture. J Gen Intern Med. 1996;11(12):765-7.

13. Perez JV, Warwick DJ, Case CP, Bannister GC. Death after proximal femoral fracture--an autopsy study. Injury. 1995;26(4):237-40.

14. Nederlandse Vereniging van Heelkunde $\mathrm{NVvH}$, Nederlandse Orthopaedische Vereniging NOV. Proximale femurfracturen (guideline). https://richtlijnendatabasenl. 2016.

15. Dripps RD. New classification of physical status. . Anesthesioly. 1963;24(111).

16. Mahoney FI, Barthel DW. Functional Evaluation: The Barthel Index. Md State Med J. 1965;14:61-5.

17. Jette M, Sidney K, Blumchen G. Metabolic equivalents (METS) in exercise testing, exercise prescription, and evaluation of functional capacity. Clin Cardiol. 1990;13(8):555-65.

18. Folstein MF, Robins LN, Helzer JE. The Mini-Mental State Examination. Arch Gen Psychiatry. 1983;40(7):812.

19. Parker MJ, Palmer CR. A new mobility score for predicting mortality after hip fracture. J Bone Joint Surg Br. 1993;75(5):797-8.

20. Mutlu H, Bilgili F, Mutlu S, Karaman O, Cakal B, Ozkaya U. The effects of preoperative non-invasive cardiac tests on delay to surgery and subsequent mortality in elderly patients with hip fracture. J Back Musculoskelet Rehabil. 2016;29(1):49-54.

21. Heyburn G, McBrien ME. Pre-operative echocardiography for hip fractures: time to make it a standard of care. Anaesthesia. 2012;67(11):1189-93.

22. Canty DJ, Royse CF, Kilpatrick D, Bowyer A, Royse AG. The impact on cardiac diagnosis and mortality of focused transthoracic echocardiography in hip fracture surgery patients with increased risk of cardiac disease: a retrospective cohort study. Anaesthesia. 2012;67(11):1202-9.

23. Marcantonio A, Steen B, Kain M, Bramlett KJ, Tilzey JF, Iorio R. The Clinical and Economic Impact of Preoperative Transthoracic Echocardiography in Elderly Patients with Hip Fractures. Bull Hosp Jt Dis (2013). 2015;73(4):23942.

24. Luttrell K, Nana A. Effect of Preoperative Transthoracic Echocardiogram on Mortality and Surgical Timing in Elderly Adults with Hip Fracture. J Am Geriatr Soc. 2015;63(12):2505-9.

25. Leibowitz D, Rivkin G, Schiffman J, Rott D, Weiss AT, Mattan Y, et al. Effect of severe aortic stenosis on the outcome in elderly patients undergoing repair of hip fracture. Gerontology. 2009;55(3):303-6.

26. McBrien ME, Heyburn G, Stevenson M, McDonald S, Johnston NJ, Elliott $J R$, et al. Previously undiagnosed aortic stenosis revealed by auscultation in the hip fracture population--echocardiographic findings, management and outcome. Anaesthesia. 2009;64(8):863-70.

27. Bretherton CP, Parker MJ. Early surgery for patients with a fracture of the 
hip decreases 30-day mortality. Bone Joint J. 2015;97-B(1):104-8.

28. Carretta E, Bochicchio V, Rucci P, Fabbri G, Laus M, Fantini MP. Hip fracture: effectiveness of early surgery to prevent 30-day mortality. Int Orthop. 2011;35(3):419-24.

29. Uzoigwe CE, Burnand HG, Cheesman CL, Aghedo DO, Faizi M, Middleton RG. Early and ultra-early surgery in hip fracture patients improves survival. Injury. 2013;44(6):726-9.

30. Lewis PM, Waddell JP. When is the ideal time to operate on a patient with a fracture of the hip? : a review of the available literature. Bone Joint J. 2016;98-B(12):1573-81.

31. Fleisher LA, Beckman JA, Brown KA, Calkins H, Chaikof EL, Fleischmann $\mathrm{KE}$, et al. ACC/AHA 2006 guideline update on perioperative cardiovascular evaluation for noncardiac surgery: focused update on perioperative betablocker therapy--a report of the American College of Cardiology/American Heart Association Task Force on Practice Guidelines (Writing Committee to Update the 2002 Guidelines on Perioperative Cardiovascular Evaluation for Noncardiac Surgery). Anesth Analg. 2007;104(1):15-26.

32. Adair C, Swart E, Seymour R, Patt J, Karunakar MA. Clinical Practice Guidelines Decrease Unnecessary Echocardiograms Before Hip Fracture Surgery. J Bone Joint Surg Am. 2017;99(8):676-80.

33. Luger TJ, Luger MF. [Anesthesiological care in orthogeriatric comanagement. Perioperative treatment of geriatric trauma patients]. Z Gerontol Geriatr. 2016;49(3):237-55.

34. Lopez MM, Guasch E, Schiraldi R, Maggi G, Alonso E, Gilsanz F. Continuous spinal anaesthesia with minimally invasive haemodynamic monitoring for surgical hip repair in two patients with severe aortic stenosis. Braz J Anesthesiol. 2016;66(1):82-5.

35. Dohler S, Klippel A, Richter S. [Continuous spinal anesthesia in very elderly patients with high anesthesia risk in traumatologic-orthopedic and general surgery interventions]. Anaesthesiol Reanim. 1999;24(6):157-63.

36. Imbelloni LE, Gouveia MA, Cordeiro JA. Continuous spinal anesthesia versus combined spinal epidural block for major orthopedic surgery: prospective randomized study. Sao Paulo Med J. 2009;127(1):7-11.

37. Lewis SR, Butler AR, Brammar A, Nicholson A, Smith AF. Perioperative fluid volume optimization following proximal femoral fracture. Cochrane Database Syst Rev. 2016;3:CD003004.

38. Roche JJ, Wenn RT, Sahota O, Moran CG. Effect of comorbidities and postoperative complications on mortality after hip fracture in elderly people: prospective observational cohort study. BMJ. 2005;331(7529):1374.

39. Murphy DK, Randell T, Brennan KL, Probe RA, Brennan ML. Treatment and displacement affect the reoperation rate for femoral neck fracture. Clin Orthop Relat Res. 2013;471(8):2691-702. 
40. Schemitsch E, Bhandari M. Femoral neck fractures: controversies and evidence. J Orthop Trauma. 2009;23(6):385.

41. Simunovic N, Devereaux PJ, Bhandari M. Surgery for hip fractures: Does surgical delay affect outcomes? Indian J Orthop. 2011;45(1):27-32.

42. Bottle A, Aylin P. Mortality associated with delay in operation after hip fracture: observational study. BMJ. 2006;332(7547):947-51.

43. Weller I, Wai EK, Jaglal S, Kreder HJ. The effect of hospital type and surgical delay on mortality after surgery for hip fracture. J Bone Joint Surg Br. 2005;87(3):361-6.

44. Mundi S, Pindiprolu B, Simunovic N, Bhandari M. Similar mortality rates in hip fracture patients over the past 31 years. Acta Orthop. 2014;85(1):54-9.

45. Giannoulis D, Calori GM, Giannoudis PV. Thirty-day mortality after hip fractures: has anything changed? Eur J Orthop Surg Traumatol. 2016;26(4):365-70. 

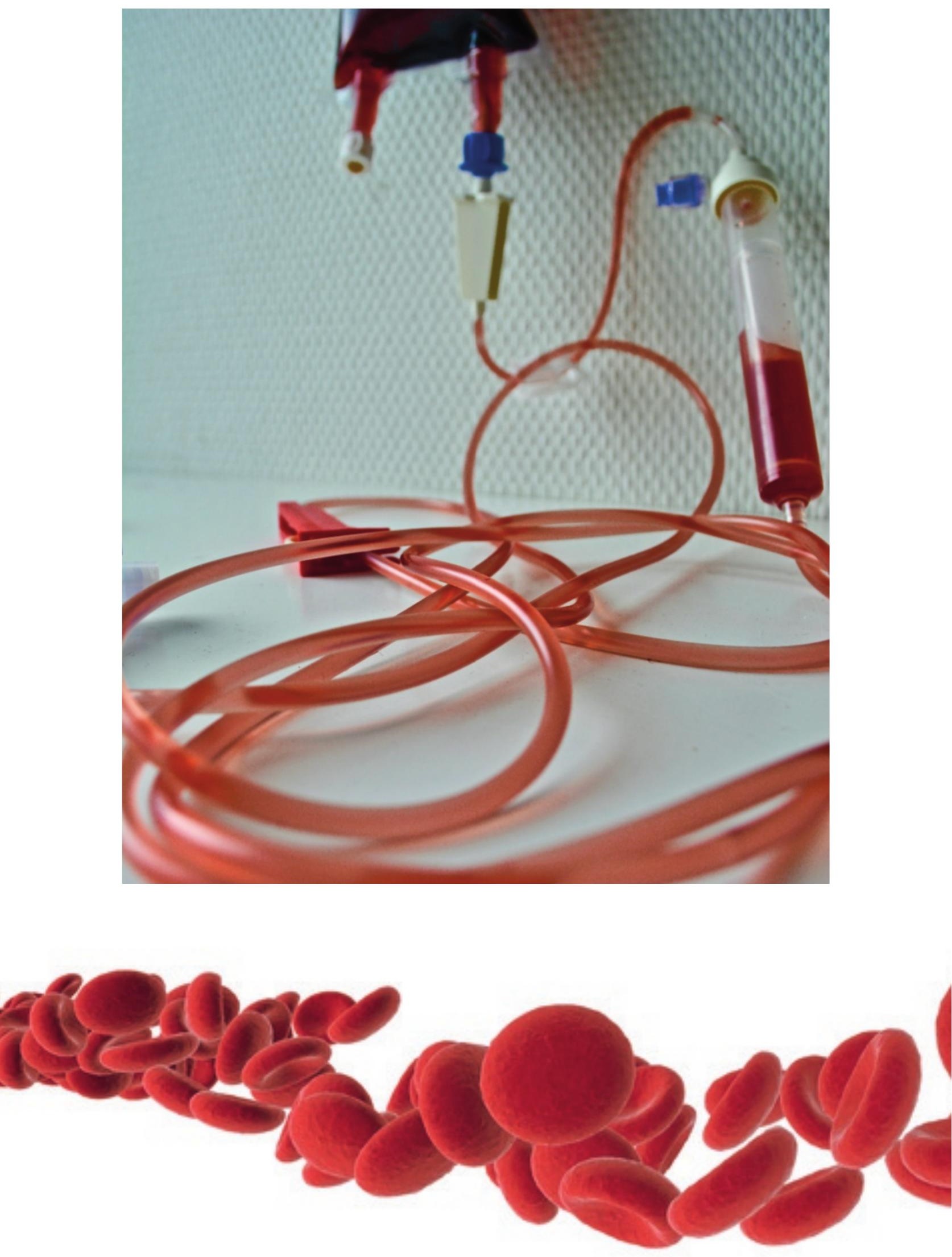


\section{CHAPTER}

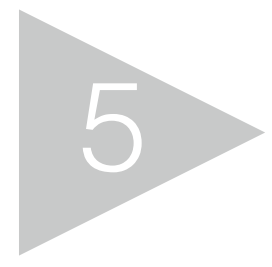

Effect of blood transfusion on survival after hip fracture surgery

S.J.M. Smeets, J.P.A.M. Verbruggen, M. Poeze

European Journal of Orthopaedic Surgery \& Traumatology May 2018 


\section{ABSTRACT}

Background: Our primary goal was to audit the incidence of erythrocyte blood transfusion (EBT) after hip fracture surgery and study the effects on perioperative complications and early and late mortality.

Methods: In a retrospective cohort study all patients 65 years old and above treated operatively for an acute hip fracture were included over a 48-month period with a two-year follow-up period. Postoperative hemoglobin levels were used to investigate at what threshold EBT was used. The relation between EBT and perioperative complications and survival was analysed with multivariate regression analysis. A propensity score for predicting the chance of receiving an EBT was calculated and used to differentiate between transfusion being a risk factor for mortality and other related confounding risk factors. Mortality was subdivided as in-hospital, 30-day, 1- and 2-year mortality.

Results: Of the 388 included patients, $41 \%$ received a blood transfusion. The postoperative hemoglobin level was the strongest predictor for EBT. Patients who received EBT had a significant longer hospital stay and more postoperative cardiac complications, even after adjustment for confounders. Multivariate analysis for mortality showed that EBT was a significant risk factor for early as well as late mortality, but after adding the propensity score, EBT was no longer associated with increased mortality.

Conclusion: There was no effect of EBT on mortality after correction with propensity scoring for predictors of EBT. Transfusion in patients treated operatively for hip fracture should be evenly matched with their cardiovascular risk during the perioperative phase. 


\section{INTRODUCTION}

Anemia is very prevalent in patients undergoing surgery for an acute hip fracture (39-69\%) [1-6]. Anemia occurs as a result of the trauma, the surgery and can be preexisting in the elderly population. Anemia causes hemodynamic stress, an increased cardiac demand and potential tissue hypoxia in the elderly patients with hip fracture [7-10]. Especially those patients with a pre-existing cardiac disease are at risk [11]. The incidence of troponin elevation after emergency orthopaedic operations varies between $22 \%$ and $52.9 \%$ [12]. In this context anemia might contribute to the high morbidity and mortality rates after hip surgery. Furthermore, anemia is an independent risk factor for patients not being able to walk postoperatively [2].

Perioperative anemia is mostly treated by erythrocyte blood transfusions (EBT) in order to prevent the postoperative morbidity and mortality. However, there is conflicting data concerning the effect of EBT on the morbidity and mortality in patients with acute hip fractures. Engoren et al. found that allogeneic erythrocyte blood transfusions are associated with an increased long-term mortality (>90 days up to 2 years) after hip fracture surgery [1]. In addition, increased risk of postoperative infections including pneumonia, delirium, short-term mortality, length of hospital stay and systemic inflammatory response syndrome in patients receiving blood transfusion(s) were reported [4, 13-17]. In contrast, other studies suggest that EBT improve short-term functional outcomes [18-21] and prevents delirium in frail elderly [22, 23].

Another study demonstrated that a restrictive transfusion policy lead to increased cardiovascular events and increased mortality rates [24], although a liberal transfusion trigger did not result in increased ambulation scores or decreased rehabilitation potential. Finally, Carson et al. demonstrated that a liberal transfusion policy was not associated with a lower postoperative morbidity and mortality when compared to a more restrictive transfusion policy in a hip fracture population [25]. Whether EBT is an independent risk factor for the development of postoperative morbidity and mortality besides the clinical factors for giving EBT remains to be seen. Vuille-Lessard et al. found that physicians mostly base their decision to transfuse on the hemoglobin concentration and that characteristics of the patients are minimally considered [26], although high age, male sex and postoperative hemoglobin levels are other identified predictors for EBT after hip surgery [5, 27, 28]. 
The aim of this study was to audit the incidence and predictors of receiving a blood transfusion after hip fracture surgery and to investigate the use of blood transfusion as an independent factor on morbidity and mortality. The hypothesis tested in this study was that EBT is not an independent risk factor for morbidity and mortality in patients undergoing surgery for hip fracture, but anemia and underlying cardiovascular disorders are determining the outcome.

\section{METHODS}

\section{STUDY POPULATION}

This retrospective study was conducted in the Maastricht University Medical Center in the Netherlands, a level 1 trauma center. All patients from age 65 or above treated operatively for hip fracture were included over a 48-month period. Patients with polytrauma, pathological fractures and patients treated with a total hip arthroplasty were excluded. Patients with a malignancy in their history were not excluded. All patients were operated by the department of trauma surgery using a protocolised treatment algorithm regarding internal fixation (and hip replacement). Duration of follow-up was 2 years. Approval for the study was granted by the Ethical Committee of the Maastricht University Medical Center with a waiver for the need of informed consent.

\section{STUDY VARIABLES AND OUTCOME MEASUREMENTS}

All medical records were evaluated for the following content: patient characteristics, fracture type, type of fracture fixation, operation time, delay to surgery, cardiovascular risk factors, preoperative laboratory results, postoperative hemoglobin levels, the use and amount of blood transfusion products, causes of perioperative and postoperative blood loss, postoperative complications and death.

The general transfusion protocol for patients with a cardiac history was to transfuse for hemoglobin levels $<10 \mathrm{~g} / \mathrm{dl}$, for elderly without a cardiac history at $<8 \mathrm{~g} / \mathrm{dl}$. The decision to transfuse was made by the attending physician. Death certificates were obtained from the National population register.

Our primary goal was to investigate the association of receiving an EBT and 
morbidity and mortality after hip fracture surgery. Mortality rates were determined as early in-hospital, 30-day mortality, 1-year and 2-year mortality. Death certificates from the National population register were collected to study postoperative mortality after hospital discharge. To analyse the correlation between cardiac morbidity and EBT, the American College of Cardiology (ACC) and the American Heart Association (AHA) guidelines for perioperative cardiac assessment were used to classify patients cardiac risk into low, intermediate and high risk by clinical risk predictors [29]. We hypothesized that patients with increased cardiac risk would receive more EBT.

\section{STATISTICAL ANALYSIS}

All analyses were performed with SPSS 23 statistical software (SPSS Inc., Chicago, Illinois, USA). $\mathrm{P}<0.05$ was considered to be statistically significant. One-way ANOVA were used to compare normally distributed and the Mann Whitney U-test for non-normally distributed continuous variables with Bonferroni correction for multiple testing. A Pearsons chi-square test $\left(X^{2}\right)$ was used to investigate whether distributions of categorical variables differed from one another. A univariate logistic analysis was performed to identify risk factors for EBT. The likelihood of receiving EBT was calculated with the help of propensity scoring, by logistic regression. The propensity score was used to differentiate between transfusion being a risk factor for mortality and the risk factors for predicting transfusion being predictors for mortality itself. The propensity score was based on all univariate variables significantly associated with transfusion: age, postoperative hemoglobin and fracture type.

To identify possible risk factors for mortality we used a univariate logistic analysis. A Cox regression analysis was used to determine which regression curve summarizes the best (goodness of fit for the regression curve is represented by R2). One model was composed with all covariates entered at once (model 1) and one with all the covariates including the propensity score (model 2).

\section{RESULTS}

In the study 388 patients were eligible for inclusion and analyzed. Of these patients, complete data could be collected in $97 \%$ of patients. Of $9(2 \%)$ patients time to surgery could not be calculated accurately. Of 4 (1\%) patients who lived abroad, 
follow-up after discharge could not be obtained. These data were regarded as missing data, but other available data of these patients were still used in other analysis.

Table 1 shows the patient and operation characteristics. $41 \%$ of patients received a blood transfusion. The transfusion group was significant older in compare with patients who did not receive blood transfusion (84 vs 81 years). There was no difference in sex distribution or cardiovascular comorbidity. There were significantly more intracapsular fractures in the non-transfused group. Transfusion was associated with a longer hospital stay (12 vs 10 days).

The median number of blood transfusion was 2.0 with a median postoperative hemoglobin level of $7.7 \mathrm{~g} / \mathrm{dl}$. The median postoperative hemoglobin level in the non-transfused group was significantly higher $(10.0 \mathrm{~g} / \mathrm{dl}, \mathrm{p}<0.001)$. Postoperative hemoglobin levels were strongly associated with use of EBT (both in univariate as in multivariate analysis $p<0.001$ ). Other factors associated with transfusion were high age and intracapsular fractures. Sex, a cardiac history, delay to surgery, and operation time were not associated with EBT. Multivariate analysis showed postoperative hemoglobin level, a cardiac history and delay to surgery $>48 \mathrm{hr}$ as significant risk factors for in-hospital mortality $(P<0.01)$. Postoperative anemia remained a predictor for 30-day, 1- and 2-year mortality, both in univariate as in multivariate analysis.

\section{CARDIAC RISK}

A cardiac history was present in $45.4 \%$ of patients. In total 37 patients were predicted to have a high perioperative complication risk, 113 an intermediate risk and 238 a low risk using the ACC/AHA guidelines. Patients with high cardiac risk did not receive more transfusions than patients with intermediate $(p=0.08)$ or low cardiac risk $(p=0.06)$ although there seems to be a trend. High risk patients had significant more cardiovascular complications after surgery and risk of mortality.

\section{EBT AND MORBIDITY}

Patients who received EBT were at risk for postoperative complications (see table 2): delirium (RR $1.595 \% \mathrm{Cl} 1.2-2.0 ; \mathrm{p}=0.002$ ), gastrointestinal bleeding (RR 14 95\% Cl 1.9 - 110.0; $p=0.001$ ), respiratory complications (RR $2.495 \% \mathrm{Cl} 1.3-4.4$; $\mathrm{p}=0.004)$ and cardiovascular complications (RR 3.8, 95\% Cl 1.9-8.0; $\mathrm{p}<0.001)$. 
Table 1. Patient and operation characteristics

$\begin{aligned} & \text { Patient and operation characteristics } \\ & (\mathrm{n}=388)\end{aligned}$
Mean age (years)
Male sex
Intracapsular fractures
Extracapsular fractures
General anesthesia
Spinal anesthesia
Median operation time (min.)
Median delay to surgery (hrs.)
$\quad>24$ hrs.
$\quad>48$ hrs.
Cardiac history
Median patient days ( $\mathrm{n}$ )
Preoperative hemoglobin ( $\mathrm{g} / \mathrm{dl})$
Postoperative hemoglobin ( $\mathrm{g} / \mathrm{dl})$
Median number of transfusions

\begin{tabular}{|c|c|c|}
\hline $\begin{array}{c}\text { EBT }(n=160) \\
\%(n)\end{array}$ & $\begin{array}{c}\text { No EBT }(n=228) \\
\%(n)\end{array}$ & P-value* \\
\hline 84 (SD 7) & 81 (SD 7) & 0.001 \\
\hline $24 \%$ (39) & $28 \%(63)$ & 0.5 \\
\hline $46 \%(73)$ & $69 \%(158)$ & $<0.001$ \\
\hline $54 \%(87)$ & $31 \%(70)$ & \\
\hline $43 \%(69)$ & $34 \%(77)$ & 0.06 \\
\hline $57 \%(91)$ & $66 \%(151)$ & \\
\hline 66 (IQR 33) & 66 (IQR 36) & 0.1 \\
\hline 22 (IQR 19) & 22 (IQR 19) & 0.8 \\
\hline $43 \%(68)$ & $38 \%$ (87 & 0.4 \\
\hline $8 \%(13)$ & $7 \%(17)$ & 0.8 \\
\hline $49 \%(79)$ & $43 \%(97)$ & 0.2 \\
\hline 12 (IQR 13) & 10 (IQR 8) & 0.01 \\
\hline 12.4 (IQR 0.9) & 13.4 (IQR 1.2) & 0.4 \\
\hline 7.7 (IQR 0.8) & 10.1 (IQR 1.3) & $<0.001$ \\
\hline 2.0 & - & - \\
\hline
\end{tabular}

SD, standard deviation; IQR, Interquartile range; EBT, Erythrocyte Blood Transfusion. ${ }^{\star}$ P-value, significant for $\mathrm{p}<0.05$ by univarite analyes between EBT and no EBT.

Even after correction for sex, age, fracture type, delay to surgery, cardiac history and postoperative hemoglobin levels did patients with EBT experience more cardiovascular complications. There was no dose-effect found between number of transfused units and morbidity or mortality when divided in 3 groups: 1-2, 3-4 or $>4$ transfused units.

\section{EBT AND MORTALITY}

A univariate analysis for in-hospital, 30-day, 1- and 2-year mortality showed that sex, age, a delay to surgery of $>48$ hour, a cardiac history and the use of blood transfusion were significant risk factors. These variables were entered in a Coxregression model (model 1) with 24 months of follow-up. Sex, age, delay to surgery $>48$ hour and EBT were significant risk factors for mortality (see table 3). After adding the propensity score as a variable in the model (model 2), EBT was no longer significant. 38\% (149/388) of patients were dead at 2-year follow-up. 50\% (75/149) of the deceased patients received EBT compared to $36 \%(85 / 239)$ who survived $(p=0.001)$. Sex and age were found the only predictors for mortality within 2 years. 


\begin{tabular}{|c|c|c|c|}
\hline Complications & EBT \% (n) & No EBT \% (n) & $\mathrm{P}^{*}$ \\
\hline Cardiovascular $^{\dagger}$ & $15 \%(24)$ & $4 \%(9)$ & $<0.001$ \\
\hline Stroke & $3 \%(4)$ & $1 \%(2)$ & 0.2 \\
\hline Rhythm disorders & $5 \%(8)$ & $1 \%(2)$ & 0.01 \\
\hline AMI & $6 \%(9)$ & $1 \%(3)$ & 0.02 \\
\hline Cardiac failure & $3 \%(4)$ & $3 \%(6)$ & 0.9 \\
\hline Respiratory\# & $16 \%(25)$ & $7 \%(15)$ & 0.004 \\
\hline Pneumonia & $11 \%(18)$ & $6 \%(14)$ & 0.07 \\
\hline Pulmonary embolism & $3 \%(4)$ & (0) & 0.02 \\
\hline Respiratory failure & $6 \%(10)$ & $0.4 \%(1)$ & 0.001 \\
\hline Delirium & $46 \%(73)$ & $37 \%(84)$ & 0.002 \\
\hline Wound infection & $9 \%(14)$ & $5 \%(11)$ & 0.1 \\
\hline Urinary tract infection & $16 \%(25)$ & $19 \%(44)$ & 0.4 \\
\hline Pressure sores & $18 \%(29)$ & $10 \%(22)$ & 0.02 \\
\hline Gastrointestinal tract bleeding & $6 \%(10)$ & $0.4 \%(1)$ & 0.001 \\
\hline DVT & $3 \%(5)$ & $1 \%(3)$ & 0.2 \\
\hline In-hospital mortality & $8 \%(12)$ & $3 \%(6)$ & 0.03 \\
\hline 30-day mortality & $14 \%(23)$ & $4 \%(10 / 224)$ & 0.001 \\
\hline 1-year mortality & $37 \%(59)$ & $22 \%(50 / 224)$ & 0.002 \\
\hline 2-year mortality & $47 \%(75)$ & $33 \%(74 / 224)$ & 0.006 \\
\hline
\end{tabular}

EBT, Erythrocyte Blood Transfusion. \# Respiratory complications consist of pneumonia, pulmonary embolism and respiratory failure together. $†$ Cardiovascular complications consist of stroke, rhythm disorders, acute myocardial infarction and cardiac failure. DVT = deep venous thrombosis. ${ }^{*}$ P-value, significant for $p<0.05$; by univariate analyses between EBT and no EBT 
Table 3. Cox-regression model for mortality

\begin{tabular}{|c|c|c|c|c|c|}
\hline Mortality & Covariates & $\begin{array}{c}\text { Cox-regression } \\
\text { model } 1^{\star} \\
(p \text {-value })\end{array}$ & $\begin{array}{l}\operatorname{Exp}(\mathrm{B}) \\
(95 \% \mathrm{Cl})\end{array}$ & $\begin{array}{l}\text { Cox-regression } \\
\text { model } 2^{\#} \\
(p-v a l u e)\end{array}$ & $\begin{array}{l}\operatorname{Exp}(\mathrm{B}) \\
(95 \% \mathrm{Cl})\end{array}$ \\
\hline \multirow[t]{6}{*}{ In-hospital } & Age & 0.6 & $1.0(1.0-1.1)$ & 0.8 & $1.0(0.9-1.0)$ \\
\hline & Sex & 0.2 & $1.8(0.7-4.5)$ & 0.1 & $2.2(0.9-5.7)$ \\
\hline & Delay $>48 \mathrm{hr}$ & 0.08 & $0.4(0.1-1.1)$ & $<0.05$ & $0.3(0.1-1.0)$ \\
\hline & Cardiac history & 0.02 & $0.3(0.1-0.8)$ & 0.03 & $0.3(0.1-0.9)$ \\
\hline & EBT & 0.04 & $0.4(0.1-0.9)$ & 0.9 & $1.0(0.3-3.6$ \\
\hline & Propensity score & - & - & 0.02 & $9.5(1.5-62)$ \\
\hline \multirow[t]{6}{*}{ 30-day } & Age & 0.1 & $1.0(10-1.1)$ & 0.2 & $1.0(1.0-1.1)$ \\
\hline & Sex & 0.6 & $1.2(0.6-2.6)$ & 0.6 & $1.2(0.6-2.7)$ \\
\hline & Delay $>48 \mathrm{hr}$ & 0.04 & $0.4(0.2-1.0)$ & 0.02 & $0.3(0.1-0.8)$ \\
\hline & Cardiac history & 0.1 & $0.6(0.3-1.1)$ & 0.1 & $0.6(0.3-1.2)$ \\
\hline & EBT & 0.004 & $0.3(0.2-0.7)$ & 0.7 & $0.8(0.3-2.2)$ \\
\hline & Propensity score & - & - & 0.02 & $5.2(1.3-22)$ \\
\hline \multirow[t]{6}{*}{ 1-year } & Age & $<0.001$ & $1.0(1.0-1.1)$ & 0.001 & $1.0(1.0-1.1)$ \\
\hline & Sex & 0.001 & $1.9(1.3-2.8)$ & $<0.001$ & $2.1(1.4-3.2$ \\
\hline & Delay $>48 \mathrm{hr}$ & 0.1 & $0.6(0.3-1.1)$ & 0.04 & $0.6(0.3-1.0)$ \\
\hline & Cardiac history & 0.1 & $0.7(0.5-1.1)$ & 0.1 & $0.7(0.5-1.1)$ \\
\hline & EBT & 0.004 & $0.6(0.4-0.8)$ & 0.7 & $0.9(0.5-1.6)$ \\
\hline & Propensity score & - & - & 0.04 & $2.3(1.0-5.1)$ \\
\hline \multirow[t]{6}{*}{ 2-year } & Age & $<0.001$ & $1.0(1.0-1.1)$ & $<0.001$ & $1.0(1.0-1.1)$ \\
\hline & Sex & $<0.001$ & $2.1(1.5-3.0)$ & $<0.001$ & $2.3(1.6-3.3)$ \\
\hline & Delay $>48 \mathrm{hr}$ & 0.4 & $0.8(0.4-1.4)$ & 0.2 & $0.7(0.4-1.3)$ \\
\hline & Cardiac history & 0.03 & $0.7(0.5-1.0)$ & 0.06 & $0.7(0.5-1.0)$ \\
\hline & EBT & 0.01 & $0.7(0.5-0.9)$ & 0.3 & $0.8(0.4-1.3)$ \\
\hline & Propensity score & - & - & 0.4 & $1.4(0.7-2.8)$ \\
\hline
\end{tabular}

* Model 1: all significant covariates for mortality entered in Cox regression analysis. \# Model 2: all covariates including the propensity score. $\operatorname{Exp}(B)=$ exponentiation of the $B$ coefficient, an odds ratio. $95 \% \mathrm{Cl}=95 \%$ confidence interval. $\mathrm{P}$-value, significant for $\mathrm{p}<0.05$ 


\section{DISCUSSION}

The hypothesis tested in this study was that the use of erythrocyte blood transfusion (EBT) in patients treated operatively for hip fracture is not a risk factor for mortality but depends primarily on the effects of anemia and underlying cardiovascular disorders. We found that $41 \%$ of patients with hip fracture received EBT. Our hospital practiced a liberal transfusion policy to transfuse elderly patients with a cardiac history (aimed at $>10 \mathrm{~g} / \mathrm{dL}$ ). Despite this, no differences existed in the frequency of EBT administered when patients were classified into low, intermediate and high cardiac risk. This study demonstrated that EBT is frequently used during the treatment of acute anemia after hip fracture surgery. The association of EBT on postoperative mortality was no longer present after correction with the propensity score for receiving a transfusion. However, EBT remained an independent risk for perioperative cardiac morbidity.

This is in contradiction with the results of Engoren et al. who used propensity matching and found a significantly increased relative risk of $3.8(95 \% \mathrm{Cl} 1.2-11.6)$ for EBT on mortality [1]. In our study we used the propensity score for receiving EBT as a variable in our Cox model in attempt to correct for the chance of receiving EBT instead of adding to many individual variables in the model. Another study showed that risk of mortality after EBT was significantly higher when the preoperative hemoglobin level was $10 \mathrm{~g} / \mathrm{dL}$ or less in patients with pre-existent cardiovascular disease [30]. Patients with low hemoglobin levels are more likely to suffer from cardiac complications in case of pre-existent cardiac comorbidity [11].

A review from Potter et al. on preoperative anemia and EBT in hip fracture patients showed that anemia on hospital admission was associated with increased mortality, relative risk 1.64 (95\% $\mathrm{Cl} 1.47-1.82), \mathrm{p}<0.0001$ in $>13.000$ patients [31]. There was no association between postoperative transfusion and mortality after adjusting for covariates. These findings suggest that anemia seems to play a more important role than EBT itself. This is exactly why we corrected our data with the use of the propensity score for the chance of receiving EBT.

In our study, EBT remained an independent risk for perioperative cardiac morbidity after correction for confounders. In a large RCT from Carson et al., the rates of inhospital acute coronary syndrome or death were $4.3 \%$ and $5.2 \%$, in the liberal and restrictive transfusion group respectively (absolute risk difference, $-0.9 \% ; 99 \% \mathrm{Cl}$, 
-3.3 to 1.6) [25]. In Potters review transfusion at $80 \mathrm{~g} / \mathrm{dl}$ vs $100 \mathrm{~g} / \mathrm{dl}$ increased acute myocardial infarction, with a relative risk of $1.67(95 \% \mathrm{Cl} 1.01-2.77)$, although with $p=0.05$ and a $97.5 \%$ weight of Carson's study [25]. No strong conclusions can be drawn.

The TRIFE trial showed comparable findings between liberal and restrictive blood transfusion protocols after hip fracture surgery but subgroup analyses for frail elderly in nursing homes showed that this group could benefit from a more liberal transfusion. Post-hoc analyses showed furthermore a reduced risk for postoperative delirium for the liberal transfusion group. Development of delirium on day 10 postoperatively after hip fracture surgery increased the risk of 90-day death, hazard ratio $3.14(95 \% \mathrm{Cl} 1.72-5.78, \mathrm{p}<0.001)$ [32].

A number of remarks must be made when interpreting the results of this study. Selection bias cannot be excluded because of the retrospective study design. It is possible that other contributing risk factors were not identified in this study and therefore not taken into account in the analyses. A limitation of propensity matching is that a variable that affects treatment assignment but not outcome is analysed the same as a variable that affects treatment assignment and has a strong relationship to outcome as well [33]. This suggests that risk factors for transfusion are predictors for mortality itself. And indeed, age and postoperative hemoglobin levels were associated with early as well as late mortality. We found no association between mortality and fracture type. Another study found no effect of EBT on mortality after hip fracture surgery when corrected for age, male sex, residential status, preoperative hemoglobin level, mobility score, and American Society of Anesthesiologists score [18].

The mechanisms by which blood transfusion might worsen outcomes are unknown. There is evidence that the storage time of erythrocytes is associated with increased mortality [34-38]. Koch et al. showed that cardiac surgical patients receiving erythrocytes that had been stored for more than 2 weeks have a higher risk of inhospital mortality and postoperative complications [36]. Storage leads to numerous effects: decreased cellular deformability, increased adhesion to the vascular endothelium [39], impaired microvascular flow [30, 40] and abnormal shape [41] which leads to limited oxygen delivery.

Another pathway is transfusion induced immunomodulation (TRIM) and focuses on the release of cytokines, allogenic leukocytes and their immune activation, resulting 
in transfusion-related lung injury or immune suppression resulting in susceptibility to infectious complications [40, 42-44]. The fact that the association between EBT and mortality is not present on the long-term mortality may indicate that such processes are contributing.

Another extensively studied phenomenon is acute transfusion-related lung injury (TRALI). The diagnosis must satisfy the criteria for acute lung injury (ALI) following $\leq 6 \mathrm{hr}$ after transfusion, including (1) acute onset, (2) hypoxemic lung disease with (3) bilateral infiltrates on frontal chest radiograph, and (4) no evidence of left atrial hypertension [45].

Anemia contributes to and is associated with reduced physiological/homeostatic reserve, reduced function and reduced mobility $[2,46]$, mechanisms through which complications and mortality may be increased beyond one postoperative year. The 'frailty syndrome', consisting of sarcopenia, anorexia and declining mobility, is associated with dysregulation of pro- inflammatory pathways, increasing inflammatory markers such as IL-6, bone marrow suppression and chronic anemia [47].

EBT was not associated with early or late mortality after hip fracture surgery. Postoperative anemia, a cardiac history and delay to surgery of $>48 \mathrm{hr}$ were predictors for in-hospital mortality. Transfusion in patients treated operatively for hip fracture should be evenly matched with their cardiovascular risk during the perioperative phase. Further research should identify subgroups that may benefit from a more liberal transfusion trigger depending on their cardiac risk and frailty characteristics or a more restrictive transfusion trigger without risk for worse outcome. 


\section{REFERENCES}

1. Engoren M, Mitchell E, Perring P, Sferra J: The effect of erythrocyte blood transfusions on survival after surgery for hip fracture. J Trauma 2008, 65(6): 1411-1415.

2. Foss NB, Kristensen MT, Kehlet $\mathrm{H}$ : Anaemia impedes functional mobility after hip fracture surgery. Age Ageing 2008, 37(2):173-178.

3. Garcia-Erce JA, Cuenca J, Haman-Alcober S, Martinez AA, Herrera A, Munoz M: Efficacy of preoperative recombinant human erythropoietin administration for reducing transfusion requirements in patients undergoing surgery for hip fracture repair. An observational cohort study. Vox Sang 2009, 97(3):260-267.

4. Spahn DR: Anemia and patient blood management in hip and knee surgery: a systematic review of the literature. Anesthesiology 2010, 113(2):482-495.

5. Verlicchi F, Desalvo F, Zanotti G, Morotti L, Tomasini I: Red cell transfusion in orthopaedic surgery: a benchmark study performed combining data from different data sources. Blood Transfus 2011:1-5.

6. Carson JL, Terrin ML, Barton FB, Aaron R, Greenburg AG, Heck DA, Magaziner J, Merlino FE, Bunce G, McClelland B et al.: A pilot randomized trial comparing symptomatic vs. hemoglobin-level-driven red blood cell transfusions following hip fracture. Transfusion 1998, 38(6):522-529.

7. Foss NB, Kehlet $\mathrm{H}$ : Hidden blood loss after surgery for hip fracture. J Bone Joint Surg Br 2006, 88(8):1053-1059.

8. Marval PD, Hardman JG: Perioperative blood loss and transfusion requirements in patients with fractured neck of femur. Eur J Anaesthesiol 2004, 21(5):412-414.

9. Carson JL, Terrin ML, Jay M: Anemia and postoperative rehabilitation. Can J Anaesth 2003, 50(6 Suppl):S60-64.

10. Kehlet H, Dahl JB: Anaesthesia, surgery, and challenges in postoperative recovery. Lancet 2003, 362(9399):1921-1928.

11. Carson JL, Duff A, Poses RM, Berlin JA, Spence RK, Trout R, Noveck $\mathrm{H}$, Strom BL: Effect of anaemia and cardiovascular disease on surgical mortality and morbidity. Lancet 1996, 348(9034):1055-1060.

12. Chong CP, van Gaal WJ, Savige J, Lim WK: Cardiac injury and troponin testing after orthopaedic surgery. Injury 2011, 42(9):855-863.

13. Pedersen AB, Mehnert F, Overgaard S, Johnsen SP: Allogeneic blood transfusion and prognosis following total hip replacement: a populationbased follow up study. BMC Musculoskelet Disord 2009, 10:167.

14. Bierbaum BE, Callaghan JJ, Galante JO, Rubash HE, Tooms RE, Welch $\mathrm{RB}$ : An analysis of blood management in patients having a total hip or knee arthroplasty. J Bone Joint Surg Am 1999, 81(1):2-10.

15. Carson JL, Altman DG, Duff A, Noveck H, Weinstein MP, Sonnenberg 
FA, Hudson JI, Provenzano G: Risk of bacterial infection associated with allogeneic blood transfusion among patients undergoing hip fracture repair. Transfusion 1999, 39(7):694-700.

16. Dunne JR, Malone DL, Tracy JK, Napolitano LM: Allogenic blood transfusion in the first 24 hours after trauma is associated with increased systemic inflammatory response syndrome (SIRS) and death. Surg Infect (Larchmt) 2004, 5(4):395-404.

17. Guo $Y$, Jia $P$, Zhang J, Wang $X$, Jiang H, Jiang W: Prevalence and risk factors of postoperative delirium in elderly hip fracture patients. J Int Med Res 2016, 44(2):317-327.

18. Johnston P, Wynn-Jones $H$, Chakravarty D, Boyle A, Parker MJ: Is perioperative blood transfusion a risk factor for mortality or infection after hip fracture? J Orthop Trauma 2006, 20(10):675-679.

19. Halm EA, Wang JJ, Boockvar K, Penrod J, Silberzweig SB, Magaziner J, Koval KJ, Siu AL: Effects of blood transfusion on clinical and functional outcomes in patients with hip fracture. Transfusion 2003, 43(10):1358-1365.

20. Carson JL, Duff A, Berlin JA, Lawrence VA, Poses RM, Huber EC, O'Hara DA, Noveck H, Strom BL: Perioperative blood transfusion and postoperative mortality. JAMA 1998, 279(3):199-205.

21. Gregersen M: Postoperative red blood cell transfusion strategy in frail anemic elderly with hip fracture. A randomized controlled trial. Dan Med J 2016, 63(4).

22. Blandfort S, Gregersen M, Borris LC, Damsgaard EM: Blood transfusion strategy and risk of postoperative delirium in nursing homes residents with hip fracture. A post hoc analysis based on the TRIFE randomized controlled trial. Aging Clin Exp Res 2016.

23. van der Zanden V, Beishuizen SJ, Scholtens RM, de Jonghe A, de Rooij SE, van Munster BC: The Effects of Blood Transfusion on Delirium Incidence. J Am Med Dir Assoc 2016, 17(8):748-753.

24. Foss NB, Kristensen MT, Jensen PS, Palm H, Krasheninnikoff M, Kehlet H: The effects of liberal versus restrictive transfusion thresholds on ambulation after hip fracture surgery. Transfusion 2009, 49(2):227-234.

25. Carson JL, Terrin ML, Noveck H, Sanders DW, Chaitman BR, Rhoads GG, Nemo G, Dragert K, Beaupre L, Hildebrand K et al.: Liberal or restrictive transfusion in high-risk patients after hip surgery. N Engl J Med 2011, 365(26):2453-2462.

26. Vuille-Lessard E, Boudreault D, Girard F, Ruel M, Chagnon M, Hardy JF: Red blood cell transfusion practice in elective orthopedic surgery: a multicenter cohort study. Transfusion 2010, 50(10):2117-2124.

27. Gombotz H, Rehak PH, Shander A, Hofmann A: Blood use in elective surgery: the Austrian benchmark study. Transfusion 2007, 47(8):14681480. 
28. Goodnough LT, Vizmeg K, Sobecks R, Schwarz A, Soegiarso W: Prevalence and classification of anemia in elective orthopedic surgery patients: implications for blood conservation programs. Vox Sang 1992, 63(2):90-95.

29. Fleisher LA, Beckman JA, Brown KA, Calkins H, Chaikof E, Fleischmann KE, Freeman WK, Froehlich JB, Kasper EK, Kersten JR et al.: ACC/AHA 2007 guidelines on perioperative cardiovascular evaluation and care for noncardiac surgery: executive summary: a report of the American College of Cardiology/American Heart Association Task Force on Practice Guidelines (Writing Committee to Revise the 2002 Guidelines on Perioperative Cardiovascular Evaluation for Noncardiac Surgery). Anesth Analg 2008, 106(3):685-712.

30. Klein HG, Spahn DR, Carson JL: Red blood cell transfusion in clinical practice. Lancet 2007, 370(9585):415-426.

31. Potter LJ, Doleman B, Moppett IK: A systematic review of pre-operative anaemia and blood transfusion in patients with fractured hips. Anaesthesia 2015, 70(4):483-500.

32. Gregersen M, Borris LC, Damsgaard EM: Postoperative blood transfusion strategy in frail, anemic elderly patients with hip fracture: the TRIFE randomized controlled trial. Acta Orthop 2015, 86(3):363-372.

33. Rubin DB: Estimating causal effects from large data sets using propensity scores. Ann Intern Med 1997, 127(8 Pt 2):757-763.

34. Basran S, Frumento RJ, Cohen A, Lee S, Du Y, Nishanian E, Kaplan HS, Stafford-Smith M, Bennett-Guerrero E: The association between duration of storage of transfused red blood cells and morbidity and mortality after reoperative cardiac surgery. Anesth Analg 2006, 103(1):15-20, table of contents.

35. Engoren MC, Habib RH, Zacharias A, Schwann TA, Riordan CJ, Durham SJ: Effect of blood transfusion on long-term survival after cardiac operation. Ann Thorac Surg 2002, 74(4):1180-1186.

36. Koch CG, Li L, Sessler DI, Figueroa P, Hoeltge GA, Mihaljevic T, Blackstone EH: Duration of red-cell storage and complications after cardiac surgery. $N$ Engl J Med 2008, 358(12):1229-1239.

37. Bennett-Guerrero E, Stafford-Smith M, Waweru PM, Bredehoeft SJ, Campbell ML, Haley NR, Phillips-Bute B, Newman MF, Bandarenko N: A prospective, double-blind, randomized clinical feasibility trial of controlling the storage age of red blood cells for transfusion in cardiac surgical patients. Transfusion 2009, 49(7):1375-1383.

38. Eikelboom JW, Cook RJ, Liu Y, Heddle NM: Duration of red cell storage before transfusion and in-hospital mortality. Am Heart J 2010, 159(5):737743 e731.

39. Tinmouth A, Fergusson D, Yee IC, Hebert PC: Clinical consequences of red cell storage in the critically ill. Transfusion 2006, 46(11):2014-2027. 
40. Raghavan M, Marik PE: Anemia, allogenic blood transfusion, and immunomodulation in the critically ill. Chest 2005, 127(1):295-307.

41. Berezina TL, Zaets SB, Morgan C, Spillert CR, Kamiyama M, Spolarics Z, Deitch EA, Machiedo GW: Influence of storage on red blood cell rheological properties. J Surg Res 2002, 102(1):6-12.

42. Blajchman MA: Transfusion immunomodulation or TRIM: what does it mean clinically? Hematology 2005, 10 Suppl 1:208-214.

43. Zallen G, Moore EE, Ciesla DJ, Brown M, Biffl WL, Silliman CC: Stored red blood cells selectively activate human neutrophils to release IL- 8 and secretory PLA2. Shock 2000, 13(1):29-33.

44. Vamvakas EC, Blajchman MA: Deleterious clinical effects of transfusionassociated immunomodulation: fact or fiction? Blood 2001, 97(5):11801195.

45. Bernard GR, Artigas A, Brigham KL, Carlet J, Falke K, Hudson L, Lamy M, Legall JR, Morris A, Spragg R: The American-European Consensus Conference on ARDS. Definitions, mechanisms, relevant outcomes, and clinical trial coordination. Am J Respir Crit Care Med 1994, 149(3 Pt 1):818824.

46. Lawrence VA, Silverstein JH, Cornell JE, Pederson T, Noveck H, Carson JL: Higher $\mathrm{Hb}$ level is associated with better early functional recovery after hip fracture repair. Transfusion 2003, 43(12):1717-1722.

47. Roy CN: Anemia in frailty. Clin Geriatr Med 2011, 27(1):67-78. 



\section{CHAPTER}

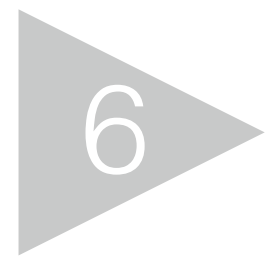

Z-effect after intramedullary nailing systems for trochanteric femur fractures

S.J.M. Smeets, G.P. Kuijt, P.V. Eerten

Chinese Journal of Traumatology Dec 2017

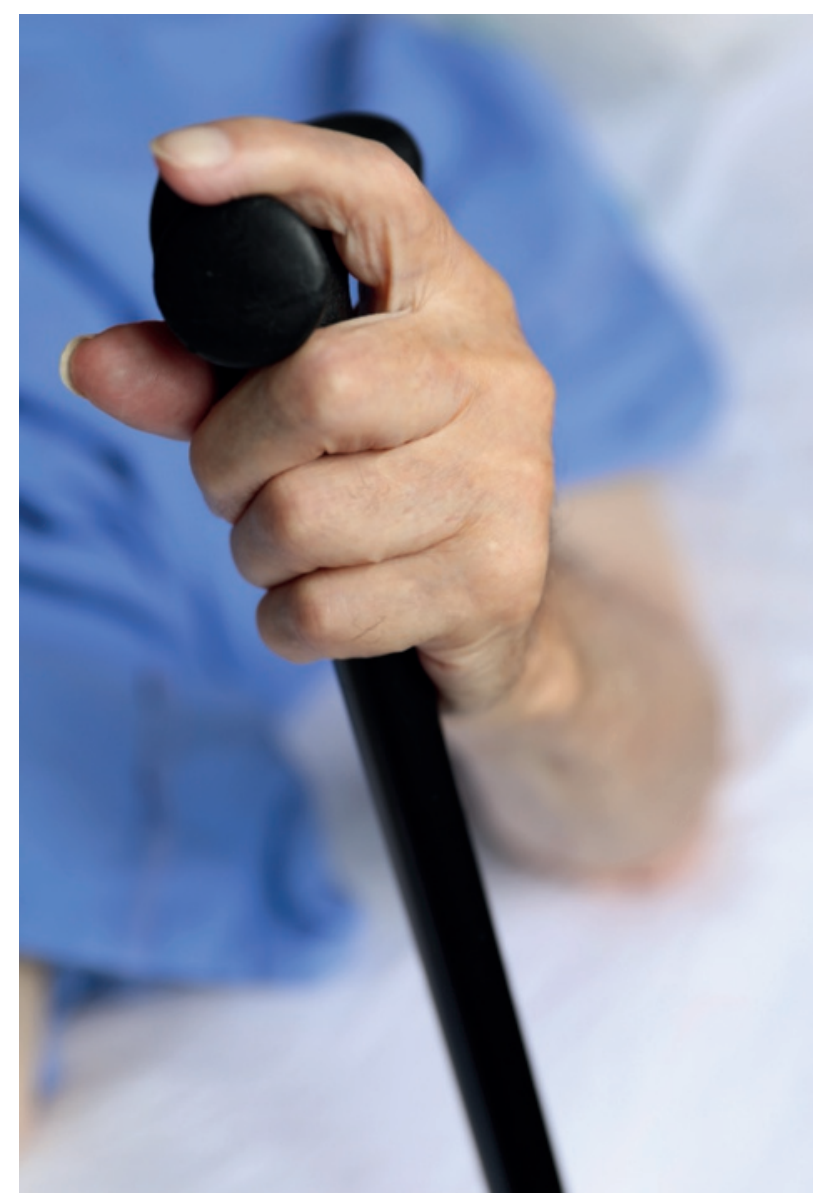




\section{ABSTRACT}

Introduction: The aim of this study was to investigate the incidence of Z-effect after dual lag screw intramedullary nailing systems and risk factors contributing to this effect. We hypothesized that long nails provide more neck strength due to a longer lever than short nails and are therefore less likely to develop a misbalance of a higher head compressive strength than neck compressive strength.

Methods: In a retrospective cohort study all patients treated operatively with a dual lag screw intramedullary nailing device for (sub)trochanteric hip fracture in 2006 and 2007 were included. We analysed patient charts regarding patient and operation characteristics. Furthermore, we conducted radiologic measurements within the 2-year follow-up period to investigate the quality of the fracture fixation, implant failure and predictors for Z-effect. The re-operation risk was investigated with multivariate regression analysis.

Results: The incidence of (reversed) Z-effect in this study was $9 \%(n=80) .6$ out of 7 Z-effects occurred in the short nail group, which was not significant. Patients who were treated with a long nail had a significant larger number of complications in comparison with the short nail group (median 2 vs $0.5, p=0.001$ ). The long nail group received more often erythrocytes blood transfusions ( $82 \%$ vs $31 \%, p \leq 0.001$ ) and had a longer hospital stay (13 vs 21 days, $p<0.05$ ). Migration of lag screws $(p \leq 0.009)$, as well as unstable fracture type $(p<0.05)$, was a risk factor for reoperation. The re-operation rate within 2 year after surgery was $21 \%$ of which one fourth was due to a Z-effect.

Conclusion: The nail length was not associated with the development of a Z-effect. Migration of lag screws after intramedullary nailing is common and a risk factor for re-operation as well as unstable fracture type. 


\section{INTRODUCTION}

The worldwide incidence of geriatric hip fracture is increasing. This phenomenon can be explained largely through the extreme increase of incidence of hip fracture in most Asian countries in the last decades. It is expected that by 2050 more than $50 \%$ of all osteoporotic fractures will occur in Asia [1,2]. Ageing is one of the major contributors to this phenomenon, as well as the incidence of osteoporosis and the process of urbanization [3]. On the contrary in most developed parts of the world has the incidence of hip fracture decreased or developed a plateau in the ageadjusted rates in the last decades [3-5].

Hip fractures are one of the most common orthopedic causes leading to hospital admission in the geriatric population and are associated with high morbidity and mortality rates [6-9]. Surgical treatment options depend greatly on fracture type and can be divided into intracapsular fractures (femoral neck) and extracapsular fractures (trochanteric fractures). Extracapsular fractures can be stabilized by extramedullary and intramedullary implants. Intramedullary nailing provides both load sharing properties while allowing immediate mobilization, low intraoperative blood loss, low operation time and postoperative complication rates. In unstable fracture patterns, intramedullary devices appear to have a biomechanical advantage over extramedullary devices, lowering the forces imposed on the implant due to the shorter lever arm of the fixation [10-12]. The most common implant related complication is lag screw migration with an incidence of 4\%-19\% [13-18].

The introduction of the dual lag screws intramedullary nail systems $[19,20]$ were designed to improve rotational stability and bony purchase within the femoral head, thus resisting cut-out and subsequent fixation failure [21]. The dual lag screw design provides equivalent rigidity and stability compared to an intramedullary nail with a single lag screw and has a significantly higher failure strength [21]. With the arrival of this implant design, also a new failure occurred: The Z-effect phenomenon. The Z-effect describes the appearance of lateral migration of the inferior lag screw and medial migration of the superior lag screw during the weight bearing rehabilitation period [10, 22-25]. The reversed Z-effect describes the opposite effect: migration of the inferior lag screw medially and the superior lag screw laterally. Most studies about intramedullary nailing report the incidence of (reversed) Z-effect but very few studies have studied this phenomenon specifically. The cause of the Z-effect is thought to be biomechanical. Possibly due to a misbalance in head- and neck 
compressive strength leading to varus collapse [26]. The precise etiology of the Z-effect requires further clarification [25]. In one of the very few biomechanic studies were explanations found for medial migration due to included lateral buttress deficiency (lateral opening in the fixture), unstable medial cortex [26], constant friction within the femoral head and axial loading in varus [27]. Another study found that a cervicodiaphyseal angle of $<125^{\circ}$ of the postoperative $x$-rays was associated with the development of a Z-effect [24]. An inadequate fracture reduction or entry point and osteoporotic bone might also be contributing factors, but convincing evidence lacks. We hypothesize that long nails provide more neck strength due to a longer lever than short nails and are therefore less likely to develop a Z-effect.

\section{MATERIALS AND METHODS}

This retrospective study was conducted in the department of Trauma surgery in the Maxima Medical Center in the Netherlands, a large rural teaching hospital. From the 1st January 2006 till 31st December 2007 all patients treated with a dual lag screws intramedullary nail for trochanteric hip fracture were analysed. In this period were two types of nails used: the Recon nail (Stryker) and the Trigen nail (Smiths \& Nephews). A follow-up period of 2 years was chosen for implant related failures to occur. We selected all patients who were operated for hip fracture and excluded the polytrauma patients and other fixation types. Patients with a malignancy in their history or pathological fractures were not excluded. A protocolised treatment algorithm regarding hip fractures was used. Standard workup after admission to the emergency department consisted of a detailed history, a complete physical examination, an electrocardiography and standard biochemical and hematologic tests.

All medical records were evaluated for patient and operation characteristics such as sex, age, ASA score, fracture type by the AO-classification system (Arbeitsgemeinschaft für Osteosynthesefragen), anesthesia type, delay to surgery, operation time and patient days. Furthermore, we investigated postoperative complications and re-interventions during the 2-year follow-up.

Radiological analyses were performed to measure the position of the superior and inferior lag screw, the cervicodiaphyseal angle and the Tip Apex Distance (TAD). The TAD is a clinically useful way to describe the position of the lag screws by the 
sum of the distance from the tip of the lag screw to the apex of the femoral head on the anteroposterior radiograph and the same distance on the axial radiograph with correction for magnification [28]. The amount of radiographic magnification was determined by dividing the diameter of the projected shaft of the lag screw as seen on the radiograph by its known diameter.

By measuring the TAD over time we studied the incidence of (reversed) Z-effect. The maximum TAD (TADmax) was measured during the follow-up period or before re-operation. To study migration of lag screws over time we calculated the TAD difference (TADdiff), which describes the maximum TAD minus the TAD directly postoperative.

The quality of the fracture reduction was based on the fracture alignment and the fracture displacement. This was judged by the cervicodiaphyseal angle, the degree of angulation and the displacement between fracture fragments and shortening. The fracture reduction status was subsequently scored as good (scored as: 2), acceptable (scored as: 1) and poor (scored as: 0) [29,30]. The position of the inferior lag screw in the femoral head was determined and judged as correct when placed as inferior or centrally on the anteroposterior radiograph and central placement on the axial radiographs [31]. All radiological measurements are displayed in figure 1.

\section{Figure 1. Radiological evaluation} scheme.

1. TAD proximal screw

2. TAD distal screw

3. Collo-diaphyseale angle

4. Angulation of the distal lag screw $(<20 \%)$

5. Fracture dislocation $(>80 \%$ overlapping in both planes; $<5 \mathrm{~mm}$ of shortening

a-f represents the zonez in which the distal screw can be placed in the femoral head.

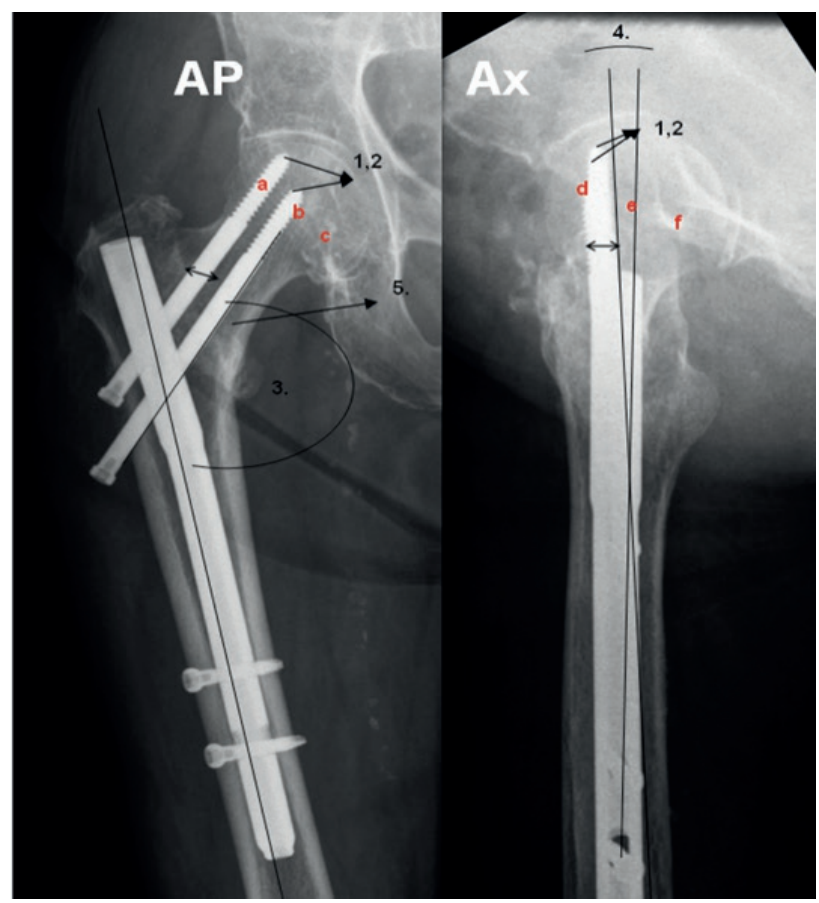




\section{STATISTICAL ANALYSIS}

All analyses were performed with SPSS 16.0 statistical software for windows (SPSS Inc., Chicago, Illinois, USA). $\mathrm{P}<0.05$ was considered to be statistically significant. Data were presented as mean for normally distributed or median when non-normally distributed variables. Percentages were used when appropriate. One-way ANOVA was used to compare normally distributed and the Mann Whitney U-test for nonnormally distributed continuous variables with Bonferroni correction for multiple testing. A Pearson's chi-square test $\left(\mathrm{X}^{2}\right)$ was used to investigate whether distributions of categorical variables differed from one another. To investigate potential predictors for re-intervention we performed a multivariate logistic regression analysis. All theoretically important variables were entered in the model. Re-intervention was chosen as outcome of the model so that other implant related complications like cut-out, cut-through and non-union could be includwed in the analysis.

\section{RESULTS}

224 patients were operatively treated for trochanteric hip fracture during the study period of 2006-2007. Of these patients 103 received an intramedullary nail system with dual lag screws. In 23/103 (22\%) patients there was only one X-ray control postoperatively. These patients were regarded as loss to follow-up. In these 23 patients there were no signs of a Z-effect during hospitalization. The remaining 80 patients enrolled in this study with 2-year follow-up.

Table 1 shows the baseline patient and operation characteristics. There were significant more unstable fractures types (A2.2, A2.3 A3.3) and A3 fracture types treated with a long nail $(p \leq 0.001)$. There were no other differences in baseline or operation characteristics between patients who received a short nail in comparison with a long nail. Patients who were treated with a long nail had a significant longer hospital stay ( 13 vs 21 days, $p<0.05$ ). In table 2 are the radiological measurements displayed and classified by nail length. The TAD, TADmax, TADdiff were not significantly different between the short nail group and the long nail group. The quality of the fracture fixation, expressed by a score, was significantly worse in the long nail group $(p<0.05)$. Furthermore, the inferior lag screw was inserted at a larger angle in the long nail group in comparison with the short nail group $(p<0.05)$. The correct position of the inferior lag screw in the femoral head was not different between 
Table 1. Baseline patient and operation characteristics

\begin{tabular}{l|ccc}
\hline & Short nail $n=58$ & Long nail $n=22$ & P-value \\
Age & $76(\mathrm{SD} 14)$ & $78(\mathrm{SD} 18)$ & 0.8 \\
Male sex & $14 / 58(24 \%)$ & $8 / 22(36 \%)$ & 0.3 \\
ASA (average) & $2.2(\mathrm{SD} 0.7)$ & $2.4(\mathrm{SD} 0.9)$ & 0.2 \\
ASA 1 & $7 / 58(12 \%)$ & $2 / 22(9 \%)$ & 0.7 \\
ASA 2 & $31 / 58(53 \%)$ & $10 / 22(46 \%)$ & 0.5 \\
ASA 3 & $19 / 58(33 \%)$ & $8 / 22(36 \%)$ & 0.8 \\
ASA 4 & $1 / 58(2 \%)$ & $2 / 22(9 \%)$ & 0.1 \\
AO-classification: & $14 / 58(24 \%)$ & $2 / 22(9 \%)$ & 0.1 \\
$\quad$ A1.1-A1.3 & $33 / 58(57 \%)$ & $3 / 22(14 \%)$ & 0.001 \\
$\quad$ A3.1 - A3.3 & $11 / 58(19 \%)$ & $17 / 22(77 \%)$ & $<0.001$ \\
Spinal anesthesia & $43 / 51(84 \%)$ & $14 / 19(74 \%)$ & 0.3 \\
General anesthesia & $8 / 51(16 \%)$ & $5 / 19(26 \%)$ & 0.3 \\
Delay to surgery (hours) & $10($ IQR 13) & $6($ IQR 13) & 0.6 \\
Operation time (min.) & $71(\mathrm{SD} 31)$ & $103(\mathrm{SD} 26)$ & 0.6 \\
Number of patient days & $13(\mathrm{IQR} 11)$ & $21(\mathrm{IQR} 29)$ & $<0.05$
\end{tabular}

Data presented as mean when normally distributed with SD = Standard Deviation. When non-normally distributed data presented as median with $I Q R=$ Interquartile Range. ASA = American Society of Anesthesiologists score, $\mathrm{AO}=$ Arbeitsgemeinschaft für Osteosynthesefragen, $\mathrm{AO}$-classification used for fracture classification.

both groups. Furthermore, there were no differences in the collodiaphyseal angle or average screw migration between both groups. 7 patients developed a (reversed) Z-effect leading to an incidence of $9 \%$. 6 out of 7 patients were treated with a short nail, which did not reach significance in comparison with the long nail group. In table 3 are the radiological measurements displayed and classified by the presence of (reversed) Z-effect. The TADdiff of the inferior lag screw was significantly different between the Z-effect group vs no Z-effect group ( $p=0.001)$. Table 4 shows the radiological measurements classified by implant failure (cut-out, cut-through and Z-effect). Significant displacement occurred of the superior and inferior lag screw over time in the implant failure group vs no implant failure $(p \leq 0.003) .4$ patients needed a re-operation because of the presence of a (reversed) Z-effect. A reversed Z-effect occurred in 2 patients ( 1 in short nail group, 1 in long nail group) and was always a reason for re-operation. Patients who were treated with a long nail had a significant larger number of complications in comparison with the short nail group 
Table 2 and 3. Radiological results classified by nail length and by the presence of a (reversed) Z-effect

\begin{tabular}{|c|c|c|c|}
\hline & Short nail $n=58$ & Long nail $n=22$ & P-value \\
\hline Superior screw TAD (mm) & 26 (IQR 16) & 25 (IQR 16) & 0.9 \\
\hline Superior screw TAD ${ }^{\max }(\mathrm{mm})$ & 28 (IQR 17) & 27 (IQR 16) & 0.7 \\
\hline Superior screw TAD diff (mm) & 4 (IQR 5) & 2 (IQR 8) & 0.3 \\
\hline Inferior screw TAD (mm) & 24 (IQR 16) & 26 (IQR 13) & 0.5 \\
\hline Inferior screw TAD $\max (\mathrm{mm})$ & 27 (IQR 21) & 25 (IQR 14) & 0.9 \\
\hline Inferior screw TADdiff (mm) & 3 (IQR 7) & 4 (IQR 6) & 0.8 \\
\hline Quality fracture reduction (score 0-2) & 2 (IQR 1) & $1.5($ IQR 2) & $<0.05$ \\
\hline Angle inferior lag screw & $4^{\circ}$ (IQR 9$)$ & $9^{\circ}(\mathrm{IQR} 12)$ & $<0.05$ \\
\hline Collodiaphyseal angle (AP) & $134^{\circ}$ (IQR 12) & $133^{\circ}($ IQR 8$)$ & 0.7 \\
\hline \multirow[t]{2}{*}{ Correct placement inferior lag screw* } & $37 / 58(64 \%)$ & $12 / 22(55 \%)$ & 0.4 \\
\hline & $\begin{array}{c}\text { Z-effect }{ }^{1} \\
(n=7)\end{array}$ & $\begin{array}{c}\text { No Z-effect } \\
(n=73)\end{array}$ & P-value \\
\hline AO-classification: A1.1-A1.3 & $2 / 7(29 \%)$ & $14 / 73(19 \%)$ & 0.5 \\
\hline $\mathrm{A} 2.1-\mathrm{A} 2.3$ & $4 / 7(57 \%)$ & $32 / 73(44 \%)$ & 0.5 \\
\hline $\mathrm{A} 3.1-\mathrm{A} 3.3$ & $1 / 7(14 \%)$ & $27 / 73(37 \%)$ & 0.2 \\
\hline Superior screw TAD (mm) & 21 (IQR 17) & 26 (IQR 17) & 0.5 \\
\hline Superior screw TAD ${ }^{\max }(\mathrm{mm})$ & 26 (IQR 41) & 28 (IQR 15) & 0.9 \\
\hline Superior screw TADdiff (mm) & $6(\operatorname{IQR} 7)$ & 3 (IQR 5) & 0.2 \\
\hline Inferior screw TAD (mm) & 24 (IQR 14) & 25 (IQR 15) & 0.6 \\
\hline Inferior screw TAD ${ }^{\max }(\mathrm{mm})$ & 26 (SD 41) & 28 (SD 15) & 0.4 \\
\hline Inferior screw TAD diff (mm) & $13(\mathrm{SD} 66)$ & 3 (SD 5) & 0.001 \\
\hline Quality fracture reduction (score $0-2$ ) & 2.0 (IQR 1.0) & 2.0 (IQR 1.0) & 0.8 \\
\hline Angle inferior lag screw & $9^{\circ}(\mathrm{SD} 8)$ & $7^{\circ}(\mathrm{SD} 9)$ & 0.7 \\
\hline Collodiaphyseal angle (AP) & $131^{\circ}(\mathrm{SD} 8)$ & 133 (SD 8) & 0.6 \\
\hline Correct placement inferior lag screw ${ }^{\star}$ & $46 / 73(63 \%)$ & $4 / 7(57 \%)$ & 0.3 \\
\hline
\end{tabular}

Data presented as mean when normally distributed with $\mathrm{SD}=$ Standard Deviation. When non-normally distributed data presented as median with $I Q R=$ Interquartile Range. ASA = American Society of Anesthesiologists score, TADdiff = Tip Apex Distance difference of TADmax (maximal measured TAD distance over time) minus the TAD (first postoperative measured TAD). AP = anteroposterior view, $A x=$ axial view. ${ }^{*}$ Correct placement in the femoral head established as inferior or centrally placement of the lag screw on the anteroposterior radiograph and central placement on the axial radiographs. ${ }^{1} Z$-effect or reversed Z-effect. 
(median 2 vs $0.5, p=0.001$ ). The long nail group received more often erythrocytes blood transfusions (82\% vs 31\%, p<0.001) (Table 5).

There were 17 re-operations performed within two year after primary surgery. In $4 / 17$ (23\%) of cases due to a (reversed) Z-effect and in 13/17 (76\%) of cases due to a screw related implant failure. All reasons for re-operation are mentioned in table 6. There were significantly more deep infections in the long nail group $(<0.05)$.

All possible predictors for re-operation were entered in a logistic regression analysis (table 7). Migration of the superior as well as the inferior lag screw over time and unstable fracture type were the only predicting variables for re-operation. All other radiological variables used in this study were not associated with re-operation.

Table 4. Radiological results classified by nail length and by the presence of implant failure (cutout, cut-through or the presence of a Z-effect or reverse Z-effect)

\begin{tabular}{|c|c|c|c|}
\hline & $\begin{array}{c}\text { Implant } \\
\text { complication }(n=17)\end{array}$ & $\begin{array}{c}\text { No implant } \\
\text { complication }(n=63)\end{array}$ & $P$-value \\
\hline AO-classification: A1.1-A1.3 & $2 / 17(12 \%)$ & $14 / 63(22 \%)$ & 0.4 \\
\hline A2.1-A2.3 & $11 / 17(65 \%)$ & $25 / 63(40 \%)$ & 0.1 \\
\hline A3.1-A3.3 & $4 / 17(24 \%)$ & 24/63 (38\%) & 0.3 \\
\hline Superior screw TAD (mm) & 21 (IQR 25) & 26 (IQR 15) & 0.8 \\
\hline Superior screw TAD $\max (\mathrm{mm})$ & 26 (IQR 43) & 28 (IQR 14) & 0.7 \\
\hline Superior screw TAD diff $(m m)$ & 10 (IQR 43) & 3 (IQR 4) & $<0.001$ \\
\hline Inferior screw TAD (mm) & 22 (IQR 12) & 25 (IQR 16) & 0.3 \\
\hline Inferior screw TAD ${ }^{\max }(\mathrm{mm})$ & 23 (IQR 51) & 25 (IQR 18) & 0.2 \\
\hline Inferior screw TAD diff (mm) & $13(\mathrm{SD} 51)$ & 3 (IQR 5) & 0.003 \\
\hline Quality fracture reduction (score $0-2$ ) & 2.0 (IQR 1.0) & $2.0 \mathrm{IQR} 1.0$ & 0.5 \\
\hline Angle inferior lag screw & $7^{\circ}(\mathrm{SD} 6)$ & $8^{\circ}(\mathrm{SD} 8)$ & 0.7 \\
\hline Collodiaphyseal angle (AP) & $131^{\circ}(\mathrm{SD} 8)$ & $134^{\circ}(\mathrm{SD} 8)$ & 0.3 \\
\hline Correct placement inferior lag screw ${ }^{\star}$ & $38 / 63(60 \%)$ & $11 / 17(65 \%)$ & 0.7 \\
\hline
\end{tabular}

Data presented as mean when normally distributed with SD = Standard Deviation. When non-normally Implant failure = cut-out, cut-through or the presence of a Z-effect or reverse Z-effect. Data presented as mean when normally distributed with $\mathrm{SD}=$ Standard Deviation. When non-normally distributed data presented as median with IQR = Interquartile Range. ASA = American Society of Anesthesiologists score, TADdiff = Tip Apex Distance difference of TADmax (maximal measured TAD distance over time) minus the TAD (first postoperative measured TAD). AP = anteroposterior view, $A x=$ axial view. ${ }^{*}$ Correct placement in the femoral head established as inferior or centrally placement of the lag screw on the anteroposterior radiograph and central placement on the axial radiographs. 


\begin{tabular}{l|ccc}
\hline & Short nail n=58 & Long nail n=22 & P-value \\
Number of complications & $0.5(\mathrm{IQR} 1)$ & $2.0(\mathrm{IQR} 2)$ & 0.001 \\
Cardiac complications & $3 / 58(5 \%)$ & $1 / 22(5 \%)$ & 0.9 \\
Pulmonary complications & $3 / 58(5 \%)$ & $2 / 22(9 \%)$ & 0.5 \\
Blood transfusion & $18 / 58(31 \%)$ & $18 / 22(82 \%)$ & $<0.001$ \\
Urinary tract infections & $13 / 58(22 \%)$ & $12 / 22(55 \%)$ & 0.006 \\
Z-effect & $5 / 58(9 \%)$ & $0 / 22(0 \%)$ & 0.2 \\
Reversed Z-effect & $1 / 58(2 \%)$ & $1 / 22(5 \%)$ & 0.5 \\
Re-operation & $11 / 58(19 \%)$ & $6 / 22(27 \%)$ & 0.4 \\
Cut-out & $1 / 58(2 \%)$ & $1 / 22(5 \%)$ & 0.5 \\
Cut-through & $8 / 58(14 \%)$ & $3 / 22(14 \%)$ & 1.0 \\
Non-union & $1 / 58(2 \%)^{\star}$ & $2 / 22(9 \%)^{\star \star}$ & 0.1
\end{tabular}

Data presented as mean when normally distributed with $S D=$ Standard Deviation. When non-normally distributed data presented as median with IQR $=$ Interquartile Range. ${ }^{*}$ non union due to avascular necrosis of the femoral head, ${ }^{* \star}$ non union due to deep infection.

Table 6. Reasons for re-operation classified by nail length

\begin{tabular}{l|ccc}
\hline & Short nail $(n=58)$ & Long nail $(n=22)$ & $P$ \\
Z-effect & $2 / 58(3 \%)$ & $0 / 22(0 \%)$ & 0.4 \\
Reversed Z-effect & $1 / 58(2 \%)$ & $1 / 22(5 \%)$ & 0.5 \\
Cut-out & $1 / 58(2 \%)$ & $0 / 22$ & 0.5 \\
Cut-through & $5 / 58(9 \%)$ & $1 / 22(5 \%)$ & 0.5 \\
Deep infection & $0 / 58$ & $2 / 22(9 \%)$ & $<0.05$ \\
AVN* of the femoral head & $1 / 58(2 \%)$ & $0 / 22$ & 0.5 \\
Pain from screws/breakage of screws & $0 / 58$ & $2 / 22(9 \%)$ & 0.1 \\
Periprosthetic fracture/break-out nail & $1 / 58(2 \%)$ & $0 / 22$ & 0.5
\end{tabular}

${ }^{*}$ AVN, Avascular necrosis. 


\begin{tabular}{l|ccc}
\hline & P-value & B & Std. Error \\
Sex & 0.4 & -0.002 & 0.003 \\
Age & 0.6 & 0.09 & 0.1 \\
ASA & 0.7 & 0.03 & 0.07 \\
Nail length & 0.6 & 0.05 & 0.1 \\
Unstable fracture type ${ }^{1}$ & $<0.05$ & 0.2 & 0.1 \\
Superior screw TAD diff & 0.009 & 0.009 & 0.003 \\
Inferior screw TAD diff & 0.007 & 0.007 & 0.003 \\
Quality fracture reduction (score 0-2) & 0.9 & 0.013 & 0.07 \\
Angle inferior lag screw & 0.7 & -0.003 & 0.006 \\
Collodiaphyseal angle (AP) & 0.5 & -0.004 & 0.005
\end{tabular}

Variables entered in Logistic regression analysis. P-value, significant for $\mathrm{p}<0.05, \mathrm{ASA}=$ American Society of Anesthesiologists score, TADdiff = Tip Apex Distance difference of TADmax (maximal measured TAD distance over time) minus the TAD (first postoperative measured TAD). ${ }^{1}$ Unstable Fracture types: A2.2, A2.3 A3.3 (AO-classification). AP = anteroposterior view, $\mathrm{Ax}=$ axial view.

\section{DISCUSSION}

The incidence of Z-effect in this study was $9 \%$. The length of the nail was not associated with the development of a Z-effect. Migration of lag screws after intramedullary nailing is common and a risk factor for re-operation as well as unstable fracture type. The re-operation rate within 2 year after surgery was $21 \%$ of which one fourth was due to a Z-effect.

We hypothesized that long nails provide more neck strength due to a longer lever and are therefore less likely to develop a misbalance of a higher head compressive strength than neck compressive strength, contributing to the Z-effect. In this study we did not find any convincing evidence for this hypothesis. There was no association between nail length and the development of a Z-effect, although 6 out of 7 Z-effects occurred in the short nail group. Despite these findings was the long nail inferior to the short nail for fracture reduction and quality of the osteosynthesis. These findings suggest that other variables are responsible for the occurrence of a Z-effect. More unstable fracture types and more high-energy trauma in the long nail group could explain the difference in quality of the osteosynthesis. This might 
also be the reason for the higher incidence of blood transfusion in the long nail group. The operation time was also longer in the long nail group but did not reach significance.

The overall incidence of Z-effect in this study was $9 \%$, which is in line with other studies that report an incidence of $7.1 \%-13 \%$ after the proximal femoral nail with antirotation screw (PFNa, dual screw device) [23, 24, 32]. The migration of lag screws in the Z-effect group (table 3 ) is probably under estimated because Z-effect $(n=5)$ and reversed $Z$-effect $(n=2)$ fade each other out. Therefor all patients with implant failure (cut-out, cut-through and Z-effect) were grouped to study migration of lag screws more closely (table 4). Patients with implant failure did not have worse baseline characteristics of the primary placed dual lag screw system regarding fracture type, fracture reduction, collodiaphyseal angle or position of the lag screws in the femoral head. Significant migration of superior and inferior lag screws occurred over time in the case of implant failure ( $p \leq 0.003)$, the maximum migration for the superior lag screw was $82 \mathrm{~mm}$, and for the inferior lag screw $97 \mathrm{~mm}$.

In 5 cases there occurred screw migration with perforation of the acetabulum. In 4 out of 5 cases due to cut-through and in 1 case in the presence of a reversed Z-effect. The cause of this phenomenon is multifactorial. Osteoporotic bone and unstable fracture types have previous been mentioned to be risk factors [33-35].

The principles behind the second or antirotation screw are clear, but strong clinical evidence for advantages are lacking. In a randomized controlled trial the Dynamic Hip Screw (DHS) was compared to the PFNa, but no statistically significant differences were found regarding implant failure [36]. Another study compared PFNa with conventional gamma nails and concluded no difference in clinical outcome. However, the PFNa demonstrated better results biomechanically in terms of less sliding of lag screw, less change of neck shaft angle, and less complications for the treatment of reverse obliquity intertrochanteric fractures [37]. A previous study reported that the PFNa did not improve the position of the implant in the femoral head compared with the PFN without antirotation screw [38]. This suggests that due to the use of a dual screw system there might be an increased risk for suboptimal placement. If the inferior lag screw is placed centrally, this results in a unavoidable cranially placed superior lag screw [39]. The key to prevent Z-effects might be a optimal position of the lag screws in the head by inserting the inferior lag screw over the calcar of the femoral neck in order to achieve better bony anchoring, 
thus preventing screw cut-out. Strauss et al. suggested in their biomechanical study that in cases of intertrochanteric hip fractures with significant medial cortical comminution, surgeons may wish to avoid the use of a dual lag screw intramedullary nail [26].

We acknowledge a few limitations for interpreting the results of our study. Of 23 patients there was a limited follow-up available; therefore, an underestimation of the results could be made. The loss to follow-up could be explained by early death or when no further radiologic follow-up was performed. Most patients that were loss to follow-up were suffering from dementia and discharged to a nursing home. Furthermore, selection bias cannot be excluded because of the retrospective study design. Although this is one of very few studies that specifically report about Z-effect after intramedullary nailing, the number of patients is relatively small, making the risk of type II error higher. The measured TAD depends on the angle the $\mathrm{X}$-rays are shot, which makes it difficult to compare accurately, but we did use all available $\mathrm{X}$-rays in the follow-up and corrected for radiographic magnification. There exists an overall difficulty of comparing long and short nails with another as well as A1 fractures with A2 or A3 fractures. We corrected our analysis for the presence of unstable fracture types.

In our study we did not only report implant related complications but also looked at predictors for re-operation. Unstable fracture type was a predictor for re-operation as well as migration of the superior or inferior lag screw over time. The contributing effect of osteoporosis to implant failure was not included in our analysis. To prevent re-operations after intramedullary nailing a stabile implant resistant to migration of lag screws is needed, even more in unstable comminuted trochanteric fractures. Dual lag screw systems have improved over the years. Henschel et al. found that the stresses were distributed more equally between the two cephalic screws in the bone and the implant if a longer inferior screw was used [40]. The Targon nail@ (B. Braun, Aesculap) interlocking nail system was developed on the same biomechanical principle. In a randomized trial the Targon nail seems to be superior to the sliding hip screw (SHS) in the case of unstable A3 trochanteric fractures [41]. Fractures treated with SHS were more likely to medialize $>50 \%$ compared with the Targon nail in A3 fractures (38.1\% vs 3.8\%, $p=0.006$ ). Medialization $>50 \%$ was a predictor for revision surgery. Another dual lag screw nail was reintroduced (Trigen Intertan, Smith-Nephew) and designed with two integrated lag screws to overcome Z-effect complications and provides immediate intraoperative linear compression 
and rotational stability. Several studies have shown reliable outcome without the presence of Z-effect [39, 42, 43]. A prospective randomized comparative study of the Endovis ${ }^{\circledR}$ Cephalomedullary dual lag screw nail vs DHS showed comparable outcome, with implant failure rates of $9 \%$ and $11 \%$ respectively [44]. Lag screw migrations only occurred in patients with unstable trochanteric fractures with comminution of the medial cortex. Finally, a recent prospective, randomized, multicenter clinical trial compared the Trigen Intertan nail (Smith-Nephew) with DHS. This study showed that most patients with intertrochanteric femur fractures could expect similar functional results whether treated with an intramedullary or extramedullary device. Sub-group analysis showed that active and functional patients with unstable trochanteric fractures have better outcome regarding less shortening, better Functional Independence Measure (FIM) and Timed Up and Go test (TUG) after 1 year follow-up when the Trigen Intertan nail is used [45]. More prospective randomized comparative studies of recent dual lag screw systems with other fixation types are warranted to conclude what osteosynthesis is preferable in unstable trochanteric fractures. 


\section{REFERENCES}

1. Gullberg B, Johnell O, Kanis JA: World-wide projections for hip fracture. Osteoporos Int 1997, 7(5):407-413.

2. Cooper C, Campion G, Melton LJ, 3rd: Hip fractures in the elderly: a worldwide projection. Osteoporos Int 1992, 2(6):285-289.

3. Ballane G, Cauley JA, Luckey MM, Fuleihan Gel H: Secular trends in hip fractures worldwide: opposing trends East versus West. J Bone Miner Res 2014, 29(8):1745-1755.

4. Cooper C, Cole ZA, Holroyd CR, Earl SC, Harvey NC, Dennison EM, Melton LJ, Cummings SR, Kanis JA, Epidemiology ICWGoF: Secular trends in the incidence of hip and other osteoporotic fractures. Osteoporos Int 2011, 22(5): 1277-1288.

5. Chau PH, Wong M, Lee A, Ling M, Woo J: Trends in hip fracture incidence and mortality in Chinese population from Hong Kong 2001-09. Age Ageing 2013, 42(2):229-233.

6. Baidwan NK, Naranje SM: Epidemiology and recent trends of geriatric fractures presenting to the emergency department for United States population from year 2004-2014. Public Health 2017, 142:64-69.

7. Katsoulis M, Benetou V, Karapetyan T, Feskanich D, Grodstein F, PetterssonKymmer U, Eriksson S, Wilsgaard T, Jorgensen L, Ahmed LA et al.: Excess mortality after hip fracture in elderly persons from Europe and the USA: the CHANCES project. J Intern Med 2017.

8. Smeets SJ, Poeze M, Verbruggen JP: Preoperative cardiac evaluation of geriatric patients with hip fracture. Injury 2012, 43(12):2146-2151.

9. Khan SK, Kalra S, Khanna A, Thiruvengada MM, Parker MJ: Timing of surgery for hip fractures: a systematic review of 52 published studies involving 291,413 patients. Injury 2009, 40(7):692-697.

10. Papasimos S, Koutsojannis CM, Panagopoulos A, Megas P, Lambiris E: A randomised comparison of $\mathrm{AMBI}$, TGN and PFN for treatment of unstable trochanteric fractures. Arch Orthop Trauma Surg 2005, 125(7):462-468.

11. Schipper IB, Steyerberg EW, Castelein RM, van der Heijden FH, den Hoed PT, Kerver AJ, van Vugt AB: Treatment of unstable trochanteric fractures. Randomised comparison of the gamma nail and the proximal femoral nail. J Bone Joint Surg Br 2004, 86(1):86-94.

12. Banan H, Al-Sabti A, Jimulia T, Hart AJ: The treatment of unstable, extracapsular hip fractures with the AO/ASIF proximal femoral nail (PFN)-our first 60 cases. Injury 2002, 33(5):401-405.

13. Davis TR, Sher JL, Horsman A, Simpson M, Porter BB, Checketts RG: Intertrochanteric femoral fractures. Mechanical failure after internal fixation. J Bone Joint Surg Br 1990, 72(1):26-31.

14. Jensen JS, Sonne-Holm S, Tondevold E: Unstable trochanteric fractures. 
A comparative analysis of four methods of internal fixation. Acta Orthop Scand 1980, 51(6):949-962.

15. Parker MJ: Cutting-out of the dynamic hip screw related to its position. J Bone Joint Surg Br 1992, 74(4):625.

16. Lobo-Escolar A, Joven E, Iglesias D, Herrera A: Predictive factors for cutting-out in femoral intramedullary nailing. Injury 2010, 41(12):1312-1316.

17. Friedenberg ZB, Gentchos E, Rutt C: Fixation in intertrochanteric fractures of the hip. Surg Gynecol Obstet 1972, 135(2):225-228.

18. Kyle RF, Gustilo RB, Premer RF: Analysis of six hundred and twenty-two intertrochanteric hip fractures. J Bone Joint Surg Am 1979, 61(2):216-221.

19. Lin J: Encouraging results of treating femoral trochanteric fractures with specially designed double-screw nails. J Trauma 2007, 63(4):866-874.

20. Wang CJ, Brown CJ, Yettram AL, Procter P: Intramedullary femoral nails: one or two lag screws? A preliminary study. Med Eng Phys 2000, 22(9):613624.

21. Kubiak EN, Bong M, Park SS, Kummer F, Egol K, Koval KJ: Intramedullary fixation of unstable intertrochanteric hip fractures: one or two lag screws. J Orthop Trauma 2004, 18(1):12-17.

22. Boldin C, Seibert FJ, Fankhauser F, Peicha G, Grechenig W, Szyszkowitz R: The proximal femoral nail (PFN)--a minimal invasive treatment of unstable proximal femoral fractures: a prospective study of 55 patients with a followup of 15 months. Acta Orthop Scand 2003, 74(1):53-58.

23. Tyllianakis M, Panagopoulos A, Papadopoulos A, Papasimos S, Mousafiris $\mathrm{K}$ : Treatment of extracapsular hip fractures with the proximal femoral nail (PFN): long term results in 45 patients. Acta Orthop Belg 2004, 70(5):444454.

24. Werner-Tutschku W, Lajtai G, Schmiedhuber G, Lang T, Pirkl C, Orthner E: [Intra- and perioperative complications in the stabilization of per- and subtrochanteric femoral fractures by means of PFN]. Unfallchirurg 2002, 105(10):881-885.

25. Pires RE, Santana EOJ, Santos LE, Giordano V, Balbachevsky D, Dos Reis FB: Failure of fixation of trochanteric femur fractures: Clinical recommendations for avoiding Z-effect and reverse Z-effect type complications. Patient Saf Surg 2011, 5(1):17.

26. Strauss EJ, Kummer FJ, Koval KJ, Egol KA: The "Z-effect" phenomenon defined: a laboratory study. J Orthop Res 2007, 25(12):1568-1573.

27. Weil YA, Gardner MJ, Mikhail G, Pierson G, Helfet DL, Lorich DG: Medial migration of intramedullary hip fixation devices: a biomechanical analysis. Arch Orthop Trauma Surg 2008, 128(2):227-234.

28. Baumgaertner MR, Solberg BD: Awareness of tip-apex distance reduces failure of fixation of trochanteric fractures of the hip. J Bone Joint Surg Br 1997, 79(6):969-971. 
29. Baumgaertner MR, Curtin SL, Lindskog DM: Intramedullary versus extramedullary fixation for the treatment of intertrochanteric hip fractures. Clin Orthop Relat Res 1998(348):87-94.

30. Park SY, Yang KH, Yoo JH, Yoon HK, Park HW: The treatment of reverse obliquity intertrochanteric fractures with the intramedullary hip nail. J Trauma 2008, 65(4):852-857.

31. Kuzyk PR, Zdero R, Shah S, Olsen M, Waddell JP, Schemitsch EH: Femoral head lag screw position for cephalomedullary nails: a biomechanical analysis. J Orthop Trauma 2012, 26(7):414-421.

32. Muller M, Seitz A, Besch L, Hilgert RE, Seekamp A: [Proximal femur fractures: results and complications after osteosynthesis with PFN and TGN]. Unfallchirurg 2008, 111(2):71-77.

33. Larsson S, Friberg S, Hansson LI: Trochanteric fractures. Influence of reduction and implant position on impaction and complications. Clin Orthop Relat Res 1990(259):130-139.

34. Barrios C, Brostrom LA, Stark A, Walheim G: Healing complications after internal fixation of trochanteric hip fractures: the prognostic value of osteoporosis. J Orthop Trauma 1993, 7(5):438-442.

35. Yoshimine F, Latta LL, Milne EL: Sliding characteristics of compression hip screws in the intertrochanteric fracture: a clinical study. J Orthop Trauma 1993, 7(4):348-353.

36. Zou J, Xu Y, Yang H: A comparison of proximal femoral nail antirotation and dynamic hip screw devices in trochanteric fractures. J Int Med Res 2009, 37(4): 1057-1064.

37. Min WK, Kim SY, Kim TK, Lee KB, Cho MR, Ha YC, Koo KH: Proximal femoral nail for the treatment of reverse obliquity intertrochanteric fractures compared with gamma nail. J Trauma 2007, 63(5):1054-1060.

38. Gardenbroek TJ, Segers MJ, Simmermacher RK, Hammacher ER: The proximal femur nail antirotation: an identifiable improvement in the treatment of unstable pertrochanteric fractures? J Trauma 2011, 71(1):169-174.

39. Kim JW, Kim TY, Ha YC, Lee YK, Koo KH: Outcome of intertrochanteric fractures treated by intramedullary nail with two integrated lag screws: A study in Asian population. Indian J Orthop 2015, 49(4):436-441.

40. Henschel J, Eberle S, Augat P: Load distribution between cephalic screws in a dual lag screw trochanteric nail. J Orthop Surg Res 2016, 11:41.

41. Bretherton CP, Parker MJ: Femoral Medialization, Fixation Failures, and Functional Outcome in Trochanteric Hip Fractures Treated With Either a Sliding Hip Screw or an Intramedullary Nail From Within a Randomized Trial. J Orthop Trauma 2016, 30(12):642-646.

42. Qin H, An Z: [Therapeutic evaluation of femoral intertrochanteric fractures by InterTan]. Zhongguo Xiu Fu Chong Jian Wai Ke Za Zhi 2010, 24(12):14241427. 
43. Ruecker AH, Rupprecht M, Gruber M, Gebauer M, Barvencik F, Briem $D$, Rueger JM: The treatment of intertrochanteric fractures: results using an intramedullary nail with integrated cephalocervical screws and linear compression. J Orthop Trauma 2009, 23(1):22-30.

44. Kouvidis G, Sakellariou VI, Mavrogenis AF, Stavrakakis J, Kampas D, Galanakis J, Papagelopoulos PJ, Katonis P: Dual lag screw cephalomedullary nail versus the classic sliding hip screw for the stabilization of intertrochanteric fractures. A prospective randomized study. Strategies Trauma Limb Reconstr 2012, 7(3):155-162.

45. Sanders D, Bryant D, Tieszer C, Lawendy AR, MacLeod M, Papp S, Liew A, Viskontas D, Coles C, Gurr K et al.: A Multicenter Randomized Control Trial Comparing a Novel Intramedullary Device (InterTAN) Versus Conventional Treatment (Sliding Hip Screw) of Geriatric Hip Fractures. J Orthop Trauma 2017, 31(1):1-8.

46. Fleisher LA, Beckman JA, Brown KA, Calkins H, Chaikof E, Fleischmann KE, Freeman WK, Froehlich JB, Kasper EK, Kersten JR et al.: ACC/AHA 2007 guidelines on perioperative cardiovascular evaluation and care for noncardiac surgery: areport of the American College of Cardiology/American Heart Association Task Force on Practice Guidelines (Writing Committee to Revise the 2002 Guidelines on Perioperative Cardiovascular Evaluation for Noncardiac Surgery): developed in collaboration with the American Society of Echocardiography, American Society of Nuclear Cardiology, Heart Rhythm Society, Society of Cardiovascular Anesthesiologists, Society for Cardiovascular Angiography and Interventions, Society for Vascular Medicine and Biology, and Society for Vascular Surgery. Circulation 2007, 116(17):e418-499. 


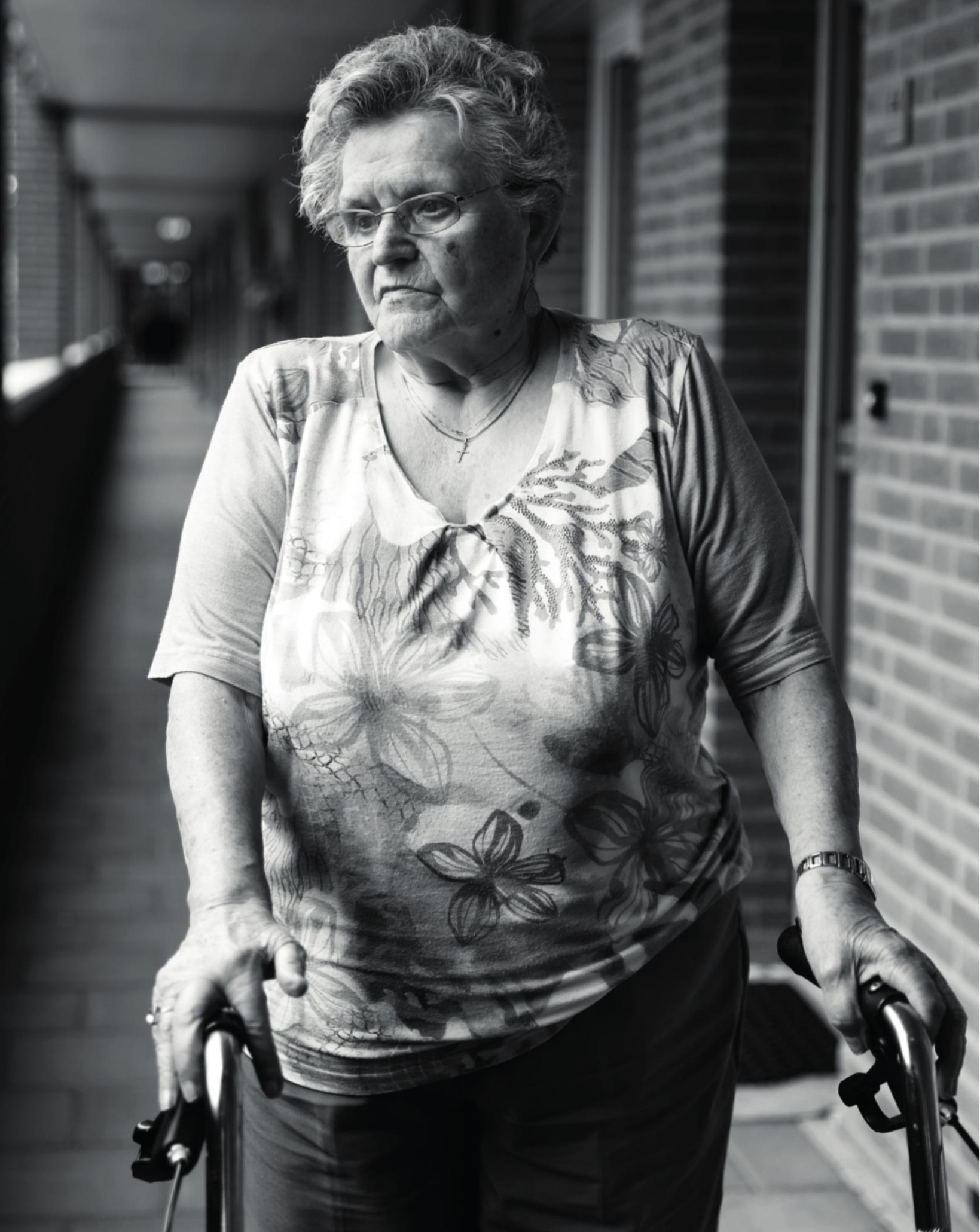




\section{CHAPTER}

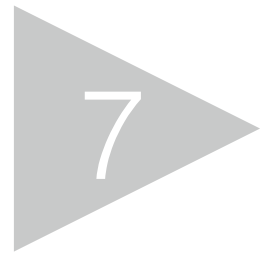

Summarizing discussion, future perspectives and conclusions

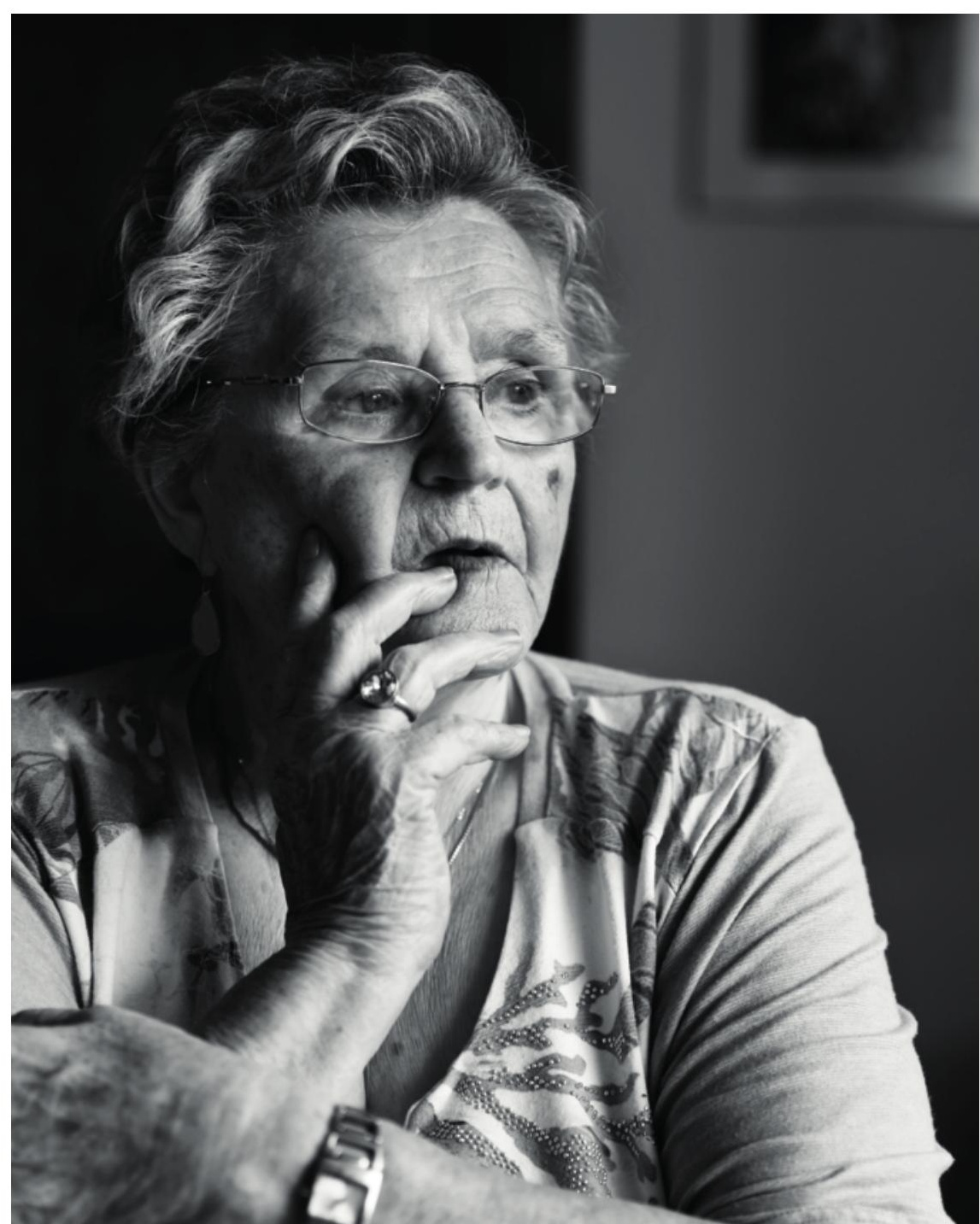




\section{DOES THE PATELLAR PUBIC PERCUSSION TEST (PPPT) HAVE A PLACE IN MODERN PRACTICE?}

It can be difficult to diagnose occult hip fractures. Previous studies show that $2-10 \%$ of hip fractures are unable to be diagnosed by radiographs only [1-4]. Clear clinical decision rules for additional imaging do not exist. Whether an additional CT or MRI-scan is justified will be determined by physical examination, the ability to ambulate, subjective pain presentation and the gut feeling of the attending clinician. Undiagnosed hip fractures may lead to secondary fracture displacement and avascular necrosis due to treatment delay [5]. In chapter 2 we presented the patellar pubic percussion test (PPPT), as a validated test to diagnose clear hip fractures as well as occult fractures. We calculated a $85 \%$ sensitivity, a $70 \%$ specificity and a positive predictive value of 0.94 . One other study found a sensitivity of $96 \%$ and a specificity of $85 \%$, although these findings were based on 1 observer only [6]. We acknowledge some limitations of the PPPT test such as previous hip/ knee surgery with osteosynthesis in place or unilateral severe cox arthrosis on the X-rays. We propose a clinical flowchart were the PPPT could help to filter patients for the need for additional imaging (see figure 1). This could increase the uniformity between physicians and possibly decrease missing fracture rates. The question remains whether the PPPT is contributory in modern medicine, where you can get a CT or MRI scan almost instantly. Our results show that the PPPT provides more objective support for additional imaging, than decision making without it. If the x-ray is negative this does not exclude a hip fracture. The PPPT could be of guidance to diagnose occult hip or pelvic fracture with somewhat more certainty. In our study, treatment for patients with suspected hip fracture could be based on X-rays only in more than $92 \%$ of cases. Additional imaging after a positive PPPT show in $73 \%$ of cases missed fractures, mostly pelvic fractures. The question remains how many of these patients would have received the same imaging based on other findings if the flowchart was not in use. The flowchart has not been tested in clinical practice, since our blinded prospective study design was focused on the properties of the PPPT itself and every clinically suspected hip fracture patient was tested before $\mathrm{x}$-rays were taken. This should be the main focus for further research to establish a diagnostic role for the PPPT. The Patellar Pubic Percussion Test: it's nostalgia, but it proves to be a reliable, quick, bedside tool test to guide for further imaging and prevent missed fractures. 


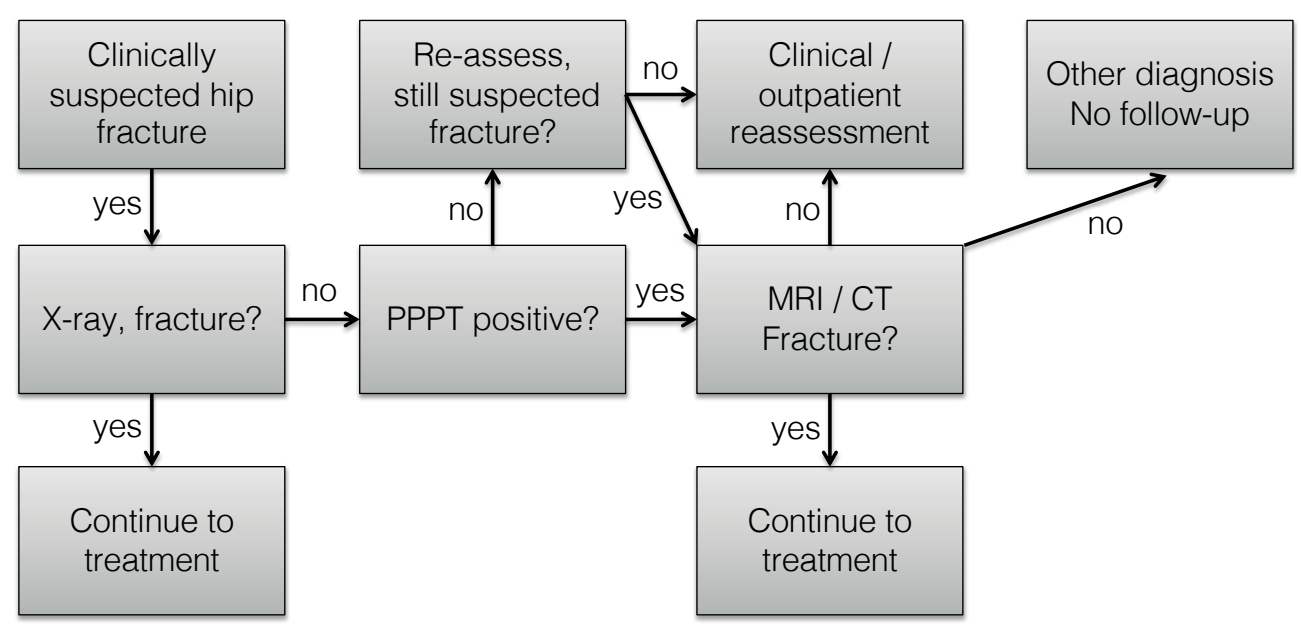

Figure 1. Suggested flowchart with a diagnostic role for the Patellar Pubic Percussion Test (PPPT).

\section{PREOPERATIVE CARDIAC SCREENING, HOW IMPORTANT IS IT?}

Before surgery all hip fracture patients receive preoperative screening for perioperative risk assessment. The preoperative screening may give rise to a preoperative cardiac consultation. The reason for this is not cardiac clearance, but cardiac risk assessment to determinate changes in perioperative patient management, including anesthesia, pharmacological and perioperative monitoring. In $6-25 \%$ of hip fracture patients additional cardiac testing with Trans Thoracic Echocardiography (TTE) is used [7-9] and this leads very rarely to a preoperative cardiac intervention [10].

In chapter $\mathbf{3}$ and $\mathbf{4}$, we showed that cardiac screening is frequently not in accordance with the clinical practice guidelines of the American College of Cardiology and American Heart Association (ACC/AHA). Overscreening is in more than $\geq 90 \%$ of the cases the reason for incorrect screening. The increase of delay to surgery between non-overscreening vs. overscreening was $9.9 \mathrm{hrs}(\mathrm{p}=0.03)$. The mean delay to surgery increased by 8.0 hours when patients had a cardiac consultation $(p=0.001)$. A cardiac consultation was a significant factor for increased delay to surgery in multivariate analysis, while age, sex, a cardiac history and preoperative mobility were not. These findings are in line with previous studies [11-13]. We 
demonstrated that an increased delay to surgery was an independent predictor for in-hospital mortality $(p<0.05)$ and 1 -month mortality $(p<0.05)$. Patients with a delay of more than 48 hours suffered from more cardiovascular $(p<0.001)$ and respiratory complications $(P<0.01)$. The effects of delay itself could partly explain increased complication risk. On the other hand, patients who encounter a delay $>48$ hours, if not system related delay, are probably the more vulnerable patients with acute medical problems and more likely to have comorbidity and higher ASA score. Patients who were classified as high risk by the ACC/AHA guidelines experienced significantly more respiratory and cardiovascular complications. This was associated with a significant more than 4-fold increased risk for in-hospital mortality for high risk patients in comparison with intermediate and low risk patients [14].

Preoperative cardiac assessment is in the first place important to strive for the best possible outcome for patients. Secondly, to prevent delay to surgery and overuse of medical resources. Unfortunately, the content of a cardiac consultation is frequently limited to a statement of the known increased surgical risk and with general recommendations concerning fluid balance, maintaining hemoglobin levels and continuing beta-blockers medication. It has been suggested to routinely perform echocardiography in elderly patients with hip fractures [15]. Some authors have reported a benefit of routine echocardiography on mortality after hip fracture surgery [16], where others have not $[10,17]$. There are no recommendations available from randomized controlled trials on the use of TTE in a hip fracture population, this should be the main focus for future research.

Screening of all hip fracture patients with trans thoracic echocardiography (TTE) identified significant aortic stenosis in $8 \%$ of patients [18]. Conversely, severe aortic stenosis is no contraindication for surgery and did not influence early mortality [19, 20]. The use of TTE as a screening tool to find cardiovascular pathology seems to have its limitations. An important matter is to identify those patients who should undergo TTE. Screening patients with a high chance of pathology is more logical than screening all hip fracture patients.

Preoperative cardiac screening and stabilization of medical issues before hip fracture surgery is essential and should be individually determined according to the patient's perioperative risk. If subsequently, the screening leads to a cardiac consultation, this assessment must be carried out efficiently with attention for timing 
to surgery and in accordance with clinical practice guidelines such as the ACC/ AHA guidelines. Overscreening leads to greater delay to surgery, which poses a risk for perioperative complications and early mortality.

\section{BLOOD TRANSFUSIONS, DO OR DON'T?}

In chapter 3, $\mathbf{4}$ and 5, we demonstrated that erythrocyte blood transfusion (EBT) is frequently used during the treatment of anemia after hip fracture surgery (41$43 \%)$. A hip fracture reduces mean haemoglobin concentrations by approximately $0.7-2.5 \mathrm{~g} / \mathrm{dl}$ depending on fracture type $[21,22]$. The haemoglobin level on admission was found to be falsely reassuring and could lead to dangerously low postoperative haemoglobin levels [22]. The hidden blood loss after hip surgery is probably underestimated $[23,24]$. Factors contributing to this are blood loss due to the fracture hematoma, especially in extracapsular fractures, which may not be reflected by the level of haemoglobin at the time of admission. Furthermore, intraoperative blood loss and insufficient haemostasis may contribute to continued haemorrhage postoperatively. Anticoagulant medication may increase perioperative bleeding. Other sources of bleeding, such as gastrointestinal bleeding, may add to the overall blood loss.

The lower a patient's haemoglobin concentration before hip fracture, the more likely they are to be transfused $[25,26]$. In chapter $\mathbf{5}$ we demonstrated that the postoperative hemoglobin level was the strongest predictor for EBT. Patients who received EBT had a significant longer hospital stay and more postoperative cardiac complications, even after adjustment for confounders. Multivariate analysis for mortality showed that EBT was a significant risk factor for early as well as late mortality, but after adding the propensity score, EBT was no longer associated with increased mortality. The propensity score was used to differentiate between transfusion being a risk factor for mortality and the risk factors for predicting transfusion being predictors for mortality itself.

During the term of this thesis, the Maastricht University Medical Center practiced a liberal transfusion policy to transfuse elderly patients with a cardiac history (aimed at $>10 \mathrm{~g} / \mathrm{dL}$ ). Given that $49 \%$ of patients enrolled in our study had a previous cardiac history. Despite this, no significant differences in transfusion rates existed when patients were classified into low, intermediate and high cardiac risk by the 
ACC/AHA guidelines.

A review from Potter et al. on preoperative anemia and EBT in hip fracture patients showed that anemia on hospital admission was associated with increased mortality, relative risk 1.64 (95\% Cl 1.47-1.82), $p<0.0001$ in $>13.000$ patients [27]. Several studies showed that anemia on admission was associated with increased mortality after hip fracture, regardless the severity of anemia [27-36]. However, four of eight studies in the review from Potter reported that anemia was not independently associated with mortality after adjustment for major confounders. There was no association between postoperative transfusion and mortality after adjusting for covariates. These findings suggest that anemia seems to play a more important role than EBT itself. This is exactly why we corrected our data in with the use of the propensity score for the chance of receiving EBT. The interpretation of a possible association of EBT with postoperative outcome is confounded by the corresponding association between admission haemoglobin concentrations and postoperative outcome and the thresholds for transfusion. Most studies report on postoperative hemoglobuline levels, where transfusion is frequently received postoperatively. EBT has paradoxical effects on the association of anemia with outcome. If hypothetically, EBT was not harmful and anemia was, transfusion would reduce mortality, but also be associated with increased mortality because of the anemia that triggered it. Unfortunately, transfusion to maintain a higher haemoglobin concentration did not reduce mortality [27].

In our study, EBT remained an independent risk for perioperative cardiac morbidity after correction for confounders. In a large RCT from Carson et al., the rates of inhospital acute coronary syndrome or death were $4.3 \%$ and $5.2 \%$, in the liberal and restrictive transfusion group respectively (absolute risk difference, $-0.9 \% ; 99 \% \mathrm{Cl}$, -3.3 to 1.6) [37]. In Potters review transfusion at $80 \mathrm{~g} / \mathrm{dl}$ vs $100 \mathrm{~g} / \mathrm{dl}$ increased acute myocardial infarction, with a relative risk of 1.67 (95\% Cl 1.01-2.77), although with $p=0.05$ and a $97.5 \%$ weight of Carson's study [27]. No strong conclusions can be drawn.

The TRIFE randomized controlled trial showed no statistically significant differences in 90-day mortality rate between the restrictive transfusion group and the liberal transfusion group, $27 \%$ vs 21\% [38]. Subgroup analysis for frail elderly from nursing homes showed equal recovery from physical disabilities but significant increased 90day mortality rate in the restrictive transfusion group (36\% vs $20 \%, \mathrm{HR}=2.0,95 \% \mathrm{Cl}$ : 
1.1-3.6; $p=0.01$ ) [38] and higher chance of postoperative delirium $21 \%$ vs $10 \%$. The presence of delirium on day 10 after surgery increased the risk of 90-day mortality, hazard ratio 3.14 (95\% Cl 1.72-5.78), p < 0.001) [39]. These findings suggest that frail elderly patients might actually benefit from a liberal transfusion trigger. Frailty is a clinical state of increased vulnerability resulting from aging-associated decline in physiologic reserves [40]. Several studies show worse postoperative outcome after hip fracture surgery for frail patients [41-43]. Anemia contributes to and is associated with reduced physiologic/homeostatic reserve, reduced function and reduced mobility [44, 45], mechanisms through which complications and mortality may be increased beyond one year postoperative. The 'frailty syndrome', consisting of sarcopenia, anorexia and declining mobility, is associated with dysregulation of pro- inflammatory pathways, increasing inflammatory markers such as IL-6, bone marrow suppression and chronic anemia [46]. EBT causes an immunological response as well, a pathway known as transfusion induced immunomodulation (TRIM) which might lead to increased susceptibility to infectious complications [4749]. Macrophages may mediate these immunosuppressive aspects of TRIM that arise as a result of EBT and their storage lesion induced by-products [50]. Another extensively studied, but rare phenomenon ( 1 in every 5000 units of packed red blood cells), is acute transfusion-related lung injury (TRALI) [51]. The diagnosis must satisfy the criteria for acute lung injury (ALI) following $\leq 6 \mathrm{hr}$ after transfusion, including (1) acute onset, (2) hypoxemic lung disease with (3) bilateral infiltrates on frontal chest radiograph, and (4) no evidence of left atrial hypertension [52].

Pre- and postoperative anemia is associated with increased mortality in a hip fracture population. Transfusion in patients treated operatively for hip fracture should be evenly matched with their cardiovascular risk during the perioperative phase. Further research should identify subgroups that may benefit from a more liberal transfusion trigger depending on their cardiac risk and frailty characteristics or a more restrictive transfusion trigger without risk for worse outcome. To determine an optimal timing of EBT could also be a topic of future research.

\section{WHAT IS THE BEST IMPLANT CHOICE FOR UNSTABLE TROCHANTERIC FRACTURES?}

Unstable trochanteric fractures can be treated with cephalomedullary nails (CMN) or extramedullary implants like Sliding Hip Screw (SHS) implants, with or without 
trochanteric support plate (TSP). According to the NICE guidelines, intramedullary fixation is the treatment of choice for subtrochanteric fractures because it allows splinting of the whole of the femoral shaft [53]. Although intramedullary nails are more expensive than extramedullary implants, they lead to fewer reoperations due to non-union [53]. A report by the Evidence-Based Working Group in Trauma concluded that failure rates of treatment of unstable subtrochanteric fractures (AO 31A3) with a sliding hip screw are too high to recommend its use [54]. Haidukewych et al. reported a failure rate of $56 \%$ when using DHS in patients with reverse oblique fractures [55]. Matre et al. compared SHS systems with intramedullary nails, involving 2716 patients with $\mathrm{AO} 31 \mathrm{A3}$ fractures from the Norwegian Hip Fracture Register. At one year, reoperation rates were $6.4 \%$ and $3.8 \%$ for SHS and IM nails, respectively $(p=0.011)$ [56]. For the challenging $A O$ type 31A2.2 and 31A2.3 there currently does not exist consensus about the best fixation method.

\section{CEPHALOMEDULLARY NAILS}

There exist a whole range of intramedullary nail types. The Gamma3 Locking Nail is a third generation Gamma nail with a self-retaining set screw, to prevent rotation and sliding of the lag screw. The Proximal Femoral Nail (PFN) is a dual lag screw system designed to prevent rotation and provide more strength. The inferior lag screw is able to compress the fracture. Another nail, the Proximal Femoral Nail Antirotation (PFNA), differs in design by having a single proximal blade. The PFNA blade compacts the cancellous bone at insertion, providing additional anchoring. The Intertan is a fourth-generation trapezoidal shaped nail with two proximal lags screws that interlock with each other to provide rotational stability and achieving primary compression at fracture site at insertion. Biomechanical studies have shown that the Intertan is almost twice as strong as contemporary nails, with load to failure noted at around 8000 Newton with ideally positioned lag screw, and 6000 Newton for a decentralized position [57].

An RCT from Xu et al. compared the use of PFNA and Gamma3 nail in unstable trochanteric fractures concluded no differences in clinical outcome [58]. Simmermacher et al. showed in a large cohort of 315 patients with unstable fractures treated with PFNA a reoperation rate of 9\% [59]. Another study randomized 210 patients with AO31-A2 fractures between a long gamma nail and DHS and found no difference in clinical outcome, re-operation rates were $3 \%$ and $2 \%$ respectively.

Ekström et al. compared the PFN (short nail) with the Medoff sliding plate (MSP) in an 
RCT and found no statistical difference in functional outcome or major complications for unstable trochanteric and subtrochanteric fractures. Reoperations were more frequent in the PFN group (9\%) compared to the MSP group (1\%; $\mathrm{P}<0.02)[60]$.

One unique problem with dual lag screw implants is the Z-effect $[61,62]$. The Z-effect phenomenon describes the appearance of a lateral migration of the inferior lag screw and medial migration of the superior lag screw during the weight bearing rehabilitation period. The reversed Z-effect describes the opposite effect: migration of the inferior lag screw medially and the superior lag screw laterally. Koyuncu et al. reports $17.7 \%$ late complications in 152 patients treated with PFN with a reoperation rate of $9.3 \%$ (due to $Z$-effect $n=3$, reverse $Z$-effect $n=2$ and screw cutouts $n=4)$ [63].

In chapter 6 we have demonstrated an incidence of $9 \%(n=80)$ Z-effect after dual lag screw nails systems. Migration of lag screws $(p \leq 0.009)$ and unstable fracture type $(p<0.05)$, were risk factors for re-operation. The re-operation rate within 2 years after surgery was $21 \%$, of which one fourth was due to a Z-effect. The majority of studies report Z-effect incidences only and have a limited follow-up. The development of the Intertan nail brought a solution to the Z-effect phenomenon and showed reliable outcome. In a meta-analysis the Intertan nail was compared with Gamma nail or PFNA. Intertan showed similar results regarding functional recovery, blood loss, postoperative complications and hospital stay, but significantly less implant cut-out and femoral fractures [64]. Surgery time was significantly increased by the Intertan in comparison with Gammanail or PFNA by approximately $10 \mathrm{~min}$. In a pair matched comparative study a significant higher incidence of cut-out (5.7\% vs $1.1 \%, p=0.02$ ) and femoral shaft fracture ( $8 \%$ vs $1.1 \%, p=0.04$ ) was found in the Gamma3 nail group ( $n=174)$ in comparison with the Intertan $(n=87)$ [65]. Reoperation rates within 1 year were $2.9 \%$ vs $2.3 \%$ respectively (non-significant).

\section{SLIDING HIP SCREW}

Sliding hip screws are extramedullary implants that allows controlled dynamic sliding of the femoral head component along the construct. Biomechanical studies have shown less rigidity when unstable fractures were fixed with DHS and constructs failed earlier with cyclical loading [66, 67]. Tucker et al. investigated 3230 patients with unstable trochanteric fractures treated with CMN, DHS and DHS + TSP [68]. The overall revision rate for the DHS group was $4.04 \%$, compared to DHS + TSP $2.53 \%$ and CMN 2.34\%. The DHS + TSP group experienced a significant increased 
duration of hospital stay and higher 1-year mortality rates. Functional outcomes were equivalent between $\mathrm{CMN}$ and DHS [68]. The authors questioned if the best plate was a nail.

$\mathrm{Xu}$ et al. randomized PFNA and DHS for unstable trochanteric fractures. The PFNA allowed earlier mobilization and faster recovery than the DHS. No significant differences were found for postoperative complications or re-operation rates due to sample size $(n=106)$ and loss to follow-up $(n=23)$ [69]. Another RCT showed a significant lower mean operative time in the PFNA group in comparison with the DHS group, a shorter fluoroscopy time and less blood loss [70]. 6/39 (15\%) of patients in DHS group had implant failure while 0/42 experienced this in PFNA group. The PFNA group had a better functional outcome than the DHS group. A prospective randomized comparative study of PFNA vs. DHS found similar complication rates, mean tip-apex distances and screw cut-out $(7.8 \%$ vs $7.3 \%, p=0.88)$ but better recovery in the PFNA group [71]

\section{CONCLUSIONS}

To choose the best implant for unstable trochanteric fractures ( $\mathrm{AO}$ type 31A2.2 and 31A2.3), patient, fracture and implant factors as well as surgical factors like the surgeon's experience and preferred type of implant should be taken in account. Differences between implants from trials are sometimes small and in experts hands they could become clinically less relevant. Individual RCT's show plausible advantages for different types of intramedullary implants over SHS in the treatment of unstable trochanteric fractures. More randomized controlled trials with longterm follow-up are warranted to compare recent dual lag screw systems with other fixation types to conclude what osteosynthesis is ultimately preferable for unstable type trochanteric fractures. 


\section{REFERENCES}

1. Parker MJ: Missed hip fractures. Arch Emerg Med 1992, 9(1):23-27.

2. Perron $\mathrm{AD}$, Miller $\mathrm{MD}$, Brady WJ: Orthopedic pitfalls in the ED: radiographically occult hip fracture. Am J Emerg Med 2002, 20(3):234-237.

3. Dominguez S, Liu P, Roberts C, Mandell M, Richman PB: Prevalence of traumatic hip and pelvic fractures in patients with suspected hip fracture and negative initial standard radiographs--a study of emergency department patients. Academic emergency medicine : official journal of the Society for Academic Emergency Medicine 2005, 12(4):366-369.

4. Gill SK, Smith J, Fox R, Chesser TJ: Investigation of occult hip fractures: the use of CT and MRI. TheScientificWorldJournal 2013, 2013:830319.

5. Clough TM: Femoral neck stress fracture: the importance of clinical suspicion and early review. Br J Sports Med 2002, 36(4):308-309.

6. Tiru M, Goh SH, Low BY: Use of percussion as a screening tool in the diagnosis of occult hip fractures. Singapore Med J 2002, 43(9):467-469.

7. Jettoo P, Kakwani R, Junejo S, Talkhani I, Dixon P: Pre-operative echocardiogram in hip fracture patients with cardiac murmur--an audit. $J$ Orthop Surg Res 2011, 6:49.

8. Alibhai M, Sharma A, Alibhai MK, Fawdington RA, Moreau AP: Does preoperative echocardiography delay hip fracture surgery? Indian J Anaesth 2013, 57(4):408-410.

9. Sawhney C, Trikha V, Janani S, Bajwa SJS, Sharma V, Khanna M: Impact of Preoperative Echocardiography on Perioperative Management in Geriatric Hip Trauma: A Retrospective Observational Study. Int J Appl Basic Med Res 2017, 7(2):104-107.

10. Marcantonio A, Steen B, Kain M, Bramlett KJ, Tilzey JF, Iorio R: The Clinical and Economic Impact of Preoperative Transthoracic Echocardiography in Elderly Patients with Hip Fractures. Bull Hosp Jt Dis (2013) 2015, 73(4):239242.

11. O'HEireamhoin S, Beyer T, Ahmed M, Mulhall KJ: The role of preoperative cardiac investigation in emergency hip surgery. J Trauma 2011, 71(5):13451347.

12. Stitgen A, Poludnianyk K, Dulaney-Cripe E, Markert R, Prayson M: Adherence to Preoperative Cardiac Clearance Guidelines in Hip Fracture Patients. J Orthop Trauma 2015, 29(11):500-503.

13. Mutlu H, Bilgili F, Mutlu S, Karaman O, Cakal B, Ozkaya U: The effects of preoperative non-invasive cardiac tests on delay to surgery and subsequent mortality in elderly patients with hip fracture. J Back Musculoskelet Rehabil 2016, 29(1):49-54.

14. Smeets SJ, Poeze M, Verbruggen JP: Preoperative cardiac evaluation of geriatric patients with hip fracture. Injury 2012, 43(12):2146-2151. 
15. Heyburn G, McBrien ME: Pre-operative echocardiography for hip fractures: time to make it a standard of care. Anaesthesia 2012, 67(11):1189-1193.

16. Canty DJ, Royse CF, Kilpatrick D, Bowyer A, Royse AG: The impact on cardiac diagnosis and mortality of focused transthoracic echocardiography in hip fracture surgery patients with increased risk of cardiac disease: a retrospective cohort study. Anaesthesia 2012, 67(11):1202-1209.

17. Luttrell K, Nana A: Effect of Preoperative Transthoracic Echocardiogram on Mortality and Surgical Timing in Elderly Adults with Hip Fracture. J Am Geriatr Soc 2015, 63(12):2505-2509.

18. Loxdale SJ, Sneyd JR, Donovan A, Werrett G, Viira DJ: The role of routine pre-operative bedside echocardiography in detecting aortic stenosis in patients with a hip fracture. Anaesthesia 2012, 67(1):51-54.

19. Leibowitz D, Rivkin G, Schiffman J, Rott D, Weiss AT, Mattan Y, Kandel $L$ : Effect of severe aortic stenosis on the outcome in elderly patients undergoing repair of hip fracture. Gerontology 2009, 55(3):303-306.

20. McBrien ME, Heyburn G, Stevenson M, McDonald S, Johnston NJ, Elliott JR, Beringer TR: Previously undiagnosed aortic stenosis revealed by auscultation in the hip fracture population--echocardiographic findings, management and outcome. Anaesthesia 2009, 64(8):863-870.

21. Association of Anaesthetists of Great B, Ireland, Griffiths R, Alper J, Beckingsale A, Goldhill D, Heyburn G, Holloway J, Leaper E, Parker M et al.: Management of proximal femoral fractures 2011: Association of Anaesthetists of Great Britain and Ireland. Anaesthesia 2012, 67(1):85-98.

22. Kumar D, Mbako AN, Riddick A, Patil S, Williams P: On admission haemoglobin in patients with hip fracture. Injury 2011, 42(2):167-170.

23. Foss NB, Kehlet H: Hidden blood loss after surgery for hip fracture. J Bone Joint Surg Br 2006, 88(8):1053-1059.

24. Guo WJ, Wang JQ, Zhang WJ, Wang WK, Xu D, Luo P: Hidden blood loss and its risk factors after hip hemiarthroplasty for displaced femoral neck fractures: a cross-sectional study. Clin Interv Aging 2018, 13:1639-1645.

25. Adunsky A, Lichtenstein A, Mizrahi E, Arad M, Heim M: Blood transfusion requirements in elderly hip fracture patients. Arch Gerontol Geriatr 2003, 36(1):75-81.

26. Dillon MF, Collins D, Rice J, Murphy PG, Nicholson P, Mac Elwaine J: Preoperative characteristics identify patients with hip fractures at risk of transfusion. Clin Orthop Relat Res 2005, 439:201-206.

27. Potter LJ, Doleman B, Moppett IK: A systematic review of pre-operative anaemia and blood transfusion in patients with fractured hips. Anaesthesia 2015, 70(4):483-500.

28. Bhaskar D, Parker MJ: Haematological indices as surrogate markers of factors affecting mortality after hip fracture. Injury 2011, 42(2):178-182.

29. Bjorkelund KB, Hommel A, Thorngren KG, Lundberg D, Larsson S: The 
influence of perioperative care and treatment on the 4-month outcome in elderly patients with hip fracture. AANA J 2011, 79(1):51-61.

30. Gruson KI, Aharonoff GB, Egol KA, Zuckerman JD, Koval KJ: The relationship between admission hemoglobin level and outcome after hip fracture. J Orthop Trauma 2002, 16(1):39-44.

31. Hagino T, Ochiai S, Sato E, Maekawa S, Wako M, Haro H: The relationship between anemia at admission and outcome in patients older than 60 years with hip fracture. J Orthop Traumatol 2009, 10(3):119-122.

32. Halm EA, Wang JJ, Boockvar K, Penrod J, Silberzweig SB, Magaziner J, Koval KJ, Siu AL: The effect of perioperative anemia on clinical and functional outcomes in patients with hip fracture. J Orthop Trauma 2004, 18(6):369-374.

33. Jiang HX, Majumdar SR, Dick DA, Moreau M, Raso J, Otto DD, Johnston DW: Development and initial validation of a risk score for predicting inhospital and 1-year mortality in patients with hip fractures. J Bone Miner Res 2005, 20(3):494-500.

34. Maxwell MJ, Moran CG, Moppett IK: Development and validation of a preoperative scoring system to predict 30 day mortality in patients undergoing hip fracture surgery. Br J Anaesth 2008, 101(4):511-517.

35. Mosfeldt M, Pedersen OB, Riis T, Worm HO, Mark S, Jorgensen HL, Duus BR, Lauritzen JB: Value of routine blood tests for prediction of mortality risk in hip fracture patients. Acta Orthop 2012, 83(1):31-35.

36. Vochteloo AJ, Borger van der Burg BL, Mertens B, Niggebrugge AH, de Vries MR, Tuinebreijer WE, Bloem RM, Nelissen RG, Pilot P: Outcome in hip fracture patients related to anemia at admission and allogeneic blood transfusion: an analysis of 1262 surgically treated patients. BMC Musculoskelet Disord 2011, 12:262.

37. Carson JL, Terrin ML, Noveck H, Sanders DW, Chaitman BR, Rhoads GG, Nemo G, Dragert K, Beaupre L, Hildebrand K et al.: Liberal or restrictive transfusion in high-risk patients after hip surgery. N Engl J Med 2011, 365(26):2453-2462.

38. Gregersen M, Borris LC, Damsgaard EM: Postoperative blood transfusion strategy in frail, anemic elderly patients with hip fracture: the TRIFE randomized controlled trial. Acta Orthop 2015, 86(3):363-372.

39. Blandfort S, Gregersen M, Borris LC, Damsgaard EM: Blood transfusion strategy and risk of postoperative delirium in nursing homes residents with hip fracture. A post hoc analysis based on the TRIFE randomized controlled trial. Aging Clin Exp Res 2017, 29(3):459-466.

40. Xue QL: The frailty syndrome: definition and natural history. Clin Geriatr Med 2011, 27(1):1-15.

41. Dayama A, Olorunfemi O, Greenbaum S, Stone ME, Jr., McNelis J: Impact of frailty on outcomes in geriatric femoral neck fracture management: An 
analysis of national surgical quality improvement program dataset. Int $\mathrm{J}$ Surg 2016, 28:185-190.

42. Dwyer JG, Reynoso JF, Seevers GA, Schmid KK, Muralidhar P, Konigsberg B, Lynch TG, Johanning JM: Assessing preoperative frailty utilizing validated geriatric mortality calculators and their association with postoperative hip fracture mortality risk. Geriatr Orthop Surg Rehabil 2014, 5(3):109-115.

43. Kistler EA, Nicholas JA, Kates SL, Friedman SM: Frailty and Short-Term Outcomes in Patients With Hip Fracture. Geriatr Orthop Surg Rehabil 2015, 6(3):209-214.

44. Foss NB, Kristensen MT, Kehlet H: Anaemia impedes functional mobility after hip fracture surgery. Age Ageing 2008, 37(2):173-178.

45. Lawrence VA, Silverstein JH, Cornell JE, Pederson T, Noveck H, Carson JL: Higher $\mathrm{Hb}$ level is associated with better early functional recovery after hip fracture repair. Transfusion 2003, 43(12):1717-1722.

46. Roy CN: Anemia in frailty. Clin Geriatr Med 2011, 27(1):67-78.

47. Raghavan M, Marik PE: Anemia, allogenic blood transfusion, and immunomodulation in the critically ill. Chest 2005, 127(1):295-307.

48. Blajchman MA: Transfusion immunomodulation or TRIM: what does it mean clinically? Hematology 2005, 10 Suppl 1:208-214.

49. Vamvakas EC, Carven JH: Allogeneic blood transfusion and postoperative duration of mechanical ventilation. Transfusion 2001, 41(7):885-892.

50. Youssef LA, Spitalnik SL: Transfusion-related immunomodulation: a reappraisal. Curr Opin Hematol 2017, 24(6):551-557.

51. Cho MS, Sharma S: Transfusion-related Acute Lung Injury (TRALI). In: StatPearls. edn. Treasure Island (FL); 2018.

52. Bernard GR, Artigas A, Brigham KL, Carlet J, Falke K, Hudson L, Lamy M, Legall JR, Morris A, Spragg R: The American-European Consensus Conference on ARDS. Definitions, mechanisms, relevant outcomes, and clinical trial coordination. Am J Respir Crit Care Med 1994, 149(3 Pt 1):818824.

53. Ftouh S, Morga A, Swift C, Guideline Development G: Management of hip fracture in adults: summary of NICE guidance. BMJ 2011, 342:d3304.

54. Kregor PJ, Obremskey WT, Kreder HJ, Swiontkowski MF: Unstable pertrochanteric femoral fractures. J Orthop Trauma 2014, 28 Suppl 8:S2528.

55. Haidukewych GJ, Israel TA, Berry DJ: Reverse obliquity fractures of the intertrochanteric region of the femur. J Bone Joint Surg Am 2001, 83A(5):643-650.

56. Matre K, Havelin LI, Gjertsen JE, Vinje T, Espehaug B, Fevang JM: Sliding hip screw versus IM nail in reverse oblique trochanteric and subtrochanteric fractures. A study of 2716 patients in the Norwegian Hip Fracture Register. Injury 2013, 44(6):735-742. 
57. Nuchtern JV, Ruecker AH, Sellenschloh K, Rupprecht M, Puschel K, Rueger JM, Morlock MM, Lehmann W: Malpositioning of the lag screws by 1- or 2-screw nailing systems for pertrochanteric femoral fractures: a biomechanical comparison of gamma 3 and intertan. J Orthop Trauma 2014, 28(5):276-282.

58. Xu Y, Geng D, Yang H, Wang X, Zhu G: Treatment of unstable proximal femoral fractures: comparison of the proximal femoral nail antirotation and gamma nail 3. Orthopedics 2010, 33(7):473.

59. Simmermacher RK, Ljungqvist J, Bail H, Hockertz T, Vochteloo AJ, Ochs $\mathrm{U}$, Werken C, studygroup AP: The new proximal femoral nail antirotation (PFNA) in daily practice: results of a multicentre clinical study. Injury 2008, 39(8):932-939.

60. EkstromW, Karlsson-Thur C, LarssonS, Ragnarsson B, Alberts KA: Functional outcome in treatment of unstable trochanteric and subtrochanteric fractures with the proximal femoral nail and the Medoff sliding plate. J Orthop Trauma 2007, 21(1):18-25.

61. Pires RE, Santana EO, Jr., Santos LE, Giordano V, Balbachevsky D, Dos Reis FB: Failure of fixation of trochanteric femur fractures: Clinical recommendations for avoiding Z-effect and reverse Z-effect type complications. Patient Saf Surg 2011, 5:17.

62. Strauss EJ, Kummer FJ, Koval KJ, Egol KA: The "Z-effect" phenomenon defined: a laboratory study. J Orthop Res 2007, 25(12):1568-1573.

63. Koyuncu S, Altay T, Kayali C, Ozan F, Yamak K: Mechanical failures after fixation with proximal femoral nail and risk factors. Clin Interv Aging 2015, 10:1959-1965.

64. Ma JX, Kuang MJ, Fan ZR, Xing F, Zhao YL, Zhang LK, Chen HT, Han C, Ma XL: Comparison of clinical outcomes with InterTan vs Gamma nail or PFNA in the treatment of intertrochanteric fractures: A meta-analysis. Sci Rep 2017, 7(1):15962.

65. Wu D, Ren G, Peng C, Zheng X, Mao F, Zhang Y: InterTan nail versus Gamma3 nail for intramedullary nailing of unstable trochanteric fractures. Diagn Pathol 2014, 9:191.

66. Friedl W, Clausen J: [Experimental examination for optimized stabilisation of trochanteric femur fractures, intra- or extramedullary implant localisation and influence of femur neck component profile on cut-out risk]. Chirurg 2001, 72(11):1344-1352.

67. Weiser L, Ruppel AA, Nuchtern JV, Sellenschloh K, Zeichen J, Puschel K, Morlock MM, Lehmann W: Extra- vs. intramedullary treatment of pertrochanteric fractures: a biomechanical in vitro study comparing dynamic hip screw and intramedullary nail. Arch Orthop Trauma Surg 2015, 135(8):1101-1106.

68. Tucker A, Donnelly KJ, Rowan C, McDonald S, Foster AP: Is the best plate 
a nail? A review of 3230 unstable intertrochanteric fractures of the proximal femur. J Orthop Trauma 2017.

69. Xu YZ, Geng DC, Mao HQ, Zhu XS, Yang HL: A comparison of the proximal femoral nail antirotation device and dynamic hip screw in the treatment of unstable pertrochanteric fracture. J Int Med Res 2010, 38(4):1266-1275.

70. Garg B, Marimuthu K, Kumar V, Malhotra R, Kotwal PP: Outcome of short proximal femoral nail antirotation and dynamic hip screw for fixation of unstable trochanteric fractures. A randomised prospective comparative trial. Hip Int 2011, 21(5):531-536.

71. Zehir S, Zehir R, Zehir S, Azboy I, Haykir N: Proximal femoral nail antirotation against dynamic hip screw for unstable trochanteric fractures; a prospective randomized comparison. Eur J Trauma Emerg Surg 2015, 41(4):393-400. 
. 
CHAPTER

Appendices 


\section{ACC/AHA APPENDICES}

The American College of Cardiology \& American Heart Association guidelines for non-cardiac surgery. The most relevant findings from the 2007 and updated 2014 ACC/AHA guidelines regarding hipw fracture surgery are stated here [1, 2]. A stepwise approach for cardiac evaluation for non-cardiac surgery is explained and presented below (figure 1). At the end of these appendices the level of evidence table is shown (LOE, figure 2).

Step 1: In patients scheduled for non cardiac surgery with risk factors for or known $C A D$, determine the urgency of surgery. If an emergency, then determine the clinical risk factors that may influence perioperative management and proceed to surgery with appropriate monitoring and management strategies based on the clinical assessment.

Step 2: If the surgery is urgent or elective, determine if the patient has an acute coronary syndrome (ACS). Hip fracture surgery is considered urgent surgery that should take place <24hours. If yes, then refer patient for cardiology evaluation and management according to guideline-directed medical therapy (GDMT) to represent recommended medical therapy as defined mainly by Class I measures. GDMT according to the unstable angina (UA) or (non-)ST-elevation myocardial infarction (NSTEMI and STEMI) guidelines $[3,4]$.

Step 3: If the patient has risk factors for stable CAD, then estimate the perioperative risk of Major Adverse Cardiac Events (MACE) on the basis of the combined clinical/ surgical risk. This estimate can use the American College of Surgeons National Surgical Quality Improvement Program ${ }^{\circledR}$ risk calculator (NSQIP, http://www. riskcalculator.facs.org) or incorporate the Revised Cardiac Risk Index (RCRI) [5] with an estimation of surgical risk.

Step 4: If the patient has a low risk of MACE $(<1 \%)$, then no further testing is needed, and the patient may proceed to surgery.

Step 5: If the patient is at elevated risk of MACE, then determine functional capacity with an objective measure or scale such as the Duke Activity Status Index (DASI, see table 1) [6]. If the patient has moderate, good, or excellent functional capacity ( $\geq 4$ MET's, Metabolic Equivalent of Task), then proceed to surgery without further evaluation. 


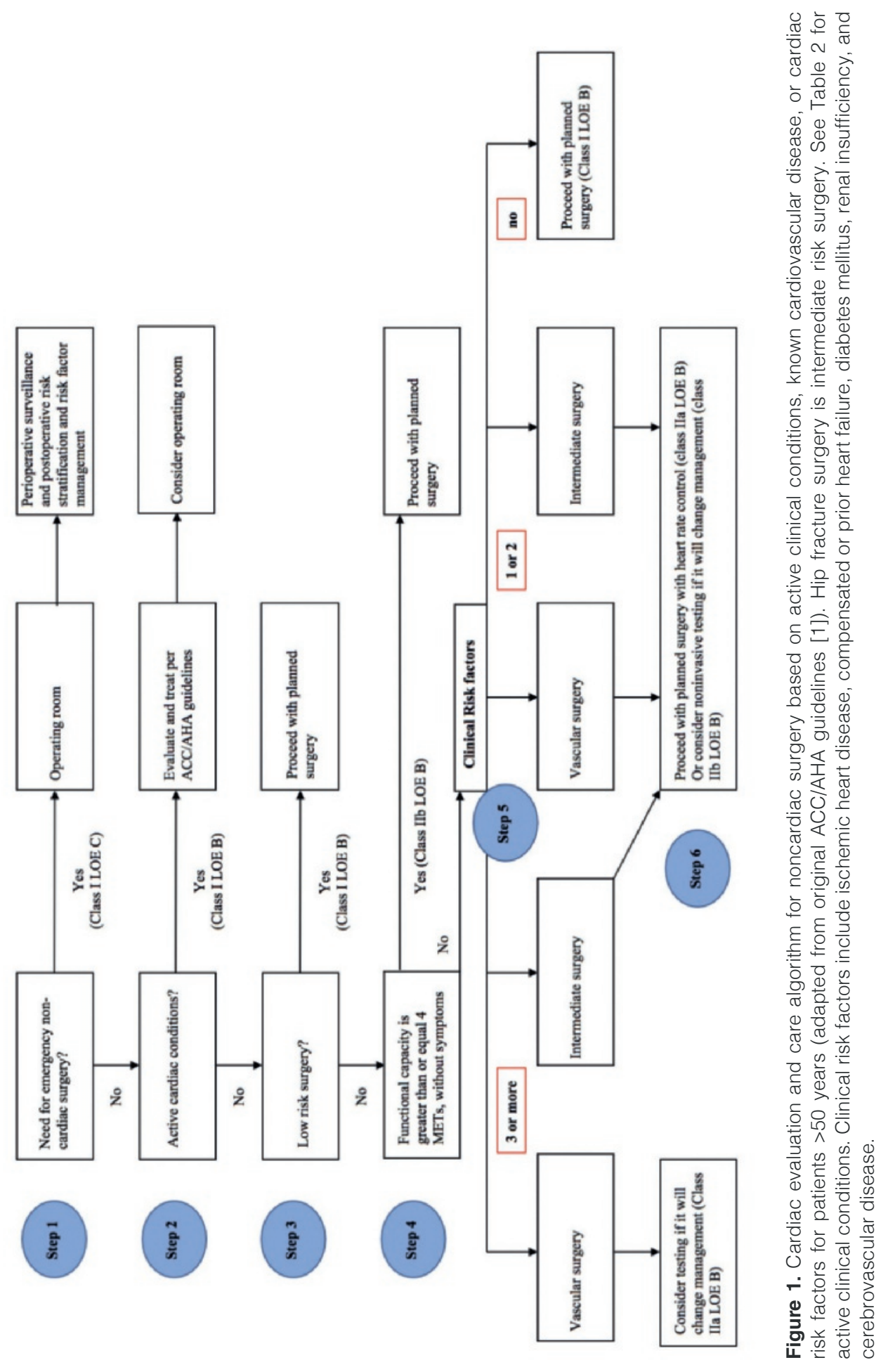


Step 6: If the patient has poor (<4 METs) or unknown functional capacity, then the clinician should consult with the patient and perioperative team to determine whether further testing will impact patient decision making or perioperative care (eg, non invasive testing with transthoracic echocardiography (TTE) or the decision to perform original surgery or willingness to undergo pharmacological stress testing, coronary artery bypass graft (CABG) or percutaneous coronary intervention (PCI)).

Step 7: If testing will not impact decision making or care, then proceed to surgery according to GDMT or consider alternative strategies, such as conservative treatment or palliation.

Table 1. Estimated energy requirements for various activities, Metabolic Equivalent of Task (MET's)

Can you...

Can you...

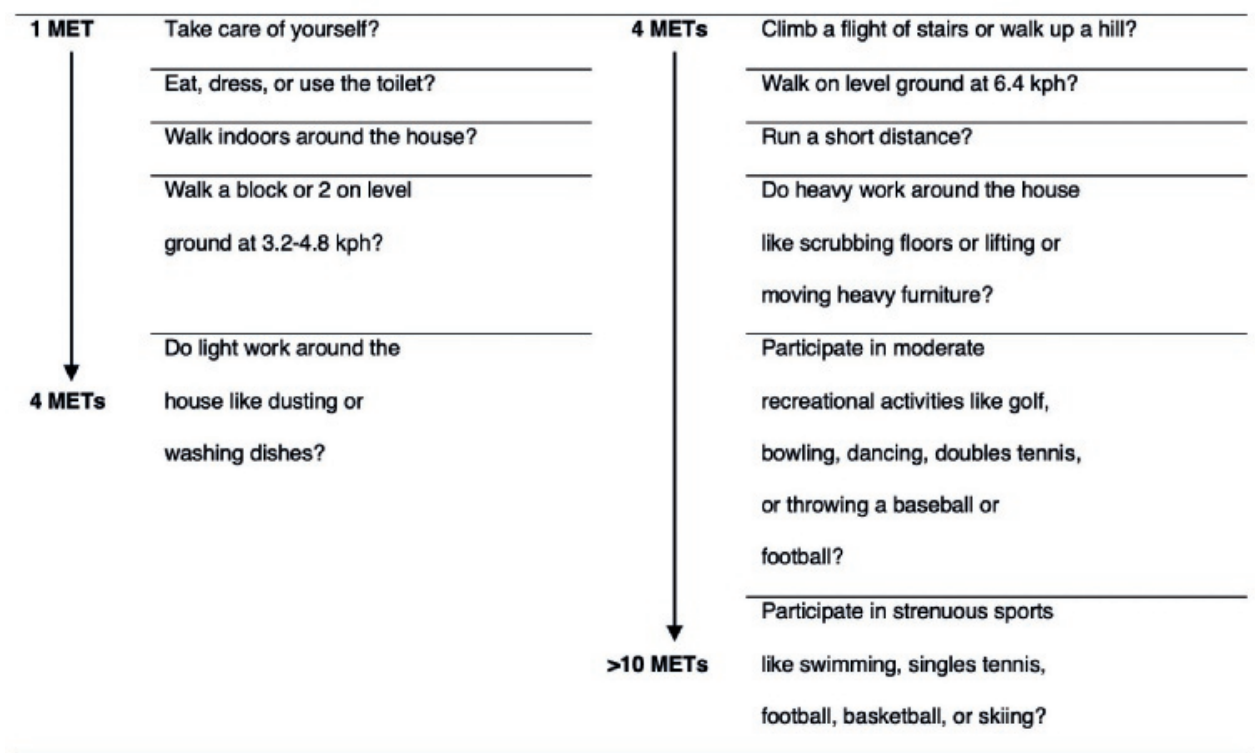

kph indicates kilometers per hour 
Table 2. The American College of Cardiology/American Heart Association clinical predictors for each each risk group

Low Risk

\begin{tabular}{ccc}
\hline Advanced age & Mild angina pectoris & $\begin{array}{c}\text { Unstable coronary } \\
\text { syndromes }\end{array}$ \\
Abnormal ECG & Prior myocardial infarction & $\begin{array}{c}\text { Decompensated cardiac } \\
\text { heart failure }\end{array}$ \\
Rhythm other than sinus & $\begin{array}{c}\text { Compensated or prior } \\
\text { cardiac heart failure }\end{array}$ & Significant arrhythmias \\
History of stroke & Diabetes Mellitus & Severe valvular disease \\
Uncontrolled & & \\
hypertension & &
\end{tabular}

Table 3. Active cardiac conditions for which the patient should undergo evaluation and treatment before non-cardiac surgery (Class I, Level of Evidence: B)

\begin{tabular}{l|l}
\multicolumn{1}{c|}{ Condition } & \multicolumn{1}{c}{ Examples } \\
\hline Unstable coronary syndromes & $\begin{array}{l}\text { Unstable or severe angina (CCS class III or IV) } \\
\text { Recent Myocardial Infarction* }\end{array}$ \\
\hline $\begin{array}{l}\text { Decompensated Heart Failure (NYHA class IV, } \\
\text { worsening or new onset) }\end{array}$ & $\begin{array}{l}\text { High grade atrioventricular block } \\
\text { Mobitz Il atrioventricular block }\end{array}$ \\
\hline Significant arrhythmias & $\begin{array}{l}\text { 3rd degree atrioventricular heart block } \\
\text { Symptomatic ventricular arrhythmias } \\
\text { Supraventricular arrhythmias (including atrial } \\
\text { fibrillation), with uncontrolled ventricular rate } \\
\text { greater than } 100 \text { beats per minute at rest } \\
\text { Symptomatic bradycardia }\end{array}$ \\
Sew recognized ventricular tachycardia \\
\hline Severe valvular disease & $\begin{array}{l}\text { Severe aortic stenosis (mean pressure gradient } \\
\text { greater than 40mm Hg, aortic valve area <1cm², } \\
\text { or symptomatic) } \\
\text { Symptomatic mitral stenosis (progressive } \\
\text { dyspnea on exertion, exertional presyncope, or } \\
\text { Heart Failure }\end{array}$ \\
\hline
\end{tabular}

CCS Canadian Cardiovascular Society (CSS) functional classification for Angina. NYHA New York Heart Association for Heart Failure. ${ }^{*}$ The American College of Cardiology National Database Library defines recent $\mathrm{Ml}$ as more than 7 days but less than or equal to 1 month (within 30 days). 
RECOMMENDATIONS FOR PERIOPERATIVE CARDIAC ASSESSMENT REGARDING HIP FRACTURE SURGERY

(Considered intermediate risk surgery with urgent indication <24hr)

Class I recommendations (figure 2). Patients with active cardiac conditions (table 3) should be evaluated and treated per ACC/AHA guidelines and, if appropriate, consider proceeding to the operating room. Level of Evidence: B.

Patients with poor (less than 4 METs) or unknown functional capacity and no clinical risk factors (table 2) should proceed with planned surgery (figure 1). Level of Evidence: B.

Class lla recommendations (figure 2). It is probably recommended that patients with functional capacity greater than or equal to 4 METs without symptoms (table 1) proceed to planned surgery (figure 1). Level of Evidence: B.

It is probably recommended that patients with poor (less than 4 METs) or unknown functional capacity and 3 or more clinical risk factors (table 2), who are scheduled for intermediate risk surgery proceed with planned surgery with heart rate control (figure 1). Level of Evidence: B.

Class Ilb recommendations (figure 2). Noninvasive testing might be considered if it will change management for patients with poor (less than 4 METs) or unknown functional capacity and 3 or more clinical risk factors (table 2) who are scheduled for intermediate risk surgery (figure 1). Level of Evidence: B.

Noninvasive testing might be considered if it will change management for patients with poor (less than 4 METs) or unknown functional capacity and 1 or 2 clinical risk factors (table 2) who are scheduled for vascular or intermediate risk surgery (figure 1). Level of Evidence: B. 
SIZE OF TREATMENT EFFECT

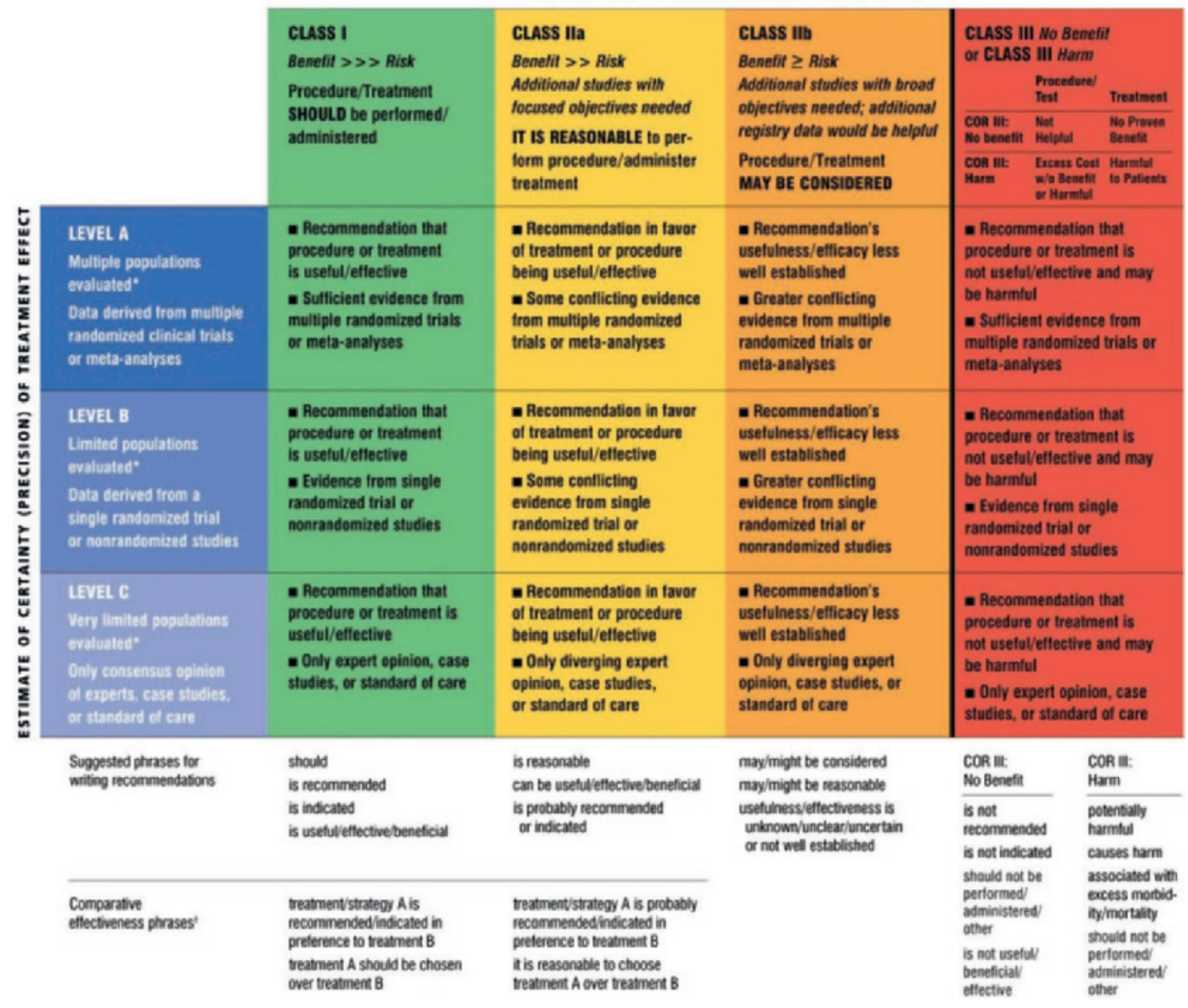

Figure 1. Level of recommendations ACC/AHA guidelines 2014. 


\section{REFERENCES}

1. Fleisher LA, Beckman JA, Brown KA, Calkins $H$, Chaikof E, Fleischmann KE, Freeman WK, Froehlich JB, Kasper EK, Kersten JR et al.: ACC/AHA 2007 guidelines on perioperative cardiovascular evaluation and care for noncardiac surgery: a report of the American College of Cardiology/American Heart Association Task Force on Practice Guidelines (Writing Committee to Revise the 2002 Guidelines on Perioperative Cardiovascular Evaluation for Noncardiac Surgery): developed in collaboration with the American Society of Echocardiography, American Society of Nuclear Cardiology, Heart Rhythm Society, Society of Cardiovascular Anesthesiologists, Society for Cardiovascular Angiography and Interventions, Society for Vascular Medicine and Biology, and Society for Vascular Surgery. Circulation 2007, 116(17):e418-499.

2. Fleisher LA, Fleischmann KE, Auerbach AD, Barnason SA, Beckman JA, Bozkurt B, Davila-Roman VG, Gerhard-Herman MD, Holly TA, Kane GC et al.: 2014 ACC/AHA guideline on perioperative cardiovascular evaluation and management of patients undergoing noncardiac surgery: executive summary: a report of the American College of Cardiology/American Heart Association Task Force on practice guidelines. Developed in collaboration with the American College of Surgeons, American Society of Anesthesiologists, American Society of Echocardiography, American Society of Nuclear Cardiology, Heart Rhythm Society, Society for Cardiovascular Angiography and Interventions, Society of Cardiovascular Anesthesiologists, and Society of Vascular Medicine Endorsed by the Society of Hospital Medicine. Journal of nuclear cardiology : official publication of the American Society of Nuclear Cardiology 2015, 22(1):162215.

3. O'Gara PT, Kushner FG, Ascheim DD, Casey DE, Jr., Chung MK, de Lemos JA, Ettinger SM, Fang JC, Fesmire FM, Franklin BA et al.: 2013 ACCF/ AHA guideline for the management of ST-elevation myocardial infarction: executive summary: a report of the American College of Cardiology Foundation/American Heart Association Task Force on Practice Guidelines: developed in collaboration with the American College of Emergency Physicians and Society for Cardiovascular Angiography and Interventions. Catheterization and cardiovascular interventions : official journal of the Society for Cardiac Angiography \& Interventions 2013, 82(1):E1-27.

4. Jneid H, Anderson JL, Wright RS, Adams CD, Bridges CR, Casey DE, Jr., Ettinger SM, Fesmire FM, Ganiats TG, Lincoff AM et al.: 2012 ACCF/ AHA focused update of the guideline for the management of patients with unstable angina/non-ST-elevation myocardial infarction (updating the 2007 guideline and replacing the 2011 focused update): a report of the American College of Cardiology Foundation/American Heart Association Task Force on Practice Guidelines. Journal of the American College of Cardiology 2012, 60(7):645-681.

5. Ford MK, Beattie WS, Wijeysundera DN: Systematic review: prediction of 
perioperative cardiac complications and mortality by the revised cardiac risk index. Annals of internal medicine 2010, 152(1):26-35.

6. Hlatky MA, Boineau RE, Higginbotham MB, Lee KL, Mark DB, Califf RM, Cobb FR, Pryor DB: A brief self-administered questionnaire to determine functional capacity (the Duke Activity Status Index). The American journal of cardiology 1989, 64(10):651-654. 


\section{NEDERLANDSE SAMENVATTING}

Dit proefschrift beschrijft verschillende klinische studies rond de perioperatieve zorg voor ouderen met een heupfractuur. Dit betreft een kwetsbare patiëntenpopulatie met dikwijls veel comorbiditeit en polyfarmacie. De gevolgen van een heupfractuur zijn ernstig. Er bestaat een grote kans op complicaties en overlijden na de operatie. Tevens komen veel patiënten niet meer terug op hun oude niveau van functioneren.

Hoofdstuk 2 richt zich op de preoperatieve fase. Een typische heupfractuur patiënt heeft een adequaat trauma gehad, pijn ter hoogte van de heup-lies regio, kan niet belasten en heeft een bewegingsbeperking. Om een heupfractuur te diagnosticeren worden röntgenfoto's gemaakt (anteroposterieure en laterale opname). Echter bekend is dat 2-10\% van de heupfracturen gemist worden op een reguliere röntgenfoto. Dit noemt men een occulte heupfractuur. Het lichamelijk onderzoek, de mogelijkheid tot belasten van de heup, de subjectieve pijnbeleving van de patiënt en het 'onderbuikgevoel' van de arts bepalen of er bij een verdenking op een occulte heupfractuur een CT of MRI-scan gemaakt wordt. Er bestaan geen klinische beslisregels die bepalen welk vervolgonderzoek, wanneer geïndiceerd is. Gemiste heupfracturen lopen de kans op secundaire dislocatie en avasculaire necrose van de heup kop door de vertraging in de behandeling. In dit hoofdstuk behandelen we het gebruik van de Patella Pubis Percussie Test (PPPT) om te kijken of deze betrouwbaar is om zowel standaard heupfracturen als occulte fracturen te diagnosticeren. De PPPT wordt uitgevoerd door met de vinger op de knieschijf te kloppen, terwijl met een stethoscoop op het schaambeen geluisterd wordt. Beide benen worden achtereenvolgens met elkaar vergeleken. Een duidelijk verschil is te horen in botgeleiding in het geval van een fractuur. 191 patiënten met een verdenking heupfractuur, werden op de spoedeisende hulp (SEH) onderzocht met de PPPT door twee geblindeerde onderzoekers, voordat er een röntgenfoto gemaakt werd. Dit leverde bij 161 patiënten (84\%) een fractuur op (heup $n=142$, bekken $\mathrm{n}=19$ ). De PPPT heeft een sensitiviteit van $85 \%$, een specificiteit van $70 \%$, een 0,94 positief voorspellende waarde en een 0,47 negatief voorspellende waarde. De interobserver betrouwbaarheid is goed (kappa=0,7). $11 \mathrm{CT}$-scans werden verricht wegens een 'mismatch' tussen uitkomst PPPT (positief) en röntgenfoto (negatief) en leverde 8 aanvullende fracturen op (73\%). Een multivariate analyse toonde dat een pijnlijk passief bewegingsonderzoek en de PPPT voorspellende onderzoeken zijn voor een heupfractuur. De PPPT kan behulpzaam zijn in de beslisvorming tot aanvullende beeldvorming bij de verdenking op een occulte heupfractuur. 
Hoofdstuk 3 behandeld de preoperatieve cardiologische screening. In een retrospectieve studie met 388 heupfractuur patiënten werd de preoperatieve cardiologische screening onder de loep genomen en vergeleken met de aanbevelingen vanuit de 'American College of Cardiology' (ACC) en de 'American Heart Association' (AHA) richtlijn. Heupfracturen vallen onder intermediair risico operaties, waarbij geldt dat het risico op majeure cardiologische events perioperatief $<5 \%$ is. Onderzoek wijst echter uit dat er een veel hogere incidentie van cardiale ischemie bestaat van $35-42 \%$, gemeten aan de hand van troponine bepalingen perioperatief. Verder is bekend dat overlijden in het ziekenhuis na een heupfractuur meestal de oorzaak is van hartfalen of een hartinfarct, welke kort na het optreden van de heupfractuur voorkomen.

De kern van de ACC/AHA richtlijn beschrijft een stapsgewijze benadering voor preoperatieve cardiologische screening van patiënten op basis van hun klinische predictoren en functionele capaciteit, gemeten doormiddel van de MET score (metabolic equivalent of task). Een patiënt zou minimaal enkele trappen moeten kunnen lopen en of een stukje moeten kunnen wandelen met ongeveer 5,5km/uur om voldoende inspanningstolerantie te hebben. De ACC/AHA richtlijn verdeelt patiënten in een laag, intermediair en hoog risico op basis van hun klinische predictoren. $82 \%$ van de patiënten in de lage risicogroep ontvingen de juiste preoperatieve cardiale screening voor hun operatie, $46 \%$ in de intermediaire en $86 \%$ in de hoge risicogroep patiënten. De meest frequente reden voor het incorrect screenen was overscreenen (>95\%). De vertraging tot aan de operatie nam met 9.9 uur toe wanneer er sprake was van overscreening. Vertraging tot aan de operatie en het hebben van een cardiale voorgeschiedenis waren risico's voor meer cardiovasculaire complicaties en vroege mortaliteit ( $<1$ maand). Een hoge leeftijd en mannelijk geslacht waren de sterkste predictoren voor overlijden 1- of 2-jaar na de operatie. De kans op pulmonale (RR 37, 95\%Cl 9-156; $p<0.0001$ ), of cardiovasculaire (RR 9, 95\% Cl 3-24; $p<0.0001$ ) complicaties postoperatief waren significant hoger in de hoog risicogroep in vergelijking met de intermediaire en/ of laag risicogroep. De kans op overlijden na een operatie voor een heupfractuur betreft $5 \%$ binnen de ziekenhuisopname, 9\%<1 maand, 29\% binnen 1 jaar, en 39\% binnen 2 jaar.

Hoofdstuk 4 is een vervolg op het onderzoek in hoofdstuk 3. In een prospectief cohort van 166 patiënten worden de bevindingen van hoofdstuk 3 bevestigd in een prospectieve studie met een grotere bewijslast. De baseline karakteristieken van 
de patiënten zijn hierbij in meer detail gemeten, denk hierbij aan de 'ASA-score' (American Society of Anesthesiologists) voor de fysieke status, de 'Barthel index' voor het functioneren prefractuur, de MET-score (Metabolic Equivalent of Task) voor de functionele capaciteit, het MMSE (Mini Mental State Examination) voor het cognitief functioneren en de 'Palmer \& Parker' score voor de prefractuur mobiliteit.

Hoofdstuk 5 beschrijft het gebruik van bloedtransfusies na heupfractuur chirurgie en de mogelijke associaties met morbiditeit en mortaliteit. Het betreft een retrospectieve studie met 388 patiënten waarbij met behulp van 'propensity matching' de data gecorrigeerd is. De propensity score werd gebruikt om te differentiëren of het ontvangen van een bloedtransfusie een risicofactor was voor mortaliteit na heupfractuur chirurgie of dat de voorspellende factoren voor een bloedtransfusie zelf geassicieerd zijn met mortaliteit. Dit wil zeggen dat factoren die van invloed zouden kunnen zijn op het ontvangen van een bloedtransfusie gelijktijdig van invloed kunnen zijn op mortaliteit postoperatief. De propensity score werd berekend met behulp van logistische regressieanalyse van alle univariate risicofactoren voor een bloedtransfusie: leeftijd, postoperatief hemoglobinegehalte en fractuurtype. Anemie komt zeer frequent voor na heupfractuur chirurgie, waarbij $41 \%$ van de patiënten een bloedtransfusie na de operatie ontvangt. Patiënten die een bloedtransfusie ontvingen hadden een langere opnameduur en meer cardiale complicaties ook na correctie voor confounders. Multivariate analyse liet zien dat na correctie met de propensity score er geen associatie meer bestond tussen bloedtransfusie en mortaliteit.

Hoofdstuk 6 beschrijft de resultatenna gebruik van intramedullaire penosteosynthese systemen met 2 collumschroeven voor extracapsulaire heupfracturen. De introductie van deze implantaten kwam voort vanuit de gedachte meer rotatie stabiliteit te willen verkrijgen en bot afsteun in een dikwijls osteoporotische heupkop. Biomechanische tests lieten eenzelfde rigiditeit en stabiliteit zien als systemen met een enkele collumschroef, maar er bestond wel een hogere weerstand tot falen. Met de introductie van deze implantaten ontstond ook een nieuwe complicatie: het Z-effect. Het Z-effect beschrijft het naar buiten komen van de onderste (inferieure) collumschroef en de mediale migratie van de bovenste (superieure) collumschroef. Het 'reversed Z-effect' beschrijt het tegenovergestelde. Een conceptuele verklaring voor het optreden van een Z-effect bestaat uit complexe biomechanische processen waarbij osteoporose, beperkte laterale afsteun, mediale instabiliteit en een constante frictie tussen heupkop en axiale belasting in varus mogelijk een rol 
spelen. We hebben de hypothese getoetst of het gebruik van een lange pen een Z-effect zou kunnen voorkomen aangezien dit een langere kracht-arm opleverde en laterale afsteun over een langer gedeelte van de femurschacht. In totaal zijn er 80 patiënten geïncludeerd waarbij tot 2 jaar postoperatief de röntgenfoto's uitvoerig beoordeeld werden op radiologische uitkomstmaten. De incidentie van het (reversed) Z-effect was 9\%. 6 van de 7 Z-effect patiënten hadden een korte pen gekregen (niet significant). Patiënten met een lange pen had significant meer postoperative complicaties in vergelijking met patiënten die een korte pen hadden ontvangen (mediaan 2 vs $0.5, p=0.001$ ). De lange pen groep kreeg vaker een bloedtransfusie ( $82 \%$ vs $31 \%, p \leq 0.001$ ) en had een langere opname duur (13 vs 21 dagen, $p<0.05)$. Migratie van een van de collumschroeven $(p \leq 0.009)$ en de aanwezigheid van een instabiel fractuurtype $(p<0.05)$, waren risicofactoren voor reoperatie. $21 \%$ van de patiënten kreeg binnen 2 jaar na plaatsing van het implantaat een re-operatie, waarvan een kwart kwam door het optreden van een Z-effect. 


\section{VALORIZATION ADDENDUM}

\section{RELEVANCE}

Hip fractures are a major socioeconomic- and health burden. This thesis contributes to the improvement of various aspects of care for hip fracture patients. Even with optimal care, improved techniques and implants, elderly hip fracture patients suffer from high morbidity and mortality rates, which is associated with increased health care costs [1].

In the Netherlands more than 20.000 patients sustained a hip fracture in 2010 [6]. Prognostic calculations predict that the proportion of the population aged 65 and above will increase from 18\% in 2017 to 26\% in 2040 [7]. An increasing proportion of the population will be over 80 years old [7]. This will result in an increased incidence of hip fractures in the future. This thesis showed that the consequences of a fractured hip are serious for elderly patients. Up to $9 \%$ of patients die within 30days, 29\% within 1 year and 38\% within 2 years after surgery [8]. Postoperatively, expensive aftercare is needed for rehabilitation, but the chance of full recovery to pre-fracture level of mobility is low [2-4]. Institutionalized elderly regained only in $17 \%$ of their overall functional ability and $13 \%$ returned to their pre-injury ambulatory status [5]. This thesis offers an extensive overview of perioperative care of hip fracture patients.

\section{TARGET POPULATION}

The results of this thesis are relevant for health care professionals who are involved in the treatment of hip fracture patients such as orthopaedic and trauma surgeons, anesthesiologists, geriatricians, emergency physicians, cardiologists but also general practitioners, emergency staff, ambulance staff and nursing home physicians. In addition, the results of this thesis are of interest for (medical) companies (profit and non-profit), which are developing medical devices, products, apps and more to improve care for hip fracture patients.

\section{THIS THESIS}

With the patella pubic percussion test (PPPT) we propose a bedside technique to guide for further imaging when no clear fracture is found on X-rays, but clinically suspected (occult hip fracture). The PPPT has the potential to prevent missed 
fractures and the costs associated with it. Missed hip fractures lead to secondary hip displacement, with increased risk of avascular necrosis of the femoral head, non-union and higher chances of morbidity after future operations [10]. We have organized local hands-on workshops for emergency staff, ambulance personal, general practitioners and surgeons about the PPPT. During these workshops we discussed the use of PPPT in a prehospital setting vs. the use of the PPPT in the case of expected occult hip fracture on an emergency department.

With a proper preoperative assessment we aim to reduce the risk associated with surgery and anaesthesia, to increase the quality of perioperative care, to restore the patient to the desired level of function, and to obtain the patients informed consent [11]. We have demonstrated shortcomings in preoperative cardiac screening of elderly with hip fracture. This thesis showed that 'cardiac overscreening' is a commonly occurring phenomenon and leads to increased delay to surgery, which poses a risk for perioperative complications and early mortality. These results show that it is important for treating teams to evaluate their own hip fracture care path and preoperative screening. National guidelines and quality indicators for Dutch hospitals advocate definitive treatment within 24 hours [12]. Preoperative cardiac screening should be executed in accordance with the American College of Cardiology \& American Heart Association (ACC / AHA) guidelines, in this way unnecessary delay or excessive use of medical recourses and costs are prevented.

Finally, we performed a clinical study on implant failure after intramedullary nailing with dual lag screws for extracapsular hip fractures. The secondary purpose of this study was to evaluate the use of such implants for different fracture types in our institution. Studies on implant failure, are of great value for medical industries and indirectly lead to further improvement of their products.

\section{REFERENCES}

1. Carpintero P, Caeiro JR, Carpintero R, Morales A, Silva S, Mesa M: Complications of hip fractures: A review. World J Orthop 2014, 5(4):402411.

2. Osnes EK, Lofthus CM, Meyer HE, Falch JA, Nordsletten L, Cappelen I, Kristiansen IS: Consequences of hip fracture on activities of daily life and residential needs. Osteoporos Int 2004, 15(7):567-574.

3. Shah MR, Aharonoff GB, Wolinsky P, Zuckerman JD, Koval KJ: Outcome after hip fracture in individuals ninety years of age and older. $J$ Orthop Trauma 2001, 15(1):34-39. 
4. Vochteloo AJ, Moerman S, Tuinebreijer WE, Maier AB, de Vries MR, Bloem RM, Nelissen RG, Pilot P: More than half of hip fracture patients do not regain mobility in the first postoperative year. Geriatr Gerontol Int 2013, 13(2):334-341.

5. Folman Y, Gepstein R, Assaraf A, Liberty S: Functional recovery after operative treatment of femoral neck fractures in an institutionalized elderly population. Arch Phys Med Rehabil 1994, 75(4):454-456.

6. Statistiek CBvd: Ziekenhuisopnamen heupfracturen; geslacht, leeftijd en diagnose-indeling. National database. 2014.

7. (CBS) CBvdS: Prognose: 18,4 miljoen inwoners in 2060. 2017.

8. Smeets SJ, Poeze M, Verbruggen JP: Preoperative cardiac evaluation of geriatric patients with hip fracture. Injury 2012, 43(12):2146-2151.

9. Mundi S, Pindiprolu B, Simunovic N, Bhandari M: Similar mortality rates in hip fracture patients over the past 31 years. Acta Orthop 2014, 85(1):54-59.

10. Parker MJ: Missed hip fractures. Arch Emerg Med 1992, 9(1):23-27.

11. Garcia-Miguel FJ, Serrano-Aguilar PG, Lopez-Bastida J: Preoperative assessment. Lancet 2003, 362(9397):1749-1757.

12. Nederlandse Vereniging van Heelkunde NVvH, Nederlandse Orthopaedische Vereniging NOV: Proximale femurfracturen (guideline). https://richtlijnendatabasenl 2016. 


\section{ABOUT THE AUTHOR}

Stef Jozef Marie Smeets was born on the 27th of August 1985, in Emmen, the Netherlands. He competed in gymnastics and due to his top sport career, he attended a sports talent high school (Atheneum, Katholiek Drents College). After graduating in 2003, he studied medicine from 2003 to 2009 at the University of Maastricht. He had the chance to experience two internships abroad: immunology, at the University of Linköping, Sweden in 2004 and internal medicine, at Tygerberg Hospital, South-Africa in 2007. It was in South-Africa where he met the love of his life, Lena Bilet from Moss, Norway. After graduating as a medical doctor in 2009 he started as a surgical trainee at the Maastricht University Medical Center. At the department of trauma surgery, he started with clinical research on preoperative cardiac screening of elderly patients with hip fracture. After two years he continued as a surgical trainee at the Maxima Medical Center in Eindhoven/Veldhoven and achieved a resident position in 2012. After a successful surgical residency, with the specialization gastro-enterology and surgical oncology he started a consultant position at the MC Zuiderzee in Lelystad, in 2018. His primary work consisted of treating patients with colorectal disease, morbid obesity and proctological disorders. In 2019 he continued as a gastro-intestinal surgeon at Flevoziekenhuis in Almere. Stef lives together with Lena Bilet, Sebastian (5) and Filippa (1). In October 2019 they are expecting their 3rd child. 


\section{LIST OF PUBLICATIONS}

S.J.M. Smeets, B.P.W. van Wunnik, M. Poeze, G.D. Slooter, J.P.A.M. Verbruggen. Cardiac overscreening hip fracture patients. Archives of Orthopaedic and Trauma Surgery Aug 2019

S.J.M. Smeets, W. Vening, M.B. Winkes, G.P. Kuijt, G.D. Slooter, P.V. van Eerten. The patellar pubic percussion test (PPPT): A simple bedside tool for suspected occult hip fractures. International Orthopaedics. Nov 2018;42(11):2521-2524. PMID: 30019126

S.J.M. Smeets, J.P.A.M. Verbruggen, M. Poeze. Effect of blood transfusion on survival after hip fracture surgery. European Journal of Orthopaedic Surgery \& Traumatology. May 2018. PMID 29752534

S.J.M. Smeets, G.P. Kuijt, P.V. van Eerten. Z-effect after intramedullary nailing systems for trochanteric femur fractures. Published: Chinese Journal of Traumatology. Dec 2017; 20(6):333-338. PMID:29221656

M.B. Winkes, A.P.M. van Zantvoort, J.A. de Bruijn, S.J.M. Smeets, M. van der Cruijsen-Raaijmakers, A.R. Hoogeveen, M.R.Scheltinga. Fasciotomy for Deep Posterior Compartment Syndrome in the Lower Leg: A Prospective Study. American Journal of Sports Medicine. May 2016;44(5):1309-16. PMID: 26888880

S.J.M. Smeets, M. Poeze, J.P.A.M. Verbruggen. Preoperative cardiac evaluation of geriatric patients with hip fracture. Injury. Dec 2012; 43(12):2146-51. PMID: 22995981 


\section{DANKWOORD}

Het is dan eindelijk zover: het proefschrift is af! Het was 2009 in mijn afstudeerjaar van Geneeskunde toen ik mijn semi-artsstage bij de traumachirurgie ging doen in het MUMC+, een half jaar kliniek onder begeleiding van professor Peter Brink en een half jaar onderzoek bij Jan Verbruggen. Hier werd de basis van mijn promotietraject gelegd.

Het heeft vervolgens 10 jaar geduurd om mijn promotie te kunnen voltooien, naast mijn klinische werk als ANIOS, opleidingsassistent chirurgie of chirurg. Het is zeker niet altijd gemakkelijk geweest, soms met horten en stoten gegaan, maar de aanhouder heeft gewonnen. Gelukkig waren er die verblijde mailtjes van Martijn Poeze die mij na enkele maanden in de periferie weer eens stuurde: 'Stef hoe is het met je promotie...?'.

In het Máxima Medisch Centrum vond ik een mooie aansluiting met enkele studies onder begeleiding van Percy van Eerten, Gert Kuijt en Gerrit Slooter. Wanneer ik dan aardig op weg was kon ik dit laten toetsen bij het 'wetenschapsbureau' RoumenScheltinga. De snelheid waarmee een artikel van Marc Scheltinga, volledig rood van de 'track changes', terugkwam is nog altijd legendarisch. Uiteindelijk heb ik voor mijn promotie een fraaie combi kunnen vinden van studies uit zowel het MUMC+ en het MMC met als rode draad de perioperatieve zorg voor de oudere patiënt met een heupfractuur. Een speciaal woord van dank wil ik dan ook uitspreken aan iedereen die dit mogelijk gemaakt heeft. Daarnaast wil ik dit dankwoord gebruiken om degenen te bedanken die bepalend zijn geweest in de jaren van mijn opleiding tot chirurg, hier is nooit een goed moment voor geweest.

Mijn dank gaat uit naar de leden van de leescommissie, Prof. dr. W.F.F.A. Buhre, Prof. dr. L.W. van Rhijn Dr. R.K.J. Simmermacher \& Dr. M.J. Heetveld. Verder wil ik mijn dank uitspreken aan de leden in de corona. Ik kijk ernaar uit om met u van gedachte te wisselen over de inhoud.

Dank aan de gehele vakgroep chirurgie MUMC+ voor jullie aandeel aan mijn persoonlijke ontwikkeling, chirurgische vaardigheden en jarenlange prettige samenwerking. Dankzij jullie allen heb ik werkelijk een fantastische opleiding genoten en ben ik klaar gestoomd tot chirurg. Met deze beperkte woorden doe ik jullie feitelijk te kort! Dank aan de sectie traumachirurgie MUMC+ voor hun bijdrage aan deze thesis. 
Beste Jan Verbruggen, als student ben ik bij je begonnen en je hebt me geënthousiasmeerd voor de chirurgie. Dank voor je jarenlange begeleiding, dank voor de vele gezellige congressen. Het congres dat me het best is bijgebleven, is de Küntscher Society bijeenkomst in 2011, in Thessaloniki, Griekenland. Een intiem congres voor een select internationaal gezelschap dat het erfgoed van Gerhard Küntscher een warm hart toedraagt en alles wat met intramedullary nailing te maken heeft. Ik ben jarenlang lid geweest van de club. Het was dit congres waar ik de 'best oral presentation' won. Dank dat je mijn copromotor bent. Beste Martijn Poeze, dank voor jouw ultieme begeleiding, volhardende geloof dat ik dit ging voltooien, steun op momenten dat het moeilijk was. Met je zeer van pas komende kennis van de statistiek als epidemioloog stuurde je me altijd weer op pad. Samen brainstormden we al jaren geleden naar de stelling: 'niet het penneke, maar het menneke'. Deze wordt in deze thesis in ieder geval vereeuwigd. Ik ben blij dat je mijn Promotor bent. Chapeau, hoe je als hoogleraar met zoveel promovendi, het klinische werk weet te combineren. Prof. Peter Brink, dank voor uw begeleiding in het begin van mijn carrière. $U$ bent tevens groot uitdrager van de Patella Pubis Percussie test. Samen hebben we workshops gegeven aan medici en paramedici in Zuid-Limburg. Geniet van uw pensioen!

In het bijzonder dank aan Prof. Cees Dejong, dank voor het in mij gestelde vertrouwen, dank voor uw steun en bijdrage in het sturen van mijn carrière pad en verkrijgen van de opleiding. Ik val nog regelmatig terug op uw wijze chirurgische lessen en de kennis en kunde die ik bij de HPB heb opgedaan. Ik ga lekker verder met 'restore anatomy'! Prof Laurents Stassen, mijn academische opleider dank voor uw steun in het verkrijgen van de opleiding. Dank aan u en Jarno Melenhorst als mijn laparoscopie opleiders dank voor het in mij gestelde vertrouwen, de talloze rectum operaties (PME, TME, APR en robot) die we samen hebben mogen doen. Jarno dank voor de fijne chemie op de werkvloer, mooi om te zien dat jouw perifere drive zo floreert binnen de academische zorg, je bent een voorbeeld.

Alle chirurgen MMC, dankzij jullie heb ik een fantastische opleiding gehad en een boven gemiddeld aantal meters kunnen maken. Dankzij jullie was ik klaar voor het 'echte' chirurgenwerk. Dank voor het in mij gestelde vertrouwen. Ik zal mijn gehele carrière heugen dat mijn basis bij jullie is gelegd.

Arijan 'best een bypass doen' Luijten, een van mijn laparoscopie opleiders, dank voor jouw rust op OK, vertrouwen in mij en dank dat ik je af en toe nog eens een 
casus kan voorleggen als chirurg. François 'no guts no glory' van Dielen, dank voor die heerlijke straten bariatrie die we samen onder het genot van Q-music 'het foute uur' er doorheen knalden. Wouter 'mensen zijn net uien' Leclercq, dank voor jouw altijd kritische noot en prettige samenwerking op een van die vele GE, bariatrie of lever OK's! Gerrit Slooter, mijn laparoscopie opleider met het minste geduld, maar ik heb veel aan je te danken. Was ik eens in een uurtje op de bekkenbodem met een TME, dan was het nog 'tjah.. had eigenlijk in 45 minuten gemoeten Smeets', of als TEP koning 14 liezen op een dag plannen om je vriendje uit Curaçao te laten zien hoe wij dat hier deden. Op de klok kreeg ik dan een tijdsbestek tot mat plaatsing. Dit heeft bij mij altijd het beste in me naar boven gehaald. Een van jouw vele quotes was: 'die patiënt heeft het geestelijk vermogen van een AIOS'. Dank voor alles, dank dat je mijn copromotor bent. Rudi 'mezzzzzzzzz' Roumen, mijn perifere opleider, charismatisch als je bent, weet je iets fantastisch een ruimte in te bulderen. Van jou heb ik geleerd 'verder te kijken' en soms tot het uiterste te gaan voor een patiënt. Ik denk met veel vreugde terug aan de lever OK's die we samen deden met de door jouw zelf ontwikkelde drup-coagulator, de zwaffelaar. Marc 'science races on' Schel-tin-ga, intern opleider, dank voor de directe begeleiding van mijn proefschrift, de fijne beoordelingsgesprekken waarbij je op prettige wijze me soms een spiegel wist voor te houden. Ik citeer jouw legendarische woorden: 'het mag wel ruiken, maar niet stinken'. Dank aan het 'Triomferaat' opleiders MMC: Mart Bender, Marc Scheltinga en Rudi Roumen.

Beste assistenten chirurgie in het MUMC+ \& MMC, dank voor die nooit te vergeten tijd die wij als AIOS/ANIOS doormaakten met elkaar met o.a. geniale wintersport trips, feestjes, congressen, assistentenweekend Ardenne en altijd pret op de assistentenkamer. Chirurgie is: 'work hard, play harder'. Geniet met volle teugen van jullie assistententijd, voordat je weet is het al weer voorbij! Michiel Winkes (Winky) dank voor het samen publiceren. Wij hielden er altijd graag de beuk in op de acute OK lijst en als geen ander wisten we feilloos het consultensein te combineren met OK. Samen hebben we een legendarisch weekend naar Porto voor de vakgroep chirurgie MMC neergezet in 2015.

Alle chirurgen MC Zuiderzee: Gijs Algie, Yves Montauban, Stefan Damen, Ruben Schouten, Dominika Chadanova en Afzal Amir. Wat hadden we een mooie club!

Beste huidige collega's Flevoziekenhuis, ik ben op een bijzondere manier in de vakgroep gekomen, maar ik heb dit als een bijzonder warm welkom ervaren. Wij 
hebben de bariatrie behoorlijk op de rit gekregen en timmeren aan de weg met de laser voor proctologische doeleinden. Wat zijn we een mooie toekomstbestendige vakgroep.

\section{FRIENDS \& FAMILY}

Lieve Mam, tegenwoordig hoeven we niet dagelijks meer te bellen, maar het liefst wel om de dag. Je bent altijd geïnteresseerd in alles, attent en enthousiast over alles dat ik doe. Blijf dit vooral doen. Je hebt er alles voorover om je kleinkinderen te zien of dit nu in Maastricht, Opgrimbie (BE), Maasmechelen (BE), Bergeijk of Lelystad is. Je bent de beste, ik hou van je. Je bent nu gelukkig met Peter, dank dat jij er voor mam bent. Rest in peace lieve Ruud. Dank voor al die goede gesprekken samen en de prachtmomenten die je samen met Sebastian had.

Pa, dank voor jouw onvoorwaardelijke steun, kritische kijk op zaken. Ik weet hoe ontzettend trots je op me bent! Carla je bent een pracht mens en zo begaan met ons en de kinderen. Ik vind het fantastisch hoe jullie de family telkens weer bij elkaar zien te krijgen in een mooi oord met een zwembad. Enorm genieten altijd, dank. Pa \& Carla, jullie zijn er altijd voor ons, ik hou van jullie.

Tim, broertje, the champ, wat ben ik trots op je! Je laat je door niemand iets wijs maken en specialiseert je nu tot ziekenhuisapotheker. Paranimf zijn gaat je ook redelijk af, misschien dat ik ooit deze dienst terug kan verlenen? Ayfa wat moest ik zonder jou?! Dit is nu het 2e boekje dat je aflevert in the family. Samen onder het genot van een wijntje, brainstormden we over hoe het eruit moest komen te zien. Helaas had ik geen 'moodboard' gemaakt, maar we kwamen er direct uit. Wat een prachtig eindproduct heb je neergezet en dank voor het presteren onder deze enorme druk. Tim \& Ayfa, wat zijn jullie mooi samen, love you. Myrth, zusje, wat heb je een lieve, warme persoonlijkheid, nog even en dan ben je GZ-psycholoog (en dan kan ik je ook gebruiken voor de bariatrie, haha!). Joep je bent Sebastians held en daarmee ook de mijne. Myrthe \& Joep, het wordt tijd dat we wat dichter bij elkaar komen wonen. Wat zijn jullie mooi samen, love you. Juul, lief zusje, de jongste en de knapste van het stel! Had ik nog maar eens zo'n bruisend leven als jou. Ik ben enorm trots op je! Joeri, je bent enorm oprecht en hebt een fantastische chemie met Sebastian. Goed oefenen met ceremoniemeester zijn, ik heb je misschien ooit nog nodig. Juliette \& Joeri, wat zijn jullie mooi samen, love you.

Kjære svigerforeldre, Roy \& Marianne, søte svigerinne Sofie-Elise, kjære svoger 
Cato. En gang kidnappet jeg deres vakre datter eller søster fra Sør-Afrika og tok henne med meg til Nederland. Takk for deres enorme gjestfrihet, vi setter alltid huset på hodet når vi kommer med hele flokken. Vi koser oss masse hos dere, og dere varter opp med god mat og drikke! Dere gjør virkelig alt for oss. Tusen takk!

Opa Piet, dit hadden we niet afgesproken hé! Ik weet niet of dit een verwoede poging van je is om wat extra symboliek aan deze thesis toe te voegen? 2 weken na je photo shoot een mediale collum fractuur oplopen en een kophalsprothese krijgen. Wat heb je een bijzonder leven gehad en veel van de wereld gezien. Altijd heb ik van je verhalen genoten. Op veel vlakken herken ik mij in jouw, je bent handig, creatief en altijd in voor een gekke actie, we hebben altijd veel gedeelde interesses gehad. Oma Lies, zorg je dat opa zich een beetje gedraagt in het ziekenhuis? Laten we hopen dat hij er bovenop komt. Je bent altijd zo lief en zorgzaam en wilt het ons graag naar de zin maken. Elke keer heb je wat lekkers gebakken of in huis gehaald. Ik vind het prachtig om te zien hoe jullie van de achterkleinkinderen genieten, we komen altijd graag op bezoek. Dank voor alle fijne herinneringen uit mijn jeugd.

Wijlen oma José \& opa Sef, lieve opa en oma Echt, met veel vreugde denk ik terug aan mijn jeugd en de fijne tijd bij jullie tijdens de Carnaval of Echter kermis. Oma, zeer plots heb je ons verlaten op 10-augustus. Ik blij dat ik je vlak daarvoor nog gezien heb met de photo shoot. Dank voor alles.

Dank lieve familie, Jan, Monique, Aniek, Rian, Peter, Desiree, Celine, Esmee, Mon, Daan, lieve Anka was je nog maar hier.

Terug naar het begin, zonder studententijd was er geen thesis geweest nu. In 2003 startte ik geneeskunde in Maastricht, verder weg uit Emmen kon ik niet komen: 4.5uur treinen. Dit betekende nieuwe stad, nieuw begin. Ik begon mijn avontuur vanuit de ruime zolder bij mijn oom en tante in Maastricht zodat ik mij kon oriënteren op een kamer. Lieve Marian, Theij en Caro, ik kijk terug op een super gezellige tijd bij jullie in huis. Stef eet je mee? Ga je weer op stap? Kom je thuis? Studeren? Alles was altijd goed. Uiteindelijk vond ik een kamer aan de Bolderikweerd in Heugem. Dicht bij de fitness, dicht bij de Uni en 10 minuten fietsen naar het Vrijthof. Jullie regelde direct een bijbaantje op basisschool de Spiegel via Ankie en ik kwam wekelijks nog bij jullie eten. In die jaren vierden we altijd samen Carnaval en dat proberen we elk jaar nog altijd te doen. Dank voor alles. 
In mijn studententijd waren wij de onlosmakelijke drie-eenheid: Oliver, Bart, Stef. Een soort van mini-dispuut dat op maandag, woensdag en donderdag de stad onveilig maakte in de Cliniq, de Celebration, 2 Heren en dan eindigen in de Allebonneur (de Alla) of de Feesfebrik. 4-5x per week gingen we oud ijzer pompen in de sportschool bij Emil, wat een ware dagbesteding was die dikwijls 2.5uur duurde door al dat ouwehoeren. Motto: no pain no gain. In de zomer door buffelen in het Witte Vrouwenveld bij TopForm en later toen Samefko aansloot ook nog bij 'Barry's Gym' met 60kg dumbells, 'lightweights... lightweights'. Oohja en ook nog studeren in die tijd. Samefko, Sander, Guy, Cas, Faro, Wims, Daniel, dank voor de mooie 'Maastricht tijd'!

Later werden we serieuzer, kregen kinderen, gingen in opleiding, ofwel moesten we stapavonden wat vaker inruilen voor wetenschap. Weekenden werden spelletjesavonden Canasta met Bart \& Dominique of Risk met Esther \& Darius. Avonden met te veel goede wijn, maar ach: goede wijn verheugt een mensenhart. Dank voor dit vertier, de reden dat ik het allemaal heb volgehouden. Dank voor jullie hechtte vriendschap. Dagelijkse updates over het leven en de kinderen delen we in de 'Decibel/Defqon/Qlimax-app met ook Rob \& Suzan. Dit helpt mij ontsnappen aan de dagelijkse sores als ik lees welke zaken weer allemaal de revue passeren. Bart, maatje voor het leven, dank dat je mijn paranimf bent.

Dan mijn lieve schat. Lena the Norwegian princess, alias the Viking. Ons sprookje begon in Zuid-Afrika 2007 en kijk eens wat een mooi gezinnetje hieruit voort kwam! Ik zeg je wel eens: jij bent de reden dat ik succesvol kan zijn in dit vak. Jij bent de reden dat ik überhaupt een boekje in mijn handen heb, wat een werk heb jij je op de hals gehaald door mijn lay-out te doen in In-design. Zoveel avonden die wij niet Netflixend op de bank doorbrachten, maar zij aan zij aan iMac en Macbook gekluisterd om de laatste loodjes te voltooien. Ik ben je eeuwig dankbaar. We hebben een prachtige zoon Sebastian (5) en dochter Filippa (1) samen. Met nummer 3 op komst kan ons geluk niet op. Ik hoop wel dat hij/zij nog in ieder geval zitten blijft tot na de verdediging. Django the Frenchy maakt het plaatje af. Hvis jeg vet hva kjærlighet er, er det på grunn av deg. Jeg elsker deg. Lieve Sebastian \& Filippa, jullie geven zoveel rijkdom, jullie maken het leven zoveel mooier, Ik hou zielsveel van jullie!

Tenslotte, het is niet vaak dat je in het leven iets aan je ouders kunt opdragen. 
Mijn ouders - deze thesis is voor jullie 




In this thesis from Stef J.M. Smeets essential topics about perioperative care of elderly with a hip fracture are discussed. After a comprehensive and broad introduction, several clinical studies are presented. The author studied the value of the Patella Pubic Percussion Test (PPPT) and discusses whether this test has a place in modern practice. The topic of preoperative cardiac screening is extensively studied, and the importance of correct screening is emphasized. Thereafter, the author tries to unravel the truth about the association between blood transfusion and mortality after hip fracture surgery. Finally, a rare complication after intramedullary

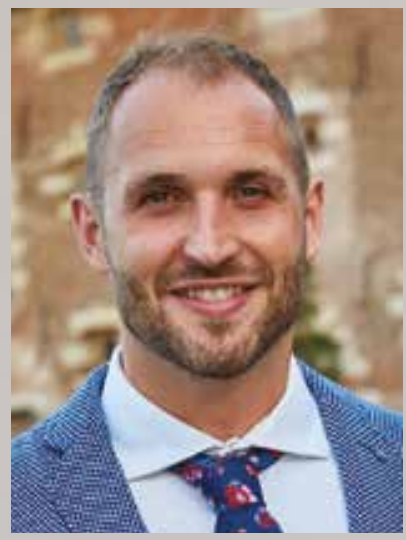
nailing with dual lag screws is revealed: the Z-effect phenomenon. Additionally, an overwhelming amount of data regarding postoperative complications and mortality after hip fracture surgery is included. 